\title{
Extensive literature search for studies related to fumonisins and their modified forms
}

Nielsen, Elsa Ebbesen; Egebjerg, Mikael Mandrup; Olesen, Pelle Thonning; Sharma, Anoop Kumar; Nørby, Karin Kristiane; Beltoft, Vibe Meister; Rasmussen, Peter Have; Bredsdorff, Lea; Hansen, Max; Eriksen, Folmer Damsted

Total number of authors:

13

Published in:

EFSA Supporting Publications

Link to article, DOI:

10.2903/sp.efsa.2018.EN-1148

Publication date:

2018

Document Version

Publisher's PDF, also known as Version of record

Link back to DTU Orbit

Citation (APA):

Nielsen, E. E., Egebjerg, M. M., Olesen, P. T., Sharma, A. K., Nørby, K. K., Beltoft, V. M., Rasmussen, P. H., Bredsdorff, L., Hansen, M., Eriksen, F. D., Pilegaard, K., Ravn-Haren, G., \& Jørgensen, K. (2018). Extensive literature search for studies related to fumonisins and their modified forms. EFSA Supporting Publications, 15(2), [1148E]. https://doi.org/10.2903/sp.efsa.2018.EN-1148

\section{General rights}

Copyright and moral rights for the publications made accessible in the public portal are retained by the authors and/or other copyright owners and it is a condition of accessing publications that users recognise and abide by the legal requirements associated with these rights.

- Users may download and print one copy of any publication from the public portal for the purpose of private study or research.

- You may not further distribute the material or use it for any profit-making activity or commercial gain

- You may freely distribute the URL identifying the publication in the public portal 


\title{
Extensive literature search for studies related to fumonisins and their modified forms
}

\author{
National Food Institute, Technical University of Denmark
}

Elsa Nielsen, Mikael Mandrup Egebjerg, Pelle Thonning Olesen, Anoop Kumar Sharma, Karin Nørby, Vibe Beltoft, Peter Have Rasmussen, Lea Bredsdorff, Max Hansen, Folmer Eriksen, Kirsten Pilegaard, Gitte Ravn-Haren and Kevin Jørgensen

\begin{abstract}
An extensive literature search to identify and collect all studies related to fumonisins and their modified forms was performed in the two databases PubMed and Web of Science for nine Areas. After combination of the searches from the two databases and removal of the duplicates, the total number of hits for Area 1 was 4456, for Area 2 was 2261, for Area 3 was 1649, for Area 4 was 3555, for Area 5 was 1632, for Area 6 was 2424, for Area 7 was 5087, for Area 8 was 3284, and for Area 9 was 3283. The evaluation of all retrieved references for relevance by screening the title and abstract (if available) and applying eligibility criteria (inclusion/exclusion) resulted in a total number of relevant references for Area 1 of 532, for Area 2 of 114, for Area 3 of 273, for Area 4 of 87, for Area 5 of 138, for Area 6 of 38, for Area 7 of 270, for Area 8 of 709, and for Area 9 of 270.
\end{abstract}

(C) European Food Safety Authority, 2018

Key words: fumonisins, toxicity, occurrence in food and feed, chemistry, extensive literature search

Question number: EFSA-Q-2016-00366

Correspondence: biocontam@efsa.europa.eu 
Disclaimer: The present document has been produced and adopted by the bodies identified above as authors. This task has been carried out exclusively by the authors in the context of a contract between the European Food Safety Authority and the authors, awarded following a tender procedure. The present document is published complying with the transparency principle to which the Authority is subject. It may not be considered as an output adopted by the Authority. The European Food Safety Authority reserves its rights, view and position as regards the issues addressed and the conclusions reached in the present document, without prejudice to the rights of the authors.

Suggested citation: NFI-DTU (National Food Institute - Technical University of Denmark), 2018. Extensive literature search for studies related to fumonisins and their modified forms. EFSA supporting publication 2018:EN-1148. 175 pp. doi:10.2903/sp.efsa.2018.EN-1148

ISSN: $2397-8325$

(C) European Food Safety Authority, 2018

Reproduction is authorised provided the source is acknowledged. 


\section{Summary}

The overall aim of this assignment was to identify and collect all relevant literature related to fumonisins and their modified forms to support preparatory work for the human and animal risk assessment of these substances.

Initially, nine tailored search strings were designed to retrieve all potentially relevant studies within the following nine areas:

- Area 1: Data on chemistry and analysis (substance identification and characterisation, analytical detection and determination, formation).

- Area 2: Data on toxicokinetics (absorption, distribution, metabolism, excretion) in experimental animals, farm and companion animals, humans and from in vitro studies and on biomarkers.

- Area 3: Data on in vitro and in vivo mode of action (MoA) of toxicity.

- Area 4: Data on toxicity in vivo (e.g. acute, subacute, subchronic, chronic toxicity; genotoxicity, carcinogenicity, toxicity to specific organs) in laboratory animals.

- Area 5: Data on toxicity in vitro.

- Area 6: Data on observations in humans (e.g. epidemiological studies, case reports, intervention studies).

- Area 7: Data on adverse effects in farm and companion animals (studies in the different species e.g. ruminants, pigs, poultry, rabbits, fish, cats, dogs etc.).

- Area 8: Data on occurrence in food.

- Area 9: Data on occurrence in feed and animal exposure (including feed occurrence in the different feed commodities, feed intake and animal exposure).

The search strings were tailored to the databases PubMed and Web of Science and consisted of two major steps each designed to search titles and abstracts in PubMed and Web of Science, as well as full text in PubMed. Combinations of search terms were used, starting with a broad search for fumonisins and their modified forms, synonyms and abbreviations (step 1) and followed by an Area specific step with the addition of search terms relevant to each Area (step 2).

Then the nine tailored search strings were employed to retrieve all relevant studies from the two databases. Data published since year 2000 were retrieved for Area 1-6 and Area 8-9. Data published since year 1980 were retrieved for Area 7. All retrieved references were exported as separate files into EndNote $^{\mathrm{TM}}$. Duplicate studies were then removed after combining the two EndNote ${ }^{\mathrm{TM}}$ files per Area into one single combined file per Area.

The total number of hits from each database, as well as the total number of hits (combined total) and total number of hits after removal of the duplicates (combined) are summarised in the table below.

\begin{tabular}{c|c|c|c|c}
\hline Area & PubMed & Web of Science & Combined total & Combined \\
\hline 1 & 2209 & 4145 & 6354 & 4456 \\
\hline 2 & 1531 & 1661 & 3192 & 2261 \\
\hline 3 & 923 & 1551 & 2474 & 1649 \\
\hline 4 & 1667 & 3272 & 4939 & 3555 \\
\hline 5 & 796 & 1504 & 2300 & 1632 \\
\hline 6 & 1748 & 1363 & 3111 & 2424 \\
\hline 7 & 2966 & 4331 & 7297 & 5087 \\
\hline 8 & 1823 & 3053 & 4876 & 3284 \\
\hline 9 & 1755 & 3076 & 4831 & 3283 \\
\hline
\end{tabular}


All retrieved references were then evaluated for relevance by applying eligibility criteria (inclusion/exclusion). The selection for relevance was conducted by screening the title and abstract (if available) and all the retrieved studies were ultimately sorted into one of the following three categories:

- Relevant to the research objectives: References ultimately evaluated to be relevant were included in this category.

- Maybe relevant to the research objectives: In case the relevance could not be evaluated because e.g. of missing or vague abstracts or because the reference addressed and discussed mycotoxins in general and fumonisins could not be excluded based on the title and abstract of the reference, the references were included in this category, as a conservative approach.

- Not relevant to the research objectives: References ultimately evaluated not to be in-scope were included in this category.

The results of the reference selection process were reported in summary tables (Excel files), one table per Area. The summary tables include all pertinent information for each of the references in the 'Relevant' category as identified by the eligibility criteria and which could be retrieved from the title and abstract (when available). The summary tables also include references in the 'Maybe relevant' and the 'Not relevant' categories, but without any study details except for including the reason for exclusion for the 'Not relevant' references, i.e. not target compound or not relevant for the specific Area is presented.

The evaluation for relevance resulted in a total number of relevant references for Area 1 of 532, for Area 2 of 114, for Area 3 of 273, for Area 4 of 87, for Area 5 of 138, for Area 6 of 38, for Area 7 of 270, for Area 8 of 709, and for Area 9 of 270. 


\section{Table of contents}

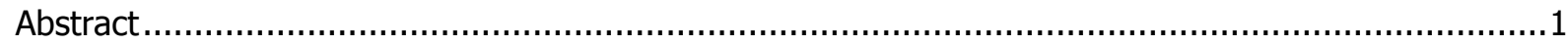

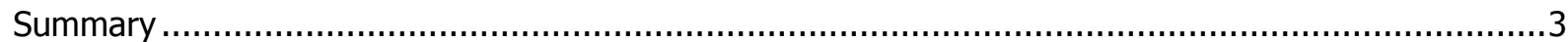

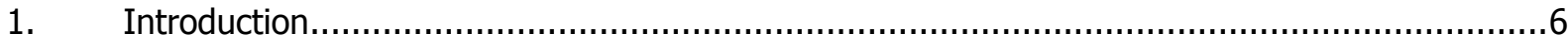

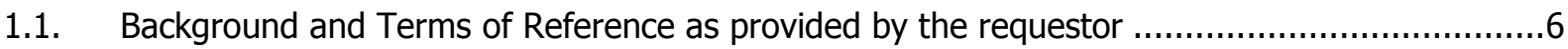

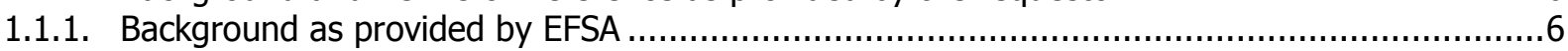

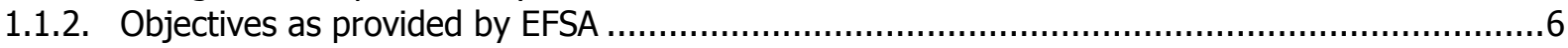

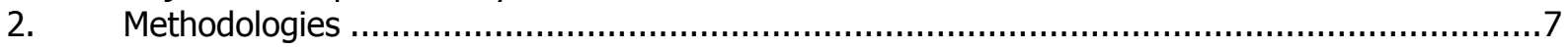

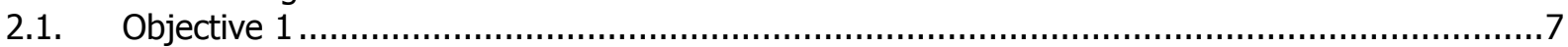

2.1.1. Task 1 Developing tailored search strategies and search strings for collecting relevant studies 7

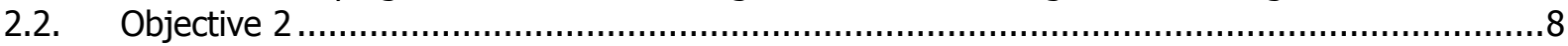

2.2.1. Task 2 Execution of the extensive literature searches using the tailored search strings

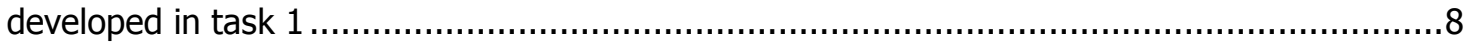

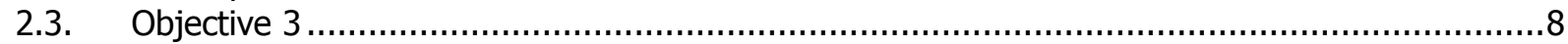

2.3.1. Task 3 Selection of all relevant studies retrieved by the extensive literature searches..............8

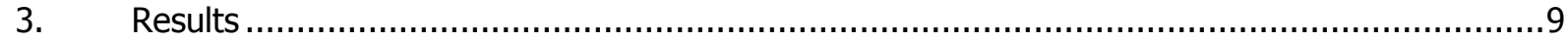

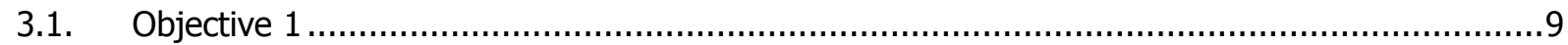

3.1.1. Task 1 Developing tailored search strategies and search strings for collecting relevant studies 9

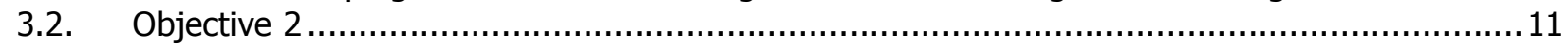

3.2.1. Task 2 Execution of the extensive literature searches using the tailored search strings

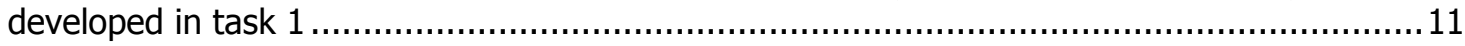

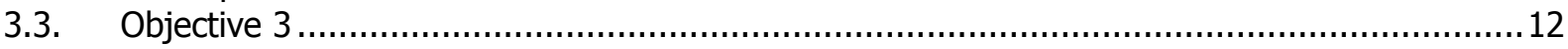

3.3.1. Task 3 Selection of all relevant studies retrieved by the extensive literature searches........... 12

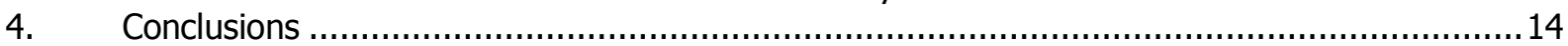

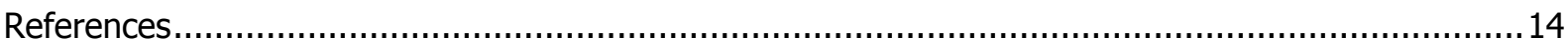

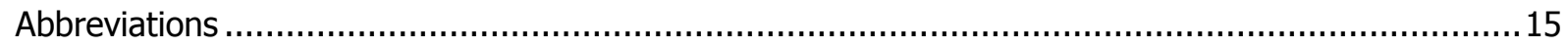

Appendix A - $\quad$ Log file for the tailored search strings to retrieve all relevant data on fumonisins and

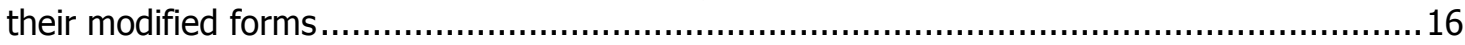

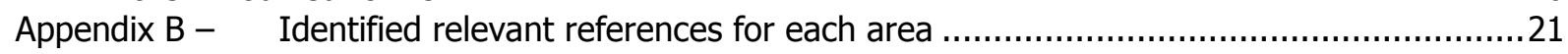




\section{Introduction}

\subsection{Background and Terms of Reference as provided by the requestor}

This contract/grant was awarded by EFSA to:

Contractor: National Food Institute, Technical University of Denmark

Contract title: Extensive literature search for studies related to fumonisins and their modified forms

Contract number: RC/EFSA/BIOCONTAM/2016/03

\subsubsection{Background as provided by EFSA}

The Unit on Biological Hazard and Contaminants (BIOCONTAM Unit) supports the Panel on Contaminants in the Food Chain (CONTAM Panel), which provides scientific advice on contaminants in the food chain and undesirable substances such as natural toxicants, mycotoxins and residues of unauthorised substances.

In April 2015 EFSA received from the European Commission a mandate for a scientific opinion on the appropriateness to set a group health based guidance value for fumonisins and their modified forms (EFSA-Q-2015-00227) and a mandate for a scientific opinion on the risks for animal health related to the presence of fumonisins and their modified forms in feed (EFSA-Q-2015-00248). These mandates were allocated to the CONTAM Panel. Working Groups have been established to develop these scientific opinions.

To support preparatory work for the hazard identification and characterization steps in the human and animal risk assessment, EFSA wishes to outsource an extensive literature search (ELS) related to fumonisins and their modified forms.

The present Call is based on EFSA's 2016 Work Programme for Grants and operational Procurements Financing Decision found in Annex II of the Programming Document 2016-2018, available on EFSA's website $^{1}$.

\subsubsection{Objectives as provided by EFSA}

The overall aim of the assignment is to identify and collect all relevant literature related to fumonisins and their modified forms to support preparatory work for the human and animal risk assessment of these substances.

The three specific objectives in this assignment include:

Objective 1:

To design a tailored search strategy to retrieve all potentially relevant studies on fumonisins and their modified forms as defined by EFSA (2014) in the following areas:

- Area 1: Data on chemistry and analysis (substance identification and characterisation, analytical detection and determination, formation).

- Area 2: Data on toxicokinetics (absorption, distribution, metabolism, excretion) in experimental animals, farm and companion animals, humans and from in vitro studies and on biomarkers.

- Area 3: Data on in vitro and in vivo mode of action (MoA) of toxicity.

- Area 4: Data on toxicity in vivo (e.g. acute, subacute, subchronic, chronic toxicity; genotoxicity, carcinogenicity, toxicity to specific organs) in laboratory animals.

- Area 5: Data on toxicity in vitro.

\footnotetext{
${ }^{1}$ http://www.efsa.europa.eu/sites/default/files/mb151203-a2.pdf 
- Area 6: Data on observations in humans (e.g. epidemiological studies, case reports, intervention studies).

- Area 7: Data on adverse effects in farm and companion animals (studies in the different species e.g. ruminants, pigs, poultry, rabbits, fish, cats, dogs etc.).

- Area 8: Data on occurrence in food.

- Area 9: Data on occurrence in feed and animal exposure (including feed occurrence in the different feed commodities, feed intake and animal exposure).

Objective 2:

To retrieve all potentially relevant studies for fumonisins and their modified forms by execution of an extensive literature search (ELS) using the tailored search strings for the nine areas developed under objective 1.

Objective 3:

To determine the relevance of the retrieved studies by screening titles and abstracts according to preselected eligibility criteria and prepare the outcome of the project for presentation to EFSA.

\section{Methodologies}

The methodology for systematic reviews including guidance for development and optimisation of a search strategy and for selecting relevant studies has been described by EFSA (2010). This methodology was implemented as appropriate in the Tasks described below.

\subsection{Objective 1}

\subsubsection{Task 1 Developing tailored search strategies and search strings for collecting relevant studies}

A tailored search string for each of the nine areas described above was developed for identifying all potentially relevant studies for the human and animal risk assessment of fumonisins and their modified forms.

The search strings are driven by eligibility criteria for each Area (1-9) developed by the Contractor and agreed with EFSA. The eligibility criteria contained both inclusion and exclusion criteria. The search strings were tailored to the databases PubMed and Web of Science ${ }^{2}$. Therefore the search strings consisted of two major steps each designed to search titles and abstracts in PubMed and Web of Science, as well as full text in PubMed. Combinations of search terms were used. Use of the Boolean operator "NOT" is generally to be avoided as a relevant reference can contain discussions on both relevant and excluded search terms.

Step 1 consisted of a broad search for fumonisins and their modified forms, synonyms and abbreviations. The dominant fumonisins found as contaminants in food and feed belong to the $B$ group (FB) and comprise FB1 to FB6. Modified forms of fumonisin B (FB) include hydrolysed fumonisin $B(H F B)$, partially hydrolysed fumonisin B (PHFB), N-deoxyfructos-1-yl fumonisin B (NDF-FB) and $\mathrm{N}$-carboxymethyl fumonisin B (NCM-FB) (EFSA 2014). The search strategies were designed to capture the fumonisin $B$ group and their modified forms, as well as to capture other fumonisin groups (e.g. A, C and P) and their modified forms, if any.

Step 2 was Area specific with the addition of search terms relevant to each specific Area.

\footnotetext{
${ }^{2}$ Including the following databases: Web of ScienceTM Core Collection, BIOSIS Citation IndexSM, CABI: CAB Abstracts ${ }^{\circledR}$, Current Contents Connect $\AA$, Data Citation index SM, FSTA $®$ - the food science resource, MEDLINE $₫$, SciELO Citation Index and Zoological Recored $囚$.
} 
Search terms were identified in collaboration with the entire project team to identify as many relevant as possible. The search terms were developed in order to retrieve the largest number of potentially relevant studies on fumonisins and their modified forms within Area 1-9. The search strings were presented and discussed with EFSA at the kick-off meeting.

\subsection{Objective 2}

\subsubsection{Task 2 Execution of the extensive literature searches using the tailored search strings developed in task 1}

The tailored search strings developed in Task 1 and agreed upon by EFSA were employed to retrieve all relevant studies from the databases PubMed and Web of Science on fumonisins and their modified forms.

Data published since year 2000 were retrieved for Area 1-6 and Area 8-9. Data published since year 1980 were retrieved for Area 7.

All references located in the extensive literature searches in PubMed and Web of Science were exported as separate files into EndNote ${ }^{T M}$. Title, author, journal, year of publication and abstract were included for each study imported to EndNote ${ }^{T M}$ and the number of hits resulting from each of the tailored search strings in each of the two databases were recorded in a log file. Duplicate studies were then removed after combining the two EndNote ${ }^{\mathrm{TM}}$ files per Area into one single combined file per Area.

\subsection{Objective 3}

\subsubsection{Task 3 Selection of all relevant studies retrieved by the extensive literature searches}

All studies retrieved by the extensive literature searches and imported into the combined EndNote ${ }^{\mathrm{TM}}$ files, one file per Area (Task 2), were evaluated for relevance by applying eligibility criteria (inclusion/exclusion) for each subject Area (1-9) developed by the Contractor and agreed upon by EFSA. The selection for relevance was conducted by screening their title and abstract (if available) and all the retrieved studies were ultimately sorted into one of the following three categories:

- Relevant to the research objectives: References ultimately evaluated to be relevant were included in this category.

- Maybe relevant to the research objectives: In case the relevance could not be evaluated because e.g. of missing or vague abstracts or because the reference addressed and discussed mycotoxins in general and fumonisins could not be excluded based on the title and abstract of the reference, the references were included in this category, as a conservative approach.

- $\quad$ Not relevant to the research objectives: References ultimately evaluated not to be in-scope were included in this category.

To ensure a uniform understanding of the eligibility criteria in each Area, these were discussed in an internal meeting before all references were assessed for relevance.

According to the original protocol proposed by the Contractor, "Each reference will be individually assessed by two reviewers in order to prevent the introduction of errors and personal bias. In the possible event of disagreements between reviewers a third member of the project team will assist in solving the specific issue as recommended by EFSA (2010)." However, as a result of the very broad search strings for each Area, a huge number of irrelevant hits were retrieved in the ELS for each Area. Furthermore, as a result of the many Areas, a great number of references appeared in more than one area. It was therefore decided that one principal team member for each Area performed an initial sorting of the hits into one of the following four categories: 1) Relevant, 2) Maybe relevant, 3) Not relevant, and 4) to be further assessed. All the references in the fourth category ('to be further 
assessed') were then evaluated by a principal team member eventually in collaboration with another team member and the references were then included either in the 'Relevant', the 'Maybe relevant' or in the 'Not relevant' category. The project coordinator also assisted in this evaluation. In case relevance still remained uncertain, the references were included in the 'Maybe relevant' category, as a conservative approach. This deviation from the original protocol is not considered to invalidate the outcome of the selection for relevance of the studies retrieved from the ELSs because of the control measures and quality check taken in the execution of this task.

During the selection of relevance process the principal team member for a specific Area also identified references of potential relevance for other Areas. After the selection of relevance process was finalised for each Area a cross check was made between one specific Area and all other Areas to ensure that all relevant references have been captured for each Area. References that were identified in another Area / other Areas as being potential relevant for the specific Area, but not retrieved in the Area specific literature searches in PubMed and Web of Science were included in both the Area specific summary table (in an additional sheet) and in the Area Specific EndNote file (in a separate folder).

To ensure a uniform reporting in the summary tables, representative references within each Area were assessed for relevance by all principal team members and discussed in an internal meeting before all references were assessed for relevance. These described measures were implemented to avoid the introduction of time-consuming mistakes.

The results of the reference selection process were reported in summary tables (Excel files), one table per Area. The summary tables included all pertinent information from each of the relevant studies as identified by the eligibility criteria developed by the Contractor and agreed with EFSA. The information included in the summary tables ensures that all eligibility criteria of the studies were considered. Additional fields for relevance (answered by yes/no based on the eligibility criteria), indication of other potential Areas, the person(s) responsible for the screening and comments were also included in the summary tables.

All references found relevant for the human and animal risk assessment of fumonisins and their modified forms within Area 1-9 were collected in a single EndNote ${ }^{\mathrm{TM}}$ file including all indexed fields per reference (i.e. title, author, publication year, journal and abstract).

All relevant studies were collected in a reference list, one list per Area, see Appendix B.

\section{Results}

\subsection{Objective 1}

\subsubsection{Task 1 Developing tailored search strategies and search strings for collecting relevant studies}

The tailored search strings were developed in order to retrieve the largest number of potentially relevant studies for the human and animal risk assessment of fumonisins and their modified forms within Area 1-9.

The proposed search strings were submitted to EFSA on 7 July 2016 (email) as part of Deliverable 1, and were discussed, revised and agreed with EFSA at the kick-off meeting on 11-12 July. The agreed search strings for Step 1 and Step 2, for Area 1-9 are presented below.

The search string for step 1 was developed in order to capture all known fumonisin groups (e.g. A, B, $C$ and $P$ ) by using the search term fumonisin*. Regarding modified forms of fumonisins the search terms have been restricted to include the known modified forms of the fumonisin $B$ group defined in the EFSA CONTAM Panel (2014) opinion as modified forms of other fumonisin groups are not known to the Contractor.

The search strings for step 2, Area 2-6 were developed based on the experiences obtained in a similar procurement recently carried out for EFSA 'Identifying and collecting relevant literature related to the 
oral toxicity of furan and its methyl analogues, 2-methylfuran and 3-methylfuran, final report submitted to EFSA on 14 June 2016. In that procurement, the search terms were combined and tested in the databases PubMed and Web of Science to develop the most sensitive and appropriate search string. The search strings were also tested by assessing whether they retrieved relevant papers already known to the project team as recommended in EFSA (2010).

The search strings for step 2, Area 1 and 7-9 were deliberately developed as very broad and detailed in order to capture all potentially relevant data within these Areas. For Area 7, many of the search terms regarding farm and companion animal species were suggested as it is known to the Contractor that fumonisins cause adverse effects in these species; other search terms regarding species were suggested in order to achieve completeness regarding major farm and companion animal species. For Area 8 and 9, many of the search terms regarding food (Area 8) and feed (Area 9) were suggested as it is known to the Contractor that fumonisins have been detected in these foods/feeds; other search terms were suggested in order to achieve completeness regarding major foods/feeds.

In the proposed search strings, "OR" is the Boolean operator that expands the amount of references returned when used in a search string as just one of the search terms need to be present in the returned references. "*" symbolises truncation and is used for finding singular and plural forms of words and various endings. Both PubMed and Web of Science use an asterisk as their truncation symbol.

Step 1:

The search string agreed for step 1 is as follows:

Fumonisin*
OR HFB*
OR PHFB*
OR NDF-FB*
OR NDF/FB*
OR NCM-FB*
OR NCM/FB*

Step 2:

The Area specific search strings agreed for step 2 are as follows:

Area 1: Data on chemistry and analysis (substance identification and characterisation, analytical detection and determination, formation).

(Fusarium OR chem* OR analy* OR identi* OR charact* OR detect* OR determin* OR method* OR form* OR degrad* OR hydroly* OR reaction* OR GC* OR HPLC OR LC-MS OR ICP-MS)

Area 2: Data on toxicokinetics (absorption, distribution, metabolism, excretion) in experimental animals, farm and companion animals, humans and from in vitro studies and on biomarkers.

(in vitro OR absor* OR tissue* OR metaboli* OR excret* OR kinetic* OR toxicokinetic* OR pharmacokinetic* OR degrad* OR biotrans* OR eliminat* OR biomark*)

Area 3: Data on in vitro and in vivo mode of action (MoA) of toxicity.

(in vitro OR in vivo OR mode OR action OR mechanism* OR glycol* OR sphingolipid* OR apoptosis OR oxidative)

Area 4: Data on toxicity in vivo (e.g. acute, subacute, subchronic, chronic toxicity; genotoxicity, carcinogenicity, toxicity to specific organs) in laboratory animals.

(in vivo OR acute OR chronic OR tox* OR genotox* OR muta* OR DNA OR damage OR repair OR clastogen* OR aneugen* OR chromosom* OR cancer* OR carcino* OR tumor* OR tumour* OR organ* OR tissue* OR immun* OR neuro* OR developmental OR teratogen* OR repro* OR liver OR 
kidney* OR brain* OR lung* OR cardiovascular OR rat* OR mouse OR mice OR rabbit* OR guinea OR hamster* OR primate* OR monkey*)

Area 5: Data on toxicity in vitro.

(in vitro OR cytotox* OR genotox* OR muta* OR DNA OR damage OR repair OR clastogen* OR aneugen* OR chromosom* OR culture)

Area 6: Data on observations in humans (e.g. epidemiological studies, case reports, intervention studies).

(epidemio* OR intervention OR exposure* OR case* OR poison* OR cohort* OR cross-sectional OR random* OR work*)

Area 7: Data on adverse effects in farm and companion animals (studies in the different species e.g. ruminants, pigs, poultry, rabbits, fish, cats, dogs etc.).

(tox* OR poison* OR cancer* OR carcino* OR tumor* OR tumour* OR organ* OR tissue* OR immun* OR neuro* OR developmental OR teratogen* OR repro* OR liver OR kidney* OR brain* OR lung* OR cardiovascular OR health OR clinical OR growth OR weight OR farm animals OR horse* OR stallion* OR mare* OR foal* OR equine OR ruminant* OR livestock OR herd OR cow* OR cattle OR bull* OR calf OR calves OR heifer* OR bovine OR sheep* OR ewe* OR ram* OR lamb OR goat* OR caprine OR ovine OR pig* OR swine* OR sow* OR gilt* OR boar* OR porcine OR mink* OR poultry OR chicken* OR hen* OR cock* OR rooster* OR broiler* OR duck* OR goose OR geese OR geesling* OR turkey* OR quail* OR guinea OR rabbit* OR fish* OR salmon OR trout OR piscine OR zebrafish OR pet* OR cat* OR kitten* OR dog* OR bitch* OR pupp*)

Area 8: Data on occurrence in food.

(Fusarium OR concentration* OR occurrence OR food* OR diet* OR commod* OR fruit* OR pineapple OR Ananas comosus OR vegetable* OR garlic OR Allium sativum OR asparagus OR cereal* OR corn* OR maize OR Zea mays OR wheat OR Triticum aestivum OR rye OR Secale cereale OR barley OR Hordeum vulgare OR oat OR Avena sativa OR rice OR Oryza sativa OR soybean OR Glycine max OR sorghum OR sugarcane OR Saccharum officinarum OR millet OR Eleusine sp. OR Pennisetum glaucum OR starch OR flour OR bran OR germ OR dairy OR milk OR egg* OR meat OR liver OR kidney* OR offal OR coffee)

Area 9: Data on occurrence in feed and animal exposure (including feed occurrence in the different feed commodities, feed intake and animal exposure).

(Fusarium OR concentration* OR expos* OR occurrence OR intake OR feed* OR fodder OR diet* OR meal OR cereal* OR corn OR maize OR Zea mays OR wheat OR Triticum aestivum OR rye OR Secale cereale OR barley OR Hordeum vulgare OR oat OR Avena sativa OR grain* OR seed* OR forage OR silage OR grass OR Poaceae OR hay OR rape OR Raptio OR Brassica napus OR soybean OR Glycine max OR DDGS OR WDG)

DDGS: Dried Distillers Grains with Solubles

WDG: Wet Distillers Grains

\subsection{Objective 2}

\subsubsection{Task 2 Execution of the extensive literature searches using the tailored search strings developed in task 1}

The number of hits resulting from each of the tailored search strings in each of the two databases PubMed and Web of Science were recorded in a log file, see Appendix A.

The total number of hits from each database, as well as the total number of hits after removal of the duplicates (combined) are summarised in the table below. The duplicates in the combined file for each Area 1-9 were removed by the EndNote tool; however, duplicates may still be present in the combined 
files as the EndNote tool for various reasons is not able to remove all duplicates. These duplicates were identified during the execution of Task 3 and then removed manually. The revised versions of the combined files were submitted as part of the final deliverable.

\begin{tabular}{|c|c|c|c|c|}
\hline Area & PubMed & Web of Science & Combined total & Combined \\
\hline 1 & 2209 & 4145 & 6354 & 4456 \\
\hline 2 & 1531 & 1661 & 3192 & 2261 \\
\hline 3 & 923 & 1551 & 2474 & 1649 \\
\hline 4 & 1667 & 3272 & 4939 & 3555 \\
\hline 5 & 796 & 1504 & 2300 & 1632 \\
\hline 6 & 1748 & 1363 & 3111 & 2424 \\
\hline 7 & 2966 & 4331 & 7297 & 5087 \\
\hline 8 & 1823 & 3053 & 4876 & 3284 \\
\hline 9 & 1755 & 3076 & 4831 & 3283 \\
\hline
\end{tabular}

The search terms NDF-FB*, NDF/FB* and NCM/FB* gave no hits in Web of Science and NDF-FB* gave no hits in PubMed.

The search term GC* in the Area 1 search string gave no hits. The search term GC alone gave 88295 hits, which have been included in the final search for Area 1.

The results of the ELS on fumonisins and their modified forms for Area 1-9 were submitted to EFSA on 29 July (Interim report N2 by email, EndNote files uploaded to the DMS) as Deliverable 2.

For each of Area 1-9, three EndNote files were submitted: One including all hits from PubMed (named: My EndNote Library_AREA X_PubMed.enlx), one including all hits from Web of Science (named: My EndNote Library_AREA X_WoS.enlx), and one including the combined hits from PubMed and Web of Science with duplicate records removed (named: My EndNote Library_AREA $\mathrm{X}$ _combined.enlx).

\subsection{Objective 3}

\subsubsection{Task 3 Selection of all relevant studies retrieved by the extensive literature searches}

The total number of relevant references for Area 1 was 532, for Area 2 114, for Area 3 273, for Area 4 87, for Area 5 138, for Area 6 38, for Area 7 270, for Area 8 709, and for Area 9270.

The final protocol and project plan implemented by the Contractor to carry out the project was submitted to EFSA on 7 November (uploaded to the DMS and by email) as part of the draft final deliverable, the final version was submitted to EFSA on 21 November (uploaded to the DMS and by email), and the revised final version was submitted to EFSA on 2 December (uploaded to the DMS and by email) as part of the final deliberable.

\section{Summary tables}

A proposal for the information (eligibility criteria) to be included in the summary tables for each area (combined pdf) was submitted to EFSA on 7 July (email) as part of Deliverable 1. The proposed summary tables were discussed with EFSA at the kick-off meeting on 11-12 July. EFSA had a few suggestions for revisions which were agreed at the kick-off meeting, and reflected in the revised version of the summary tables submitted to EFSA on 20 July (email), and again on 27 July (email).

Summary tables (Excel files) were prepared, one table for each Area 1-9. The summary tables include all pertinent information for each of the references in the 'Relevant' category as identified by the eligibility criteria suggested by the Contractor and agreed by EFSA, which could be retrieved from the title and abstract (when available). 
According to the tender specifications, the summary tables should only include the relevant studies. However, for transparency reasons, it was agreed at the kick-off meeting also to include the 'Maybe relevant' and 'Not relevant' studies, but without any study details. For the 'Not relevant' studies, the reason for exclusion, i.e. not target compound or not relevant for the specific Area is presented. In addition, there is also an indication if a specific reference is considered of potential relevance for other Area(s).

All references included in the 'Relevant' category appear on a green background; all references included in the 'Maybe relevant' category appear on a yellow background; and all references included in the 'Not relevant' category appear on a white background. An additional sheet has been added in the summary tables for all Areas, except for Area 7. This additional sheet includes the references that were identified in another Area / other Areas as being potential relevant for the specific Area, but not retrieved in the Area specific literature searches in PubMed and Web of Science.

The summary tables were submitted to EFSA on 7 November (uploaded to the DMS) as part of the draft final deliverable and the final versions were submitted to EFSA on 21 November (uploaded to the DMS) as part of the final deliverable.

\section{EndNote $^{\mathrm{TM}}$ files}

In the EndNote files, one file per Area (named: My EndNote Library_AREA X_deliverable 3.enlx), all hits were separated into 5 or 6 folders and named as follows:

- 'Relevant': Containing hits evaluated to be of relevance for this procurement

- 'Maybe relevant': Containing hits for which the relevance could not be evaluated because e.g. of missing or vague abstracts or because the reference addressed and discussed mycotoxins in general and fumonisins could not be excluded based on the title and abstract of the reference

- 'Not relevant': Containing hits evaluated not to be in-scope for this procurement

- 'Relevant from other areas': Containing hits evaluated to be of relevance for this procurement that were identified in another Area / other Areas than the specific Area, but not retrieved in the Area specific literature searches in PubMed and Web of Science.

- 'May-be relevant from other areas': Containing hits that may be relevant that were identified in another Area / other Areas that the specific Area, but not retrieved in the Area specific literature searches in PubMed and Web of Science.

- 'Trash': Containing the removed duplicates.

The EndNote files were submitted to EFSA on 7 November (uploaded to the DMS) as part of the draft final deliverable, the final versions were submitted to EFSA on 21 November (uploaded to the DMS), and the revised final versions were submitted to EFSA on 2 December (uploaded to the DMS) as part of the final deliverable.

\section{Reference lists}

All relevant references were collected in a reference list (Word file), one file per Area. The reference lists are included in Appendix B to this report. 


\section{Conclusions}

An extensive literature search to identify and collect all studies related to fumonisins and their modified forms was performed in the two databases PubMed and Web of Science for nine Areas.

The total number of hits from each database, as well as the total number of hits (combined total) and total number of hits after removal of the duplicates (combined) are summarised in the table below.

\begin{tabular}{c|c|c|c|c}
\hline Area & PubMed & Web of Science & Combined total & Combined \\
\hline 1 & 2209 & 4145 & 6354 & 4456 \\
\hline 2 & 1531 & 1661 & 3192 & 2261 \\
\hline 3 & 923 & 1551 & 2474 & 1649 \\
\hline 4 & 1667 & 3272 & 4939 & 3555 \\
\hline 5 & 796 & 1504 & 2300 & 1632 \\
\hline 6 & 1748 & 1363 & 3111 & 2424 \\
\hline 7 & 2966 & 4331 & 7297 & 5087 \\
\hline 8 & 1823 & 3053 & 4876 & 3284 \\
\hline 9 & 1755 & 3076 & 4831 & 3283 \\
\hline
\end{tabular}

The evaluation of all retrieved references for relevance by screening the title and abstract (if available) and applying eligibility criteria (inclusion/exclusion) resulted in a total number of relevant references for Area 1 of 532, for Area 2 of 114, for Area 3 of 273, for Area 4 of 87, for Area 5 of 138, for Area 6 of 38, for Area 7 of 270, for Area 8 of 709, and for Area 9 of 270.

\section{References}

EFSA (European Food Safety Authority), 2010. Application of systematic review methodology to food and feed safety assessments to support decision making. EFSA Journal 2010;8(6):1637, 90 pp. doi:10.2903/j.efsa.2010.1637

EFSA CONTAM Panel (EFSA Panel on Contaminants in the Food Chain), 2014. Scientific Opinion on the risks for human and animal health related to the presence of modified forms of certain mycotoxins in food and feed. EFSA Journal 2014;12(12):3916, 107 pp. doi:10.2903/j.efsa.2014.3916 


\section{Abbreviations}

DDGS Dried Distillers Grains with Solubles

EFSA European Food Safety Authority

ELS Extensive literature search

FB Fumonisin B

GC Gas Chromatography

HFB Hydrolysed fumonisin B

HPLC High Performance Liquid Chromatography

ICP-MS Inductively Coupled Plasma Mass Spectrometry

LC-MS Liquid Chromatography Mass Spectrometry

MoA Mode of Action

NCM-FB N-carboxymethyl fumonisin B

NCM/FB N-carboxymethyl fumonisin B

NDF-FB N-deoxyfructos-1-yl fumonisin B

NDF/FB N-deoxyfructos-1-yl fumonisin B

PHFB Partially hydrolysed fumonisin B

WDG Wet Distillers Grains 


\section{Appendix A - Log file for the tailored search strings to retrieve all relevant data on fumonisins and their modified forms}

The search terms NDF-FB*; NDF/FB* and NCM/FB* gave no hits in Web of Science and NDF-FB* gave no hits in PubMed.

\begin{tabular}{|c|c|c|c|c|c|c|c|}
\hline $\begin{array}{l}\text { Date } \\
\text { search }\end{array}$ & & $\begin{array}{l}\text { Substance } \\
\text { name }\end{array}$ & $\begin{array}{l}\text { Databases } \\
\text { \& Search } \\
\text { Engines }\end{array}$ & Search terms & $\begin{array}{l}\text { Limitations } \\
\text { applied to } \\
\text { search }\end{array}$ & $\begin{array}{l}\text { No } \\
\text { of } \\
\text { 'hits' }\end{array}$ & $\begin{array}{l}\text { Comments } \\
\text { \& follow- } \\
\text { up actions }\end{array}$ \\
\hline $\begin{array}{l}\text { July } \\
2016\end{array}$ & 20 & Fumonisin & $\begin{array}{ll}\text { Web } & \text { of } \\
\text { Science }\end{array}$ & $\begin{array}{l}\text { (Fumonisin* OR HFB* OR PHFB* } \\
\text { OR NCM-FB*) AND (Fusarium OR } \\
\text { chem* OR analy* OR identi* OR } \\
\text { charact* OR detect* OR determin* } \\
\text { OR method* OR form* OR degrad* } \\
\text { OR hydroly* OR reaction* OR GC } \\
\text { OR HPLC OR LC-MS OR ICP-MS) }\end{array}$ & $\begin{array}{l}\text { Year: 2000- } \\
\text { Language: } \\
\text { English }\end{array}$ & 4145 & $\begin{array}{l}\text { AREA 1 } \\
\text { [Comment: } \\
\text { The search } \\
\text { term GC* } \\
\text { gave no } \\
\text { hits. GC } \\
\text { alone gave } \\
88295 \text { hits, } \\
\text { which have } \\
\text { been in } \\
\text { included in } \\
\text { the final } \\
\text { search] } \\
\text { Has been } \\
\text { exported to } \\
\text { EndNote }\end{array}$ \\
\hline $\begin{array}{l}\text { July } \\
2016\end{array}$ & 20 & Fumonisin & $\begin{array}{l}\text { Web of } \\
\text { Science }\end{array}$ & $\begin{array}{l}\text { (Fumonisin* OR HFB* OR PHFB* } \\
\text { OR NCM-FB*) AND ("in vitro" OR } \\
\text { absor* OR tissue* OR metaboli* } \\
\text { OR excret* OR kinetic* OR } \\
\text { toxicokinetic* OR pharmacokinetic* } \\
\text { OR degrad* OR biotrans* OR } \\
\text { eliminat* OR biomark*) }\end{array}$ & $\begin{array}{l}\text { Year: 2000- } \\
\text { Language: } \\
\text { English }\end{array}$ & 1661 & $\begin{array}{l}\text { AREA } 2 \\
\text { Has been } \\
\text { exported to } \\
\text { EndNote }^{T M}\end{array}$ \\
\hline $\begin{array}{l}\text { July } \\
2016\end{array}$ & 20 & Fumonisin & $\begin{array}{l}\text { Web of } \\
\text { Science }\end{array}$ & 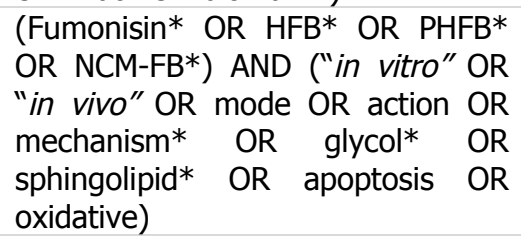 & $\begin{array}{l}\text { Year: 2000- } \\
\text { Language: } \\
\text { English }\end{array}$ & 1551 & $\begin{array}{l}\text { AREA } 3 \\
\text { Has been } \\
\text { exported to } \\
\text { EndNote }^{T M}\end{array}$ \\
\hline $\begin{array}{l}\text { July } \\
2016\end{array}$ & 20 & Fumonisin & $\begin{array}{l}\text { Web of } \\
\text { Science }\end{array}$ & $\begin{array}{l}\text { (Fumonisin* OR HFB* OR PHFB* } \\
\text { OR NCM-FB*) AND ("in vivo" OR } \\
\text { acute OR chronic OR tox* OR } \\
\text { genotox* OR muta* OR DNA OR } \\
\text { damage OR repair OR clastogen* } \\
\text { OR aneugen* OR chromosom* OR } \\
\text { cancer* OR carcino* OR tumor* } \\
\text { OR tumour* OR organ* OR tissue* } \\
\text { OR immun* OR neuro* OR } \\
\text { developmental OR teratogen* OR } \\
\text { repro* OR liver OR kidney* OR } \\
\text { brain* OR lung* OR cardiovascular } \\
\text { OR rat* OR mouse OR mice OR } \\
\text { rabbit* OR hamster* OR primate* } \\
\text { OR monkey*) }\end{array}$ & $\begin{array}{l}\text { Year: 2000- } \\
\text { Language: } \\
\text { English }\end{array}$ & 3272 & $\begin{array}{l}\text { AREA } 4 \\
\text { Has been } \\
\text { exported to } \\
\text { EndNote }^{T M}\end{array}$ \\
\hline $\begin{array}{l}\text { July } \\
2016\end{array}$ & 20 & Fumonisin & $\begin{array}{l}\text { Web } \\
\text { Science }\end{array}$ & $\begin{array}{l}\text { (Fumonisin* OR HFB* OR PHFB* } \\
\text { OR NCM-FB*) AND ("in vitro" OR } \\
\text { cytotox* OR genotox* OR muta* } \\
\text { OR DNA OR damage OR repair OR } \\
\text { clastogen* OR aneugen* OR } \\
\text { chromosom* OR culture) }\end{array}$ & $\begin{array}{l}\text { Year: 2000- } \\
\text { Language: } \\
\text { English }\end{array}$ & 1504 & $\begin{array}{l}\text { AREA } 5 \\
\text { Has been } \\
\text { exported to } \\
\text { EndNote }^{T M}\end{array}$ \\
\hline July & 20 & Fumonisin & Web & (Fumonisin* OR HFB* OR PHFB* & Year: 2000- & 1363 & AREA 6 \\
\hline
\end{tabular}




\begin{tabular}{|c|c|c|c|c|c|c|}
\hline $\begin{array}{l}\text { Date of } \\
\text { search }\end{array}$ & $\begin{array}{l}\text { Substance } \\
\text { name }\end{array}$ & $\begin{array}{l}\text { Databases } \\
\text { \& Search } \\
\text { Engines } \\
\end{array}$ & Search terms & $\begin{array}{l}\text { Limitations } \\
\text { applied to } \\
\text { search }\end{array}$ & $\begin{array}{l}\text { No } \\
\text { of } \\
\text { 'hits' }\end{array}$ & $\begin{array}{l}\text { Comments } \\
\text { \& follow- } \\
\text { up actions }\end{array}$ \\
\hline 2016 & & Science & $\begin{array}{l}\text { OR NCM-FB*) AND (epidemio* OR } \\
\text { intervention OR exposure* OR } \\
\text { case* OR poison* OR cohort* OR } \\
\text { cross-sectional OR random* OR } \\
\text { work*) }\end{array}$ & $\begin{array}{l}\text { Language: } \\
\text { English }\end{array}$ & & $\begin{array}{l}\text { Has been } \\
\text { exported to } \\
\text { EndNote }^{T M}\end{array}$ \\
\hline $\begin{array}{l}\text { July 20, } \\
2016\end{array}$ & Fumonisin & $\begin{array}{l}\text { Web of } \\
\text { Science }\end{array}$ & $\begin{array}{l}\text { (Fumonisin* OR HFB* OR PHFB* } \\
\text { OR NCM-FB*) AND (tox* OR } \\
\text { poison* OR cancer* OR carcino* } \\
\text { OR tumor* OR tumour* OR organ* } \\
\text { OR tissue* OR immun* OR neuro* } \\
\text { OR developmental OR teratogen* } \\
\text { OR repro* OR liver OR kidney* OR } \\
\text { brain* OR lung* OR cardiovascular } \\
\text { OR health OR clinical OR growth } \\
\text { OR weight OR "farm animals" OR } \\
\text { horse* OR stallion* OR mare* OR } \\
\text { foal* OR equine OR ruminant* OR } \\
\text { livestock OR herd OR cow* OR } \\
\text { cattle OR bull* OR calf OR calves } \\
\text { OR heifer* OR bovine OR sheep* } \\
\text { OR ewe* OR ram* OR lamb OR } \\
\text { goat* OR caprine OR ovine OR } \\
\text { pig* OR swine* OR sow* OR gilt* } \\
\text { OR boar* OR porcine OR mink* OR } \\
\text { poultry OR chicken* OR hen* OR } \\
\text { cock* OR rooster* OR broiler* OR } \\
\text { duck* OR goose OR geese OR } \\
\text { geesling* OR turkey* OR quail* OR } \\
\text { guinea OR rabbit* OR fish* OR } \\
\text { salmon OR trout OR piscine OR } \\
\text { zebrafish OR pet* OR cat* OR } \\
\text { kitten* OR dog* OR bitch* OR } \\
\text { pupp*) }\end{array}$ & Year: 1980- & 4331 & $\begin{array}{l}\text { AREA } 7 \\
\text { Has been } \\
\text { exported to } \\
\text { EndNote }^{T M}\end{array}$ \\
\hline $\begin{array}{l}\text { July 21, } \\
2016\end{array}$ & Fumonisin & $\begin{array}{l}\text { Web } \\
\text { Science }\end{array}$ & $\begin{array}{l}\text { (Fumonisin* OR HFB* OR PHFB* } \\
\text { OR NCM-FB*) AND (Fusarium OR } \\
\text { concentration* OR occurrence OR } \\
\text { food* OR diet* OR commod* OR } \\
\text { fruit* OR pineapple OR "Ananas } \\
\text { comosus" OR vegetable* OR garlic } \\
\text { OR "Allium sativum" OR asparagus } \\
\text { OR cereal* OR corn* OR maize OR } \\
\text { "Zea mays" OR wheat OR "Triticum } \\
\text { aestivum" OR rye OR "Secale } \\
\text { cereal" OR barley OR "Hordeum } \\
\text { vulgare" OR oat OR "Avena sativa" } \\
\text { OR rice OR "Oryza sativa" OR } \\
\text { soybean OR "Glycine max" OR } \\
\text { sorghum OR sugarcane OR } \\
\text { "Saccharum officinarum" OR millet } \\
\text { OR "Eleusine sp." OR "Pennisetum } \\
\text { glaucum" OR starch OR flour OR } \\
\text { bran OR germ OR dairy OR milk OR } \\
\text { egg* OR meat OR liver OR kidney* } \\
\text { OR offal OR coffee) }\end{array}$ & $\begin{array}{l}\text { Year: 2000- } \\
\text { Language: } \\
\text { English }\end{array}$ & 3053 & $\begin{array}{l}\text { AREA } 8 \\
\text { Has been } \\
\text { exported to } \\
\text { EndNote }^{T M}\end{array}$ \\
\hline $\begin{array}{l}\text { July 21, } \\
2016\end{array}$ & Fumonisin & $\begin{array}{l}\text { Web of } \\
\text { Science }\end{array}$ & $\begin{array}{l}\text { (Fumonisin* OR HFB* OR PHFB* } \\
\text { OR NCM-FB*) AND (Fusarium OR } \\
\text { concentration* OR expos* OR }\end{array}$ & $\begin{array}{l}\text { Year: 2000- } \\
\text { Language: } \\
\text { English }\end{array}$ & 3076 & $\begin{array}{l}\text { AREA } 9 \\
\text { Has been } \\
\text { exported to }\end{array}$ \\
\hline
\end{tabular}




\begin{tabular}{|c|c|c|c|c|c|c|}
\hline $\begin{array}{l}\text { Date of } \\
\text { search }\end{array}$ & $\begin{array}{l}\text { Substance } \\
\text { name }\end{array}$ & $\begin{array}{l}\text { Databases } \\
\text { \& Search } \\
\text { Engines }\end{array}$ & Search terms & $\begin{array}{l}\text { Limitations } \\
\text { applied to } \\
\text { search }\end{array}$ & $\begin{array}{l}\text { No } \\
\text { of } \\
\text { 'hits' } \\
\end{array}$ & $\begin{array}{l}\text { Comments } \\
\& \text { follow- } \\
\text { up actions }\end{array}$ \\
\hline & & & $\begin{array}{l}\text { occurrence OR intake OR feed* OR } \\
\text { fodder OR diet* OR meal OR } \\
\text { cereal* OR corn OR maize OR "Zea } \\
\text { mays" OR wheat OR "Triticum } \\
\text { aestivum" OR rye OR "Secale } \\
\text { cereal" OR barley OR "Hordeum } \\
\text { vulgare" OR oat OR "Avena sativa" } \\
\text { OR grain* OR seed* OR forage OR } \\
\text { silage OR grass OR Poaceae OR } \\
\text { hay OR rape OR Raptio OR } \\
\text { "Brassica napus" OR soybean OR } \\
\text { "Glycine max" OR DDGS OR WDG } \\
\text { OR (dried AND distillers AND grains } \\
\text { AND with AND solubles) OR (wet } \\
\text { AND distillers AND grain)) }\end{array}$ & & & EndNote $^{T M}$ \\
\hline $\begin{array}{l}\text { July } 21, \\
2016\end{array}$ & Fumonisin & PubMed & $\begin{array}{l}\text { (Fumonisin* OR HFB* OR PHFB* } \\
\text { OR NDF-FB* OR NDF/FB* OR NCM- } \\
\text { FB* OR NCM/FB*) AND (Fusarium } \\
\text { OR chem* OR analy* OR identi* } \\
\text { OR charact* OR detect* OR } \\
\text { determin* OR method* OR form* } \\
\text { OR degrad* OR hydroly* OR } \\
\text { reaction* OR GC OR HPLC OR LC- } \\
\text { MS OR ICP-MS) }\end{array}$ & $\begin{array}{l}\text { Year: 2000- } \\
\text { Language: } \\
\text { English }\end{array}$ & 2209 & $\begin{array}{l}\text { AREA } 1 \\
\text { Has been } \\
\text { exported to } \\
\text { EndNote }^{T M}\end{array}$ \\
\hline $\begin{array}{l}\text { July } 28, \\
2016\end{array}$ & Fumonisin & PubMed & 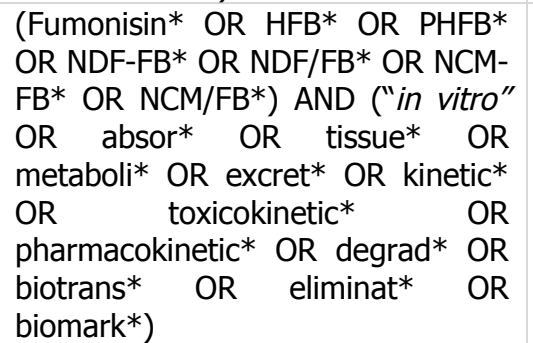 & $\begin{array}{l}\text { Year: 2000- } \\
\text { Language: } \\
\text { English }\end{array}$ & 1531 & $\begin{array}{l}\text { AREA } 2 \\
\text { Has been } \\
\text { exported to } \\
\text { EndNote }^{T M}\end{array}$ \\
\hline $\begin{array}{l}\text { July } 28, \\
2016\end{array}$ & Fumonisin & PubMed & $\begin{array}{l}\text { (Fumonisin* OR HFB* OR PHFB* } \\
\text { OR NDF-FB* OR NDF/FB* OR NCM- } \\
\text { FB* OR NCM/FB*) AND ("in vitro" } \\
\text { OR "in vivo" OR mode OR action } \\
\text { OR mechanism* OR glycol* OR } \\
\text { sphingolipid* OR apoptosis OR } \\
\text { oxidative) }\end{array}$ & $\begin{array}{l}\text { Year: 2000- } \\
\text { Language: } \\
\text { English }\end{array}$ & 923 & $\begin{array}{l}\text { AREA } 3 \\
\text { Has been } \\
\text { exported to } \\
\text { EndNote }^{T M}\end{array}$ \\
\hline $\begin{array}{l}\text { July } 26, \\
2016\end{array}$ & Fumonisin & PubMed & $\begin{array}{l}\text { (Fumonisin* OR HFB* OR PHFB* } \\
\text { OR NDF-FB* OR NDF/FB* OR NCM- } \\
\text { FB* OR NCM/FB*) AND ("in vivo" } \\
\text { OR acute OR chronic OR tox* OR } \\
\text { genotox* OR muta* OR DNA OR } \\
\text { damage OR repair OR clastogen* } \\
\text { OR aneugen* OR chromosom* OR } \\
\text { cancer* OR carcino* OR tumor* } \\
\text { OR tumour* OR organ* OR tissue* } \\
\text { OR immun* OR neuro* OR } \\
\text { developmental OR teratogen* OR } \\
\text { repro* OR liver OR kidney* OR } \\
\text { brain* OR lung* OR cardiovascular } \\
\text { OR rat* OR mouse OR mice OR } \\
\text { rabbit* OR hamster* OR primate* } \\
\text { OR monkey*) }\end{array}$ & $\begin{array}{l}\text { Year: 2000- } \\
\text { Language: } \\
\text { English }\end{array}$ & 1667 & $\begin{array}{l}\text { AREA } 4 \\
\text { Has been } \\
\text { exported to } \\
\text { EndNote }^{T M}\end{array}$ \\
\hline July 26 , & Fumonisin & PubMed & (Fumonisin* OR HFB* OR PHFB* & Year: 2000- & 796 & AREA 5 \\
\hline
\end{tabular}




\begin{tabular}{|c|c|c|c|c|c|c|}
\hline $\begin{array}{l}\text { Date of } \\
\text { search }\end{array}$ & $\begin{array}{l}\text { Substance } \\
\text { name }\end{array}$ & $\begin{array}{l}\text { Databases } \\
\text { \& Search } \\
\text { Engines }\end{array}$ & Search terms & $\begin{array}{l}\text { Limitations } \\
\text { applied to } \\
\text { search }\end{array}$ & $\begin{array}{l}\text { No } \\
\text { of } \\
\text { 'hits' }\end{array}$ & $\begin{array}{l}\text { Comments } \\
\& \text { follow- } \\
\text { up actions }\end{array}$ \\
\hline 2016 & & & $\begin{array}{l}\text { OR NDF-FB* OR NDF/FB* OR NCM- } \\
\text { FB* OR NCM/FB*) AND ("in vitro" } \\
\text { OR cytotox* OR genotox* OR } \\
\text { muta* OR DNA OR damage OR } \\
\text { repair OR clastogen* OR aneugen* } \\
\text { OR chromosom* OR culture) }\end{array}$ & $\begin{array}{l}\text { Language: } \\
\text { English }\end{array}$ & & $\begin{array}{l}\text { Has been } \\
\text { exported to } \\
\text { EndNote }^{\mathrm{TM}}\end{array}$ \\
\hline $\begin{array}{l}\text { July 26, } \\
2016\end{array}$ & Fumonisin & PubMed & $\begin{array}{l}\text { (Fumonisin* OR HFB* OR PHFB* } \\
\text { OR NDF-FB* OR NDF/FB* OR NCM- } \\
\text { FB* OR NCM/FB*) AND (epidemio* } \\
\text { OR intervention OR exposure* OR } \\
\text { case* OR poison* OR cohort* OR } \\
\text { cross-sectional OR random* OR } \\
\text { work*) }\end{array}$ & $\begin{array}{l}\text { Year: 2000- } \\
\text { Language: } \\
\text { English }\end{array}$ & 1748 & $\begin{array}{l}\text { AREA } 6 \\
\text { Has been } \\
\text { exported to } \\
\text { EndNote }^{T M}\end{array}$ \\
\hline $\begin{array}{l}\text { July 28, } \\
2016\end{array}$ & Fumonisin & PubMed & $\begin{array}{l}\text { (Fumonisin* OR HFB* OR PHFB* } \\
\text { OR NCM-FB*) AND (tox* OR } \\
\text { poison* OR cancer* OR carcino* } \\
\text { OR tumor* OR tumour* OR organ* } \\
\text { OR tissue* OR immun* OR neuro* } \\
\text { OR developmental OR teratogen* } \\
\text { OR repro* OR liver OR kidney* OR } \\
\text { brain* OR lung* OR cardiovascular } \\
\text { OR health OR clinical OR growth } \\
\text { OR weight OR "farm animals" OR } \\
\text { horse* OR stallion* OR mare* OR } \\
\text { foal* OR equine OR ruminant* OR } \\
\text { livestock OR herd OR cow* OR } \\
\text { cattle OR bull* OR calf OR calves } \\
\text { OR heifer* OR bovine OR sheep* } \\
\text { OR ewe* OR ram* OR lamb OR } \\
\text { goat* OR caprine OR ovine OR } \\
\text { pig* OR swine* OR sow* OR gilt* } \\
\text { OR boar* OR porcine OR mink* OR } \\
\text { poultry OR chicken* OR hen* OR } \\
\text { cock* OR rooster* OR broiler* OR } \\
\text { duck* OR goose OR geese OR } \\
\text { geesling* OR turkey* OR quail* OR } \\
\text { guinea OR rabbit* OR fish* OR } \\
\text { salmon OR trout OR piscine OR } \\
\text { zebrafish OR pet* OR cat* OR } \\
\text { kitten* OR dog* OR bitch* OR } \\
\text { pupp*) }\end{array}$ & Year: 1980- & 2966 & $\begin{array}{l}\text { AREA } 7 \\
\text { Has been } \\
\text { exported to } \\
\text { EndNote }^{T M}\end{array}$ \\
\hline $\begin{array}{l}\text { July } 25, \\
2016\end{array}$ & Fumonisin & PubMed & $\begin{array}{l}\text { (Fumonisin* OR HFB* OR PHFB* } \\
\text { OR NDF-FB* OR NDF/FB* OR NCM- } \\
\text { FB* OR NCM/FB*) AND (Fusarium } \\
\text { OR concentration* OR occurrence } \\
\text { OR food* OR diet* OR commod* } \\
\text { OR fruit* OR pineapple OR "Ananas } \\
\text { comosus" OR vegetable* OR garlic } \\
\text { OR "Allium sativum" OR asparagus } \\
\text { OR cereal* OR corn* OR maize OR } \\
\text { "Zea mays" OR wheat OR "Triticum } \\
\text { aestivum" OR rye OR "Secale } \\
\text { cereal" OR barley OR "Hordeum } \\
\text { vulgare" OR oat OR "Avena sativa" } \\
\text { OR rice OR "Oryza sativa" OR } \\
\text { soybean OR "Glycine max" OR } \\
\text { sorghum OR sugarcane OR }\end{array}$ & $\begin{array}{l}\text { Year: 2000- } \\
\text { Language: } \\
\text { English }\end{array}$ & 1823 & $\begin{array}{l}\text { AREA } 8 \\
\text { Has been } \\
\text { exported to } \\
\text { EndNote }^{T M}\end{array}$ \\
\hline
\end{tabular}




\begin{tabular}{|c|c|c|c|c|c|c|}
\hline $\begin{array}{l}\text { Date of } \\
\text { search }\end{array}$ & $\begin{array}{l}\text { Substance } \\
\text { name }\end{array}$ & $\begin{array}{l}\text { Databases } \\
\text { \& Search } \\
\text { Engines }\end{array}$ & Search terms & $\begin{array}{l}\text { Limitations } \\
\text { applied to } \\
\text { search }\end{array}$ & $\begin{array}{l}\text { No } \\
\text { of } \\
\text { 'hits' }\end{array}$ & $\begin{array}{l}\text { Comments } \\
\text { \& follow- } \\
\text { up actions }\end{array}$ \\
\hline & & & $\begin{array}{l}\text { "Saccharum officinarum" OR millet } \\
\text { OR "Eleusine sp." OR "Pennisetum } \\
\text { glaucum" OR starch OR flour OR } \\
\text { bran OR germ OR dairy OR milk OR } \\
\text { egg* OR meat OR liver OR kidney* } \\
\text { OR offal OR coffee) }\end{array}$ & & & \\
\hline $\begin{array}{l}\text { July } 25, \\
2016\end{array}$ & Fumonisin & PubMed & $\begin{array}{l}\text { (Fumonisin* OR HFB* OR PHFB* } \\
\text { OR NDF-FB* OR NDF/FB* OR NCM- } \\
\text { FB* OR NCM/FB*) AND (Fusarium } \\
\text { OR concentration* OR expos* OR } \\
\text { occurrence OR intake OR feed* OR } \\
\text { fodder OR diet* OR meal OR } \\
\text { cereal* OR corn OR maize OR "Zea } \\
\text { mays" OR wheat OR "Triticum } \\
\text { aestivum" OR rye OR "Secale } \\
\text { cereal" OR barley OR "Hordeum } \\
\text { vulgare" OR oat OR "Avena sativa" } \\
\text { OR grain* OR seed* OR forage OR } \\
\text { silage OR grass OR Poaceae OR } \\
\text { hay OR rape OR Raptio OR } \\
\text { "Brassica napus" OR soybean OR } \\
\text { "Glycine max" OR DDGS OR WDG } \\
\text { OR (dried AND distillers AND grains } \\
\text { AND with AND solubles) OR (wet } \\
\text { AND distillers AND grain)) }\end{array}$ & $\begin{array}{l}\text { Year: 2000- } \\
\text { Language: } \\
\text { English }\end{array}$ & 1755 & $\begin{array}{l}\text { AREA } 9 \\
\text { Has been } \\
\text { exported to } \\
\text { EndNote }^{T M}\end{array}$ \\
\hline
\end{tabular}




\section{Appendix B - Identified relevant references for each area}

Appendix B contains the systematic review of the relevant literature. Versions in excel format are available for all nine areas in the online version of this output (in the "Supporting information" section): http://dx.doi.org/10.2903/sp.efsa.2018.EN-1148

\section{AREA 1 CHEMISTRY AND ANALYSIS}

Reference list with all relevant references identified for AREA 1: Data on chemistry and analysis (substance identification and characterisation, analytical detection and determination, formation) published in English since year 2000.

\section{Relevant references retrieved in the literature searches for Area 1 CHEMISTRY AND ANALYSIS:}

Chemical and physical characteristics of the principal mycotoxins, 2012. IARC Sci Publ, 31-38.

Aberg, A. T.; Solyakov, A.; Bondesson, U., 2013. Development and in-house validation of an Ic-ms/ms method for the quantification of the mycotoxins deoxynivalenol, zearalenone, $\mathrm{t}-2$ and ht-2 toxin, ochratoxin a and fumonisin b1 and b2 in vegetable animal feed, Food Addit Contam Part A Chem Anal Control Expo Risk Assess, 30, 541-549.

Abia, W. A.; Warth, B.; Sulyok, M.; Krska, R.; Tchana, A. N.; Njobeh, P. B.; Dutton, M. F.; Moundipa, P. F., 2013. Determination of multi-mycotoxin occurrence in cereals, nuts and their products in cameroon by liquid chromatography tandem mass spectrometry (Ic-ms/ms), Food Control, 31, 438453.

Aboul-Nasr, M. B.; Obied-Allah, M. R. A., 2013. Biological and chemical detection of fumonisins produced on agar medium by fusarium verticillioides isolates collected from corn in sohag, egypt, Microbiology-Sgm, 159, 1720-1724.

Abramovic, B. F.; Jaksic, S. M.; Masic, Z. S., 2005. Liquid chromatographic determination of fumonisins $b-1$ and $b-2$ in corn samples after reusable immunoaffinity column clean-up, Journal of the Serbian Chemical Society, 70, 899-910.

Abrunhosa, L.; Calado, T.; Resende, T.; Venancio, A., 2011. A fluorescence-Ic method with nda precolumn derivatization for fumonisin b-2 determination in black aspergilli cultures, Journal of Liquid Chromatography \& Related Technologies, 34, 1594-1603.

Abrunhosa, L.; Calado, T.; Venancio, A., 2011. Incidence of fumonisin b-2 production by aspergillus niger in portuguese wine regions, Journal of Agricultural and Food Chemistry, 59, 7514-7518.

Adejumo, T. O.; Hettwer, U.; Karlovsky, P., 2007. Survey of maize from south-western nigeria for zearalenone, alpha- and beta-zearalenols, fumonisin b-1 and enniatins produced by fusarium species, Food Additives and Contaminants, 24, 993-1000.

Ahn, J.; Kim, D.; Kim, H.; Jahng, K. Y., 2010. Quantitative determination of mycotoxins in urine by Icms/ms, Food Addit Contam Part A Chem Anal Control Expo Risk Assess, 27, 1674-1682.

Alghuthaymi, M. A.; Bahkali, A. H., 2015. Toxigenic profiles and trinucleotide repeat diversity of fusarium species isolated from banana fruits, Biotechnol Biotechnol Equip, 29, 324-330.

Al-Taher, F.; Banaszewski, K.; Jackson, L.; Zweigenbaum, J.; Ryu, D.; Cappozzo, J., 2013. Rapid method for the determination of multiple mycotoxins in wines and beers by Ic-ms/ms using a stable isotope dilution assay, J Agric Food Chem, 61, 2378-2384.

Amato, B.; Pfohl, K.; Tonti, S.; Nipoti, P.; Dastjerdi, R.; Pisi, A.; Karlovsky, P.; Prodi, A., 2015. Fusarium proliferatum and fumonisin b1 co-occur with fusarium species causing fusarium head blight in durum wheat in Italy, Journal of Applied Botany and Food Quality, 88, 228-233. 
Anderson, G. P.; Kowtha, V. A.; Taitt, C. R., 2010. Detection of fumonisin b1 and ochratoxin a in grain products using microsphere-based fluid array immunoassays, Toxins (Basel), 2, 297-309.

Anfossi, L.; Calderara, M.; Baggiani, C.; Giovannoli, C.; Arletti, E.; Giraudi, G., 2010. Development and application of a quantitative lateral flow immunoassay for fumonisins in maize, Anal Chim Acta, 682, 104-109.

Aprodu, I.; Banu, I., 2015. Co-occurrence of fumonisins and t-2 toxins in milling maize fractions under industrial conditions, Cyta-Journal of Food, 13, 102-106.

Arino, A.; Juan, T.; Estopanan, G.; Gonzalez-Cabo, J. F., 2007. Natural occurrence of fusarium species, fumonisin production by toxigenic strains, and concentrations of fumonisins $b-1$ and $b-2$ in conventional and organic maize grown in spain, Journal of Food Protection, 70, 151-156.

Arranz, I.; Baeyens, W. R. G.; Van der Weken, G.; De Saeger, S.; Van Peteghem, C., 2004. Review: Hplc determination of fumonisin mycotoxins, Critical Reviews in Food Science and Nutrition, 44, 195-203.

Arroyo-Manzanares, N.; Garcia-Campana, A. M.; Gamiz-Gracia, L., 2013. Multiclass mycotoxin analysis in silybum marianum by ultra high performance liquid chromatography-tandem mass spectrometry using a procedure based on quechers and dispersive liquid-liquid microextraction, J Chromatogr $A$, $1282,11-19$.

Arroyo-Manzanares, N.; Huertas-Perez, J. F.; Gamiz-Gracia, L.; Garcia-Campana, A. M., 2013. A new approach in sample treatment combined with uhplc-ms/ms for the determination of multiclass mycotoxins in edible nuts and seeds, Talanta, 115, 61-67.

Arroyo-Manzanares, N.; Huertas-Perez, J. F.; Gamiz-Gracia, L.; Garcia-Campana, A. M., 2015. Simple and efficient methodology to determine mycotoxins in cereal syrups, Food Chem, 177, 274-279.

Arroyo-Manzanares, N.; Huertas-Perez, J. E.; Garcia-Campana, A. M.; Gamiz-Gracia, L., 2014. Simple methodology for the determination of mycotoxins in pseudocereals, spelt and rice, Food Control, $36,94-101$.

Ates, E.; Mittendorf, K.; Stroka, J.; Senyuva, H., 2013. Determination of fusarium mycotoxins in wheat, maize and animal feed using on-line clean-up with high resolution mass spectrometry, Food Addit Contam Part A Chem Anal Control Expo Risk Assess, 30, 156-165.

Avantaggiato, G.; De la Campa, R.; Miller, J. D.; Visconti, A., 2003. Effects of muffin processing on fumonisins from c-14-labeled toxins produced in cultured corn kernels, Journal of Food Protection, $66,1873-1878$.

Avantaggiato, G.; Greco, D.; Damascelli, A.; Solfrizzo, M.; Visconti, A., 2014. Assessment of multimycotoxin adsorption efficacy of grape pomace, J Agric Food Chem, 62, 497-507.

Awaludin, N.; Nagata, R.; Kawasaki, T.; Kushiro, M., 2009. Preparation of an in-house reference material containing fumonisins in thai rice and matrix extension of the analytical method for japanese rice, Toxins (Basel), 1, 188-195.

Ayalew, A.; Fehrmann, H.; Lepschy, J.; Beck, R.; Abate, D., 2006. Natural occurrence of mycotoxins in staple cereals from ethiopia, Mycopathologia, 162, 57-63.

Azaiez, I.; Font, G.; Manes, J.; Fernandez-Franzon, M., 2015. Survey of mycotoxins in dates and dried fruits from tunisian and spanish markets, Food Control, 51, 340-346.

Azaiez, I.; Giusti, F.; Sagratini, G.; Manes, J.; Fernandez-Franzon, M., 2014. Multi-mycotoxins analysis in dried fruit by $\mathrm{lc} / \mathrm{ms} / \mathrm{ms}$ and a modified quechers procedure, Food Analytical Methods, 7, 935945.

Bailly, J. D.; Querin, A.; Tardieu, D.; Guerre, P., 2005. Production and purification of fumonisins from a highly toxigenic fusarium verticilloides strain, Revue De Medecine Veterinaire, 156, 547-554.

Bansal, J.; Pantazopoulos, P.; Tam, J.; Cavlovic, P.; Kwong, K.; Turcotte, A. M.; Lau, B. P. Y.; Scott, P. 
M., 2011. Surveys of rice sold in canada for aflatoxins, ochratoxin a and fumonisins, Food Additives and Contaminants Part a-Chemistry Analysis Control Exposure \& Risk Assessment, 28, 767-774.

Barna-Vetro, I.; Szabo, E.; Fazekas, B.; Solti, L., 2000. Development of a sensitive elisa for the determination of fumonisin b-1 in cereals, Journal of Agricultural and Food Chemistry, 48, 28212825.

Bartok, T.; Szecsi, A.; Szekeres, A.; Mesterhazy, A.; Bartok, M., 2006. Detection of new fumonisin mycotoxins and fumonisin-like compounds by reversed-phase high-performance liquid chromatography/electrospray ionization ion trap mass spectrometry, Rapid Commun Mass Spectrom, 20, 2447-2462.

Bartok, T.; Szecsi, A.; Juhasz, K.; Bartok, M.; Mesterhazy, A., 2013. Esi-ms and ms/ms identification of the first ceramide analogues of fumonisin $b-1$ mycotoxin from a fusarium verticillioides culture following rp-hplc separation, Food Additives and Contaminants Part a-Chemistry Analysis Control Exposure \& Risk Assessment, 30, 1651-1659.

Bartok, T.; Szekeres, A.; Szecsi, A.; Bartok, M.; Mesterhazy, A., 2008. A new type of fumonisin series appeared on the scene of food and feed safety, Cereal Research Communications, 36, 315-319.

Bartok, T.; Tolgyesi, L.; Szekeres, A.; Varga, M.; Bartha, R.; Szecsi, A.; Bartok, M.; Mesterhazy, A., 2010. Detection and characterization of twenty-eight isomers of fumonisin b-1 (fb1) mycotoxin in a solid rice culture infected with fusarium verticillioides by reversed-phase high-performance liquid chromatography/electrospray ionization time-of-flight and ion trap mass spectrometry, Rapid Communications in Mass Spectrometry, 24, 35-42.

Bartok, T.; Tolgyesi, L.; Szecsi, A.; Mesterhazy, A.; Bartok, M.; Gyimes, E.; Veha, A., 2014. Detection of previously unknown fumonisin $\mathrm{p}$ analogue mycotoxins in a fusarium verticillioides culture by high-performance liquid chromatography-electrospray ionization time-of-flight and ion trap mass spectrometry, J Chromatogr Sci, 52, 508-513.

Bartok, T.; Tolgyesi, L.; Mesterhazy, A.; Bartok, M.; Szecsi, A., 2010. Identification of the first fumonisin mycotoxins with three acyl groups by esi-itms and esi-tofms following rp-hplc separation: Palmitoyl, linoleoyl and oleoyl efb(1) fumonisin isomers from a solid culture of fusarium verticillioides, Food Addit Contam Part A Chem Anal Control Expo Risk Assess, 27, 1714-1723.

Bartok, T.; Tolgyesi, L.; Szecsi, A.; Varga, J.; Bartok, M.; Mesterhazy, A.; Gyimes, E.; Veha, A., 2013. Identification of unknown isomers of fumonisin b- 5 mycotoxin in a fusarium verticillioides culture by high-performance liquid chromatography/electrospray ionization time-of-flight and ion trap mass spectrometry, Journal of Liquid Chromatography \& Related Technologies, 36, 1549-1561.

Belajova, E.; Rauova, D., 2010. Single laboratory-validated hplc methods for determination of ochratoxin a, fumonisin b1 and b2, zearalenone and deoxynivalenol in cereals and cereal-based foods, Journal of Food and Nutrition Research, 49, 57-68.

Beloglazova, N. V.; Speranskaya, E. S.; Wu, A.; Wang, Z.; Sanders, M.; Goftman, V. V.; Zhang, D.; Goryacheva, I. Y.; De Saeger, S., 2014. Novel multiplex fluorescent immunoassays based on quantum dot nanolabels for mycotoxins determination, Biosens Bioelectron, 62, 59-65.

Beltran, E.; Ibanez, M.; Portoles, T.; Ripolles, C.; Sancho, J. V.; Yusa, V.; Marin, S.; Hernandez, F., 2013. Development of sensitive and rapid analytical methodology for food analysis of 18 mycotoxins included in a total diet study, Anal Chim Acta, 783, 39-48.

Benedetti, R.; Nazzi, F.; Locci, R.; Firrao, G., 2006. Degradation of fumonisin b1 by a bacterial strain isolated from soil, Biodegradation, 17, 31-38.

Berardo, N.; Pisacane, V.; Battilani, P.; Scandolara, A.; Pietri, A.; Marocco, A., 2005. Rapid detection of kernel rots and mycotoxins in maize by near-infrared reflectance spectroscopy, J Agric Food Chem, 53, 8128-8134.

Bergmann, D.; Hubner, F.; Humpf, H. U., 2013. Stable isotope dilution analysis of small molecules 
with carboxylic acid functions using o-18 labeling for hplc-esi-ms/ms: Analysis of fumonisin b-1, Journal of Agricultural and Food Chemistry, 61, 7904-7908.

Berthiller, F.; Burdaspal, P. A.; Crews, C.; Iha, M. H.; Krska, R.; Lattanzio, V. M. T.; MacDonald, S.; Malone, R. J.; Maragos, C.; Solfrizzo, M.; Stroka, J.; Whitaker, T. B., 2014. Developments in mycotoxin analysis: An update for 2012-2013, World Mycotoxin Journal, 7, 3-33.

Berthiller, F.; Brera, C.; Crews, C.; Iha, M. H.; Krska, R.; Lattanzio, V. M. T.; MacDonald, S.; Malone, R. J.; Maragos, C.; Solfrizzo, M.; Stroka, J.; Whitaker, T. B., 2015. Developments in mycotoxin analysis: An update for 2013-2014, World Mycotoxin Journal, 8, 5-35.

Berthiller, F.; Brera, C.; Crews, C.; Iha, M. H.; Krska, R.; Lattanzio, V. M. T.; MacDonald, S.; Malone, R. J.; Maragos, C.; Solfrizzo, M.; Stroka, J.; Whitaker, T. B., 2016. Developments in mycotoxin analysis: An update for 2014-2015, World Mycotoxin Journal, 9, 5-29.

Berthiller, F.; Crews, C.; Dall'Asta, C.; De Saeger, S.; Haesaert, G.; Karlovsky, P.; Oswald, I. P.; Seefelder, W.; Speijers, G.; Stroka, J., 2013. Masked mycotoxins: A review, Molecular Nutrition \& Food Research, 57, 165-186.

Bertuzzi, T.; Mulazzi, A.; Rastelli, S.; Pietri, A., 2016. Hidden fumonisins: Simple and innovative extractions for their determination in maize and derived products, Food Analytical Methods, 9, 1970-1979.

Bian, Y. N.; Huang, X. Y.; Ren, J. C., 2016. Sensitive and homogenous immunoassay of fumonisin in foods using single molecule fluorescence correlation spectroscopy, Analytical Methods, 8, 13331338.

Bird, C. B.; Malone, B.; Rice, L. G.; Ross, P. F.; Eppley, R.; Abouzied, M. M., 2002. Determination of total fumonisins in corn by competitive direct enzyme-linked immunosorbent assay: Collaborative study, J AOAC Int, 85, 404-410.

Blesa, J.; Molto, J. C.; El Akhdari, S.; Manes, J.; Zinedine, A., 2014. Simultaneous determination of fusarium mycotoxins in wheat grain from morocco by liquid chromatography coupled to triple quadrupole mass spectrometry, Food Control, 46, 1-5.

Bolduan, C.; Montes, J. M.; Dhillon, B. S.; Mirdita, V.; Melchinger, A. E., 2009. Determination of mycotoxin concentration by elisa and near-infrared spectroscopy in fusarium-inoculated maize, Cereal Research Communications, 37, 521-529.

Bolechova, M.; Benesova, K.; Belakova, S.; Caslavsky, J.; Pospichalova, M.; Mikulikova, R., 2015. Determination of seventeen mycotoxins in barley and malt in the czech republic, Food Control, 47, 108-113.

Boonzaaijer, G.; van Osenbruggen, W. A.; Kleinnijenhuis, A. J.; van Dongen, W. D., 2008. An exploratory investigation of several mycotoxins and their natural occurrence in flavour ingredients and spices, using a multi-mycotoxin Ic-ms/ms method, World Mycotoxin Journal, 1, 167-174.

Bordin, K.; Rottinghaus, G. E.; Landers, B. R.; Ledoux, D. R.; Kobashigawa, E.; Corassin, C. H.; Oliveira, C. A. F., 2015. Evaluation of fumonisin exposure by determination of fumonisin b-1 in human hair and in brazilian corn products, Food Control, 53, 67-71.

Borutova, R.; Aragon, Y. A.; Nahrer, K.; Berthiller, F., 2012. Co-occurrence and statistical correlations between mycotoxins in feedstuffs collected in the asia-oceania in 2010, Animal Feed Science and Technology, 178, 190-197.

Boutsiadou-Theurillat, X.; Meier, P.; Richard, C., 2014. Development and in-house validation of a rapid Ic-ms/ms method for the semi-quantification of eleven mycotoxins in maize samples, Chimia (Aarau), 68, 716-720.

Bowers, E.; Hellmich, R.; Munkvold, G., 2014. Comparison of fumonisin contamination using hplc and elisa methods in bt and near-isogenic maize hybrids infested with european corn borer or western bean cutworm, J Agric Food Chem, 62, 6463-6472. 
Bravin, F.; Duca, R. C.; Loiseau, N.; Pean, M.; Puel, O.; Delaforge, M., 2008. Production and use of mycotoxins uniformly enriched with stable isotopes for their dosage in biological samples, World Mycotoxin Journal, 1, 275-281.

Broggi, L. E.; Pacin, A. M.; Gasparovic, A.; Sacchi, C.; Rothermel, A.; Gallay, A.; Resnik, S., 2007. Natural occurrence of aflatoxins, deoxynivalenol, fumonisins and zearalenone in maize from entre rios province, argentina, Mycotoxin Res, 23, 59-64.

Bryla, M.; Jedrzejczak, R.; Roszko, M.; Szymczyk, K.; Obiedzinski, M. W.; Sekul, J.; Rzepkowska, M., 2013. Application of molecularly imprinted polymers to determine $b-1, b-2$, and $b-3$ fumonisins in cereal products, Journal of Separation Science, 36, 578-584.

Bryla, M.; Roszko, M.; Szymczyk, K.; Jedrzejczak, R.; Slowik, E.; Obiedzinski, M. W., 2014. Effect of baking on reduction of free and hidden fumonisins in gluten-free bread, J Agric Food Chem, 62, 10341-10347.

Bryla, M.; Roszko, M.; Szymczyk, K.; Jedrzejczak, R.; Obiedzinski, M. W., 2016. Fumonisins and their masked forms in maize products, Food Control, 59, 619-627.

Bryla, M.; Szymczyk, K.; Jedrzejczak, R.; Obiedzinski, M. W., 2015. Free and hidden fumonisins in various fractions of maize dry milled under model conditions, Lwt-Food Science and Technology, 64, 171-176.

Bueno, D.; Istamboulie, G.; Munoz, R.; Marty, J. L., 2015. Determination of mycotoxins in food: A review of bioanalytical to analytical methods, Applied Spectroscopy Reviews, 50, 728-774.

Burkin, A. A.; Kononenko, G. P., 2014. Secondary fungal metabolites (mycotoxins) in lichens of different taxonomic groups, Biology Bulletin, 41, 216-222.

Burmistrova, N. A.; Rusanova, T. Y.; Yurasov, N. A.; Goryacheva, I. Y.; De Saeger, S., 2014. Multidetection of mycotoxins by membrane based flow-through immunoassay, Food Control, 46, 462469.

Burmistrova, N. A.; Rusanova, T. Y.; Yurasov, N. A.; De Saeger, S.; Goryacheva, I. Y., 2014. Simultaneous determination of several mycotoxins by rapid immunofiltration assay, Journal of Analytical Chemistry, 69, 525-534.

Caldas, E. D.; Silva, A. C. S., 2007. Mycotoxins in corn-based food products consumed in brazil: An exposure assessment for fumonisins, Journal of Agricultural and Food Chemistry, 55, 7974-7980.

Candlish, A.; Aidoo, K.; Smith, J.; Pearson, S., 2000. A limited survey of aflatoxins and fumonisins in retail maizebased products in the uk using immunoassay detection, Mycotoxin Res, 16, 2-8.

Cano-Sancho, G.; Ramos, A. J.; Marin, S.; Sanchis, V., 2012. Occurrence of fumonisins in catalonia (spain) and an exposure assessment of specific population groups, Food Addit Contam Part A Chem Anal Control Expo Risk Assess, 29, 799-808.

Cano-Sancho, G.; Ramos, A. J.; Marin, S.; Sanchis, V., 2012. Presence and co-occurrence of aflatoxins, deoxynivalenol, fumonisins and zearalenone in gluten-free and ethnic foods, Food Control, 26, 282-286.

Capriotti, A. L.; Cavaliere, C.; Foglia, P.; Samperi, R.; Stampachiacchiere, S.; Ventura, S.; Lagana, A., 2014. Multiclass analysis of mycotoxins in biscuits by high performance liquid chromatographytandem mass spectrometry. Comparison of different extraction procedures, J Chromatogr A, 1343, 69-78.

Castegnaro, M.; Tozlovanu, M.; Wild, C.; Molinie, A.; Sylla, A.; Pfohl-Leszkowicz, A., 2006. Advantages and drawbacks of immunoaffinity columns in analysis of mycotoxins in food, Mol Nutr Food Res, $50,480-487$.

Castoria, R.; Lima, G.; Ferracane, R.; Ritieni, A., 2005. Occurrence of mycotoxin in farro samples from southern italy, J Food Prot, 68, 416-420. 
Cavaliere, C.; Foglia, P.; Pastorini, E.; Samperi, R.; Lagana, A., 2005. Development of a multiresidue method for analysis of major fusarium mycotoxins in corn meal using liquid chromatography/tandem mass spectrometry, Rapid Commun Mass Spectrom, 19, 2085-2093.

Cavaliere, C.; Foglia, P.; Guarino, C.; Motto, M.; Nazzari, M.; Samperi, R.; Lagana, A.; Berardo, N., 2007. Mycotoxins produced by fusarium genus in maize: Determination by screening and confirmatory methods based on liquid chromatography tandem mass spectrometry, Food Chemistry, 105, 700-710.

Chelule, P. K.; Gqaleni, N.; Chuturgoon, A. A.; Dutton, M. F., 2000. The determination of fumonisin b1 in human faeces: A short term marker for assessment of exposure, Biomarkers, 5, 1-8.

Chen, X. J.; Bai, X. J.; Li, H. Y.; Zhang, B. L., 2015. Aptamer-based microcantilever array biosensor for detection of fumonisin b-1, Rsc Advances, 5, 35448-35452.

Chen, X. J.; Huang, Y. K.; Ma, X. Y.; Jia, F.; Guo, X. F.; Wang, Z. P., 2015. Impedimetric aptamerbased determination of the mold toxin fumonisin b1, Microchimica Acta, 182, 1709-1714.

Chen, X. J.; Huang, Y. K.; Duan, N.; Wu, S. J.; Xia, Y.; Ma, X. Y.; Zhu, C. Q.; Jiang, Y.; Ding, Z. S.; Wang, Z. P., 2014. Selection and characterization of single stranded DNA aptamers recognizing fumonisin b-1, Microchimica Acta, 181, 1317-1324.

Cho, Y. J.; Chun, H. S.; Kim, C. J.; Kim, C. T.; Hong, J. Y., 2005. Detection of fumonisin b-1 by a batch type surface plasmon resonance biosensor, Food Science and Biotechnology, 14, 698-699.

Christensen, H. R.; Yu, F. Y.; Chu, F. S., 2000. Development of a polyclonal antibody-based sensitive enzyme-linked immunosorbent assay for fumonisin b(4), J Agric Food Chem, 48, 1977-1984.

Chung, S. H.; Cho, T. Y.; Oh, K. S.; Kim, D. S.; Hong, M. K., 2008. Fumonisin contamination in corn and processed corn products commercialized in korea, Cereal Research Communications, 36, 353355.

Cirlini, M.; Hahn, I.; Varga, E.; Dall'Asta, M.; Falavigna, C.; Calani, L.; Berthiller, F.; Del Rio, D.; Dall'Asta, C., 2015. Hydrolysed fumonisin b-1 and n-(deoxy-d-fructos-1-yl)-fumonisin b-1: Stability and catabolic fate under simulated human gastrointestinal conditions, International Journal of Food Sciences and Nutrition, 66, 98-103.

Coronel, M. B.; Vicente, S.; Resnik, S. L.; Aizamora, S. M.; Pacin, A., 2016. Fumonisins in maize and gluten meal analysed in argentinean wet milling industrial plants by elisa compared with hplc-fld method, Food Control, 67, 285-291.

Cruz, A.; Marin, P.; Gonzalez-Jaen, M. T.; Aguilar, K. G. I.; Cumagun, C. J. R., 2013. Phylogenetic analysis, fumonisin production and pathogenicity of fusarium fujikuroi strains isolated from rice in the philippines, Journal of the Science of Food and Agriculture, 93, 3032-3039.

Czeh, A.; Mandy, F.; Feher-Toth, S.; Torok, L.; Mike, Z.; Koszegi, B.; Lustyik, G., 2012. A flow cytometry based competitive fluorescent microsphere immunoassay (cfia) system for detecting up to six mycotoxins, J Immunol Methods, 384, 71-80.

Dall'Asta, C.; Falavigna, C.; Galaverna, G.; Dossena, A.; Marchelli, R., 2010. In vitro digestion assay for determination of hidden fumonisins in maize, J Agric Food Chem, 58, 12042-12047.

Dall'Asta, C.; Galaverna, G.; Mangia, M.; Sforza, S.; Dossena, A.; Marchelli, R., 2009. Free and bound fumonisins in gluten-free food products, Mol Nutr Food Res, 53, 492-499.

Dall'Asta, C.; Galaverna, G.; Aureli, G.; Dossena, A.; Marchelli, R., 2008. A Ic/ms/ms method for the simultaneous quantification of free and masked fumonisins in maize and maize-based products, World Mycotoxin Journal, 1, 237-246.

Dall'Asta, C.; Mangia, M.; Berthiller, F.; Molinelli, A.; Sulyok, M.; Schuhmacher, R.; Krska, R.; Galaverna, G.; Dossena, A.; Marchelli, R., 2009. Difficulties in fumonisin determination: The issue of hidden fumonisins, Anal Bioanal Chem, 395, 1335-1345. 
D'Arco, G.; Fernandez-Franzon, M.; Font, G.; Damiani, P.; Manes, J., 2008. Analysis of fumonisins b-1, b-2 and b-3 in corn-based baby food by pressurized liquid extraction and liquid chromatography/tandem mass spectrometry, Journal of Chromatography A, 1209, 188-194.

Dasko, E.; Rauova, D.; Belajova, E.; Kovac, M., 2005. Determination of fumonisins b-1 and b-2 in beer, Czech Journal of Food Sciences, 23, 20-26.

Dasko, L.; Rauova, D.; Belajova, E., 2006. Comparison of the suitability of derivatisation agents in hplc - fluorescence detection analysis of fumonisins, Journal of Food and Nutrition Research, 45, 127133.

de Galarreta, J. I. R.; Butron, A.; Ortiz-Barredo, A.; Malvar, R. A.; Ordas, A.; Landa, A.; Revilla, P., 2015. Mycotoxins in maize grains grown in organic and conventional agriculture, Food Control, 52, 98-102.

De Girolamo, A.; Lattanzio, V. M. T.; Schena, R.; Visconti, A.; Pascale, M., 2014. Use of liquid chromatography-high-resolution mass spectrometry for isolation and characterization of hydrolyzed fumonisins and relevant analysis in maize-based products, Journal of Mass Spectrometry, 49, 297305.

De Girolamo, A.; Pascale, M.; Visconti, A., 2011. Comparison of methods and optimisation of the analysis of fumonisins $b(1)$ and $b(2)$ in masa flour, an alkaline cooked corn product, Food Addit Contam Part A Chem Anal Control Expo Risk Assess, 28, 667-675.

De Girolamo, A.; Pereboom-de Fauw, D.; Sizoo, E.; van Egmond, H. P.; Gambacorta, L.; Bouten, K.; Stroka, J.; Visconti, A.; Solfrizzo, M., 2010. Determination of fumonisins b-1 and b-2 in maizebased baby food products by hplc with fluorimetric detection after immunoaffinity column clean-up, World Mycotoxin Journal, 3, 135-146.

De Girolamo, A.; Solfrizzo, M.; von Holst, C.; Visconti, A., 2001. Comparison of different extraction and clean-up procedures for the determination of fumonisins in maize and maize-based food products, Food Addit Contam, 18, 59-67.

De Girolamo, A.; Solfrizzo, M.; Lattanzio, V. M. T.; Stroka, J.; Alldrick, A.; van Egmond, H. P.; Visconti, A., 2013. Critical evaluation of lc-ms-based methods for simultaneous determination of deoxynivalenol, ochratoxin a, zearalenone, aflatoxins, fumonisins and t-2/ht-2 toxins in maize, World Mycotoxin Journal, 6, 317-334.

De Liguoro, M.; Petterino, C.; Mezzalira, G.; Tenti, S.; Ravarotto, L., 2004. Field observations in pigs exposed to fumonisin b1 contaminated feed, Vet Hum Toxicol, 46, 303-305.

De Saeger, S.; Sibanda, L.; Paepens, C.; Lobeau, M.; Delmulle, B.; Barna-Vetro, I.; Van Peteghem, C., 2006. Novel developments in rapid mycotoxin detection, Mycotoxin Res, 22, 100-104.

De Smet, D.; Dubruel, P.; Van Peteghem, C.; Schacht, E.; De Saeger, S., 2009. Molecularly imprinted solid-phase extraction of fumonisin $b$ analogues in bell pepper, rice and corn flakes, Food Addit Contam Part A Chem Anal Control Expo Risk Assess, 26, 874-884.

de Souza, M. D. M.; Sulyok, M.; Freitas-Silva, O.; Costa, S. S.; Brabet, C.; Machinski, M.; Sekiyama, B. L.; Vargas, E. A.; Krska, R.; Schuhmacher, R., 2013. Cooccurrence of mycotoxins in maize and poultry feeds from brazil by liquid chromatography/tandem mass spectrometry, Scientific World Journal.

Deng, G. Z.; Xu, K.; Sun, Y.; Chen, Y.; Zheng, T. S.; Li, J. L., 2013. High sensitive immunoassay for multiplex mycotoxin detection with photonic crystal microsphere suspension array, Analytical Chemistry, 85, 2833-2840.

Desmarchelier, A.; Oberson, J. M.; Tella, P.; Gremaud, E.; Seefelder, W.; Mottier, P., 2010. Development and comparison of two multiresidue methods for the analysis of 17 mycotoxins in cereals by liquid chromatography electrospray ionization tandem mass spectrometry, J Agric Food Chem, 58, 7510-7519. 
Desmarchelier, A.; Tessiot, S.; Bessaire, T.; Racault, L.; Fiorese, E.; Urbani, A.; Chan, W. C.; Cheng, P.; Mottier, P., 2014. Combining the quick, easy, cheap, effective, rugged and safe approach and clean-up by immunoaffinity column for the analysis of 15 mycotoxins by isotope dilution liquid chromatography tandem mass spectrometry, J Chromatogr A, 1337, 75-84.

Devreese, M.; De Baere, S.; De Backer, P.; Croubels, S., 2012. Quantitative determination of several toxicological important mycotoxins in pig plasma using multi-mycotoxin and analyte-specific high performance liquid chromatography-tandem mass spectrometric methods, J Chromatogr A, 1257, 74-80.

Di Mavungu, J. D.; Monbaliu, S.; Scippo, M. L.; Maghuin-Rogister, G.; Schneider, Y. J.; Larondelle, Y.; Callebaut, A.; Robbens, J.; Van Peteghem, C.; De Saeger, S., 2009. Lc-ms/ms multi-analyte method for mycotoxin determination in food supplements, Food Additives and Contaminants Part a-Chemistry Analysis Control Exposure \& Risk Assessment, 26, 885-895.

Di Nardo, F.; Anfossi, L.; Giovannoli, C.; Passini, C.; Goftman, V. V.; Goryacheva, I. Y.; Baggiani, C., 2016. A fluorescent immunochromatographic strip test using quantum dots for fumonisins detection, Talanta, 150, 463-468.

Diaz, R.; Ibanez, M.; Sancho, J. V.; Hernandez, F., 2012. Target and non-target screening strategies for organic contaminants, residues and illicit substances in food, environmental and human biological samples by uhplc-qtof-ms, Analytical Methods, 4, 196-209.

Dilkin, P.; Mallmann, C. A.; de Almeida, C. A. A.; Correa, B., 2001. Robotic automated clean-up for detection of fumonisins $b-1$ and $b-2$ in corn and corn-based feed by high-performance liquid chromatography, Journal of Chromatography A, 925, 151-157.

Dohnal, V.; Jezkova, A.; Polisenska, I.; Kuca, K., 2010. Determination of fumonisins in milled corn grains using hplc-ms, J Chromatogr Sci, 48, 680-684.

Domijan, A. M.; Peraica, M.; Jurjevic, Z.; Ivic, D.; Cvjetkovic, B., 2005. Fumonisin b-1, fumonisin b-2, zearalenone and ochratoxin a contamination of maize in croatia, Food Additives and Contaminants, $22,677-680$.

Domijan, A. M.; Peraica, M.; Cvjetkovic, B.; Turcin, S.; Jurjevic, Z.; Ivic, D., 2005. Mould contamination and co-occurrence of mycotoxins in maize grain in croatia, Acta Pharm, 55, 349356.

Dowell, F. E.; Pearson, T. C.; Maghirang, E. B.; Xie, F.; Wicklow, D. T., 2002. Reflectance and transmittance spectroscopy applied to detecting fumonisin in single corn kernels infected with fusarium verticillioides, Cereal Chemistry, 79, 222-226.

Driehuis, F.; Spanjer, M. C.; Scholten, J. M.; Giffel, M. C. T., 2008. Occurrence of mycotoxins in feedstuffs of dairy cows and estimation of total dietary intakes, Journal of Dairy Science, 91, 42614271.

Driehuis, F.; Spanjer, M. C.; Scholten, J. M.; Giffel, M. C. T., 2008. Occurrence of mycotoxins in maize, grass and wheat silage for dairy cattle in the netherlands, Food Additives \& Contaminants Part BSurveillance, 1, 41-50.

Ediage, E. N.; Di Mavungu, J. D.; Song, S. Q.; Sioen, I.; De Saeger, S., 2013. Multimycotoxin analysis in urines to assess infant exposure: A case study in cameroon, Environment International, 57-58, 50-59.

Ediage, E. N.; Di Mavungu, J. D.; Goryacheva, I. Y.; Van Peteghem, C.; De Saeger, S., 2012. Multiplex flow-through immunoassay formats for screening of mycotoxins in a variety of food matrices, Anal Bioanal Chem, 403, 265-278.

Ediage, E. N.; Di Mavungu, J. D.; Monbaliu, S.; Van Peteghem, C.; De Saeger, S., 2011. A validated multianalyte Ic-ms/ms method for quantification of 25 mycotoxins in cassava flour, peanut cake and maize samples, J Agric Food Chem, 59, 5173-5180. 
Ediage, E. N.; Van Poucke, C.; De Saeger, S., 2015. A multi-analyte Ic-ms/ms method for the analysis of 23 mycotoxins in different sorghum varieties: The forgotten sample matrix, Food Chemistry, $177,397-404$.

Egbuta, M. A.; Chilaka, C. A.; Phoku, J. Z.; Mwanza, M.; Dutton, M. F., 2013. Co-contamination of nigerian cocoa and cocoa-based powder beverages destined for human consumption by mycotoxins, Studies on Ethno-Medicine, 7, 187-194.

Ezekiel, C. N.; Abia, W. A.; Ogara, I. M.; Sulyok, M.; Warth, B.; Krska, R., 2015. Fate of mycotoxins in two popular traditional cereal-based beverages (kunu-zaki and pito) from rural nigeria, Lwt-Food Science and Technology, 60, 137-141.

Ezquerra, A.; Vidal, J. C.; Bonel, L.; Castillo, J. R., 2015. A validated multi-channel electrochemical immunoassay for rapid fumonisin b1 determination in cereal samples, Analytical Methods, 7, 37423749.

Faberi, A.; Foglia, P.; Pastorini, E.; Samperi, R.; Lagana, A., 2005. Determination of type b fumonisin mycotoxins in maize and maize-based products by liquid chromatography/tandem mass spectrometry using a qqqlinear ion trap mass spectrometer, Rapid Commun Mass Spectrom, 19, 275-282.

Fabregat-Cabello, N.; Zomer, P.; Sancho, J. V.; Roig-Navarro, A. F.; Mol, H. G. J., 2016. Comparison of approaches to deal with matrix effects in Ic-ms/ms based determinations of mycotoxins in food and feed, World Mycotoxin Journal, 9, 149-161.

Falasconi, M.; Gobbi, E.; Pardo, M.; Della Torre, M.; Bresciani, A.; Sberveglieri, G., 2005. Detection of toxigenic strains of fusarium verticillioides in corn by electronic olfactory system, Sensors and Actuators B-Chemical, 108, 250-257.

Falavigna, C.; Cirlini, M.; Galaverna, G.; Sforza, S.; Dossena, A.; Dall'Asta, C., 2012. Lc/esi-ms/ms analysis outlines the different fumonisin patterns produced by $\mathrm{f}$. Verticillioides in culture media and in maize kernels, J Mass Spectrom, 47, 1170-1176.

Falavigna, C.; Cirlini, M.; Galaverna, G.; Dall'Asta, C., 2012. Masked fumonisins in processed food: Cooccurrence of hidden and bound forms and their stability under digestive conditions, World Mycotoxin Journal, 5, 325-334.

Falavigna, C.; Lazzaro, I.; Galaverna, G.; Battilani, P.; Dall'Asta, C., 2013. Fatty acid esters of fumonisins: First evidence of their presence in maize, Food Addit Contam Part A Chem Anal Control Expo Risk Assess, 30, 1606-1613.

Fernandes, P. J.; Barros, N.; Santo, J. L.; Camara, J. S., 2015. High-throughput analytical strategy based on modified quechers extraction and dispersive solid-phase extraction clean-up followed by liquid chromatography-triple-quadrupole tandem mass spectrometry for quantification of multiclass mycotoxins in cereals, Food Analytical Methods, 8, 841-856.

Firrao, G.; Torelli, E.; Gobbi, E.; Raranciuc, S.; Bianchi, G.; Locci, R., 2010. Prediction of milled maize fumonisin contamination by multispectral image analysis, Journal of Cereal Science, 52, 327-330.

Frenich, A. G.; Vidal, J. L. M.; Romero-Gonzalez, R.; Aguilera-Luiz, M. D., 2009. Simple and highthroughput method for the multimycotoxin analysis in cereals and related foods by ultra-high performance liquid chromatography/tandem mass spectrometry, Food Chemistry, 117, 705-712.

Freudenschuss, M.; Jaunecker, G.; Krska, R., 2003. Fumonisin b1 - isolation and analytical characterisation for the application as reference material, Mycotoxin Res, 19, 194-197.

Frisvad, J. C.; Larsen, T. O.; Thrane, U.; Meijer, M.; Varga, J.; Samson, R. A.; Nielsen, K. F., 2011. Fumonisin and ochratoxin production in industrial aspergillus niger strains, PLoS One, 6, e23496.

Frisvad, J. C.; Smedsgaard, J.; Samson, R. A.; Larsen, T. O.; Thrane, U., 2007. Fumonisin b2 production by aspergillus niger, J Agric Food Chem, 55, 9727-9732. 
Fu, M.; Li, R. J.; Guo, C. C.; Pang, M. H.; Liu, Y. C.; Dong, J. G., 2015. Natural incidence of fusarium species and fumonisins b-1 and b-2 associated with maize kernels from nine provinces in china in 2012, Food Additives and Contaminants Part a-Chemistry Analysis Control Exposure \& Risk Assessment, 32, 503-511.

Galaverna, G.; Dall'asta, C.; Mangia, M. A.; Dossena, A.; Marchelli, R., 2009. Masked mycotoxins: An emerging issue for food safety, Czech Journal of Food Sciences, 27, S89-S92.

Gambacorta, L.; Solfrizzo, M.; Visconti, A.; Powers, S.; Cossalter, A. M.; Pinton, P.; Oswald, I. P., 2013. Validation study on urinary biomarkers of exposure for aflatoxin $b-1$, ochratoxin $a$, fumonisin b-1, deoxynivalenol and zearalenone in piglets, World Mycotoxin Journal, 6, 299-308.

Garcia-Fonseca, S.; Rubio, S., 2016. Restricted access supramolecular solvents for removal of matrixinduced ionization effects in mass spectrometry: Application to the determination of fusarium toxins in cereals, Talanta, 148, 370-379.

Garcia-Moraleja, A.; Font, G.; Manes, J.; Ferrer, E., 2015. Analysis of mycotoxins in coffee and risk assessment in spanish adolescents and adults, Food Chem Toxicol, 86, 225-233.

Garcia-Moraleja, A.; Font, G.; Manes, J.; Ferrer, E., 2015. Development of a new method for the simultaneous determination of 21 mycotoxins in coffee beverages by liquid chromatography tandem mass spectrometry, Food Research International, 72, 247-255.

Garcia-Moraleja, A.; Font, G.; Manes, J.; Ferrer, E., 2015. Simultaneous determination of mycotoxin in commercial coffee, Food Control, 57, 282-292.

Garrido, C. E.; Gonzalez, H. H. L.; Salas, M. P.; Resnik, S. L.; Pacin, A. M., 2013. Mycoflora and mycotoxin contamination of roundup ready soybean harvested in the pampean region, argentina, Mycotoxin Research, 29, 147-157.

Gaspardo, B.; Del Zotto, S.; Torelli, E.; Cividino, S. R.; Firrao, G.; Della Riccia, G.; Stefanon, B., 2012. A rapid method for detection of fumonisins $b-1$ and $b-2$ in corn meal using fourier transform near infrared (ft-nir) spectroscopy implemented with integrating sphere, Food Chemistry, 135, 16081612.

Gazzotti, T.; Lugoboni, B.; Zironi, E.; Barbarossa, A.; Serraino, A.; Pagliuca, G., 2009. Determination of fumonisin b1 in bovine milk by lc-ms/ms, Food Control, 20, 1171-1174.

Gazzotti, T.; Zironi, E.; Lugoboni, B.; Barbarossa, A.; Piva, A.; Pagliuca, G., 2011. Analysis of fumonisins b1, b2 and their hydrolysed metabolites in pig liver by Ic-ms/ms, Food Chemistry, 125, 1379-1384.

Geary, P. A.; Chen, G. Y.; Kimanya, M. E.; Shirima, C. P.; Oplatowska-Stachowiak, M.; Elliott, C. T.; Routledge, M. N.; Gong, Y. Y., 2016. Determination of multi-mycotoxin occurrence in maize based porridges from selected regions of tanzania by liquid chromatography tandem mass spectrometry (Ic-ms/ms), a longitudinal study, Food Control, 68, 337-343.

Gelderblom, W. C. A.; Sewram, V.; Shephard, G. S.; Snijman, P. W.; Tenza, K.; van der Westhuizen, L.; Vleggaar, R., 2007. Structure and natural occurrence of stereoisomers of the fumonisin b series mycotoxins, Journal of Agricultural and Food Chemistry, 55, 4388-4394.

Generotti, S.; Cirlini, M.; Dall'Asta, C.; Suman, M., 2015. Influence of the industrial process from caryopsis to cornmeal semolina on levels of fumonisins and their masked forms, Food Control, 48, 170-174.

Gerding, J.; Ali, N.; Schwartzbord, J.; Cramer, B.; Brown, D. L.; Degen, G. H.; Humpf, H. U., 2015. A comparative study of the human urinary mycotoxin excretion patterns in bangladesh, germany, and haiti using a rapid and sensitive lc-ms/ms approach, Mycotoxin Res, 31, 127-136.

Gerding, J.; Cramer, B.; Humpf, H. U., 2014. Determination of mycotoxin exposure in germany using an Ic-ms/ms multibiomarker approach, Mol Nutr Food Res, 58, 2358-2368. 
Ghali, R.; Ghorbel, H.; Hedilli, A., 2009. Fumonisin determination in tunisian foods and feeds. Elisa and hplc methods comparison, J Agric Food Chem, 57, 3955-3960.

Ghiasian, S. A.; Maghsood, A. H.; Yazdanpanah, H.; Shephard, G. S.; Van der Westhuizen, L.; Vismer, H. F.; Rheeder, J. P.; Marasas, W. F. O., 2006. Incidence of fusarium verticillioides and levels of fumonisins in corn from main production areas in iran, Journal of Agricultural and Food Chemistry, $54,6118-6122$.

Giacomo, D.; Stefania, D., 2013. A multivariate regression model for detection of fumonisins content in maize from near infrared spectra, Food Chemistry, 141, 4289-4294.

Gobbi, E.; Falasconi, M.; Torelli, E.; Sberveglieri, G., 2011. Electronic nose predicts high and low fumonisin contamination in maize cultures, Food Research International, 44, 992-999.

Guo, C.; Liu, Y.; Jiang, Y.; Li, R.; Pang, M.; Liu, Y.; Dong, J., 2016. Fusarium species identification and fumonisin production in maize kernels from shandong province, china, from 2012 to 2014, Food Addit Contam Part B Surveill, 9, 203-209.

Guo, W. B.; Han, Z.; Yang, J. H.; Rao, Q. X.; Zhao, Z. H., 2016. Simultaneous preparation and characterization of three high-purity type $b$ fumonisins from maize culture, Analytical Methods, 8 , 2737-2742.

Han, Z.; Ren, Y. P.; Liu, X. S.; Luan, L. J.; Wu, Y. J., 2010. A reliable isotope dilution method for simultaneous determination of fumonisins $b 1, b 2$ and $b 3$ in traditional chinese medicines by ultrahigh-performance liquid chromatography-tandem mass spectrometry, Journal of Separation Science, 33, 2723-2733.

Han, Z.; Tangni, E. K.; Huybrechts, B.; Munaut, F.; Scauflaire, J.; Wu, A.; Callebaut, A., 2014. Screening survey of co-production of fusaric acid, fusarin c, and fumonisins b-1, b-2 and b-3 by fusarium strains grown in maize grains, Mycotoxin Research, 30, 231-240.

Harrer, H.; Laviad, E. L.; Humpf, H. U.; Futerman, A. H., 2013. Identification of n-acyl-fumonisin b1 as new cytotoxic metabolites of fumonisin mycotoxins, Mol Nutr Food Res, 57, 516-522.

Hartl, M.; Humpf, H. U., 2001. Combined synthetic/cd strategy for the stereochemical assignment of the tricarballylic acid side chains of fumonisin b-1, Journal of Organic Chemistry, 66, 3678-3681.

He, Q. H.; Xu, Y.; Wang, D.; Kang, M.; Huang, Z. B.; Li, Y. P., 2012. Simultaneous multiresidue determination of mycotoxins in cereal samples by polyvinylidene fluoride membrane based dot immunoassay, Food Chemistry, 134, 507-512.

Heinl, S.; Hartinger, D.; Thamhesl, M.; Schatzmayr, G.; Moll, W. D.; Grabherr, R., 2011. An aminotransferase from bacterium atcc 55552 deaminates hydrolyzed fumonisin b-1, Biodegradation, 22, 25-30.

Heyndrickx, E.; Sioen, I.; Bellemans, M.; De Maeyer, M.; Callebaut, A.; De Henauw, S.; De Saeger, S., 2014. Assessment of mycotoxin exposure in the belgian population using biomarkers: Aim, design and methods of the biomyco study, Food Addit Contam Part A Chem Anal Control Expo Risk Assess, 31, 924-931.

Hickert, S.; Gerding, J.; Ncube, E.; Hubner, F.; Flett, B.; Cramer, B.; Humpf, H. U., 2015. A new approach using micro hplc-ms/ms for multi-mycotoxin analysis in maize samples, Mycotoxin Res, 31, 109-115.

Hinojo, M. J.; Medina, A.; Valle-Algarra, F. M.; Gimeno-Adelantado, J. V.; Jimenez, M.; Mateo, R., 2006. Fumonisin production in rice cultures of fusarium verticillioides under different incubation conditions using an optimized analytical method, Food Microbiol, 23, 119-127.

Ho, J. A. A.; Durst, R. A., 2003. Detection of fumonisin b1: Comparison of flow-injection liposome immunoanalysis with high-performance liquid chromatography, Analytical Biochemistry, 312, 7-13.

Ho, J. A. A.; Durst, R. A., 2000. Development of a flow-injection liposome immunoanalysis system for 
fumonisin b1, Analytica Chimica Acta, 414, 61-69.

Ho, J. A. A.; Durst, R. A., 2000. Preparation of reagents for the determination of fumonisin b1 by flowinjection immunoanalysis, Analytica Chimica Acta, 414, 51-60.

Hu, Z. Q.; Li, H. P.; Wu, P.; Li, Y. B.; Zhou, Z. Q.; Zhang, J. B.; Liu, J. L.; Liao, Y. C., 2015. An affinity improved single-chain antibody from phage display of a library derived from monoclonal antibodies detects fumonisins by immunoassay, Anal Chim Acta, 867, 74-82.

Hubner, F.; Harrer, H.; Fraske, A.; Kneifel, S.; Humpf, H. U., 2012. Large scale purification of b-type fumonisins using centrifugal partition chromatography (cpc), Mycotoxin Res, 28, 37-43.

Inoue, T.; Nagatomi, Y.; Uyama, A.; Mochizuki, N., 2013. Fate of mycotoxins during beer brewing and fermentation, Bioscience Biotechnology and Biochemistry, 77, 1410-1415.

Jaksic, S.; Zivkov-Balos, M.; Mihaljev, Z.; Masic, Z.; Jajic, I.; Banic, N.; Abramovic, B., 2015. Extraction without organic solvents in the determination of fumonisins $b-1, b-2$, and $b-3$ in maize by hplc-fld and elisa tests, Food Analytical Methods, 8, 1446-1455.

Jenkins, G. R.; Tolleson, W. H.; Newkirk, D. K.; Roberts, D. W.; Rowland, K. L.; Saheki, T.; Kobayashi, K.; Howard, P. C.; Melchior, W. B., 2000. Identification of fumonisin b-1 as an inhibitor of argininosuccinate synthetase using fumonisin affinity chromatography and in vitro kinetic studies, Journal of Biochemical and Molecular Toxicology, 14, 320-328.

Jettanajit, A.; Nhujak, T., 2016. Determination of mycotoxins in brown rice using quechers sample preparation and uhplc-ms-ms, J Chromatogr Sci, 54, 720-729.

Jimenez, M.; Rodriguez, S.; Mateo, J. J.; Gil, J. V.; Mateo, R., 2000. Characterization of gibberella fujikuroi complex isolates by fumonisin b-1 and b-2 analysis and by rapd and restriction analysis of pcr-amplified internal transcribed spacers of ribosomal DNA, Systematic and Applied Microbiology, 23, 546-555.

Jodra, A.; Lopez, M. A.; Escarpa, A., 2015. Disposable and reliable electrochemical magnetoimmunosensor for fumonisins simplified determination in maize-based foodstuffs, Biosens Bioelectron, 64, 633-638.

Johansson, A. S.; Whitaker, T. B.; Hagler, W. M.; Bowman, D. T.; Slate, A. B.; Payne, G., 2006. Predicting aflatoxin and fumonisin in shelled corn lots sing poor-quality grade components, Journal of Aoac International, 89, 433-440.

Joshi, S.; Segarra-Fas, A.; Peters, J.; Zuilhof, H.; van Beek, T. A.; Nielen, M. W. F., 2016. Multiplex surface plasmon resonance biosensing and its transferability towards imaging nanoplasmonics for detection of mycotoxins in barley, Analyst, 141, 1307-1318.

Juan, C.; Covarelli, L.; Beccari, G.; Colasante, V.; Manes, J., 2016. Simultaneous analysis of twenty-six mycotoxins in durum wheat grain from italy, Food Control, 62, 322-329.

Jung, S. Y.; Choe, B. C.; Choi, E. J.; Jeong, H. J.; Hwang, Y. S.; Shin, G. Y.; Kim, J. H., 2015. Survey of mycotoxins in commonly consumed korean grain products using an Ic-ms/ms multimycotoxin method in combination with immunoaffinity clean-up, Food Science and Biotechnology, 24, 11931199.

Kadir, M. K. A.; Tothill, I. E., 2010. Development of an electrochemical immunosensor for fumonisins detection in foods, Toxins, 2, 382-398.

Kamala, A.; Kimanya, M.; Haesaert, G.; Tiisekwa, B.; Madege, R.; Degraeve, S.; Cyprian, C.; De Meulenaer, B., 2016. Local post-harvest practices associated with aflatoxin and fumonisin contamination of maize in three agro ecological zones of tanzania, Food Addit Contam Part A Chem Anal Control Expo Risk Assess, 33, 551-559.

Karimla, A.; Ortiz, J.; Kimanya, M.; Haesaert, G.; Donoso, S.; Tiisekwa, B.; De Meulenaer, B., 2015. Multiple mycotoxin co-occurrence in maize grown in three agro-ecological zones of tanzania, Food 
Control, 54, 208-215.

Katay, G.; Szecsi, A.; Tyihak, E., 2001. Separation of fumonisins by oplc, Jpc-Journal of Planar Chromatography-Modern Tlc, 14, 53-56.

Kawashima, L. M.; Vieira, A. P.; Soares, L. M. V., 2007. Famonisin b(1) and ochratoxin a in beers made in brazil, Ciencia E Tecnologia De Alimentos, 27, 317-323.

Keller, K. M.; Queiroz, B. D.; Keller, L. A. M.; Ribeiro, J. M. M.; Cavaglieri, L. R.; Pereyra, M. L. G.; Dalcero, A. M.; Rosa, C. A. R., 2007. The mycobiota and toxicity of equine feeds, Veterinary Research Communications, 31, 1037-1045.

Khayoon, W. S.; Saad, B.; Salleh, B.; Ismail, N. A.; Manaf, N. H. A.; Latiff, A. A., 2010. A reversed phase high performance liquid chromatography method for the determination of fumonisins $b-1$ and $b-2$ in food and feed using monolithic column and positive confirmation by liquid chromatography/tandem mass spectrometry, Analytica Chimica Acta, 679, 91-97.

Kim, E. K.; Maragos, C. M.; Kendra, D. F., 2004. Liquid chromatographic determination of fumonisins b-1, b-2, and b-3 in corn silage, Journal of Agricultural and Food Chemistry, 52, 196-200.

Kim, E. K.; Scott, P. M.; Lau, B. P. Y.; Lewis, D. A., 2002. Extraction of fumonisins b-1, and b-2 from white rice flour and their stability in white rice flour, cornstarch, cornmeal, and glucose, Journal of Agricultural and Food Chemistry, 50, 3614-3620.

Kim, E. K.; Scott, P. M.; Lau, B. P. Y., 2003. Hidden fumonisin in corn flakes, Food Additives and Contaminants Part a-Chemistry Analysis Control Exposure \& Risk Assessment, 20, 161-169.

Kim, E. K.; Shon, D. H.; Chung, S. H.; Kim, Y. B., 2002. Survey for fumonisin b-1 in korean corn-based food products, Food Additives and Contaminants, 19, 459-464.

Kirincic, S.; Skrjanc, B.; Kos, N.; Kozolc, B.; Pirnat, N.; Tavcar-Kalcher, G., 2015. Mycotoxins in cereals and cereal products in slovenia - official control of foods in the years 2008-2012, Food Control, 50, 157-165.

Klaric, M. S.; Cvetnic, Z.; Pepeljnjak, S.; Kosalec, I., 2009. Co-occurrence of aflatoxins, ochratoxin a, fumonisins, and zearalenone in cereals and feed, determined by competitive direct enzyme-linked immunosorbent assay and thin-layer chromatography, Arh Hig Rada Toksikol, 60, 427-434.

Knudsen, P. B.; Mogensen, J. M.; Larsen, T. O.; Nielsen, K. F., 2011. Occurrence of furnonisins b-2 and b-4 in retail raisins, Journal of Agricultural and Food Chemistry, 59, 772-776.

Kokkonen, M. K.; Jestoi, M. N., 2009. A multi-compound Ic-ms/ms method for the screening of mycotoxins in grains, Food Analytical Methods, 2, 128-140.

Kong, D. Z.; Liu, L. Q.; Song, S. S.; Suryoprabowo, S.; Li, A. K.; Kuang, H.; Wang, L. B.; Xu, C. L., 2016. A gold nanoparticle-based semi-quantitative and quantitative ultrasensitive paper sensor for the detection of twenty mycotoxins, Nanoscale, 8, 5245-5253.

Kong, W.; Xie, T.; Li, J.; Wei, J.; Qiu, F.; Qi, A.; Zheng, Y.; Yang, M., 2012. Analysis of fumonisins b1 and b2 in spices and aromatic and medicinal herbs by hplc-fld with on-line post-column derivatization and positive confirmation by lc-ms/ms, Analyst, 137, 3166-3174.

Kononenko, G. P.; Burkin, A. A.; Gavrilova, O. P.; Gagkaeva, T. Y., 2015. Fungal species and multiple mycotoxin contamination of cultivated grasses and legumes crops, Agricultural and Food Science, 24, 323-330.

Kosicki, R.; Blajet-Kosicka, A.; Grajewski, J.; Twaruzek, M., 2016. Multiannual mycotoxin survey in feed materials and feedingstuffs, Animal Feed Science and Technology, 215, 165-180.

Kritzinger, Q.; Aveling, T. A. S.; Marasas, W. F. O.; Rheeder, J. P.; Van der Westhuizen, L.; Shephard, G. S., 2003. Mycoflora and furnonisin mycotoxins associated with cowpea vigna unguiculata (I.) walp seeds, Journal of Agricultural and Food Chemistry, 51, 2188-2192. 
Krska, R.; Welzig, E.; Boudra, H., 2007. Analysis of fusarium toxins in feed, Animal Feed Science and Technology, 137, 241-264.

Krynitsky, A. J.; Trucksess, M. W.; Wong, J. W.; Zhang, K., 2016. Perspective on advancing fda regulatory monitoring for mycotoxins in foods using liquid chromatography and mass spectrometry (review), J AOAC Int.

Kulisek, E. S.; Hazebroek, J. P., 2000. Comparison of extraction buffers for the detection of fumonisin b-1 in corn by immunoassay and high-performance liquid chromatography, Journal of Agricultural and Food Chemistry, 48, 65-69.

Kushiro, M.; Tanaka, K.; Miyazaki, S.; Nagata, T., 2006. Advances of liquid chromatographic determination of fumonisins; potential mycotoxins for humans, Current Pharmaceutical Analysis, 2, 289-297.

Labuda, R.; Parich, A.; Vekiru, E.; Tancinova, D., 2005. Incidence of fumonisins, moniliformin and fusarium species in poultry feed mixtures from slovakia, Ann Agric Environ Med, 12, 81-86.

Lamberti, I.; Tanzarella, C.; Solinas, I.; Padula, C.; Mosiello, L., 2009. An antibody-based microarray assay for the simultaneous detection of aflatoxin b1 and fumonisin b 1, Mycotoxin Res, 25, 193200.

Latorre, A.; Dagnac, T.; Lorenzo, B. F.; Llompart, M., 2015. Occurrence and stability of masked fumonisins in corn silage samples, Food Chem, 189, 38-44.

Lattanzio, V. M. T.; Ciasca, B.; Powers, S.; Visconti, A., 2014. Improved method for the simultaneous determination of aflatoxins, ochratoxin a and fusarium toxins in cereals and derived products by liquid chromatography-tandem mass spectrometry after multi-toxin immunoaffinity clean up, Journal of Chromatography A, 1354, 139-143.

Lattanzio, V. M. T.; Nivarlet, N.; Lippolis, V.; Della Gatta, S.; Huet, A. C.; Delahaut, P.; Granier, B.; Visconti, A., 2012. Multiplex dipstick immunoassay for semi-quantitative determination of fusarium mycotoxins in cereals, Analytica Chimica Acta, 718, 99-108.

Lattanzio, V. M. T.; Solfrizzo, M.; Powers, S.; Visconti, A., 2007. Simultaneous determination of aflatoxins, ochratoxin a and fusarium toxins in maize by liquid chromatography/tandem mass spectrometry after multitoxin immunoaffinity cleanup, Rapid Communications in Mass Spectrometry, 21, 3253-3261.

Lattanzio, V. M. T.; von Holst, C.; Visconti, A., 2014. Collaborative study for evaluating performances of a multiplex dipstick immunoassay for fusarium mycotoxin screening in wheat and maize, Quality Assurance and Safety of Crops \& Foods, 6, 299-307.

Lattanzio, V. M. T.; von Holst, C.; Visconti, A., 2013. Experimental design for in-house validation of a screening immunoassay kit. The case of a multiplex dipstick for fusarium mycotoxins in cereals, Analytical and Bioanalytical Chemistry, 405, 7773-7782.

Lauer, B.; Ottleben, I.; Jacobsen, H. J.; Reinard, T., 2005. Production of a single-chain variable fragment antibody against fumonisin b1, J Agric Food Chem, 53, 899-904.

Lawrence, J. F.; Menard, C.; Yeung, J.; Ben Rejeb, S., 2000. Evaluation of silica- and sepharose-based immunoaffinity sorbents for sample cleanup in determination of fumonisins b-1 and b-2 in corn products, Journal of Aoac International, 83, 597-603.

Lawrence, J. F.; Niedzwiadek, B.; Scott, P. M., 2000. Effect of temperature and solvent composition on extraction of fumonisins b-1 and b-2 from corn products, Journal of Aoac International, 83, 604611.

Lazzaro, I.; Falavigna, C.; Dall'asta, C.; Proctor, R. H.; Galaverna, G.; Battilani, P., 2012. Fumonisins $\mathrm{b}$, $\mathrm{a}$ and $\mathrm{c}$ profile and masking in fusarium verticillioides strains on fumonisin-inducing and maizebased media, Int J Food Microbiol, 159, 93-100. 
Lee, K. M.; Herrman, T. J., 2016. Determination and prediction of fumonisin contamination in maize by surface-enhanced raman spectroscopy (sers), Food and Bioprocess Technology, 9, 588-603.

Leggieri, M. C.; Bertuzzi, T.; Pietri, A.; Battilani, P., 2015. Mycotoxin occurrence in maize produced in northern italy over the years 2009-2011: Focus on the role of crop related factors, Phytopathologia Mediterranea, 54, 212-221.

Lehner, S. M.; Neumann, N. K. N.; Sulyok, M.; Lemmens, M.; Krska, R.; Schuhmacher, R., 2011. Evaluation of Ic-high-resolution ft-orbitrap ms for the quantification of selected mycotoxins and the simultaneous screening of fungal metabolites in food, Food Additives and Contaminants Part aChemistry Analysis Control Exposure \& Risk Assessment, 28, 1457-1468.

Lemke, S. L.; Ottinger, S. E.; Ake, C. L.; Mayura, K.; Phillips, T. D., 2001. Deamination of fumonisin $\mathrm{b}(1)$ and biological assessment of reaction product toxicity, Chem Res Toxicol, 14, 11-15.

Levasseur-Garcia, C.; Bailly, S.; Kleiber, D.; Bailly, J. D., 2015. Assessing risk of fumonisin contamination in maize using near-infrared spectroscopy, Journal of Chemistry.

Levasseur-Garcia, C.; Kleiber, D., 2015. A method for the allotment of maize contaminated by toxins, Journal of near Infrared Spectroscopy, 23, 255-265.

Li, C. L.; Wen, K.; Mi, T. J.; Zhang, X. Y.; Zhang, H. Y.; Zhang, S. X.; Shen, J. Z.; Wang, Z. H., 2016. A universal multi-wavelength fluorescence polarization immunoassay for multiplexed detection of mycotoxins in maize, Biosensors \& Bioelectronics, 79, 258-265.

Li, C.; Mi, T.; Conti, G. O.; Yu, Q.; Wen, K.; Shen, J.; Ferrante, M.; Wang, Z., 2015. Development of a screening fluorescence polarization immunoassay for the simultaneous detection of fumonisins $b(1)$ and $b(2)$ in maize, J Agric Food Chem, 63, 4940-4946.

Li, C.; Wu, Y. L.; Yang, T.; Huang-Fu, W. G., 2012. Rapid determination of fumonisins b-1 and b-2 in corn by liquid chromatography-tandem mass spectrometry with ultrasonic extraction, Journal of Chromatographic Science, 50, 57-63.

Li, F.; Jiang, D.; Zheng, F.; Chen, J.; Li, W., 2015. Fumonisins $b(1), b(2)$ and $b(3)$ in corn products, wheat flour and corn oil marketed in shandong province of china, Food Addit Contam Part B Surveill, 8, 169-174.

Li, L.; Xia, L. R.; Zhao, Y. F.; Wang, H. Y., 2016. Development of immune-affinity 96 spots monolith array for multiple mycotoxins detection in food samples, J Chromatogr B Analyt Technol Biomed Life Sci, 1029-1030, 72-80.

Li, M. H.; Kong, W. J.; Li, Y. J.; Liu, H. M.; Liu, Q. T.; Dou, X. W.; Ou-Yang, Z.; Yang, M. H., 2016. High-throughput determination of multi-mycotoxins in chinese yam and related products by ultra fast liquid chromatography coupled with tandem mass spectrometry after one-step extraction, Journal of Chromatography B-Analytical Technologies in the Biomedical and Life Sciences, 1022, 118-125.

Li, R. J.; Guo, C. C.; Zhang, Q. G.; Pang, M. H.; Liu, Y. C.; Dong, J. G., 2015. Fumonisins b-1 and b-2 in maize harvested in hebei province, china, during 2011-2013, Food Additives \& Contaminants Part B-Surveillance, 8, 1-6.

Li, R. J.; Tao, B.; Pang, M. H.; Liu, Y. C.; Dong, J. G., 2015. Natural occurrence of fumonisins b-1 and b-2 in maize from three main maize-producing provinces in china, Food Control, 50, 838-842.

Li, W.; Herrman, T. J.; Dai, S. Y., 2010. Rapid determination of fumonisins in corn-based products by liquid chromatography/tandem mass spectrometry, J AOAC Int, 93, 1472-1481.

Li, Y. S.; Zhou, Y.; Lu, S. Y.; Guo, D. J.; Ren, H. L.; Meng, X. M.; Zhi, B. H.; Lin, C.; Wang, Z.; Li, X. B.; Liu, Z. S., 2012. Development of a one-step test strip for rapid screening of fumonisins b1, b2 and b3 in maize, Food Control, 24, 72-77.

Liao, C. D.; Wong, J. W.; Zhang, K.; Hayward, D. G.; Lee, N. S.; Trucksess, M. W., 2013. Multi- 
mycotoxin analysis of finished grain and nut products using high-performance liquid chromatography-triple-quadrupole mass spectrometry, J Agric Food Chem, 61, 4771-4782.

Liao, C. D.; Wong, J. W.; Zhang, K.; Yang, P.; Wittenberg, J. B.; Trucksess, M. W.; Hayward, D. G.; Lee, N. S.; Chang, J. S., 2015. Multi-mycotoxin analysis of finished grain and nut products using ultrahigh-performance liquid chromatography and positive electrospray ionization-quadrupole orbital ion trap high-resolution mass spectrometry, J Agric Food Chem, 63, 8314-8332.

Ligler, F. S.; Taitt, C. R.; Shriver-Lake, L. C.; Sapsford, K. E.; Shubin, Y.; Golden, J. P., 2003. Array biosensor for detection of toxins, Anal Bioanal Chem, 377, 469-477.

Lim, C. W.; Yoshinari, T.; Layne, J.; Chan, S. H., 2015. Multi-mycotoxin screening reveals separate occurrence of aflatoxins and ochratoxin a in asian rice, J Agric Food Chem, 63, 3104-3113.

Lin, X.; Guo, X., 2016. Advances in biosensors, chemosensors and assays for the determination of fusarium mycotoxins, Toxins (Basel), 8.

Ling, S.; Pang, J.; Yu, J.; Wang, R.; Liu, L.; Ma, Y.; Zhang, Y.; Jin, N.; Wang, S., 2014. Preparation and identification of monoclonal antibody against fumonisin $b(1)$ and development of detection by ic-elisa, Toxicon, 80, 64-72.

Ling, S.; Wang, R.; Gu, X.; Wen, C.; Chen, L.; Chen, Z.; Chen, Q. A.; Xiao, S.; Yang, Y.; Zhuang, Z.; Wang, S., 2015. Rapid detection of fumonisin b1 using a colloidal gold immunoassay strip test in corn samples, Toxicon, 108, 210-215.

Lino, C. M.; Silva, L. J. G.; Pena, A. L. S.; Silveira, M. I., 2006. Determination of fumonisins b1 and b2 in portuguese maize and maize-based samples by hplc with fluorescence detection, Analytical and Bioanalytical Chemistry, 384, 1214-1220.

Lippolis, V.; Maragos, C., 2014. Fluorescence polarisation immunoassays for rapid, accurate and sensitive determination of mycotoxins, World Mycotoxin Journal, 7, 479-489.

Liu, C. L.; Liu, F. M.; Xu, W. N.; Kofoet, A.; Humpf, H. U.; Jiang, S. R., 2005. Occurrence of fumonisins b-1 and b-2 in asparagus from shandong province, p.R. China, Food Additives and Contaminants, 22, 673-676.

Liu, F. M.; Chen, P. C.; Fu, Y. M.; Shih, D. Y. C., 2005. Determination of fumonisin b-1 and b-2 in corn products, Journal of Food and Drug Analysis, 13, 273-278.

Liu, Q. T.; Kong, W. J.; Guo, W. Y.; Yang, M. H., 2015. Multi-class mycotoxins analysis in angelica sinensis by ultra fast liquid chromatography coupled with tandem mass spectrometry, Journal of Chromatography B-Analytical Technologies in the Biomedical and Life Sciences, 988, 175-181.

Logrieco, A.; Ferracane, R.; Visconti, A.; Ritieni, A., 2010. Natural occurrence of fumonisin b2 in red wine from italy, Food Addit Contam Part A Chem Anal Control Expo Risk Assess, 27, 1136-1141.

Logrieco, A. F.; Ferracane, R.; Cozzi, G.; Haidukowsky, M.; Susca, A.; Mule, G.; Ritieni, A., 2011. Fumonisin $b-2$ by aspergillus niger in the grape-wine chain: An additional potential mycotoxicological risk, Annals of Microbiology, 61, 1-3.

Lombaert, G. A.; Pellaers, P.; Roscoe, V.; Mankotia, M.; Neil, R.; Scott, P. M., 2003. Mycotoxins in infant cereal foods from the canadian retail market, Food Addit Contam, 20, 494-504.

Lopez-Errasquin, E.; Vazquez, C.; Jimenez, M.; Gonzalez-Jaen, M. T., 2007. Real-time rt-pcr assay to quantify the expression of fum 1 and fum19 genes from the fumonisin-producing fusarium verticillioides, J Microbiol Methods, 68, 312-317.

Lu, Y.; Clifford, L.; Hauck, C. C.; Hendrich, S.; Osweiler, G.; Murphy, P. A., 2002. Characterization of fumonisin $b(1)$-glucose reaction kinetics and products, J Agric Food Chem, 50, 4726-4733.

Ma, L. Y.; Xu, W. T.; He, X. Y.; Huang, K. L.; Wang, Y.; Luo, Y. B., 2013. Determination of fumonisins b1 and b2 in chinese rice wine by hplc using aqc precolumn derivatisation, Journal of the Science of Food and Agriculture, 93, 1128-1133. 
Machinski, M.; Soares, L. M. V., 2000. Fumonisins b-1 and b-2 in brazilian corn-based food products, Food Additives and Contaminants, 17, 875-879.

Maenetje, P. W.; Dutton, M. F., 2007. The incidence of fungi and mycotoxins in south african barley and barley products, J Environ Sci Health B, 42, 229-236.

Magoha, H.; De Meulenaer, B.; Kimanya, M.; Hipolite, D.; Lachat, C.; Kolsteren, P., 2014. Fumonisin b1 contamination in breast milk and its exposure in infants under 6 months of age in rombo, northern tanzania, Food Chem Toxicol, 74, 112-116.

Mahnine, N.; Meca, G.; Fernandez-Franzon, M.; Manes, J.; Zinedine, A., 2012. Occurrence of fumonisins b1, b2 and b3 in breakfast and infant cereals from morocco, Phytopathologia Mediterranea, 51, 193-197.

Malachova, A.; Sulyok, M.; Schuhmacher, R.; Berthiller, F.; Hajslova, J.; Veprikova, Z.; Zachariasova, M.; Lattanzio, V. M. T.; De Saeger, S.; Di Mavungu, J. D.; Malysheva, S. V.; Biselli, S.; Winkelmann, O.; Breidbach, A.; Hird, S.; Krska, R., 2013. Collaborative investigation of matrix effects in mycotoxin determination by high performance liquid chromatography coupled to mass spectrometry, Quality Assurance and Safety of Crops \& Foods, 5, 91-103.

Malhotra, B. D.; Srivastava, S.; Ali, M. A.; Singh, C., 2014. Nanomaterial-based biosensors for food toxin detection, Appl Biochem Biotechnol, 174, 880-896.

Mansson, M.; Klejnstrup, M. L.; Phipps, R. K.; Nielsen, K. F.; Frisvad, J. C.; Gotfredsen, C. H.; Larsen, T. O., 2010. Isolation and nmr characterization of fumonisin b-2 and a new fumonisin b-6 from aspergillus niger, Journal of Agricultural and Food Chemistry, 58, 949-953.

Maragos, C., 2009. Fluorescence polarization immunoassay of mycotoxins: A review, Toxins (Basel), 1, 196-207.

Maragos, C. M., 2006. Fluorescence polarization for mycotoxin determination, Mycotoxin Res, 22, 9699.

Maragos, C. M.; Busman, M., 2010. Rapid and advanced tools for mycotoxin analysis: A review, Food Addit Contam Part A Chem Anal Control Expo Risk Assess, 27, 688-700.

Maragos, C. M.; Jolley, M. E.; Plattner, R. D.; Nasir, M. S., 2001. Fluorescence polarization as a means for determination of fumonisins in maize, J Agric Food Chem, 49, 596-602.

Marschik, S.; Hepperle, J.; Lauber, U.; Schnaufer, R.; Maier, S.; Kuhn, C.; Schwab-Bohnert, G., 2013. Extracting fumonisins from maize: Efficiency of different extraction solvents in multi-mycotoxin analytics, Mycotoxin Res, 29, 119-129.

Martins, H. M.; Guerra, M. M.; Bernardo, F., 2006. Zearalenone, deoxynivalenol and fumonisins in mixed-feed for laying hens, Mycotoxin Res, 22, 206-210.

Martins, M. L.; Martins, H. M.; Bernardo, F., 2001. Fumonisins b-1 and b-2 in black tea and medicinal plants, Journal of Food Protection, 64, 1268-1270.

Martos, P. A.; Thompson, W.; Diaz, G. J., 2010. Multiresidue mycotoxin analysis in wheat, barley, oats, rye and maize grain by high-performance liquid chromatography-tandem mass spectrometry, World Mycotoxin Journal, 3, 205-223.

Mashinini, K.; Dutton, M. F., 2006. The incidence of fungi and mycotoxins in south africa wheat and wheat-based products, J Environ Sci Health B, 41, 285-296.

Masikini, M.; Mailu, S. N.; Tsegaye, A.; Njomo, N.; Molapo, K. M.; Ikpo, C. O.; Sunday, C. E.; Rassie, C.; Wilson, L.; Baker, P. G. L.; Iwuoha, E. I., 2015. A fumonisins immunosensor based on polyanilino-carbon nanotubes doped with palladium telluride quantum dots, Sensors, 15, 529-546.

Masikini, M.; Williams, A. R.; Sunday, C. E.; Waryo, T. T.; Nxusani, E.; Wilson, L.; Qakala, S.; Bilibana, M.; Douman, S.; Jonnas, A.; Baker, P. G. L.; Iwuoha, E. I., 2016. Label free poly(2,5dimethoxyaniline)-multi-walled carbon nanotubes impedimetric immunosensor for fumonisin b-1 
detection, Materials, 9.

Mata, A. T.; Ferreira, J. P.; Oliveira, B. R.; Batoreu, M. C.; Crespo, M. T. B.; Pereira, V. J.; Bronze, M. R., 2015. Bottled water: Analysis of mycotoxins by lc-ms/ms, Food Chemistry, 176, 455-464.

Mateo, J. J.; Jimenez, M., 2000. Trichothecenes and fumonisins produced in autoclaved tiger nuts by strains of fusarium sporotrichioides and fusarium moniliforme, Food Microbiology, 17, 167-176.

Mateo, J. J.; Mateo, R.; Jimenez, M., 2001. Determination of fumonisins b1 and b2 produced by isolates of gibberella fujikuroi complex in corn and rice, Food Science and Technology International, 7, 231-236.

Mateo, J. J.; Mateo, R.; Hinojo, M. J.; Llorens, A.; Jimenez, M., 2002. Liquid chromatographic determination of toxigenic secondary metabolites produced by fusarium strains, J Chromatogr A, 955, 245-256.

Matsuo, Y.; Takahara, K.; Sago, Y.; Kushiro, M.; Nagashima, H.; Nakagawa, H., 2015. Detection of n(1-deoxy-d-fructos-1-yl) fumonisins b-2 and b-3 in corn by high-resolution Ic-orbitrap ms, Toxins, 7, 3700-3714.

Matumba, L.; Van Poucke, C.; Ediage, E. N.; Jacobs, B.; De Saeger, S., 2015. Effectiveness of hand sorting, flotation/washing, dehulling and combinations thereof on the decontamination of mycotoxin-contaminated white maize, Food Additives and Contaminants Part a-Chemistry Analysis Control Exposure \& Risk Assessment, 32, 960-969.

Matumba, L.; Van Poucke, C.; Biswick, T.; Monjerezi, M.; Mwatseteza, J.; De Saeger, S., 2014. A limited survey of mycotoxins in traditional. Maize based opaque beers in malawi, Food Control, 36, 253-256.

Mayer, S.; Twaruzek, M.; Blajet-Kosicka, A.; Grajewski, J., 2016. Occupational exposure to mould and microbial metabolites during onion sorting-insights into an overlooked workplace, Environmental Monitoring and Assessment, 188.

Mbugua, S. K.; Gathumbi, J. K., 2004. The contamination of kenyan lager beers with fusarium mycotoxins, Journal of the Institute of Brewing, 110, 227-229.

McDonald, F. E.; Pereira, C. L.; Chen, Y. H., 2011. Fumonisin: A template for methodology development and drug discovery, Pure and Applied Chemistry, 83, 445-459.

McKeague, M.; Bradley, C. R.; De Girolamo, A.; Visconti, A.; Miller, J. D.; DeRosa, M. C., 2010. Screening and initial binding assessment of fumonisin b-1 aptamers, International Journal of Molecular Sciences, 11, 4864-4881.

Medina-Martinez, M. S.; Martinez, A. J., 2000. Mold occurrence and aflatoxin b-1 and fumonisin b-1 determination in corn samples in venezuela, Journal of Agricultural and Food Chemistry, 48, 28332836.

Meirelles, P. G.; Ono, M. A.; Ohe, M. C. T.; Maroneze, D. M.; Itano, E. N.; Garcia, G. T.; Sugiura, Y.; Ueno, Y.; Hirooka, E. Y.; Ono, E. Y. S., 2006. Detection of fusarium sp contamination in corn by enzyme-linked immunosorbent assay, Food and Agricultural Immunology, 17, 79-89.

Meister, U., 2001. Investigations on the change of fumonisin content of maize during hydrothermal treatment of maize. Analysis by means of hplc methods and elisa, European Food Research and Technology, 213, 187-193.

Meyer, K.; Mohr, K.; Bauer, J.; Horn, P.; Kovacs, M., 2003. Residue formation of fumonisin b1 in porcine tissues, Food Addit Contam, 20, 639-647.

Min, W. K.; Cho, Y. J.; Park, J. B.; Bae, Y. H.; Kim, E. J.; Park, K.; Park, Y. C.; Seo, J. H., 2010. Production and characterization of monoclonal antibody and its recombinant single chain variable fragment specific for a food-born mycotoxin, fumonisin b-1, Bioprocess and Biosystems Engineering, 33, 109-115. 
Mirasoli, M.; Buragina, A.; Dolci, L. S.; Simoni, P.; Anfossi, L.; Giraudi, G.; Roda, A., 2012. Chemiluminescence-based biosensor for fumonisins quantitative detection in maize samples, Biosens Bioelectron, 32, 283-287.

Mirasoli, M.; Zangheri, M.; Anfossi, L.; Di Nardo, F.; Calabria, D.; Giovannoli, C.; Baggiani, C.; Roda, A., 2014. Chemiluminescence-based biosensor for fumonisins and aflatoxins quantitative detection in maize samples, Luminescence, 29, 31-32.

Mogensen, J. M.; Frisvad, J. C.; Thrane, U.; Nielsen, K. F., 2010. Production of fumonisin b2 and b4 by aspergillus niger on grapes and raisins, J Agric Food Chem, 58, 954-958.

Mogensen, J. M.; Larsen, T. O.; Nielsen, K. F., 2010. Widespread occurrence of the mycotoxin fumonisin b-2 in wine, Journal of Agricultural and Food Chemistry, 58, 4853-4857.

Mogensen, J. M.; Moller, K. A.; von Freiesleben, P.; Labuda, R.; Varga, E.; Sulyok, M.; Kubatova, A.; Thrane, U.; Andersen, B.; Nielsen, K. F., 2011. Production of fumonisins b-2 and b-4 in tolypocladium species, Journal of Industrial Microbiology \& Biotechnology, 38, 1329-1335.

Mogensen, J. M.; Sorensen, S. M.; Sulyok, M.; van der Westhuizen, L.; Shephard, G. S.; Frisvad, J. C.; Thrane, U.; Krska, R.; Nielsen, K. F., 2011. Single-kernel analysis of fumonisins and other fungal metabolites in maize from south african subsistence farmers, Food Addit Contam Part A Chem Anal Control Expo Risk Assess, 28, 1724-1734.

Mogensen, J. M.; Varga, J.; Thrane, U.; Frisvad, J. C., 2009. Aspergillus acidus from puerh tea and black tea does not produce ochratoxin a and fumonisin b-2, International Journal of Food Microbiology, 132, 141-144.

Molinelli, A.; Grossalber, K.; Krska, R., 2009. A rapid lateral flow test for the determination of total type $b$ fumonisins in maize, Anal Bioanal Chem, 395, 1309-1316.

Molinie, A.; Faucet, V.; Castegnaro, P.; Pfohl-Leszkowicz, A., 2005. Analysis of some breakfast cereals on the french market for their contents of ochratoxin a, citrinin and fumonisin b-1: Development of a method for simultaneous extraction of ochratoxin a and citrinin, Food Chemistry, 92, 391-400.

Moller, T. E.; Gustavsson, H. F., 2000. Determination of fumonisins b-1 and b-2 in various maize products by a combined sax+c-18 column and immunoaffinity column, Journal of Aoac International, 83, 99-103.

Momany, F. A.; Dombrink-Kurtzman, M. A., 2001. Molecular dynamics simulations on the mycotoxin fumonisin b1, J Agric Food Chem, 49, 1056-1061.

Monbaliu, S.; Van Poucke, C.; Van Peteghem, C.; Van Poucke, K.; Heungens, K.; De Saeger, S., 2009. Development of a multi-mycotoxin liquid chromatography/tandem mass spectrometry method for sweet pepper analysis, Rapid Commun Mass Spectrom, 23, 3-11.

Monbaliu, S.; Van Poucke, C.; Detavernier, C.; Dumoulin, F.; Van De Velde, M.; Schoeters, E.; Van Dyck, S.; Averkieva, O.; Van Peteghem, C.; De Saeger, S., 2010. Occurrence of mycotoxins in feed as analyzed by a multi-mycotoxin Ic-ms/ms method, J Agric Food Chem, 58, 66-71.

Monbaliu, S.; Wu, A. B.; Zhang, D. B.; Van Peteghem, C.; De Saeger, S., 2010. Multimycotoxin uplc$\mathrm{ms} / \mathrm{ms}$ for tea, herbal infusions and the derived drinkable products, Journal of Agricultural and Food Chemistry, 58, 12664-12671.

Mudili, V.; Siddaih, C. N.; Nagesh, M.; Garapati, P.; Kumar, K. N.; Murali, H. S.; Mattila, T. Y.; Batra, $\mathrm{H}$. V., 2014. Mould incidence and mycotoxin contamination in freshly harvested maize kernels originated from india, Journal of the Science of Food and Agriculture, 94, 2674-2683.

Mueller, A.; Appell, M., 2016. Mycotoxin analysis using imprinted materials technology: Recent developments, ] AOAC Int.

Munitz, M. S.; Resnik, S. L.; Pacin, A.; Salas, P. M.; Gonzalez, H. H. L.; Montti, M. I. T.; Drunday, V.; Guillin, E. A., 2014. Mycotoxigenic potential of fungi isolated from freshly harvested argentinean 
blueberries, Mycotoxin Research, 30, 221-229.

Muscarella, M.; Magro, S. L.; Nardiello, D.; Palermo, C.; Centonze, D., 2011. Determination of fumonisins $b(1)$ and $b(2)$ in maize food products by a new analytical method based on highperformance liquid chromatography and fluorimetric detection with post-column derivatization, Methods Mol Biol, 739, 187-194.

Muscarella, M.; Magroa, S. L.; Nardiello, D.; Palermo, C.; Centonze, D., 2008. Development of a new analytical method for the determination of fumonisins b-1 and b-2 in food products based on high performance liquid chromatography and fluorimetric detection with post-column derivatization, Journal of Chromatography A, 1203, 88-93.

Musser, S. M.; Eppley, R. M.; Trucksess, M. W. 2002. Electrospray mass spectrometry for fumonisin detection and method validation. in J. W.; Trucksess DeVries, M. W.; Jackson, L. S. (ed.), Mycotoxins and food safety.

Nardiello, D.; Lo Magro, S.; Iammarino, M.; Palermo, C.; Muscarella, M.; Centonze, D., 2014. Recent advances in the post-column derivatization for the determination of mycotoxins in food products and feed materials by liquid chromatography and fluorescence detection, Current Analytical Chemistry, 10, 355-365.

Nasir, M. S.; Jolley, M. E., 2003. Fluorescence polarization (fp) assays for the determination of grain mycotoxins (fumonisins, don vomitoxin and aflatoxins), Comb Chem High Throughput Screen, 6, 267-273.

Nayaka, S. C.; Shankar, A. C. U.; Niranjana, S. R.; Wulff, E. G.; Mortensen, C. N.; Prakash, H. S., 2010. Detection and quantification of fumonisins from fusarium verticillioides in maize grown in southern india, World Journal of Microbiology \& Biotechnology, 26, 71-78.

Nazari, F.; Sulyok, M.; Yazdanpanah, H.; Kobarfard, F.; Krska, R., 2014. A survey of mycotoxins in domestic rice in iran by liquid chromatography tandem mass spectrometry, Toxicol Mech Methods, 24, 37-41.

Ndube, N.; van der Westhuizen, L.; Shephard, G. S., 2009. Determination of fumonisins in maize by hplc with ultraviolet detection of o-phthaldialdehyde derivatives, Mycotoxin Res, 25, 225-228.

Ndube, N.; van der Westhuizen, L.; Green, I. R.; Shephard, G. S., 2011. Hplc determination of fumonisin mycotoxins in maize: A comparative study of naphthalene-2,3-dicarboxaldehyde and ophthaldialdehyde derivatization reagents for fluorescence and diode array detection, J Chromatogr B Analyt Technol Biomed Life Sci, 879, 2239-2243.

Nielsen, K. F.; Frisvad, J. C.; Logrieco, A., 2015. "Analyses of black aspergillus species of peanut and maize for ochratoxins and fumonisins," a comment on: J. Food prot. 77(5):805-813 (2014), J Food Prot, 78, 6-8.

Nielsen, K. F.; Mogensen, J. M.; Johansen, M.; Larsen, T. O.; Frisvad, J. C., 2009. Review of secondary metabolites and mycotoxins from the aspergillus niger group, Anal Bioanal Chem, 395, 1225-1242.

Nielsen, K. F.; Ngemela, A. F.; Jensen, L. B.; de Medeiros, L. S.; Rasmussen, P. H., 2015. Uhplc$\mathrm{ms} / \mathrm{ms}$ determination of ochratoxin a and fumonisins in coffee using quechers extraction combined with mixed-mode spe purification, J Agric Food Chem, 63, 1029-1034.

Njobeh, P. B.; Dutton, M. F.; Aberg, A. T.; Haggblom, P., 2012. Estimation of multi-mycotoxin contamination in south african compound feeds, Toxins (Basel), 4, 836-848.

Njobeh, P. B.; Dutton, M. F.; Koch, S. H.; Chuturgoon, A. A.; Stoev, S. D.; Mosonik, J. S., 2010. Simultaneous occurrence of mycotoxins in human food commodities from cameroon, Mycotoxin Res, 26, 47-57.

Nkwe, D. O.; Taylor, J. E.; Siame, B. A., 2005. Fungi, aflatoxins, fumonisin b-1 and zearalenone contaminating sorghum-based traditional malt, wort and beer in botswana, Mycopathologia, 160, 
177-186.

Nomura, M.; Ishibashi, T.; Komoriya, T.; Nagahara, T.; Chihara, T., 2015. Development and interlaboratory study of a method for quantification of fumonisin b-1, b-2 and b-3 in pet foods, World Mycotoxin Journal, 8, 55-61.

Noonim, P.; Mahakarnchanakul, W.; Nielsen, K. F.; Frisvad, J. C.; Samson, R. A., 2009. Fumonisin b2 production by aspergillus niger in thai coffee beans, Food Addit Contam Part A Chem Anal Control Expo Risk Assess, 26, 94-100.

Nuryono, ; Noviandi, C. T.; Agus, A.; Wedhastri, S.; Maryudani, Y. B.; Bohm, J.; Razzazi, E., 2002. A survey of fumonisins (b1, b2, b3) in indonesian corn-based food and feed samples, Mycotoxin Res, 18 Suppl 2, 117-120.

Ofitserova, M.; Nerkar, S.; Pickering, M.; Torma, L.; Thiex, N., 2009. Multiresidue mycotoxin analysis in corn grain by column high-performance liquid chromatography with postcolumn photochemical and chemical derivatization: Single-laboratory validation, J AOAC Int, 92, 15-25.

Oh, K. S.; Scott, P. M.; Chung, S. H., 2009. Incomplete recoveries of fumonisins present in naturally contaminated corn foods from an immunoaffinity column, J AOAC Int, 92, 496-501.

Oles, C. J.; Trucksess, M. W., 2010. Determination of fumonisin b-1 in botanical roots by liquid chromatography with fluorescence detection: Single-laboratory validation, Journal of Aoac International, 93, 1155-1160.

Oliveira, M. S.; Diel, A. C. L.; Rauber, R. H.; Fontoura, F. P.; Mallmann, A.; Dilkin, P.; Mallmann, C. A., 2015. Free and hidden fumonisins in brazilian raw maize samples, Food Control, 53, 217-221.

Omurtag, G. Z., 2001. Determination of fumonisin b-1 and b-2 in corn and corn-based products in turkey by high-performance liquid chromatography, Journal of Food Protection, 64, 1072-1075.

Omurtag, G. Z.; Yazicioglu, D., 2004. Determination of fumonisins b-1 and b-2 in herbal tea and medicinal plants in turkey by high-performance liquid chromatography, Journal of Food Protection, $67,1782-1786$.

Ono, E. Y. S.; Kawamura, O.; Ono, M. A.; Ueno, Y.; Hirooka, E. Y., 2000. A comparative study of indirect competitive elisa and hplc for fumonisin detection in corn of the state of parana, brazil, Food and Agricultural Immunology, 12, 5-14.

Ono, E. Y. S.; Ono, M. A.; Funo, F. Y.; Medina, A. E.; Oliveira, Tcrm; Kawamura, O.; Ueno, Y.; Hirooka, E. Y., 2001. Evaluation of fumonisin-aflatoxin co-occurrence in brazilian corn hybrids by elisa, Food Additives and Contaminants Part a-Chemistry Analysis Control Exposure \& Risk Assessment, 18, 719-729.

Oplatowska-Stachowiak, M.; Haughey, S. A.; Chevallier, O. P.; Galvin-King, P.; Campbell, K.; Magowan, E.; Adam, G.; Berthiller, F.; Krska, R.; Elliott, C. T., 2015. Determination of the mycotoxin content in distiller's dried grain with solubles using a multianalyte uhplc-ms/ms method, J Agric Food Chem, 63, 9441-9451.

Ortiz, J.; Van Camp, J.; Mestdagh, F.; Donoso, S.; De Meulenaer, B., 2013. Mycotoxin co-occurrence in rice, oat flakes and wheat noodles used as staple foods in ecuador, Food Addit Contam Part A Chem Anal Control Expo Risk Assess, 30, 2165-2176.

Oruc, H. H.; Cengiz, M.; Kalkanli, O., 2006. Comparison of aflatoxin and fumonisin levels in maize grown in turkey and imported from the USA, Animal Feed Science and Technology, 128, 337-341.

Ostry, V.; Ruprich, J.; Skarkova, J., 2001. The mycotoxin research in foodstuffs in the czech republic in the 90th years, Mycotoxin Res, 17 Suppl 2, 183-187.

Oswald, S.; Karsunke, X.; Dietrich, R.; Martlbauer, E.; Niessner, R.; Knopp, D., 2013. Automated regenerable microarray-based immunoassay for rapid parallel quantification of mycotoxins in cereals, Analytical and Bioanalytical Chemistry, 405, 6405-6415. 
Oueslati, S.; Romero-Gonzalez, R.; Lasram, S.; Frenich, A. G.; Vidal, J. L. M., 2012. Multi-mycotoxin determination in cereals and derived products marketed in tunisia using ultra-high performance liquid chromatography coupled to triple quadrupole mass spectrometry, Food and Chemical Toxicology, 50, 2376-2381.

Paepens, C.; De Saeger, S.; Van Poucke, C.; Dumoulin, F.; Van Calenbergh, S.; Van Peteghem, C., 2005. Development of a liquid chromatography/tandem mass spectrometry method for the quantification of fumonisin b1, b2 and b3 in cornflakes, Rapid Commun Mass Spectrom, 19, 20212029.

Paepens, C.; De Saeger, S.; Sibanda, L.; Barna-Vetro, I.; Anselme, M.; Larondelle, Y.; Van Peteghem, C., 2005. Evaluation of fumonisin contamination in cornflakes on the belgian market by "flowthrough" assay screening and Ic-ms/ms analyses, J Agric Food Chem, 53, 7337-7343.

Paepens, C.; De Saeger, S.; Sibanda, L.; Barna-Vetro, I.; Leglise, I.; Van Hove, F.; Van Peteghem, C., 2004. A flow-through enzyme immunoassay for the screening of fumonisins in maize, Analytica Chimica Acta, 523, 229-235.

Pagliuca, G.; Zironi, E.; Ceccolini, A.; Matera, R.; Serrazanetti, G. P.; Piva, A., 2005. Simple method for the simultaneous isolation and determination of fumonisin b-1 and its metabolite aminopentol- 1 in swine liver by liquid chromatography-fluorescence detection, Journal of Chromatography BAnalytical Technologies in the Biomedical and Life Sciences, 819, 97-103.

Palacios, S. A.; Ramirez, M. L.; Zalazar, M. C.; Farnochi, M. C.; Zappacosta, D.; Chiacchiera, S. M.; Reynoso, M. M.; Chulze, S. N.; Torres, A. M., 2011. Occurrence of fusarium spp. And fumonisin in durum wheat grains, Journal of Agricultural and Food Chemistry, 59, 12264-12269.

Palencia, E. R.; Mitchell, T. R.; Snook, M. E.; Glenn, A. E.; Gold, S.; Hinton, D. M.; Riley, R. T.; Bacon, C. W., 2014. Analyses of black aspergillus species of peanut and maize for ochratoxins and fumonisins, J Food Prot, 77, 805-813.

Palencia, E.; Torres, O.; Hagler, W.; Meredith, F. I.; Williams, L. D.; Riley, R. T., 2003. Total fumonisins are reduced in tortillas using the traditional nixtamalization method of mayan communities, J Nutr, 133, 3200-3203.

Park, J. W.; Kim, E. K.; Shon, D. H.; Kim, Y. B., 2002. Natural co-occurrence of aflatoxin b-1, fumonisin $b-1$ and ochratoxin $a$ in barley and corn foods from korea, Food Additives and Contaminants, 19, 1073-1080.

Park, J. W.; Scott, P. M.; Lau, B. P. Y., 2013. Analysis of $n$-fatty acyl fumonisins in alkali-processed corn foods, Food Science and Biotechnology, 22, 147-152.

Peluque, E.; Neres, N. B.; Michelin, E. C.; Reis, T. A.; Rosim, R. E.; Oliveira, C. A. F.; Sousa, R. L. M.; Correa, B.; Fernandes, A. M., 2014. Fumonisin b-1 in cereal mixtures marketed in brazil, Food Additives \& Contaminants Part B-Surveillance, 7, 46-48.

Pereyra, M. L.; Rosa, C. A. R.; Dalcero, A. M.; Cavaglieri, L. R., 2011. Mycobiota and mycotoxins in malted barley and brewer's spent grain from argentinean breweries, Letters in Applied Microbiology, 53, 649-655.

Peters, J.; Bienenmann-Ploum, M.; de Rijk, T.; Haasnoot, W., 2011. Development of a multiplex flow cytometric microsphere immunoassay for mycotoxins and evaluation of its application in feed, Mycotoxin Res, 27, 63-72.

Peters, J.; Cardall, A.; Haasnoot, W.; Nielen, M. W. F., 2014. 6-plex microsphere immunoassay with imaging planar array detection for mycotoxins in barley, Analyst, 139, 3968-3976.

Peters, J.; Thomas, D.; Boers, E.; de Rijk, T.; Berthiller, F.; Haasnoot, W.; Nielen, M. W. F., 2013. Colour-encoded paramagnetic microbead-based direct inhibition triplex flow cytometric immunoassay for ochratoxin a, fumonisins and zearalenone in cereals and cereal-based feed, Analytical and Bioanalytical Chemistry, 405, 7783-7794. 
Petersen, A.; Thorup, I., 2001. Preliminary evaluation of fumonisins by the nordic countries and occurrence of fumonisins ( $\mathrm{fb} 1$ and $\mathrm{fb} 2$ ) in corn-based foods on the danish market, Food Addit Contam, 18, 221-226.

Petrarca, M. H.; Rossi, E. A.; de Sylos, C. M., 2016. In-house method validation, estimating measurement uncertainty and the occurrence of fumonisin b-1 in samples of brazilian commercial rice, Food Control, 59, 439-446.

Petrarca, M. H.; Rodrigues, M. I.; Rossi, E. A.; de Sylos, C. M., 2014. Optimisation of a sample preparation method for the determination of fumonisin b-1 in rice, Food Chemistry, 158, 270-277.

Phuong, N. H.; Thieu, N. Q.; Ogle, B.; Pettersson, H., 2015. Aflatoxins, fumonisins and zearalenone contamination of maize in the southeastern and central highlands provinces of vietnam, Agriculture-Basel, 5, 1195-1203.

Pietri, A.; Bertuzzi, T., 2012. Simple phosphate buffer extraction for the determination of fumonisins in masa, maize, and derived products, Food Analytical Methods, 5, 1088-1096.

Pleadin, J.; Persi, N.; Zadravec, M.; Sokolovic, M.; Vulic, A.; Jaki, V.; Mitak, M., 2012. Correlation of deoxynivalenol and fumonisin concentration determined in maize by elisa methods, J Immunoassay Immunochem, 33, 414-421.

Pleadin, J.; Vahcic, N.; Persi, N.; Sevelj, D.; Markov, K.; Frece, J., 2013. Fusarium mycotoxins' occurrence in cereals harvested from croatian fields, Food Control, 32, 49-54.

Pocsfalvi, G.; Ritieni, A.; Randazzo, G.; Dobo, A.; Malorni, A., 2000. Interaction of fusarium mycotoxins, fusaproliferin and fumonisin b-1, with DNA studied by electrospray ionization mass spectrometry, Journal of Agricultural and Food Chemistry, 48, 5795-5801.

Poling, S. M.; Plattner, R. D.; Weisleder, D., 2002. N-(1-deoxy-d-fructos-1-yl) fumonisin b-1, the initial reaction product of fumonisin b-1 and d-glucose, Journal of Agricultural and Food Chemistry, 50, 1318-1324.

Preis, R. A.; Vargas, E. A., 2000. A method for determining fumonisin b-1 in corn using immunoaffinity column clean-up and thin layer chromatography/densitometry, Food Additives and Contaminants, $17,463-468$.

Quan, Y.; Zhang, Y.; Wang, S.; Lee, N.; Kennedy, I. R., 2006. A rapid and sensitive chemiluminescence enzyme-linked immunosorbent assay for the determination of fumonisin b-1 in food samples, Analytica Chimica Acta, 580, 1-8.

Rai, M.; Jogee, P. S.; Ingle, A. P., 2015. Emerging nanotechnology for detection of mycotoxins in food and feed, Int J Food Sci Nutr, 66, 363-370.

Rasmussen, R. R.; Storm, Imld; Rasmussen, P. H.; Smedsgaard, J.; Nielsen, K. F., 2010. Multimycotoxin analysis of maize silage by Ic-ms/ms, Analytical and Bioanalytical Chemistry, 397, 765776.

Reinholds, I.; Pugajeva, I.; Bartkevics, V., 2016. A reliable screening of mycotoxins and pesticide residues in paprika using ultra-high performance liquid chromatography coupled to high resolution orbitrap mass spectrometry, Food Control, 60, 683-689.

Ren, W. J.; Huang, Z. B.; Xu, Y.; Li, Y. P.; Ji, Y. W.; Su, B. W., 2015. Urchin-like gold nanoparticlebased immunochromatographic strip test for rapid detection of fumonisin b-1 in grains, Analytical and Bioanalytical Chemistry, 407, 7341-7348.

Ren, Y.; Zhang, Y.; Lai, S.; Han, Z.; Wu, Y., 2011. Simultaneous determination of fumonisins b1, b2 and b3 contaminants in maize by ultra high-performance liquid chromatography tandem mass spectrometry, Anal Chim Acta, 692, 138-145.

Renaud, J. B.; Kelman, M. J.; Qi, T. Y. F.; Seifert, K. A.; Sumarah, M. W., 2015. Product ion filtering with rapid polarity switching for the detection of all fumonisins and aal-toxins, Rapid 
Communications in Mass Spectrometry, 29, 2131-2139.

Richard, E.; Heutte, N.; Bouchart, V.; Garon, D., 2009. Evaluation of fungal contamination and mycotoxin production in maize silage, Animal Feed Science and Technology, 148, 309-320.

Richard, E.; Heutte, N.; Sage, L.; Pottier, D.; Bouchart, V.; Lebailly, P.; Garon, D., 2007. Toxigenic fungi and mycotoxins in mature corn silage, Food Chem Toxicol, 45, 2420-2425.

Riley, R. T.; Torres, O.; Showker, J. L.; Zitomer, N. C.; Matute, J.; Voss, K. A.; Gelineau-van Waes, J.; Maddox, J. R.; Gregory, S. G.; Ashley-Koch, A. E., 2012. The kinetics of urinary fumonisin b1 excretion in humans consuming maize-based diets, Mol Nutr Food Res, 56, 1445-1455.

Rofiat, A. S.; Fanelli, F.; Atanda, O.; Sulyok, M.; Cozzi, G.; Bavaro, S.; Krska, R.; Logrieco, A. F.; Ezekiel, C. N., 2015. Fungal and bacterial metabolites associated with natural contamination of locally processed rice (oryza sativa I.) in nigeria, Food Addit Contam Part A Chem Anal Control Expo Risk Assess, 32, 950-959.

Roger, D. D., 2011. Deoxynivanol (don) and fumonisins b-1 (fb1) in artisanal sorghum opaque beer brewed in north cameroon, African Journal of Microbiology Research, 5, 1565-1567.

Romero-Gonzalez, R.; Vidal, J. L. M.; Aguilera-Luiz, M. M.; Frenich, A. G., 2009. Application of conventional solid-phase extraction for multimycotoxin analysis in beers by ultrahigh-performance liquid chromatography-tandem mass spectrometry, Journal of Agricultural and Food Chemistry, 57, 9385-9392.

Royer, D.; Humpf, H. U.; Guy, P. A., 2004. Quantitative analysis of fusarium mycotoxins in maize using accelerated solvent extraction before liquid chromatography atmospheric pressure chemical ionization tandem mass spectrometry, Food Additives and Contaminants, 21, 678-692.

Rubert, J.; Manes, J.; James, K. J.; Soler, C., 2011. Application of hybrid linear ion trap-high resolution mass spectrometry to the analysis of mycotoxins in beer, Food Addit Contam Part A Chem Anal Control Expo Risk Assess, 28, 1438-1446.

Rubert, J.; Soler, C.; Manes, J., 2012. Occurrence of fourteen mycotoxins in tiger-nuts, Food Control, $25,374-379$.

Rubert, J.; Soriano, J. M.; Manes, J.; Soler, C., 2011. Rapid mycotoxin analysis in human urine: A pilot study, Food Chem Toxicol, 49, 2299-2304.

Sakamaki, H.; Uchida, T.; Lim, L. W.; Takeuchi, T., 2015. Evaluation of column carryover of phosphorylated peptides and fumonisins by duplicated solvent gradient method in liquid chromatography/tandem mass spectrometry, Anal Sci, 31, 91-97.

Samapundo, S.; De Meulenaer, B.; De Muer, N.; Debevere, J.; Devlieghere, F., 2006. Influence of experimental parameters on the fluorescence response and recovery of the high-performance liquid chromatography analysis of fumonisin b-1, Journal of Chromatography A, 1109, 312-316.

Sapsford, K. E.; Ngundi, M. M.; Moore, M. H.; Lassman, M. E.; Shriver-Lake, L. C.; Taitt, C. R.; Ligler, F. S., 2006. Rapid detection of foodborne contaminants using an array biosensor, Sensors and Actuators B-Chemical, 113, 599-607.

Savard, M. E.; Sinha, R. C.; Lau, R.; Seguin, C.; Buffam, S., 2003. Monoclonal antibodies for fumonisins b1, b2 and b3, Food and Agricultural Immunology, 15, 127-134.

Scarpino, V.; Reyneri, A.; Sulyok, M.; Krska, R.; Blandino, M., 2015. Effect of fungicide application to control fusarium head blight and 20 fusarium and alternaria mycotoxins in winter wheat (triticum aestivum I.), World Mycotoxin Journal, 8, 499-510.

Schmidt, P.; Novinski, C. O.; Junges, D.; Almeida, R.; de Souza, C. M., 2015. Concentration of mycotoxins and chemical composition of corn silage: A farm survey using infrared thermography, J Dairy Sci, 98, 6609-6619.

Schmidt-Heydt, M.; Geisen, R., 2007. A microarray for monitoring the production of mycotoxins in 
food, Int J Food Microbiol, 117, 131-140.

Scott, P. M., 2012. Recent research on fumonisins: A review, Food Addit Contam Part A Chem Anal Control Expo Risk Assess, 29, 242-248.

Scudamore, K. A.; Patel, S., 2000. Survey for aflatoxins, ochratoxin a, zearalenone and fumonisins in maize imported into the united kingdom, Food Addit Contam, 17, 407-416.

Scussel, V. M.; Savi, G. D.; Costas, L. L. F.; Xavier, J. J. M.; Manfio, D.; Bittencourt, K. O.; Aguiar, K.; Stein, S. M., 2014. Fumonisins in corn (zea mays I.) from southern brazil, Food Additives \& Contaminants Part B-Surveillance, 7, 151-155.

Sedova, I. B.; Kiseleva, M. G.; Zakharova, L. P.; Eller, K. I.; Tutel'yan, V. A., 2004. Optimization of conditions for the determination of fuminosins $b-1$ and $b-2$ in corn and its products of its processing by high-performance liquid chromatography, Journal of Analytical Chemistry, 59, 730736.

Seefelder, W.; Gossmann, M.; Humpf, H. U., 2002. Analysis of fumonisin b-1 in fusarium proliferatuminfected asparagus spears and garlic bulbs from germany by liquid chromatography - electrospray ionization mass spectrometry, Journal of Agricultural and Food Chemistry, 50, 2778-2781.

Seefelder, W.; Hartl, M.; Humpf, H. U., 2001. Determination of n-(carboxymethyl)fumonisin b-1 in corn products by liquid chromatography/electrospray ionization-mass spectrometry, Journal of Agricultural and Food Chemistry, 49, 2146-2151.

Seefelder, W.; Humpf, H. U., 2002. Formation of fumonisin artefacts in thermal treated food, Mycotoxin Res, 18 Suppl 2, 121-123.

Seefelder, W.; Knecht, A.; Humpf, H. U., 2003. Bound fumonisin b-1: Analysis of fumonisin-b-1 glyco and amino acid conjugates by liquid chromatography-electrospray ionization-tandem mass spectrometry, Journal of Agricultural and Food Chemistry, 51, 5567-5573.

Seefelder, W.; Knecht, A.; Gobetamann, M.; Kleta, S.; Buttner, C.; Humpf, H. U., 2004. Occurrence of fumonisins in asparagus (asparagus officinalis I.) and garlic (allium sativum I.) from germany, Mycotoxin Res, 20, 29-30.

Selvaraj, J. N.; Zhou, L.; Wang, Y.; Zhao, Y. J.; Xing, F. G.; Dai, X. F.; Liu, Y., 2015. Mycotoxin detection - recent trends at global level, Journal of Integrative Agriculture, 14, 2265-2281.

Senyuva, H.; Gilbert, J.; Ozcan, S.; Gurel, N., 2008. Rapid Ic and Ic/ms for routine analysis of mycotoxins in foods, World Mycotoxin Journal, 1, 229-235.

Senyuva, H. Z.; Gilbert, J.; Stroka, J., 2010. Determination of fumonisins b-1 and b-2 in corn by Ic/ms with immunoaffinity column cleanup: Interlaboratory study, Journal of Aoac International, 93, 611621.

Senyuva, H. Z.; Gilbert, J., 2008. Identification of fumonisin b-2, ht-2 toxin, patulin, and zearalenone in dried figs by liquid chromatography-time-of-flight mass spectrometry and liquid chromatography-mass spectrometry, Journal of Food Protection, 71, 1500-1504.

Senyuva, H. Z.; Ozcan, S.; Cimen, D.; Gilbert, J., 2008. Determination of fumonisins b-1 and b2 in corn by liquid chromatography/mass spectrometry with immunoaffinity column cleanup: Singlelaboratory method validation, Journal of Aoac International, 91, 598-606.

Sewram, V.; Mshicileli, N.; Shephard, G. S.; Marasas, W. F. O., 2003. Fumonisin mycotoxins in human hair, Biomarkers, 8, 110-118.

Sewram, V.; Mshicileli, N.; Shephard, G. S.; Vismer, H. F.; Rheeder, J. P.; Lee, Y. W.; Leslie, J. F.; Marasas, W. F. O., 2005. Production of fumonisin $b$ and $c$ analogues by several fusarium species, Journal of Agricultural and Food Chemistry, 53, 4861-4866.

Sewram, V.; Shepard, G. S.; Marasas, W. F. O.; de Castro, Mfpm, 2003. Improving extraction of fumonisin mycotoxins from brazilian corn-based infant foods, Journal of Food Protection, 66, 854- 
859.

Sewram, V.; Shephard, G. S.; van der Merwe, L.; Jacobs, T. V., 2006. Mycotoxin contamination of dietary and medicinal wild plants in the eastern cape province of south africa, J Agric Food Chem, 54, 5688-5693.

Sforza, S.; Dall'asta, C.; Marchelli, R., 2006. Recent advances in mycotoxin determination in food and feed by hyphenated chromatographic techniques/mass spectrometry, Mass Spectrom Rev, 25, 5476.

Shala-Mayrhofer, V.; Varga, E.; Marjakaj, R.; Berthiller, F.; Musolli, A.; Berisha, D.; Kelmendi, B.; Lemmens, M., 2013. Investigations on fusarium spp. And their mycotoxins causing fusarium ear rot of maize in kosovo, Food Addit Contam Part B Surveill, 6, 237-243.

Sharma, M., 2007. Detection of hydrolyzed fumonisins b-1 and b-2 by use of high performance liquid chromatography in sorghum, Asian Journal of Chemistry, 19, 499-504.

Sharma, M.; Montes, R.; Marques, C.; Bravo, L. L.; Flores, M. H. E., 2007. Incidence and quantification of fumonisins $b-1$ and $b-2$ at harvest stage in sorghum, Asian Journal of Chemistry, $19,396-400$.

Sheng, Y. J.; Jiang, W. X.; De Saeger, S.; Shen, J. Z.; Zhang, S. X.; Wang, Z. H., 2012. Development of a sensitive enzyme-linked immunosorbent assay for the detection of fumonisin b-1 in maize, Toxicon, 60, 1245-1250.

Shephard, G. S.; Berthiller, F.; Dorner, J.; Krska, R.; Lombaert, G. A.; Malone, B.; Maragos, C.; Sabino, M.; Solfrizzo, M.; Trucksess, M. W.; van Egmond, H. P.; Whitaker, T. B., 2009. Developments in mycotoxin analysis: An update for 2007-2008, World Mycotoxin Journal, 2, 3-21.

Shephard, G. S.; Berthiller, F.; Dorner, J.; Krska, R.; Lombaert, G. A.; Malone, B.; Maragos, C.; Sabino, M.; Solfrizzo, M.; Trucksess, M. W.; van Egmond, H. P.; Whitaker, T. B., 2010. Developments in mycotoxin analysis: An update for 2008-2009, World Mycotoxin Journal, 3, 3-23.

Shephard, G. S.; Berthiller, F.; Burdaspal, P.; Crews, C.; Jonker, M. A.; Krska, R.; MacDonald, S.; Malone, B.; Maragos, C.; Sabino, M.; Solfrizzo, M.; van Egmond, H. P.; Whitaker, T. B., 2011. Developments in mycotoxin analysis: An update for 2009-2010, World Mycotoxin Journal, 4, 3-28.

Shephard, G. S.; Berthiller, E.; Burdaspal, P. A.; Crews, C.; Jonker, M. A.; Krska, R.; MacDonald, S.; Malone, R. J.; Maragos, C.; Sabino, M.; Solfrizzo, M.; Van Egmond, H. P.; Whitaker, T. B., 2012. Developments in mycotoxin analysis: An update for 2010-2011, World Mycotoxin Journal, 5, 3-30.

Shephard, G. S.; Berthiller, F.; Burdaspal, P. A.; Crews, C.; Jonker, M. A.; Krska, R.; Lattanzio, V. M. T.; MacDonald, S.; Malone, R. J.; Maragos, C.; Sabino, M.; Solfrizzo, M.; van Egmond, H. P.; Whitaker, T. B., 2013. Developments in mycotoxin analysis: An update for 2011-2012, World Mycotoxin Journal, 6, 3-30.

Shephard, G. S.; Burger, H. M.; Gambacorta, L.; Gong, Y. Y.; Krska, R.; Rheeder, J. P.; Solfrizzo, M.; Srey, C.; Sulyok, M.; Visconti, A.; Warth, B.; van der Westhuizen, L., 2013. Multiple mycotoxin exposure determined by urinary biomarkers in rural subsistence farmers in the former transkei, south africa, Food Chem Toxicol, 62, 217-225.

Shephard, G. S.; Burger, H. M.; Gambacorta, L.; Krska, R.; Powers, S. P.; Rheeder, J. P.; Solfrizzo, M.; Sulyok, M.; Visconti, A.; Warth, B.; van der Westhuizen, L., 2013. Mycological analysis and multimycotoxins in maize from rural subsistence farmers in the former transkei, south africa, J Agric Food Chem, 61, 8232-8240.

Shephard, G. S.; Marasas, W. F. O.; Leggott, N. L.; Yazdanpanah, H.; Rahimian, H.; Safavi, N., 2000. Natural occurrence of fumonisins in corn from iran, Journal of Agricultural and Food Chemistry, 48, 1860-1864.

Shephard, G. S.; Sewram, V., 2004. Determination of the mycotoxin fumonisin b-1 in maize by reversed-phase thin-layer chromatography: A collaborative study, Food Additives and 
Contaminants Part a-Chemistry Analysis Control Exposure \& Risk Assessment, 21, 498-505.

Shephard, G. S.; Van der Westhuizen, L.; Gatyeni, P. A.; Katerere, D. R.; Marasas, W. F. O., 2005. Do fumonisin mycotoxins occur in wheat?, Journal of Agricultural and Food Chemistry, 53, 9293-9296.

Shephard, G. S.; van der Westhuizen, L.; Gatyeni, P. M.; Somdyala, N. I. M.; Burger, H. M.; Marasas, W. F. O., 2005. Fumonisin mycotoxins in traditional xhosa maize beer in south africa, Journal of Agricultural and Food Chemistry, 53, 9634-9637.

Shephard, G. S.; van der Westhuizen, L.; Sewram, V.; van Zyl, J.; Rheeder, J. P., 2011. Occurrence of the $c$-series fumonisins in maize from the former transkei region of south africa, Food Addit Contam Part A Chem Anal Control Expo Risk Assess, 28, 1712-1716.

Shi, Z. Y.; Zheng, Y. T.; Zhang, H. B.; He, C. H.; Wu, W. D.; Zhang, H. B., 2015. DNA electrochemical aptasensor for detecting fumonisins b-1 based on graphene and thionine nanocomposite, Electroanalysis, 27, 1097-1103.

Shimshoni, J. A.; Cuneah, O.; Sulyok, M.; Krska, R.; Galon, N.; Sharir, B.; Shlosberg, A., 2013. Mycotoxins in corn and wheat silage in israel, Food Addit Contam Part A Chem Anal Control Expo Risk Assess, 30, 1614-1625.

Shiu, C. M.; Wang, J. J.; Yu, F. Y., 2010. Sensitive enzyme-linked immunosorbent assay and rapid one-step immunochromatographic strip for fumonisin b1 in grain-based food and feed samples, J Sci Food Agric, 90, 1020-1026.

Shu, M.; Xu, Y.; Wang, D.; Liu, X.; Li, Y. P.; He, Q. H.; Tu, Z.; Qiu, Y. L.; Ji, Y. W.; Wang, X. X., 2015. Anti-idiotypic nanobody: A strategy for development of sensitive and green immunoassay for fumonisin b-1, Talanta, 143, 388-393.

Shu, M.; Xu, Y.; Liu, X.; Li, Y. P.; He, Q. H.; Tu, Z.; Fu, J. H.; Gee, S. J.; Hammock, B. D., 2016. Antiidiotypic nanobody-alkaline phosphatase fusion proteins: Development of a one-step competitive enzyme immunoassay for fumonisin b-1 detection in cereal, Analytica Chimica Acta, 924, 53-59.

Silva, L.; Fernandez-Franzon, M.; Font, G.; Pena, A.; Silveira, I.; Lino, C.; Manes, J., 2009. Analysis of fumonisins in corn-based food by liquid chromatography with fluorescence and mass spectrometry detectors, Food Chemistry, 112, 1031-1037.

Silva, L. J. G.; Pena, A.; Lino, C. M.; Fernandez, M. F.; Manes, J., 2010. Fumonisins determination in urine by Ic-ms-ms, Analytical and Bioanalytical Chemistry, 396, 809-816.

Skrbic, B.; Zivancev, J.; Godula, M., 2014. Multimycotoxin analysis of crude extracts of nuts with ultrahigh performance liquid chromatography/tandem mass spectrometry, Journal of Food Composition and Analysis, 34, 171-177.

Soleimany, F.; Jinap, S.; Abas, F., 2012. Determination of mycotoxins in cereals by liquid chromatography tandem mass spectrometry, Food Chemistry, 130, 1055-1060.

Soleimany, F.; Jinap, S.; Rahmani, A.; Khatib, A., 2011. Simultaneous detection of 12 mycotoxins in cereals using rp-hplc-pda-fld with phred and a post-column derivatization system, Food Addit Contam Part A Chem Anal Control Expo Risk Assess, 28, 494-501.

Soleimany, F.; Jinap, S.; Faridah, A.; Khatib, A., 2012. A uplc-ms/ms for simultaneous determination of aflatoxins, ochratoxin a, zearalenone, don, fumonisins, t-2 toxin and ht-2 toxin, in cereals, Food Control, 25, 647-653.

Solfrizzo, M.; Alldrick, A. J.; van Egmond, H. P.; Moni, Q. A. Mycotoxins Phycotoxins Work, 2009. The use of mycotoxin methodology in practice: A need for harmonization, Quality Assurance and Safety of Crops \& Foods, 1, 121-132.

Solfrizzo, M.; De Girolamo, A.; Gambacorta, L.; Visconti, A.; Stroka, J.; van Egmond, H. P., 2011. Determination of fumonisins $b-1$ and $b-2$ in corn-based foods for infants and young children by lc with immunoaffinity column cleanup: Interlaboratory validation study, Journal of Aoac 
International, 94, 900-908.

Solfrizzo, M.; De Girolamo, A.; Visconti, A., 2001. Determination of fumonisins b-1 and b-2 in cornflakes by high performance liquid chromatography and immunoaffinity clean-up, Food Additives and Contaminants, 18, 227-235.

Solfrizzo, M.; De Girolamo, A.; Lattanzio, V. M. T.; Visconti, A.; Stroka, J.; Alldrick, A.; van Egmond, H. P., 2013. Results of a proficiency test for multi-mycotoxin determination in maize by using methods based on Ic-ms/(ms), Quality Assurance and Safety of Crops \& Foods, 5, 15-48.

Solfrizzo, M.; Gambacorta, L.; Warth, B.; White, K.; Srey, C.; Sulyok, M.; Krska, R.; Gong, Y. Y., 2013. Comparison of single and multi-analyte methods based on Ic-ms/ms for mycotoxin biomarker determination in human urine, World Mycotoxin Journal, 6, 355-366.

Solfrizzo, M.; Gambacorta, L.; Lattanzio, V. M. T.; Powers, S.; Visconti, A., 2011. Simultaneous Ic$\mathrm{ms} / \mathrm{ms}$ determination of aflatoxin $\mathrm{m}-1$, ochratoxin a, deoxynivalenol, de-epoxydeoxynivalenol, alpha and beta-zearalenols and fumonisin b-1 in urine as a multi-biomarker method to assess exposure to mycotoxins, Analytical and Bioanalytical Chemistry, 401, 2831-2841.

Song, S. Q.; Ediage, E. N.; Wu, A. B.; De Saeger, S., 2013. Development and application of salting-out assisted liquid/liquid extraction for multi-mycotoxin biomarkers analysis in pig urine with high performance liquid chromatography/tandem mass spectrometry, Journal of Chromatography $A$, $1292,111-120$.

Sorensen, L. K.; Elbaek, T. H., 2005. Determination of mycotoxins in bovine milk by liquid chromatography tandem mass spectrometry, J Chromatogr B Analyt Technol Biomed Life Sci, 820, 183-196.

Sorensen, L. M.; Mogensen, J.; Nielsen, K. F., 2010. Simultaneous determination of ochratoxin a, mycophenolic acid and fumonisin b-2 in meat products, Analytical and Bioanalytical Chemistry, 398, 1535-1542.

Soyogul, U. G.; Korkmaz, I. O.; Dumlu, M. U.; Omurtag, G. Z., 2016. Occurrence of fumonisins b-1 and b-2 in homemade medicinal plants: Exposure assessment in northern turkey, Acta Alimentaria, $45,54-60$.

Spanjer, M. C.; Rensen, P. M.; Scholten, J. M., 2008. Lc-ms/ms multi-method for mycotoxins after single extraction, with validation data for peanut, pistachio, wheat, maize, cornflakes, raisins and figs, Food Addit Contam Part A Chem Anal Control Expo Risk Assess, 25, 472-489.

Srobarova, A.; Moretti, A.; Ferracane, R.; Ritieni, A.; Logrieco, A., 2002. Toxigenic fusarium species of liseola section in pre-harvest maize ear rot, and associated mycotoxins in slovakia, European Journal of Plant Pathology, 108, 299-306.

Stankovic, S.; Levic, J.; Ivanovic, D.; Krnjaja, V.; Stankovic, G.; Tancic, S., 2012. Fumonisin b-1 and its co-occurrence with other fusariotoxins in naturally-contaminated wheat grain, Food Control, 23, 384-388.

Stroka, J.; Capelletti, C.; Papadopoulou-Bouraoui, A.; Pallaroni, L.; Anklam, E., 2002. Investigation of alternative reagents to 2-mercaptoethanol for the pre-column derivatization of fumonisins with ophthaldialdehyde, for hplc analysis, Journal of Liquid Chromatography \& Related Technologies, 25, 1821-1833.

Sulyok, M.; Berthiller, F.; Krska, R.; Schuhmacher, R., 2006. Development and validation of a liquid chromatography/tandem mass spectrometric method for the determination of 39 mycotoxins in wheat and maize, Rapid Commun Mass Spectrom, 20, 2649-2659.

Sun, Y.; Xu, J.; Li, W.; Cao, B.; Wang, D. D.; Yang, Y.; Lin, Q. X.; Li, J. L.; Zheng, T. S., 2014. Simultaneous detection of ochratoxin a and fumonisin b1 in cereal samples using an aptamerphotonic crystal encoded suspension array, Analytical Chemistry, 86, 11797-11802.

Szabo-Fodor, J.; Bors, I.; Szabo, A.; Kovacs, M., 2016. Comparison of the amount of bioaccessible 
fumonisin b1 and b2 in maize and rice inoculated with fusarium verticillioides (mrc 826) and determined by in vitro digestion-preliminary results, Mycotoxin Res, 32, 173-178.

Szabo-Fodor, J.; Dall'Asta, C.; Falavigna, C.; Kachlek, M.; Szecsi, A.; Szabo, A.; Kovacs, M., 2015. Determination of the amount of bioaccessible fumonisin b-1 in different matrices after in vitro digestion, World Mycotoxin Journal, 8, 261-267.

Szekeres, A.; Budai, A.; Bencsik, O.; Nemeth, L.; Bartok, T.; Szecsi, A.; Mesterhazy, A.; Vagvolgyi, C., 2014. Fumonisin measurement from maize samples by high-performance liquid chromatography coupled with corona charged aerosol detector, J Chromatogr Sci, 52, 1181-1185.

Szekeres, A.; Lorantfy, L.; Bencsik, O.; Kecskemeti, A.; Szecsi, A.; Mesterhazy, A.; Vagvolgyi, C., 2013. Rapid purification method for fumonisin b1 using centrifugal partition chromatography, Food Addit Contam Part A Chem Anal Control Expo Risk Assess, 30, 147-155.

Tamura, M.; Mochizuki, N.; Nagatomi, Y.; Toriba, A.; Hayakawa, K., 2014. Characterization of fumonisin a-series by high-resolution liquid chromatography-orbitrap mass spectrometry, Toxins (Basel), 6, 2580-2593.

Tamura, M.; Mochizuki, N.; Nagatomi, Y.; Harayama, K.; Toriba, A.; Hayakawa, K., 2015. Identification and quantification of fumonisin $\mathrm{a} 1, \mathrm{a} 2$, and $\mathrm{a} 3$ in corn by high-resolution liquid chromatography-orbitrap mass spectrometry, Toxins (Basel), 7, 582-592.

Tamura, M.; Mochizuki, N.; Nagatomi, Y.; Harayama, K.; Toriba, A.; Hayakawa, K., 2015. A method for simultaneous determination of 20 fusarium toxins in cereals by high-resolution liquid chromatography-orbitrap mass spectrometry with a pentafluorophenyl column, Toxins (Basel), 7, 1664-1682.

Tamura, M.; Matsumoto, K.; Watanabe, J.; Iida, J.; Nagatomi, Y.; Mochizuki, N., 2014. Minimization of carryover for high-throughput liquid chromatography with tandem mass spectrometry analysis of 14 mycotoxins in corn grits, J Sep Sci, 37, 1552-1560.

Tamura, M.; Takahashi, A.; Uyama, A.; Mochizuki, N., 2012. A method for multiple mycotoxin analysis in wines by solid phase extraction and multifunctional cartridge purification, and ultra-highperformance liquid chromatography coupled to tandem mass spectrometry, Toxins (Basel), 4, 476486.

Tamura, M.; Uyama, A.; Mochizuki, N., 2011. Development of a multi-mycotoxin analysis in beerbased drinks by a modified quechers method and ultra-high-performance liquid chromatography coupled with tandem mass spectrometry, Anal Sci, 27, 629-635.

Tang, Y. Y.; Lin, H. Y.; Chen, Y. C.; Su, W. T.; Wang, S. C.; Chiueh, L. C.; Shin, Y. C., 2013. Development of a quantitative multi-mycotoxin method in rice, maize, wheat and peanut using uplc-ms/ms, Food Analytical Methods, 6, 727-736.

Tansakul, N.; Jala, P.; Laopiem, S.; Tangmunkhong, P.; Limsuwan, S., 2013. Co-occurrence of five fusarium toxins in corn-dried distiller's grains with solubles in thailand and comparison of elisa and Ic-ms/ms for fumonisin analysis, Mycotoxin Res, 29, 255-260.

Tardieu, D.; Auby, A.; Bluteau, C.; Bailly, J. D.; Guerre, P., 2008. Determination of fumonisin b-1 in animal tissues with immunoaffinity purification, Journal of Chromatography B-Analytical Technologies in the Biomedical and Life Sciences, 870, 140-144.

Taye, W.; Ayalew, A.; Chala, A.; Dejene, M., 2016. Aflatoxin b1 and total fumonisin contamination and their producing fungi in fresh and stored sorghum grain in east hararghe, ethiopia, Food Addit Contam Part B Surveill, 1-9.

Tolosa, J.; Font, G.; Manes, J.; Ferrer, E., 2016. Multimycotoxin analysis in water and fish plasma by liquid chromatography-tandem mass spectrometry, Chemosphere, 145, 402-408.

Trebstein, A.; Lauber, U.; Humpf, H. U., 2009. Analysis of fusarium toxins via hplc-ms/ms multimethods: Matrix effects and strategies for compensation, Mycotoxin Res, 25, 201-213. 
Trucksess, M. W.; Cho, T. H.; Ready, D. E., 2000. Liquid chromatographic method for fumonisin b-1 in sorghum syrup and corn-based breakfast cereals, Food Additives and Contaminants, 17, 161-166.

Trucksess, M. W.; Dombrink-Kurtzman, M. A.; Tournas, V. H.; White, K. D., 2002. Occurrence of aflatoxins and fumonisins in incaparina from guatemala, Food Addit Contam, 19, 671-675.

Uhlig, S.; Eriksen, G. S.; Hofgaard, I. S.; Krska, R.; Beltran, E.; Sulyok, M., 2013. Faces of a changing climate: Semi-quantitative multi-mycotoxin analysis of grain grown in exceptional climatic conditions in norway, Toxins (Basel), 5, 1682-1697.

Vaclavik, L.; Vaclavikova, M.; Begley, T. H.; Krynitsky, A. J.; Rader, J. I., 2013. Determination of multiple mycotoxins in dietary supplements containing green coffee bean extracts using ultrahighperformance liquid chromatography-tandem mass spectrometry (uhplc-ms/ms), J Agric Food Chem, 61, 4822-4830.

Vaclavikova, M.; MacMahon, S.; Zhang, K.; Begley, T. H., 2013. Application of single immunoaffinity clean-up for simultaneous determination of regulated mycotoxins in cereals and nuts, Talanta, 117, 345-351.

Van de Perre, E.; Deschuyffeleer, N.; Jacxsens, L.; Vekeman, F.; Van Der Hauwaert, W.; Asam, S.; Rychlik, M.; Devlieghere, F.; De Meulenaer, B.; Food2Know,, 2014. Screening of moulds and mycotoxins in tomatoes, bell peppers, onions, soft red fruits and derived tomato products, Food Control, 37, 165-170.

van der Westhuizen, L.; Shephard, G. S.; Rheeder, J. P.; Burger, H. M.; Gelderblom, W. C. A.; Wild, C. P.; Gong, Y. Y., 2011. Optimising sorting and washing of home-grown maize to reduce fumonisin contamination under laboratory-controlled conditions, Food Control, 22, 396-400.

Van Pamel, E.; Verbeken, A.; Vlaemynck, G.; De Boever, J.; Daeseleire, E., 2011. Ultrahighperformance liquid chromatographic-tandem mass spectrometric multimycotoxin method for quantitating 26 mycotoxins in maize silage, J Agric Food Chem, 59, 9747-9755.

Varga, E.; Glauner, T.; Koppen, R.; Mayer, K.; Sulyok, M.; Schuhmacher, R.; Krska, R.; Berthiller, F., 2012. Stable isotope dilution assay for the accurate determination of mycotoxins in maize by uhplc$\mathrm{ms} / \mathrm{ms}$, Anal Bioanal Chem, 402, 2675-2686.

Varga, J.; Kocsube, S.; Suri, K.; Szigeti, G.; Szekeres, A.; Varga, M.; Toth, B.; Bartok, T., 2010. Fumonisin contamination and fumonisin producing black aspergilli in dried vine fruits of different origin, Int J Food Microbiol, 143, 143-149.

Vega, V. A., 2016. A quick assay for the quantitation of fumonisin b-1 and b-2 in maize samples by liquid chromatography and mass spectrometry, Journal of Aoac International, 99, 717-720.

Vekiru, E.; Fuchs, E.; Schatzmayr, G.; Taubel, M.; Binder, E. M.; Krska, R., 2003. Determination of fumonisins and hydrolyzed fumonisin b1 in microbial culture media by Ic/esi-ms, Mycotoxin Res, $19,198-202$.

Velazquez, C.; Llovera, M.; Plana, J.; Canela, R., 2000. Effect of solvents on the fumonisins analysis by high-performance liquid chromatography with accq.Fluor as the derivatizing reagent, J Chromatogr A, 870, 469-472.

Velluti, A.; Marin, S.; Sanchis, V.; Ramos, A. J., 2001. Note. Occurrence of fumonisin b-1 in spanish corn-based foods for animal and human consumption, Food Science and Technology International, 7, 433-437.

Venkataramana, M.; Navya, K.; Chandranayaka, S.; Priyanka, S. R.; Murali, H. S.; Batra, H. V., 2014. Development and validation of an immunochromatographic assay for rapid detection of fumonisin b1 from cereal samples, J Food Sci Technol, 51, 1920-1928.

Vesonder, R. F.; Wu, W.; Weisleder, D.; Gordon, S. H.; Krick, T.; Xie, W.; Abbas, H. K.; McAlpin, C. E., 2000. Toxigenic strains of fusarium moniliforme and fusarium proliferatum isolated from dairy cattle feed produce fumonisins, moniliformin and a new c21h38n206 metabolite phytotoxic to 
lemna minor I, J Nat Toxins, 9, 103-112.

Visconti, A.; Solfrizzo, M.; De Girolamo, A., 2001. Determination of fumonisins b-1 and b-2 in corn and corn flakes by liquid chromatography with immunoaffinity column cleanup: Collaborative study, Journal of Aoac International, 84, 1828-1837.

Voss, K. A.; Poling, S. M.; Meredith, F. I.; Bacon, C. W.; Saunders, D. S., 2001. Fate of fumonisins during the production of fried tortilla chips, J Agric Food Chem, 49, 3120-3126.

Vrabcheva, T.; Stroka, J.; Anklam, E., 2002. Occurrence of fumonisin b1 in bulgarian maize samples determined by elisa and tlc methods using different clean up steps, Mycotoxin Res, 18, 46-56.

Wang, J. S.; Zhou, Y.; Wang, Q. M., 2008. Analysis of mycotoxin fumonisins in corn products by highperformance liquid chromatography coupled with evaporative light scattering detection, Food Chemistry, 107, 970-976.

Wang, J. S.; Zhou, Y.; Liu, W. B.; Zhu, X. C.; Du, L. C.; Wang, Q. M., 2008. Fumonisin level in cornbased food and feed from linxian county, a high-risk area for esophageal cancer in china, Food Chemistry, 106, 241-246.

Wang, S.; Quan, Y.; Lee, N.; Kennedy, I. R., 2006. Rapid determination of fumonisin b-1 in food samples by enzyme-linked immunosorbent assay and colloidal gold immunoassay, Journal of Agricultural and Food Chemistry, 54, 2491-2495.

Wang, X. C.; Bao, M.; Li, F. H.; Fan, H. X.; Li, H. S.; Li, Y.; Feng, S. B.; Wu, J. J., 2016. Development of a sensitive, competitive, indirect elisa for the detection of fumonisin b-1 in corn originating from anhui province, china, Journal of Environmental Science and Health Part B-Pesticides Food Contaminants and Agricultural Wastes, 51, 107-112.

Wang, X. C.; Fan, H. X.; Fan, M. X.; Li, F. H.; Feng, S. B.; Li, J. C.; Wu, J. J.; Li, Y.; Wang, J. S., 2016. A sensitive immunochromatographic assay using colloidal gold-antibody probe for rapid detection of fumonisin b1 in corn, Food Addit Contam Part A Chem Anal Control Expo Risk Assess.

Wang, X. C.; Zhang, H. B.; Liu, H. M.; He, C. H.; Zhang, A. H.; Ma, J. R.; Ma, Y. N.; Wu, W. D.; Zheng, $H_{\text {., }}$ 2011. An immunoarray for the simultaneous detection of two mycotoxins, ochratoxin a and fumonisin b-1, Journal of Food Safety, 31, 408-416.

Wang, Y. K.; Shi, Y. B.; Zou, Q.; Sun, J. H.; Chen, Z. F.; Wang, H. A.; Li, S. Q.; Yan, Y. X., 2013. Development of a rapid and simultaneous immunochromatographic assay for the determination of zearalenone and fumonisin b1 in corn, wheat and feedstuff samples, Food Control, 31, 180-188.

Wang, Y. K.; Wang, Y. C.; Wang, H. A.; Ji, W. H.; Sun, J. H.; Yan, Y. X., 2014. An immunomagneticbead-based enzyme-linked immunosorbent assay for sensitive quantification of fumonisin b1, Food Control, 40, 41-45.

Wang, Y. K.; Yan, Y. X.; Ji, W. H.; Wang, H. A.; Li, S. Q.; Zou, Q.; Sun, J. H., 2013. Rapid simultaneous quantification of zearalenone and fumonisin b1 in corn and wheat by lateral flow dual immunoassay, J Agric Food Chem, 61, 5031-5036.

Wang, Y. K.; Yan, Y. X.; Li, S. Q.; Wang, H. A.; Ji, W. H.; Sun, J. H., 2013. Simultaneous quantitative determination of multiple mycotoxins in cereal and feedstuff samples by a suspension array immunoassay, J Agric Food Chem, 61, 10948-10953.

Wang, Y.; Liu, S. L.; Zheng, H.; He, C. H.; Zhang, H. B., 2013. T-2 toxin, zearalenone and fumonisin b-1 in feedstuffs from china, Food Additives \& Contaminants Part B-Surveillance, 6, 116-122.

Wang, Y. T.; Xiao, C. X.; Guo, J.; Yuan, Y. H.; Wang, J. G.; Liu, L. P.; Yue, T. L., 2013. Development and application of a method for the analysis of 9 mycotoxins in maize by hplc-ms/ms, Journal of Food Science, 78, M1752-M1756.

Wang, Z.; Li, H.; Li, C.; Yu, Q.; Shen, J.; De Saeger, S., 2014. Development and application of a quantitative fluorescence-based immunochromatographic assay for fumonisin b1 in maize, J Agric 
Food Chem, 62, 6294-6298.

Warth, B.; Parich, A.; Atehnkeng, J.; Bandyopadhyay, R.; Schuhmacher, R.; Sulyok, M.; Krska, R., 2012. Quantitation of mycotoxins in food and feed from burkina faso and mozambique using a modern Ic-ms/ms multitoxin method, J Agric Food Chem, 60, 9352-9363.

Warth, B.; Petchkongkaew, A.; Sulyok, M.; Krska, R., 2014. Utilising an Ic-ms/ms-based multibiomarker approach to assess mycotoxin exposure in the bangkok metropolitan area and surrounding provinces, Food Addit Contam Part A Chem Anal Control Expo Risk Assess, 31, 20402046.

Warth, B.; Sulyok, M.; Fruhmann, P.; Mikula, H.; Berthiller, F.; Schuhmacher, R.; Hametner, C.; Abia, W. A.; Adam, G.; Frohlich, J.; Krska, R., 2012. Development and validation of a rapid multibiomarker liquid chromatography/tandem mass spectrometry method to assess human exposure to mycotoxins, Rapid Commun Mass Spectrom, 26, 1533-1540.

Waskiewicz, A.; Beszterda, M.; Bocianowski, J.; Golinski, P., 2013. Natural occurrence of fumonisins and ochratoxin $a$ in some herbs and spices commercialized in poland analyzed by uplc-ms $/ \mathrm{ms}$ method, Food Microbiol, 36, 426-431.

Wei, T.; Zhu, W.; Pang, M.; Liu, Y.; Dong, J., 2013. Natural occurrence of fumonisins b1 and b2 in corn in four provinces of china, Food Addit Contam Part B Surveill, 6, 270-274.

Whitaker, T. B.; Doko, M. B.; Maestroni, B. M.; Slate, A. B.; Ogunbanwo, B. F., 2007. Evaluating the performance of sampling plans to detect fumonisin b-1 in maize lots marketed in nigeria, Journal of Aoac International, 90, 1050-1059.

Whitaker, T. B.; Hagler, W. M., Jr.; Johansson, A. S.; Giesbrecht, F. G.; Trucksess, M. W., 2001. Distribution among sample test results when testing shelled corn lots for fumonisin, J AOAC Int, 84, 770-776.

Wilcox, J.; Donnelly, C.; Leeman, D.; Marley, E., 2015. The use of immunoaffinity columns connected in tandem for selective and cost-effective mycotoxin clean-up prior to multi-mycotoxin liquid chromatographic-tandem mass spectrometric analysis in food matrices, J Chromatogr A, 1400, 9197.

Williams, L. D.; Bacon, C. W.; Meredith, F. I.; Franzluebbers, A. J.; Wyatt, R. D.; Smith, M. A.; Riley, R. T., 2003. Leaching and binding of fumonisins in soil microcosms, J Agric Food Chem, 51, 685690.

Williams, L. D.; Meredith, F. I.; Riley, R. T., 2004. Fumonisin-ortho-phthalaldehyde derivative is stabilized at low temperature, J Chromatogr B Analyt Technol Biomed Life Sci, 806, 311-314.

Wu, S. J.; Duan, N.; Li, X. L.; Tan, G. L.; Ma, X. Y.; Xia, Y.; Wang, Z. P.; Wang, H. X., 2013. Homogenous detection of fumonisin $b-1$ with a molecular beacon based on fluorescence resonance energy transfer between nayf4: $\mathrm{Yb}$, ho upconversion nanoparticles and gold nanoparticles, Talanta, 116, 611-618.

Wu, S. J.; Duan, N.; Ma, X. Y.; Xia, Y.; Wang, H. G.; Wang, Z. P.; Zhang, Q., 2012. Multiplexed fluorescence resonance energy transfer aptasensor between upconversion nanoparticles and graphene oxide for the simultaneous determination of mycotoxins, Analytical Chemistry, 84, 62636270.

Xu, J.; Li, W.; Liu, R.; Yang, Y.; Lin, Q. X.; Xu, J. J.; Shen, P.; Zheng, Q.; Zhang, Y.; Han, Z. F.; Li, J. L.; Zheng, T. S., 2016. Ultrasensitive low-background multiplex mycotoxin chemiluminescence immunoassay by silica-hydrogel photonic crystal microsphere suspension arrays in cereal samples, Sensors and Actuators B-Chemical, 232, 577-584.

Xu, K.; Sun, Y.; Li, W.; Xu, J.; Cao, B.; Jiang, Y. K.; Zheng, T. S.; Li, J. L.; Pan, D. D., 2014. Multiplex chemiluminescent immunoassay for screening of mycotoxins using photonic crystal microsphere suspension array, Analyst, 139, 771-777. 
Xu, Y.; Chen, B.; He, Q. H.; Qiu, Y. L.; Liu, X.; He, Z. Y.; Xiong, Z. P., 2014. New approach for development of sensitive and environmentally friendly immunoassay for mycotoxin fumonisin b-1 based on using peptide-mbp fusion protein as substitute for coating antigen, Analytical Chemistry, $86,8433-8440$.

Yang, Q. F.; Wu, Y. L., 2012. Fast determination of fumonisin b-1 and b-2 in corn using a modified quechers method and Ic-ms-ms, Chromatographia, 75, 1075-1080.

Yang, X. X.; Zhou, X. P.; Zhang, X.; Qing, Y.; Luo, M.; Liu, X.; Li, C. R.; Li, Y. L.; Xia, H. M.; Qiu, J. F., 2015. A highly sensitive electrochemical immunosensor for fumonisin b-1 detection in corn using single-walled carbon nanotubes/chitosan, Electroanalysis, 27, 2679-2687.

Ye, H. C.; Lai, X. W.; Liu, C. L., 2013. Determination of fumonisin b-1 and b-2 in corn using matrixphase dispersion coupled to high performance liquid chromatography, Asian Journal of Chemistry, $25,6807-6810$.

Yibadatihan, S.; Jinap, S.; Mahyudin, N. A., 2014. Simultaneous determination of multi-mycotoxins in palm kernel cake (pkc) using liquid chromatography-tandem mass spectrometry (Ic-ms/ms), Food Addit Contam Part A Chem Anal Control Expo Risk Assess, 31, 2071-2079.

Yogendrarajah, P.; Jacxsens, L.; De Saeger, S.; De Meulenaer, B., 2014. Co-occurrence of multiple mycotoxins in dry chilli (capsicum annum I.) samples from the markets of sri lanka and belgium, Food Control, 46, 26-34.

Yogendrarajah, P.; Van Poucke, C.; De Meulenaer, B.; De Saeger, S., 2013. Development and validation of a quechers based liquid chromatography tandem mass spectrometry method for the determination of multiple mycotoxins in spices, J Chromatogr A, 1297, 1-11.

Yoshinari, T.; Tanaka, T.; Ishikuro, E.; Horie, M.; Nagayama, T.; Nakajima, M.; Naito, S.; Ohnishi, T.; Sugita-Konishi, Y., 2013. Inter-laboratory study of an Ic-ms/ms method for simultaneous determination of fumonisin b-1, b-2 and b-3 in corn, Food Hygiene and Safety Science, 54, 266276.

Yu, Q.; Li, H.; Li, C. L.; Zhang, S. X.; Shen, J. Z.; Wang, Z. H., 2015. Gold nanoparticles-based lateral flow immunoassay with silver staining for simultaneous detection of fumonisin $b-1$ and deoxynivalenol, Food Control, 54, 347-352.

Zainudin, Naim; Perumal, N., 2015. Mycotoxins production by fusarium and aspergillus species isolated from cornmeal, International Journal of Agriculture and Biology, 17, 440-448.

Zangheri, M.; Di Nardo, F.; Anfossi, L.; Giovannoli, C.; Baggiani, C.; Roda, A.; Mirasoli, M., 2015. A multiplex chemiluminescent biosensor for type b-fumonisins and aflatoxin b1 quantitative detection in maize flour, Analyst, 140, 358-365.

Zhang, K.; Wong, J. W.; Hayward, D. G.; Vaclavikova, M.; Liao, C. D.; Trucksess, M. W., 2013. Determination of mycotoxins in milk-based products and infant formula using stable isotope dilution assay and liquid chromatography tandem mass spectrometry, J Agric Food Chem, 61, 6265-6273.

Zhang, K.; Wong, J. W.; Krynitsky, A. J.; Trucksess, M. W., 2014. Determining mycotoxins in baby foods and animal feeds using stable isotope dilution and liquid chromatography tandem mass spectrometry, J Agric Food Chem, 62, 8935-8943.

Zhang, K.; Wong, J. W.; Jia, Z. W.; Vaclavikova, M.; Trucksess, M. W.; Begley, T. H., 2014. Screening multimycotoxins in food-grade gums by stable isotope dilution and liquid chromatography/tandem mass spectrometry, Journal of Aoac International, 97, 889-895.

Zhao, Y.; Luo, Y. D.; Li, T. T.; Song, Q. J., 2014. Au nps driven electrochemiluminescence aptasensors for sensitive detection of fumonisin b1, Rsc Advances, 4, 57709-57714.

Zimmer, I.; Dietrich, R.; Usleber, E.; Martlbauer, E.; Schneider, E., 2001. Development and application of an enzyme-linked immunosorbent assay for the analysis of hydrolyzed fumonisins, Mycotoxin 
Res, 17 Suppl 1, 120-124.

Zitomer, N. C.; Glenn, A. E.; Bacon, C. W.; Riley, R. T., 2008. A single extraction method for the analysis by liquid chromatography/tandem mass spectrometry of fumonisins and biomarkers of disrupted sphingolipid metabolism in tissues of maize seedlings, Anal Bioanal Chem, 391, 22572263.

Zitomer, N. C.; Riley, R. T., 2011. Extraction and analysis of fumonisins and compounds indicative of fumonisin exposure in plant and mammalian tissues and cultured cells, Methods Mol Biol, 739, 171185.

Zollner, P.; Mayer-Helm, B., 2006. Trace mycotoxin analysis in complex biological and food matrices by liquid chromatography-atmospheric pressure ionisation mass spectrometry, J Chromatogr A, 1136, 123-169.

Zou, L.; Xu, Y.; Li, Y. P.; He, Q. H.; Chen, B.; Wang, D., 2014. Development of a single-chain variable fragment antibody-based enzyme-linked immunosorbent assay for determination of fumonisin b-1 in corn samples, Journal of the Science of Food and Agriculture, 94, 1865-1871.

Relevant reference not retrieved in the literature searches for Area 1 CHEMISTRY AND ANALYSIS:

Min, W. K.; Cho, Y. J.; Park, J. B.; Bae, Y. H.; Kim, E. J.; Park, K.; Park, Y. C.; Seo, J. H., 2010. Production and characterization of monoclonal antibody and its recombinant single chain variable fragment specific for a food-born mycotoxin, fumonisin b1, Bioprocess Biosyst Eng, 33, 109-115. 


\section{AREA 2 TOXICOKINETICS}

Reference list with all relevant references identified for AREA 2: Data on toxicokinetics (absorption, distribution, metabolism, excretion) in experimental animals, farm and companion animals, humans and from in vitro studies and on biomarkers published in English since year 2000.

\section{Relevant references retrieved in the literature searches for Area 2 TOXICOKINETICS:}

Abia, W. A.; Warth, B.; Sulyok, M.; Krska, R.; Tchana, A.; Njobeh, P. B.; Turner, P. C.; Kouanfack, C.; Eyongetah, M.; Dutton, M.; Moundipa, P. F., 2013. Bio-monitoring of mycotoxin exposure in cameroon using a urinary multi-biomarker approach, Food Chem Toxicol, 62, 927-934.

Abnet, C. C.; Borkowf, C. B.; Qiao, Y. L.; Albert, P. S.; Wang, E.; Merrill, A. H., Jr.; Mark, S. D.; Dong, Z. W.; Taylor, P. R.; Dawsey, S. M., 2001. Sphingolipids as biomarkers of fumonisin exposure and risk of esophageal squamous cell carcinoma in china, Cancer Causes Control, 12, 821-828.

Ahn, J.; Kim, D.; Kim, H.; Jahng, K. Y., 2010. Quantitative determination of mycotoxins in urine by Icms/ms, Food Addit Contam Part A Chem Anal Control Expo Risk Assess, 27, 1674-1682.

Antonissen, G.; Devreese, M.; Van Immerseel, F.; De Baere, S.; Hessenberger, S.; Martel, A.; Croubels, S., 2015. Chronic exposure to deoxynivalenol has no influence on the oral bioavailability of fumonisin b-1 in broiler chickens, Toxins, 7, 560-571.

Avantaggiato, G.; Havenaar, R.; Visconti, A., 2007. Assessment of the multi-mycotoxin-binding efficacy of a carbon/aluminosilicate-based product in an in vitro gastrointestinal model, J Agric Food Chem, 55, 4810-4819.

Bailly, J. D.; Tardieu, D.; Auvergne, A.; Babile, R.; Guerre, P., 2007. Sphinganine and sphinganine to sphingosine ratio as a biomarker of dietary fumonisins during chronic exposure in ducks, NaunynSchmiedebergs Archives of Pharmacology, 374, 329-329.

Baldwin, T. T.; Riley, R. T.; Zitomer, N. C.; Voss, K. A.; Coulombe, R. A.; Pestka, J. J.; Williams, D. E.; Glenn, A. E., 2011. The current state of mycotoxin biomarker development in humans and animals and the potential for application to plant systems, World Mycotoxin Journal, 4, 257-270.

Benlashehr, I.; Repussard, C.; Jouglar, J. Y.; Tardieu, D.; Guerre, P., 2011. Toxicokinetics of fumonisin b-2 in ducks and turkeys, Poultry Science, 90, 1671-1675.

Cai, Q. S.; Guan, H. X.; Xu, L.; Tang, L. L.; Wang, J. S., 2009. Determination of urinary free fumonisin b1 as a biomarker of exposure to dietary fumonisins in humans by hplc and liquid chromatographytandem mass spectrometry, Abstracts of Papers of the American Chemical Society, 237, 82-82.

Cai, Q.; Tang, L.; Wang, J. S., 2007. Validation of fumonisin biomarkers in f344 rats, Toxicol Appl Pharmacol, 225, 28-39.

Caloni, F.; Spotti, M.; Pompa, G.; Zucco, F.; Stammati, A.; De Angelis, I., 2002. Evaluation of fumonisin $b-1$ and its metabolites absorption and toxicity on intestinal cells line caco-2, Toxicon, 40, 1181-1188.

Caloni, F.; Spotti, M.; Auerbach, H.; Op den Camp, H.; Gremmels, J. F.; Pompa, G., 2000. In vitro metabolism of fumonisin b1 by ruminal microflora, Vet Res Commun, 24, 379-387.

Caloni, F.; Stammati, A. L.; Raimondi, F.; De Angelis, I., 2005. In vitro study with caco-2 cells on fumonisin b-1: Aminopentol intestinal passage and role of p-glycoprotein, Veterinary Research Communications, 29, 285-287.

Cano-Sancho, G.; Marin, S.; Ramos, A. J.; Sanchis, V., 2010. Biomonitoring of fusarium spp. Mycotoxins: Perspectives for an individual exposure assessment tool, Food Sci Technol Int, 16, 266-276. 
Cano-Sancho, G.; Marin, S.; Sanchis, V.; Colom, C.; Coronel, M. B.; Ramos, A. J., 2011. Sphinganine and sphingosine levels and ratio in urine and blood samples from a catalonian population, spain, Food Addit Contam Part A Chem Anal Control Expo Risk Assess, 28, 1055-1065.

Cavret, S.; Lecoeur, S., 2006. Fusariotoxin transfer in animal, Food Chem Toxicol, 44, 444-453.

Chelule, P. K.; Gqaleni, N.; Chuturgoon, A. A.; Dutton, M. F., 2000. The determination of fumonisin b1 in human faeces: A short term marker for assessment of exposure, Biomarkers, 5, 1-8.

Cirlini, M.; Hahn, I.; Varga, E.; Dall'Asta, M.; Falavigna, C.; Calani, L.; Berthiller, F.; Del Rio, D.; Dall'Asta, C., 2015. Hydrolysed fumonisin b-1 and n-(deoxy-d-fructos-1-yl)-fumonisin b-1: Stability and catabolic fate under simulated human gastrointestinal conditions, International Journal of Food Sciences and Nutrition, 66, 98-103.

Crews, H.; Alink, G.; Andersen, R.; Braesco, V.; Holst, B.; Maiani, G.; Ovesen, L.; Scotter, M.; Solfrizzo, M.; van den Berg, R.; Verhagen, H.; Williamson, G., 2001. A critical assessment of some biomarker approaches linked with dietary intake, Br J Nutr, 86 Suppl 1, S5-35.

Dall'Asta, C.; Falavigna, C.; Galaverna, G.; Dossena, A.; Marchelli, R., 2010. In vitro digestion assay for determination of hidden fumonisins in maize, J Agric Food Chem, 58, 12042-12047.

De Angelis, I.; Frigge, G.; Raimondi, F.; Stammati, A.; Zucco, F.; Caloni, F., 2005. Absorption of fumonisin b-1 and aminopentol on an in vitro model of intestinal epithelium; the role of $\mathrm{p}$ glycoprotein, Toxicon, 45, 285-291.

Degen, G. H., 2011. Tools for investigating workplace-related risks from mycotoxin exposure, World Mycotoxin Journal, 4, 315-327.

Del Bianchi, M.; Oliveira, C. A. F.; Albuquerque, R.; Guerra, J. L.; Correa, B., 2005. Effects of prolonged oral administration of aflatoxin b-1 and fumonisin b-1 in broiler chickens, Poultry Science, 84, 1835-1840.

Delongchamp, R. R.; Young, J. F., 2001. Tissue sphinganine as a biomarker of fumonisin-induced apoptosis, Food Addit Contam, 18, 255-261.

Dilkin, P.; Direito, G.; Simas, M. M. S.; Mallmann, C. A.; Correa, B., 2010. Toxicokinetics and toxicological effects of single oral dose of fumonisin b1 containing fusarium verticillioides culture material in weaned piglets, Chemico-Biological Interactions, 185, 157-162.

Direito, G. M.; Almeida, A. P.; Aquino, S.; dos Reis, T. A.; Pozzi, C. R.; Correa, B., 2009. Evaluation of sphingolipids in wistar rats treated to prolonged and single oral doses of fumonisin $b-1$, International Journal of Molecular Sciences, 10, 50-61.

Domijan, A. M.; Peraica, M.; Markov, K.; Fuchs, R., 2009. Urine ochratoxin a and sphinganine/sphingosine ratio in residents of the endemic nephropathy area in croatia, Arh Hig Rada Toksikol, 60, 387-393.

Ediage, E. N.; Di Mavungu, J. D.; Song, S. Q.; Sioen, I.; De Saeger, S., 2013. Multimycotoxin analysis in urines to assess infant exposure: A case study in cameroon, Environment International, 57-58, 50-59.

Enongene, E. N.; Sharma, R. P.; Bhandari, N.; Voss, K. A.; Riley, R. T., 2000. Disruption of sphingolipid metabolism in small intestines, liver and kidney of mice dosed subcutaneously with fumonisin b-1, Food and Chemical Toxicology, 38, 793-799.

Escriva, L.; Font, G.; Manyes, L., 2015. In vivo toxicity studies of fusarium mycotoxins in the last decade: A review, Food Chem Toxicol, 78, 185-206.

Ezekiel, C. N.; Warth, B.; Ogara, I. M.; Abia, W. A.; Ezekiel, V. C.; Atehnkeng, J.; Sulyok, M.; Turner, P. C.; Tayo, G. O.; Krska, R.; Bandyopadhyay, R., 2014. Mycotoxin exposure in rural residents in northern nigeria: A pilot study using multi-urinary biomarkers, Environ Int, 66, 138-145. 
Falavigna, C.; Cirlini, M.; Galaverna, G.; Dall'Asta, C., 2012. Masked fumonisins in processed food: Cooccurrence of hidden and bound forms and their stability under digestive conditions, World Mycotoxin Journal, 5, 325-334.

Flores-Flores, M. E.; Lizarraga, E.; de Cerain, A. L.; Gonzalez-Penas, E., 2015. Presence of mycotoxins in animal milk: A review, Food Control, 53, 163-176.

Fodor, J.; Balogh, K.; Weber, M.; Mezes, M.; Kametler, L.; Posa, R.; Mamet, R.; Bauer, J.; Horn, P.; Kovacs, F.; Kovacs, M., 2008. Absorption, distribution and elimination of fumonisin $b(1)$ metabolites in weaned piglets, Food Additives and Contaminants Part a-Chemistry Analysis Control Exposure \& Risk Assessment, 25, 88-96.

Fodor, J.; Bauer, J.; Horn, P.; Kovacs, F.; Kovacs, M., 2005. Effect of different dietary fumonisin b-1 exposure on the toxin content of porcine tissues, Italian Journal of Animal Science, 4, 73-78.

Fodor, J.; Meyer, K.; Riedlberger, M.; Bauer, J.; Horn, P.; Kovacs, F.; Kovacs, M., 2006. Distribution and elimination of fumonisin analogues in weaned piglets after oral administration of fusarium verticillioides fungal culture, Food Addit Contam, 23, 492-501.

Fodor, J.; Meyer, K.; Riedlberger, M.; Bauer, J.; Horn, P.; Kovacs, F.; Kovacs, M., 2006. Distribution and elimination of fumonisin analogues in weaned piglets after oral administration of fusarium verticillioides fungal culture ( $v o l$ 23, pg 492, 2006), Food Additives and Contaminants, 23, 644-644.

Fodor, J.; Meyer, K.; Gottschalk, C.; Mamet, R.; Kametler, L.; Bauer, J.; Horn, P.; Kovacs, F.; Kovacs, M., 2007. In vitro microbial metabolism of fumonisin b-1, Food Additives and Contaminants, 24, 416-420.

Gambacorta, L.; Solfrizzo, M.; Visconti, A.; Powers, S.; Cossalter, A. M.; Pinton, P.; Oswald, I. P., 2013. Validation study on urinary biomarkers of exposure for aflatoxin $b-1$, ochratoxin a, fumonisin b-1, deoxynivalenol and zearalenone in piglets, World Mycotoxin Journal, 6, 299-308.

Garren, L.; Galendo, D.; Wild, C. P.; Castegnaro, M., 2001. The induction and persistence of altered sphingolipid biosynthesis in rats treated with fumonisin b1, Food Addit Contam, 18, 850-856.

Gazzotti, T.; Zironi, E.; Lugoboni, B.; Barbarossa, A.; Piva, A.; Pagliuca, G., 2011. Analysis of fumonisins b1, b2 and their hydrolysed metabolites in pig liver by lc-ms/ms, Food Chemistry, 125, 1379-1384.

Gerding, J.; Ali, N.; Schwartzbord, J.; Cramer, B.; Brown, D. L.; Degen, G. H.; Humpf, H. U., 2015. A comparative study of the human urinary mycotoxin excretion patterns in bangladesh, germany, and haiti using a rapid and sensitive lc-ms/ms approach, Mycotoxin Res, 31, 127-136.

Gerding, J.; Cramer, B.; Humpf, H. U., 2014. Determination of mycotoxin exposure in germany using an Ic-ms/ms multibiomarker approach, Mol Nutr Food Res, 58, 2358-2368.

Gong, Y. Y.; Shirima, C. P.; Srey, C.; Kimanya, M. E.; Routledge, M. N., 2015. Deoxynivalenol and fumonisin exposure in children and adults in a family study in rural tanzania, World Mycotoxin Journal, 8, 553-560.

Gong, Y. Y.; Torres-Sanchez, L.; Lopez-Carrillo, L.; Peng, J. H.; Sutcliffe, A. E.; White, K. L.; Humpf, H. U.; Turner, P. C.; Wild, C. P., 2008. Association between tortilla consumption and human urinary fumonisin b1 levels in a mexican population, Cancer Epidemiol Biomarkers Prev, 17, 688694.

Gong, Y. Y.; van der Westhuizen, L.; Shephard, G. S.; Burger, H. M.; Rheeder, J. P.; Gelderblom, W. C. A.; Wild, C. P., 2009. Urinary fumonisin b-1 biomarker validation and application in intervention studies, Mutagenesis, 24, 535-535.

Grenier, B.; Schwartz-Zimmermann, H. E.; Caha, S.; Moll, W. D.; Schatzmayr, G.; Applegate, T. J., 2015. Dose-dependent effects on sphingoid bases and cytokines in chickens fed diets prepared with fusarium verticillioides culture material containing fumonisins, Toxins (Basel), 7, 1253-1272. 
Guerre, P., 2015. Fusariotoxins in avian species: Toxicokinetics, metabolism and persistence in tissues, Toxins (Basel), 7, 2289-2305.

Hahn, I.; Nagl, V.; Schwartz-Zimmermann, H. E.; Varga, E.; Schwarz, C.; Slavik, V.; Reisinger, N.; Malachova, A.; Cirlini, M.; Generotti, S.; Dall'Asta, C.; Krska, R.; Moll, W. D.; Berthiller, F., 2015. Effects of orally administered fumonisin $b-1(\mathrm{fb} 1)$, partially hydrolysed fb1, hydrolysed fb1 and n(1-deoxy-d-fructos-1-yl) fb1 on the sphingolipid metabolism in rats, Food and Chemical Toxicology, $76,11-18$.

Harrer, H.; Humpf, H. U.; Voss, K. A., 2015. In vivo formation of n-acyl-fumonisin b-1, Mycotoxin Research, 31, 33-40.

Harrer, H.; Laviad, E. L.; Humpf, H. U.; Futerman, A. H., 2013. Identification of n-acyl-fumonisin b1 as new cytotoxic metabolites of fumonisin mycotoxins, Mol Nutr Food Res, 57, 516-522.

Heyndrickx, E.; Sioen, I.; Bellemans, M.; De Maeyer, M.; Callebaut, A.; De Henauw, S.; De Saeger, S., 2014. Assessment of mycotoxin exposure in the belgian population using biomarkers: Aim, design and methods of the biomyco study, Food Addit Contam Part A Chem Anal Control Expo Risk Assess, 31, 924-931.

Heyndrickx, E.; Sioen, I.; Huybrechts, B.; Callebaut, A.; De Henauw, S.; De Saeger, S., 2015. Human biomonitoring of multiple mycotoxins in the belgian population: Results of the biomyco study, Environ Int, 84, 82-89.

Kim, D. H.; Yoo, H. S.; Lee, Y. M.; Kie, J. H.; Jang, S.; Oh, S., 2006. Elevation of sphinganine 1phosphate as a predictive biomarker for fumonisin exposure and toxicity in mice, J Toxicol Environ Health A, 69, 2071-2082.

Kouadio, J. H.; Lattanzio, V. M.; Ouattara, D.; Kouakou, B.; Visconti, A., 2014. Assessment of mycotoxin exposure in cote d'ivoire (ivory coast) through multi-biomarker analysis and possible correlation with food consumption patterns, Toxicol Int, 21, 248-257.

Mahfoud, R.; Maresca, M.; Santelli, M.; Pfohl-Leszkowicz, A.; Puigserver, A.; Fantini, J., 2002. Phdependent interaction of fumonisin b-1 with cholesterol: Physicochemical and molecular modeling studies at the air-water interface, Journal of Agricultural and Food Chemistry, 50, 327-331.

Manyes, L.; Ruiz, M. J.; Luciano, F. B.; Meca, G., 2014. Bioaccessibility and bioavailability of fumonisin $\mathrm{b}-2$ and its reaction products with isothiocyanates through a simulated gastrointestinal digestion system, Food Control, 37, 326-335.

Meyer, K.; Mohr, K.; Bauer, J.; Horn, P.; Kovacs, M., 2003. Residue formation of fumonisin b1 in porcine tissues, Food Addit Contam, 20, 639-647.

Missmer, S. A.; Suarez, L.; Felkner, M.; Wang, E.; Merrill, A. H., Jr.; Rothman, K. J.; Hendricks, K. A., 2006. Exposure to fumonisins and the occurrence of neural tube defects along the texas-mexico border, Environ Health Perspect, 114, 237-241.

Motta, E. L.; Scott, P. M., 2009. Bioaccessibility of total bound fumonisin from corn flakes, Mycotoxin Res, 25, 229-232.

Motta, E. L.; Scott, P. M., 2007. Effect ofin vitro digestion on fumonisin b1 in corn flakes, Mycotoxin Res, 23, 166-172.

Nikiema, P. A.; Worrilow, L.; Traore, A. S.; Wild, C. P.; Turner, P. C., 2008. Fumonisin exposure and the sphinganine/sphingosine ratio in urine, serum and buccal cells in adults from burkina faso, west africa, World Mycotoxin Journal, 1, 483-491.

Orsi, R. B.; Dilkin, P.; Xavier, J. G.; Aquino, S.; Rocha, L. O.; Correa, B., 2009. Acute toxicity of a single gavage dose of fumonisin b-1 in rabbits, Chemico-Biological Interactions, 179, 351-355.

Qiu, M. F.; Liu, X. M., 2001. Determination of sphinganine, sphingosine and sa/so ratio in urine of humans exposed to dietary fumonisin b-1, Food Additives and Contaminants, 18, 263-269. 
Riley, R. T.; Torres, O.; Matute, J.; Gregory, S. G.; Ashley-Koch, A. E.; Showker, J. L.; Mitchell, T.; Voss, K. A.; Maddox, J. R.; Gelineau-van Waes, J. B., 2015. Evidence for fumonisin inhibition of ceramide synthase in humans consuming maize-based foods and living in high exposure communities in guatemala, Mol Nutr Food Res, 59, 2209-2224.

Riley, R. T.; Torres, O.; Showker, J. L.; Zitomer, N. C.; Matute, J.; Voss, K. A.; Gelineau-van Waes, J.; Maddox, J. R.; Gregory, S. G.; Ashley-Koch, A. E., 2012. The kinetics of urinary fumonisin b1 excretion in humans consuming maize-based diets, Mol Nutr Food Res, 56, 1445-1455.

Scott, P. M., 2012. Recent research on fumonisins: A review, Food Addit Contam Part A Chem Anal Control Expo Risk Assess, 29, 242-248.

Seiferlein, M.; Humpf, H. U.; Voss, K. A.; Sullards, M. C.; Allegood, J. C.; Wang, E.; Merrill, A. H., Jr., 2007. Hydrolyzed fumonisins hfb1 and hfb2 are acylated in vitro and in vivo by ceramide synthase to form cytotoxic n-acyl-metabolites, Mol Nutr Food Res, 51, 1120-1130.

Sewram, V.; Mshicileli, N.; Shephard, G. S.; Marasas, W. F. O., 2003. Fumonisin mycotoxins in human hair, Biomarkers, 8, 110-118.

Sewram, V.; Nair, J. J.; Nieuwoudt, T. W.; Gelderblom, W. C. A.; Marasas, W. F. O.; Shephard, G. S., 2001. Assessing chronic exposure to fumonisin mycotoxins: The use of hair as a suitable noninvasive matrix, Journal of Analytical Toxicology, 25, 450-455.

Shephard, G. S.; Burger, H. M.; Gambacorta, L.; Gong, Y. Y.; Krska, R.; Rheeder, J. P.; Solfrizzo, M.; Srey, C.; Sulyok, M.; Visconti, A.; Warth, B.; van der Westhuizen, L., 2013. Multiple mycotoxin exposure determined by urinary biomarkers in rural subsistence farmers in the former transkei, south africa, Food Chem Toxicol, 62, 217-225.

Shephard, G. S.; Van Der Westhuizen, L.; Sewram, V., 2007. Biomarkers of exposure to fumonisin mycotoxins: A review, Food Addit Contam, 24, 1196-1201.

Shier, W. T., 2000. The fumonisin paradox: A review of research on oral bioavailability of fumonisin $b(1)$, a mycotoxin produced by fusarium moniliforme, Journal of Toxicology-Toxin Reviews, 19, 161-187.

Shirima, C. P.; Kimanya, M. E.; Kinabo, J. L.; Routledge, M. N.; Srey, C.; Wild, C. P.; Gong, Y. Y., 2013. Dietary exposure to aflatoxin and fumonisin among tanzanian children as determined using biomarkers of exposure, Mol Nutr Food Res, 57, 1874-1881.

Shirima, C. P.; Kimanya, M. E.; Routledge, M. N.; Srey, C.; Kinabo, J. L.; Humpf, H. U.; Wild, C. P.; Tu, Y. K.; Gong, Y. Y., 2015. A prospective study of growth and biomarkers of exposure to aflatoxin and fumonisin during early childhood in tanzania, Environ Health Perspect, 123, 173-178. - Correction: A prospective study of growth and biomarkers of exposure to aflatoxin and fumonisin during early childhood in tanzania, 2015. Environ Health Perspect, 123, A32.

Shirima, ; Tu, Y. K., 2015. A prospective study of growth and biomarkers of exposure to aflatoxin and fumonisin during early childhood in tanzania (vol 123, pg 173, 2015), Environmental Health Perspectives, 123, A32-A32.

Silva, L. J. G.; Lino, C. M.; Pena, A., 2009. Sphinganine-sphingosine ratio in urine from two portuguese populations as biomarker to fumonisins exposure, Toxicon, 54, 390-398.

Solfrizzo, M.; Chulze, S. N.; Mallmann, C.; Visconti, A.; De Girolamo, A.; Rojo, F.; Torres, A., 2004. Comparison of urinary sphingolipids in human populations with high and low maize consumption as a possible biomarker of fumonisin dietary exposure, Food Addit Contam, 21, 1090-1095.

Solfrizzo, M.; Gambacorta, L.; Visconti, A., 2014. Assessment of multi-mycotoxin exposure in southern italy by urinary multi-biomarker determination, Toxins (Basel), 6, 523-538.

Solfrizzo, M.; Gambacorta, L.; Lattanzio, V. M. T.; Powers, S.; Visconti, A., 2011. Simultaneous Ic$\mathrm{ms} / \mathrm{ms}$ determination of aflatoxin $\mathrm{m}-1$, ochratoxin $\mathrm{a}$, deoxynivalenol, de-epoxydeoxynivalenol, 
alpha and beta-zearalenols and fumonisin b-1 in urine as a multi-biomarker method to assess exposure to mycotoxins, Analytical and Bioanalytical Chemistry, 401, 2831-2841.

Song, S. Q.; Ediage, E. N.; Wu, A. B.; De Saeger, S., 2013. Development and application of salting-out assisted liquid/liquid extraction for multi-mycotoxin biomarkers analysis in pig urine with high performance liquid chromatography/tandem mass spectrometry, Journal of Chromatography $A$, $1292,111-120$.

Spotti, M.; Caloni, F.; Fracchiolla, L.; Pompa, G.; Vigo, D.; Maffeo, G., 2001. Fumonisin b1 carry-over into milk in the isolated perfused bovine udder, Vet Hum Toxicol, 43, 109-111.

Spotti, M.; Pompa, G.; Caloni, F., 2001. Fumonisin b-1 metabolism by bovine liver microsomes, Veterinary Research Communications, 25, 511-516.

Szabo-Fodor, J.; Bors, I.; Szabo, A.; Kovacs, M., 2016. Comparison of the amount of bioaccessible fumonisin b1 and b2 in maize and rice inoculated with fusarium verticillioides (mrc 826) and determined by in vitro digestion-preliminary results, Mycotoxin Res, 32, 173-178.

Szabo-Fodor, J.; Dall'Asta, C.; Falavigna, C.; Kachlek, M.; Szecsi, A.; Szabo, A.; Kovacs, M., 2015. Determination of the amount of bioaccessible fumonisin b-1 in different matrices after in vitro digestion, World Mycotoxin Journal, 8, 261-267.

Szabo-Fodor, J.; Kametler, L.; Posa, R.; Mamet, R.; Rajli, V.; Bauer, J.; Horn, P.; Kovacs, F.; Kovacs, M., 2008. Kinetics of fumonisin $b-1$ in pigs and persistence in tissues after ingestion of a diet containing a high fumonisin concentration, Cereal Research Communications, 36, 331-336.

Tardieu, D.; Bailly, J. D.; Benlashehr, I.; Auby, A.; Jouglar, J. Y.; Guerre, P., 2009. Tissue persistence of fumonisin b1 in ducks and after exposure to a diet containing the maximum european tolerance for fumonisins in avian feeds, Chem Biol Interact, 182, 239-244.

Tardieu, D.; Bailly, J. D.; Skiba, F.; Grosjean, F.; Guerre, P., 2008. Toxicokinetics of fumonisin b1 in turkey poults and tissue persistence after exposure to a diet containing the maximum european tolerance for fumonisins in avian feeds, Food Chem Toxicol, 46, 3213-3218.

Tardieu, D.; Tran, S. T.; Auvergne, A.; Babile, R.; Benard, G.; Bailly, J. D.; Guerre, P., 2006. Effects of fumonisins on liver and kidney sphinganine and the sphinganine to sphingosine ratio during chronic exposure in ducks, Chem Biol Interact, 160, 51-60.

Torres, O.; Matute, J.; Gelineau-van Waes, J.; Maddox, J. R.; Gregory, S. G.; Ashley-Koch, A. E.; Showker, J. L.; Zitomer, N. C.; Voss, K. A.; Riley, R. T., 2014. Urinary fumonisin b-1 and estimated fumonisin intake in women from high-and low-exposure communities in guatemala, Molecular Nutrition \& Food Research, 58, 973-983.

Tran, S. T.; Bailly, J. D.; Tardieu, D.; Durand, S.; Benard, G.; Guerre, P., 2003. Sphinganine to sphingosine ratio and predictive biochemical markers of fumonisin b1 exposure in ducks, Chem Biol Interact, 146, 61-72.

Tran, S. T.; Tardieu, D.; Auvergne, A.; Bailly, J. D.; Babile, R.; Durand, S.; Benard, G.; Guerre, P., 2006. Serum sphinganine and the sphinganine to sphingosine ratio as a biomarker of dietary fumonisins during chronic exposure in ducks, Chem Biol Interact, 160, 41-50.

Turner, P. C.; Flannery, B.; Isitt, C.; Ali, M.; Pestka, J., 2012. The role of biomarkers in evaluating human health concerns from fungal contaminants in food, Nutr Res Rev, 25, 162-179.

Turner, P. C.; Gong, Y. Y.; Pourshams, A.; Jafari, E.; Routledge, M. N.; Malekzadeh, R.; Wild, C. P.; Boffetta, P.; Islami, F., 2012. A pilot survey for fusarium mycotoxin biomarkers in women from golestan, northern iran, World Mycotoxin Journal, 5, 195-199.

van der Westhuizen, L.; Shephard, G. S.; van Schalkwyk, D. J., 2001. The effect of a single gavage dose of fumonisin b-1 on the sphinganine and sphingosine levels in vervet monkeys, Toxicon, 39, 273-281. 
van der Westhuizen, L.; Shephard, G. S.; van Schalkwyk, D. J., 2001. The effect of a single gavage dose of fumonisin b-2 on the sphinganine and sphingosine concentrations in vervet monkeys, Food and Chemical Toxicology, 39, 455-459.

van der Westhuizen, L.; Shephard, G. S.; van Schalkwyk, D. J., 2001. The effect of repeated gavage doses of fumonisin b-1 on the sphinganine and sphingosine levels in vervet monkeys, Toxicon, 39, 969-972.

van der Westhuizen, L.; Shephard, G. S.; Burger, H. M.; Rheeder, J. P.; Gelderblom, W. C. A.; Wild, C. P.; Gong, Y. Y., 2011. Fumonisin b-1 as a urinary biomarker of exposure in a maize intervention study among south african subsistence farmers, Cancer Epidemiology Biomarkers \& Prevention, 20, 483-489.

Van der Westhuizen, L.; Shephard, G. S.; Gelderblom, W. C. A.; Torres, O.; Riley, R. T., 2013. Fumonisin biomarkers in maize eaters and implications for human disease, World Mycotoxin Journal, 6, 223-232.

van der Westhuizen, L.; Shephard, G. S.; Rheeder, J. P.; Burger, H. M., 2010. Individual fumonisin exposure and sphingoid base levels in rural populations consuming maize in south africa, Food Chem Toxicol, 48, 1698-1703.

van der Westhuizen, L.; Shephard, G. S.; Rheeder, J. P.; Somdyala, N. I. M.; Marasas, W. F. O., 2008. Sphingoid base levels in humans consuming fumonisin-contaminated maize in rural areas of the former transkei, south africa: A cross-sectional study, Food Additives and Contaminants Part aChemistry Analysis Control Exposure \& Risk Assessment, 25, 1385-1391.

Voss, K. A.; Riley, R. T.; Norred, W. P.; Bacon, C. W.; Meredith, F. I.; Howard, P. C.; Plattner, R. D.; Collins, T. F.; Hansen, D. K.; Porter, J. K., 2001. An overview of rodent toxicities: Liver and kidney effects of fumonisins and fusarium moniliforme, Environ Health Perspect, 109 Suppl 2, 259-266.

Voss, K. A.; Smith, G. W.; Haschek, W. M., 2007. Fumonisins: Toxicokinetics, mechanism of action and toxicity, Animal Feed Science and Technology, 137, 299-325.

Wallin, S.; Gambacorta, L.; Kotova, N.; Lemming, E. W.; Nalsen, C.; Solfrizzo, M.; Olsen, M., 2015. Biomonitoring of concurrent mycotoxin exposure among adults in sweden through urinary multibiomarker analysis, Food Chem Toxicol, 83, 133-139.

Warth, B.; Braun, D.; Ezekiel, C. N.; Turner, P. C.; Degen, G. H.; Marko, D., 2016. Biomonitoring of mycotoxins in human breast milk: Current state and future perspectives, Chem Res Toxicol, 29, 1087-1097.

Warth, B.; Petchkongkaew, A.; Sulyok, M.; Krska, R., 2014. Utilising an Ic-ms/ms-based multibiomarker approach to assess mycotoxin exposure in the bangkok metropolitan area and surrounding provinces, Food Addit Contam Part A Chem Anal Control Expo Risk Assess, 31, 20402046.

Warth, B.; Sulyok, M.; Fruhmann, P.; Mikula, H.; Berthiller, F.; Schuhmacher, R.; Hametner, C.; Abia, W. A.; Adam, G.; Frohlich, J.; Krska, R., 2012. Development and validation of a rapid multibiomarker liquid chromatography/tandem mass spectrometry method to assess human exposure to mycotoxins, Rapid Commun Mass Spectrom, 26, 1533-1540.

Xu, L.; Cal, Q. S.; Tang, L. L.; Hu, X.; Sun, G. J.; Wang, J. S., 2009. Dietary fumonisin b1 exposure and human esophageal cancer risk in huaian, china: Use of urinary free fumonisin b1 as biomarker of exposure, Cancer Research, 69.

Xu, L.; Cai, Q.; Tang, L.; Wang, S.; Hu, X.; Su, J.; Sun, G.; Wang, J. S., 2010. Evaluation of fumonisin biomarkers in a cross-sectional study with two high-risk populations in china, Food Addit Contam Part A Chem Anal Control Expo Risk Assess, 27, 1161-1169. 
Relevant references not retrieved in the literature searches for Area 2:

Evaluation of certain mycotoxins in food. Fifty-sixth report of the joint fao/who expert committee on food additives, 2002. World Health Organ Tech Rep Ser, 906, i-viii, 1-62.

Bordin, K.; Rottinghaus, G. E.; Landers, B. R.; Ledoux, D. R.; Kobashigawa, E.; Corassin, C. H.; Oliveira, C. A. F., 2015. Evaluation of fumonisin exposure by determination of fumonisin b-1 in human hair and in brazilian corn products, Food Control, 53, 67-71.

Magoha, H.; De Meulenaer, B.; Kimanya, M.; Hipolite, D.; Lachat, C.; Kolsteren, P., 2014. Fumonisin b1 contamination in breast milk and its exposure in infants under 6 months of age in rombo, northern tanzania, Food Chem Toxicol, 74, 112-116.

Persson, E. C.; Sewram, V.; Evans, A. A.; London, W. T.; Volkwyn, Y.; Shen, Y. J.; Van Zyl, J. A.; Chen, G.; Lin, W. Y.; Shephard, G. S.; Taylor, P. R.; Fan, J. H.; Dawsey, S. M.; Qiao, Y. L.; McGlynn, K. A.; Abnet, C. C., 2012. Fumonisin b-1 and risk of hepatocellular carcinoma in two chinese cohorts, Food and Chemical Toxicology, 50, 679-683. 


\section{AREA 3 MODE OF ACTION}

Reference list with all relevant references identified for AREA 3: Data on in vitro and in vivo mode of action (MoA) of toxicity published in English since year 2000.

\section{Relevant references retrieved in the literature searches for Area 3 MODE OF ACTION:}

Abdel Nour, A. M.; Ringot, D.; Gueant, J. L.; Chango, A., 2007. Folate receptor and human reduced folate carrier expression in hepg2 cell line exposed to fumonisin b1 and folate deficiency, Carcinogenesis, 28, 2291-2297.

Ahangarkani, F.; Rouhi, S.; Azizi, I. G., 2014. A review on incidence and toxicity of fumonisins, Toxin Reviews, 33, 95-100.

Alassane-Kpembi, I.; Schatzmayr, G.; Taranu, I.; Marin, D.; Puel, O.; Oswald, I. P., 2016. Mycotoxins co-contamination: Methodological aspects and biological relevance of combined toxicity studies, Crit Rev Food Sci Nutr, 0.

Anonymous, 2001. Toxicology and carcinogenesis studies of fumonisin b1 (cas no. 116355-83-0) in f344/n rats and b6c3f1 mice (feed studies), 2001. Natl Toxicol Program Tech Rep Ser, 1-352.

Baines, D.; Sumarah, M.; Kuldau, G.; Juba, J.; Mazza, A.; Masson, L., 2013. Aflatoxin, fumonisin and shiga toxin-producing escherichia coli infections in calves and the effectiveness of celmanax $r /$ dairyman's choice $t$ applications to eliminate morbidity and mortality losses, Toxins, 5, 18721895.

Banczerowski-Pelyhe, I.; Vilagi, I.; Detari, L.; Doczi, J.; Kovacs, F.; Kukorelli, T., 2002. In vivo and in vitro electrophysiological monitoring of rat neocortical activity after dietary fumonisin exposure, Mycopathologia, 153, 149-156.

Basso, K.; Gomes, F.; Bracarense, A. P. L., 2013. Deoxynivanelol and fumonisin, alone or in combination, induce changes on intestinal junction complexes and in e- cadherin expression, Toxins, 5, 2341-2352.

Behm, C.; Follmann, W.; Degen, G. H., 2012. Cytotoxic potency of mycotoxins in cultures of v79 lung fibroblast cells, J Toxicol Environ Health A, 75, 1226-1231.

Benlasher, E.; Geng, X. Y.; Ngoc, T. X. N.; Tardieu, D.; Bailly, J. D.; Auvergne, A.; Guerre, P., 2012. Comparative effects of fumonisins on sphingolipid metabolism and toxicity in ducks and turkeys, Avian Diseases, 56, 120-127.

Bernabucci, U.; Colavecchia, L.; Danieli, P. P.; Basirico, L.; Lacetera, N.; Nardone, A.; Ronchi, B., 2011. Aflatoxin b-1 and fumonisin b-1 affect the oxidative status of bovine peripheral blood mononuclear cells, Toxicology in Vitro, 25, 684-691.

Bhandari, N.; Brown, C. C.; Sharma, R. P., 2002. Fumonisin b-1-induced localized activation of cytokine network in mouse liver, Food and Chemical Toxicology, 40, 1483-1491.

Bhandari, N.; Sharma, R. P., 2002. Fumonisin b(1)-induced alterations in cytokine expression and apoptosis signaling genes in mouse liver and kidney after an acute exposure, Toxicology, 172, 8192.

Bhandari, N.; Sharma, R. P., 2002. Modulation of selected cell signaling genes in mouse liver by fumonisin b-1, Chemico-Biological Interactions, 139, 317-331.

Bondy, G.; Mehta, R.; Caldwell, D.; Coady, L.; Armstrong, C.; Savard, M.; Miller, J. D.; Chomyshyn, E.; Bronson, R.; Zitomer, N.; Riley, R. T., 2012. Effects of long term exposure to the mycotoxin fumonisin b-1 in p53 heterozygous and p53 homozygous transgenic mice, Food and Chemical Toxicology, 50, 3604-3613. 
Bondy, G. S.; Armstrong, C. L.; Curran, I. H. A.; Barker, M. G.; Mehta, R., 2000. Retrospective evaluation of serum ornithine carbamyltransferase activity as an index of hepatotoxicity in toxicological studies with rats, Toxicology Letters, 114, 163-171.

Bondy, G. S.; Pestka, J. J., 2000. Immunomodulation by fungal toxins, J Toxicol Environ Health B Crit Rev, 3, 109-143.

Bouhet, S.; Hourcade, E.; Loiseau, N.; Fikry, A.; Martinez, S.; Roselli, M.; Galtier, P.; Mengheri, E.; Oswald, I. P., 2004. The mycotoxin fumonisin b-1 alters the proliferation and the barrier function of porcine intestinal epithelial cells, Toxicological Sciences, 77, 165-171.

Bouhet, S.; Le Dorze, E.; Peres, S.; Fairbrother, J. M.; Oswald, I. P., 2006. Mycotoxin fumonisin b-1 selectively down-regulates the basal il-8 expression in pig intestine: In vivo and in vitro studies, Food and Chemical Toxicology, 44, 1768-1773.

Bouhet, S.; Oswald, I. P., 2005. The effects of mycotoxins, fungal food contaminants, on the intestinal epithelial cell-derived innate immune response, Veterinary Immunology and Immunopathology, 108, 199-209.

Bouhet, S.; Oswald, I. P., 2007. The intestine as a possible target for fumonisin toxicity, Mol Nutr Food Res, 51, 925-931.

Burenjargal, M.; Lee, Y. S.; Yoo, J. M.; Choi, M. H.; Ji, S. Y.; Lee, Y. M.; Kim, Y. C.; Oh, S.; Yun, Y. P.; Yoo, H. S., 2008. Dihydroceramide was highly elevated by the fumonisin $b(1)$ and desipramine in sphingomonas chungbukensis, Biomolecules \& Therapeutics, 16, 100-105.

Burger, H. M.; Abel, S.; Snijman, P. W.; Swanevelder, S.; Gelderblom, W. C., 2007. Altered lipid parameters in hepatic subcellular membrane fractions induced by fumonisin b1, Lipids, 42, 249261.

Callihan, P.; Zitomer, N. C.; Stoeling, M. V.; Kennedy, P. C.; Lynch, K. R.; Riley, R. T.; Hooks, S. B., 2012. Distinct generation, pharmacology, and distribution of sphingosine 1-phosphate and dihydrosphingosine 1-phosphate in human neural progenitor cells, Neuropharmacology, 62, 988996.

Caloni, F.; Stammati, A. L.; Raimondi, F.; De Angelis, I., 2005. In vitro study with caco-2 cells on fumonisin b1: Aminopentol intestinal passage and role of p-glycoprotein, Vet Res Commun, 29 Suppl 2, 285-287.

Cano-Sancho, G.; Marin, S.; Sanchis, V.; Colom, C.; Coronel, M. B.; Ramos, A. J., 2011. Sphinganine and sphingosine levels and ratio in urine and blood samples from a catalonian population, spain, Food Addit Contam Part A Chem Anal Control Expo Risk Assess, 28, 1055-1065.

Carratu, M. R.; Cassano, T.; Coluccia, A.; Borracci, P.; Cuomo, V., 2003. Antinutritional effects of fumonisin b-1 and pathophysiological consequences, Toxicology Letters, 140, 459-463.

Cavret, S.; Lecoeur, S., 2006. Fusariotoxin transfer in animal, Food Chem Toxicol, 44, 444-453.

Chalfant, C. E.; Ogretmen, B.; Galadari, S.; Kroesen, B. J.; Pettus, B. J.; Hannun, Y. A., 2001. Fas activation induces dephosphorylation of sr proteins - dependence on the de novo generation of ceramide and activation of protein phosphatase 1, Journal of Biological Chemistry, 276, 4484844855.

Charles, A. G.; Han, T. Y.; Liu, Y. Y.; Hansen, N.; Giuliano, A. E.; Cabot, M. C., 2001. Taxol-induced ceramide generation and apoptosis in human breast cancer cells, Cancer Chemother Pharmacol, 47, 444-450.

Cheli, F.; Giromini, C.; Baldi, A., 2015. Mycotoxin mechanisms of action and health impact: 'In vitro' or 'in vivo' tests, that is the question, World Mycotoxin Journal, 8, 573-589.

Chuturgoon, A. A.; Phulukdaree, A.; Moodley, D., 2015. Fumonisin b-1 inhibits apoptosis in hepg2 cells by inducing birc-8/ilp-2, Toxicology Letters, 235, 67-74. 
Chuturgoon, A. A.; Phulukdaree, A.; Moodley, D., 2014. Fumonisin b-1 modulates expression of human cytochrome p450 $1 \mathrm{~b} 1$ in human hepatoma (hepg2) cells by repressing mir-27b, Toxicology Letters, 227, 50-55.

Condrescu, M.; Reeves, J. P., 2003. Fumonisin b1, an inhibitor of sphingolipid biosynthesis, activates the cardiac na/ca exchanger expressed in cho cells, Biophysical Journal, 84, 190A-191A.

Constable, P. D.; Smith, G. W.; Rottinghaus, G. E.; Tumbleson, M. E.; Haschek, W. M., 2003. Fumonisin-induced blockade of ceramide synthase in sphingolipid biosynthetic pathway alters aortic input impedance spectrum of pigs, Am J Physiol Heart Circ Physiol, 284, H2034-2044.

Constable, P. D.; Smith, G. W.; Rottinghaus, G. E.; Haschek, W. M., 2000. Ingestion of fumonisin b1containing culture material decreases cardiac contractility and mechanical efficiency in swine, Toxicol Appl Pharmacol, 162, 151-160.

Cortinovis, C.; Caloni, F.; Schreiber, N. B.; Spicer, L. J., 2014. Effects of fumonisin b-1 alone and combined with deoxynivalenol or zearalenone on porcine granulosa cell proliferation and steroid production, Theriogenology, 81, 1042-1049.

Cortinovis, C.; Caloni, F.; Schreiber, N.; Spicer, L. J., 2013. In vitro effects of fumonisin b-1 on porcine granulosa cell steroidogenesis and gene expression, Toxicology Letters, 221, S150-S150.

Cuzzocrea, S.; Genovese, T.; Mazzon, E.; Esposito, E.; Crisafulli, C.; Di Paola, R.; Bramanti, P.; Salvemini, D., 2009. Fumonisin b1 reduces the development of multiple organ failure induced by zymosan in mice, Shock, 31, 170-177.

De Angelis, I.; Frigge, G.; Raimondi, F.; Stammati, A.; Zucco, F.; Caloni, F., 2005. Absorption of fumonisin b-1 and aminopentol on an in vitro model of intestinal epithelium; the role of $\mathrm{p}$ glycoprotein, Toxicon, 45, 285-291.

Demirel, G.; Alpertunga, B.; Ozden, S., 2015. Role of fumonisin b1 on DNA methylation changes in rat kidney and liver cells, Pharm Biol, 53, 1302-1310.

Desai, K.; Sullards, M. C.; Allegood, J.; Wang, E.; Schmelz, E. M.; Hartl, M.; Humpf, H. U.; Liotta, D. C.; Peng, Q.; Merrill, A. H., Jr., 2002. Fumonisins and fumonisin analogs as inhibitors of ceramide synthase and inducers of apoptosis, Biochim Biophys Acta, 1585, 188-192.

Devreese, M.; De Backer, P.; Croubels, S., 2013. Overview of the most important mycotoxins for the pig and poultry husbandry, Vlaams Diergeneeskundig Tijdschrift, 82, 171-180.

Devriendt, B.; Gallois, M.; Verdonck, F.; Wache, Y.; Bimczok, D.; Oswald, I. P.; Goddeeris, B. M.; Cox, E., 2009. The food contaminant fumonisin b-1 reduces the maturation of porcine cd11r1(+) intestinal antigen presenting cells and antigen-specific immune responses, leading to a prolonged intestinal etec infection, Veterinary Research, 40.

Di Bartolomeo, S.; Di Sano, F.; Piacentini, M.; Spinedi, A., 2000. Apoptosis induced by doxorubicin in neurotumor cells is divorced from drug effects on ceramide accumulation and may involve cell cycle-dependent caspase activation, J Neurochem, 75, 532-539.

Di Bartolomeo, S.; Spinedi, A., 2001. Potentiation of okadaic acid-induced ceramide elevation but not apoptosis by inhibition of glucosylceramide synthase in human neuroepithelioma cells, Biochem Pharmacol, 61, 851-856.

Dilkin, P.; Direito, G.; Simas, M. M. S.; Mallmann, C. A.; Correa, B., 2010. Toxicokinetics and toxicological effects of single oral dose of fumonisin b1 containing fusarium verticillioides culture material in weaned piglets, Chemico-Biological Interactions, 185, 157-162.

DiPietrantonio, A. M.; Hsieh, T. C.; Wu, J. M., 2000. Specific processing of poly(adp-ribose) polymerase, accompanied by activation of caspase-3 and elevation/reduction of ceramide/hydrogen peroxide levels, during induction of apoptosis in host hl-60 cells infected by the human granulocytic ehrlichiosis (hge) agent, IUBMB Life, 49, 49-55. 
Doi, K.; Uetsuka, K., 2011. Mechanisms of mycotoxin-induced neurotoxicity through oxidative stressassociated pathways, Int J Mol Sci, 12, 5213-5237.

Dombrink-Kurtzman, M. A., 2003. Fumonisin and beauvericin induce apoptosis in turkey peripheral blood lymphocytes, Mycopathologia, 156, 357-364.

Domijan, A. M., 2012. Fumonisin b-1: A neurotoxic mycotoxin, Arhiv Za Higijenu Rada I ToksikologijuArchives of Industrial Hygiene and Toxicology, 63, 531-544.

Domijan, A. M.; Abramov, A. Y., 2011. Fumonisin b-1 inhibits mitochondrial respiration and deregulates calcium homeostasis-implication to mechanism of cell toxicity, International Journal of Biochemistry \& Cell Biology, 43, 897-904.

Domijan, A. M.; Kovac, S.; Abramov, A. Y., 2012. Impact of fumonisin b-1 on glutamate toxicity and low magnesium-induced seizure activity in neuronal primary culture, Neuroscience, 202, 10-16.

Domijan, A. M.; Peraica, M.; Vrdoljak, A. L.; Radic, B.; Zlender, V.; Fuchs, R., 2007. The involvement of oxidative stress in ochratoxin a and fumonisin b-1 toxicity in rats, Molecular Nutrition \& Food Research, 51, 1147-1151.

Domijan, A. M.; Zeljezic, D.; Milic, M.; Peraica, M., 2007. Fumonisin b-1: Oxidative status and DNA damage in rats, Toxicology, 232, 163-169.

Domijan, A. M.; Zeljezic, D.; Kopjar, N.; Peraica, M., 2006. Standard and fpg-modified comet assay in kidney cells of ochratoxin a- and fumonisin b-1-treated rats, Toxicology, 222, 53-59.

Dragan, Y. P.; Bidlack, W. R.; Cohen, S. M.; Goldsworthy, T. L.; Hard, G. C.; Howard, P. C.; Riley, R. T.; Voss, K. A., 2001. Implications of apoptosis for toxicity, carcinogenicity, and risk assessment: Fumonisin b-1 as an example, Toxicological Sciences, 61, 6-17.

El-Nekeety, A. A.; El-Kholy, W.; Abbas, N. F.; Ebaid, A.; Amra, H. A.; Abdel-Wahhab, M. A., 2007. Efficacy of royal jelly against the oxidative stress of fumonisin in rats, Toxicon, 50, 256-269.

Enongene, E. N.; Sharma, R. P.; Bhandari, N.; Voss, K. A.; Riley, R. T., 2000. Disruption of sphingolipid metabolism in small intestines, liver and kidney of mice dosed subcutaneously with fumonisin b-1, Food and Chemical Toxicology, 38, 793-799.

Enongene, E. N.; Sharma, R. P.; Bhandari, N.; Miller, J. D.; Meredith, F. I.; Voss, K. A.; Riley, R. T., 2002. Persistence and reversibility of the elevation in free sphingoid bases induced by fumonisin inhibition of ceramide synthase, Toxicol Sci, 67, 173-181.

Fernandez-Blanco, C.; Frizzell, C.; Shannon, M.; Ruiz, M. J.; Connolly, L., 2016. An in vitro investigation on the cytotoxic and nuclear receptor transcriptional activity of the mycotoxins fumonisin b1 and beauvericin, Toxicol Lett, 257, 1-10.

Ferrante, M. C.; Meli, R.; Raso, G. M.; Esposito, E.; Severino, L.; Di Carlo, G.; Lucisano, A., 2002. Effect of fumonisin $b-1$ on structure and function of macrophage plasma membrane, Toxicology Letters, 129, 181-187.

Ficheux, A. S.; Sibiril, Y.; Parent-Massin, D., 2012. Co-exposure of fusarium mycotoxins: In vitro myelotoxicity assessment on human hematopoietic progenitors, Toxicon, 60, 1171-1179.

Fornelli, F.; Minervini, F.; Mule, G., 2004. Cytotoxicity induced by nivalenol, deoxynivalenol, and fumonisin b, in the sf-9 insect cell line, In Vitro Cellular \& Developmental Biology-Animal, 40, 166171.

Galineau-van Waes, J. B.; Riley, R.; Voss, K.; Maddox, J.; Bennett, G.; Starr, L., 2003. Fumonisininduced neural tube defects: Disruption of sphingolipids and folate transport, Toxicological Sciences, 72, 171-171.

Ganguly, S.; Paila, Y. D.; Chattopadhyay, A., 2011. Metabolic depletion of sphingolipids enhances the mobility of the human serotonin1a receptor, Biochem Biophys Res Commun, 411, 180-184. 
Garbetta, A.; Debellis, L.; De Girolamo, A.; Schena, R.; Visconti, A.; Minervini, F., 2015. Dosedependent lipid peroxidation induction on ex vivo intestine tracts exposed to chyme samples from fumonisins contaminated corn samples, Toxicol In Vitro, 29, 1140-1145.

Gardner, N. M.; Riley, R. T.; Showker, J. L.; Voss, K. A.; Sachs, A. J.; Maddox, J. R.; Gelineau-van Waes, J. B., 2016. Elevated nuclear sphingoid base-1-phosphates and decreased histone deacetylase activity after fumonisin b1 treatment in mouse embryonic fibroblasts, Toxicol Appl Pharmacol, 298, 56-65.

Garren, L.; Galendo, D.; Wild, C. P.; Castegnaro, M., 2001. The induction and persistence of altered sphingolipid biosynthesis in rats treated with fumonisin b1, Food Addit Contam, 18, 850-856.

Gelderblom, W. C.; Abel, S.; Smuts, C. M.; Marnewick, J.; Marasas, W. F.; Lemmer, E. R.; Ramljak, D., 2001. Fumonisin-induced hepatocarcinogenesis: Mechanisms related to cancer initiation and promotion, Environ Health Perspect, 109 Suppl 2, 291-300.

Gelderblom, W. C. A.; Marasas, W. F. O.; Lebepe-Mazur, S.; Swanevelder, S.; Abel, S., 2008. Cancer initiating properties of fumonisin b-1 in a short-term rat liver carcinogenesis assay, Toxicology, 250, 89-95.

Gelderblom, W. C. A.; Moritz, W.; Swanevelder, S.; Smuts, C. M.; Abel, S., 2002. Lipids and delta 6desaturase activity alterations in rat liver microsomal membranes induced by fumonisin $b(1)$, Lipids, 37, 869-877.

Gelineau-van Waes, J.; Rainey, M. A.; Maddox, J. R.; Voss, K. A.; Sachs, A. J.; Gardner, N. M.; Wilberding, J. D.; Riley, R. T., 2012. Increased sphingoid base-1-phosphates and failure of neural tube closure after exposure to fumonisin or fty720, Birth Defects Res A Clin Mol Teratol, 94, 790803.

Goossens, J.; Pasmans, F.; Verbrugghe, E.; Vandenbroucke, V.; De Baere, S.; Meyer, E.; Haesebrouck, F.; De Backer, P.; Croubels, S., 2012. Porcine intestinal epithelial barrier disruption by the fusarium mycotoxins deoxynivalenol and $\mathrm{t}-2$ toxin promotes transepithelial passage of doxycycline and paromomycin, BMC Vet Res, 8, 245.

Gopee, N. V.; He, Q. R.; Sharma, R. P., 2003. Fumonisin b-1-induced apoptosis is associated with delayed inhibition of protein kinase $\mathrm{c}$, nuclear factor-kappa $\mathrm{b}$ and tumor necrosis factor alpha in llcpk1 cells, Chemico-Biological Interactions, 146, 131-145.

Gopee, N. V.; Sharma, R. P., 2004. The mycotoxin fumonisin b-1 transiently activates nuclear factorkappa $b$, tumor necrosis factor alpha and caspase 3 via protein kinase $c$ alpha-dependent pathway in porcine renal epithelial cells, Cell Biology and Toxicology, 20, 197-212.

Gopee, N. V.; Sharma, R. P., 2004. Selective and transient activation of protein kinase c alpha by fumonisin $b-1$, a ceramide synthase inhibitor mycotoxin, in cultured porcine renal cells, Life Sciences, 74, 1541-1559.

Gopee, N. V.; Sharma, R. P., 2003. Sphingoid bases and their phosphates: Transient activation and delayed repression of protein kinase $\mathrm{c}$ isoforms and their possible involvement in fumonisin b-1 cytotoxicity, Toxicology, 187, 239-250.

Grenier, B.; Bracarense, Apfl; Schwartz, H. E.; Trumel, C.; Cossalter, A. M.; Schatzmayr, G.; KolfClauw, M.; Moll, W. D.; Oswald, I. P., 2012. The low intestinal and hepatic toxicity of hydrolyzed fumonisin b-1 correlates with its inability to alter the metabolism of sphingolipids, Biochemical Pharmacology, 83, 1465-1473.

Gumprecht, L. A.; Smith, G. W.; Constable, P. C.; Haschek, W. M., 2001. Species and organ specificity of fumonisin-induced endothelial alterations: Potential role in porcine pulmonary edema, Toxicology, 160, 71-79.

Harrer, H.; Humpf, H. U.; Voss, K. A., 2015. In vivo formation of n-acyl-fumonisin b-1, Mycotoxin Research, 31, 33-40. 
Harrer, H.; Laviad, E. L.; Humpf, H. U.; Futerman, A. H., 2013. Identification of n-acyl-fumonisin b1 as new cytotoxic metabolites of fumonisin mycotoxins, Mol Nutr Food Res, 57, 516-522.

Haschek, W. M.; Gumprecht, L. A.; Smith, G.; Tumbleson, M. E.; Constable, P. D., 2001. Fumonisin toxicosis in swine: An overview of porcine pulmonary edema and current perspectives, Environ Health Perspect, 109 Suppl 2, 251-257.

Hassan, A. M.; Abdel-Aziem, S. H.; El-Nekeety, A. A.; Abdel-Wahhab, M. A., 2015. Panax ginseng extract modulates oxidative stress, DNA fragmentation and up-regulate gene expression in rats sub chronically treated with aflatoxin b-1 and fumonisin b-1, Cytotechnology, 67, 861-871.

He, Q.; Kim, J.; Sharma, R. P., 2005. Fumonisin b1 hepatotoxicity in mice is attenuated by depletion of kupffer cells by gadolinium chloride, Toxicology, 207, 137-147.

He, Q.; Riley, R. T.; Sharma, R. P., 2005. Myriocin prevents fumonisin b-1-induced sphingoid base accumulation in mice liver without ameliorating hepatotoxicity, Food and Chemical Toxicology, 43, 969-979.

He, Q. R.; Bhandari, N.; Sharma, R. P., 2002. Fumonisin b-1 alters sphingolipid metabolism and tumor necrosis factor a expression in heart and lung of mice, Life Sciences, 71, 2015-2023.

He, Q. R.; Kim, J.; Sharma, R. P., 2004. Silymarin protects against liver damage in balb/c mice exposed to fumonisin b-1 despite increasing accumulation of free sphingoid bases, Toxicological Sciences, 80, 335-342.

He, Q. R.; Riley, R. T.; Sharma, R. P., 2001. Fumonisin-induced tumor necrosis factor-alpha expression in a porcine kidney cell line is independent of sphingoid base accumulation induced by ceramide synthase inhibition, Toxicology and Applied Pharmacology, 174, 69-77.

He, Q. R.; Riley, R. T.; Sharma, R. P., 2002. Pharmacological antagonism of fumonisin b-1 cytotoxicity in porcine renal epithelial cells (llc-pk1): A model for reducing fumonisin-induced nephrotoxicity in vivo, Pharmacology \& Toxicology, 90, 268-277.

He, Q. R.; Suzuki, H.; Sharma, N.; Sharma, R. P., 2006. Ceramide synthase inhibition by fumonisin b1 treatment activates sphingolipid-metabolizing systems in mouse liver, Toxicological Sciences, 94, 388-397.

He, Q. R.; Sharma, R. P., 2005. Inhibition of tumor necrosis factor alpha signaling by anti-tumor necrosis factor alpha antibodies and pentoxifylline is unable to prevent fumonisin hepatotoxicity in mice, Toxicon, 46, 404-413.

He, Q. R.; Suzuki, H.; Sharma, R. P., 2006. S-adenosylmethionine or 5 '-methylthioadenosine are unable to prevent fumonisin b-1 hepatotoxicity in mice despite increased oxidation in liver, Journal of Applied Toxicology, 26, 509-516.

He, Q.; Suzuki, H.; Sharma, N.; Sharma, R. P., 2006. Ceramide synthase inhibition by fumonisin b1 treatment activates sphingolipid-metabolizing systems in mouse liver, Toxicol Sci, 94, 388-397.

Hove, M.; Van Poucke, C.; Njumbe-Ediage, E.; Nyanga, L. K.; De Saeger, S., 2016. Review on the natural co-occurrence of afb1 and fb1 in maize and the combined toxicity of afb1 and fb1, Food Control, 59, 675-682.

Howard, P. C.; Warbritton, A.; Voss, K. A.; Lorentzen, R. J.; Thurman, J. D.; Kovach, R. M.; Bucci, T. J., 2001. Compensatory regeneration as a mechanism for renal tubule carcinogenesis of fumonisin b1 in the f344/n/nctr br rat, Environ Health Perspect, 109 Suppl 2, 309-314.

Jebali, A.; Ardakani, S. A. Y.; Shandadi, H.; Zadeh, M. H. B.; Hekmatimoghaddam, S., 2015. Modification of nanocellulose by poly-lysine can inhibit the effect of fumonisin b1 on mouse liver cells, Colloids and Surfaces B-Biointerfaces, 126, 437-443.

Jenkins, G. R.; Tolleson, W. H.; Newkirk, D. K.; Roberts, D. W.; Rowland, K. L.; Saheki, T.; Kobayashi, K.; Howard, P. C.; Melchior, W. B., 2000. Identification of fumonisin b-1 as an inhibitor of 
argininosuccinate synthetase using fumonisin affinity chromatography and in vitro kinetic studies, Journal of Biochemical and Molecular Toxicology, 14, 320-328.

Johnson, V. J.; He, Q. R.; Kim, S. H.; Kanti, A.; Sharma, R. P., 2003. Increased susceptibility of renal epithelial cells to tnf alpha-induced apoptosis following treatment with fumonisin b-1, ChemicoBiological Interactions, 145, 297-309.

Jones, C.; Ciacci-Zanella, J. R.; Zhang, Y. G.; Henderson, G.; Dickman, M., 2001. Analysis of fumonisin b-1-induced apoptosis, Environmental Health Perspectives, 109, 315-320.

Karuna, R.; Rao, B. S., 2013. Lack of micronuclei induction by fumonisin b-1 mycotoxin in balb/c mice, Mycotoxin Research, 29, 9-15.

Karuna, R.; Sashidhar, R. B., 2008. The mycotoxin fumonisin b-1 inhibits eukaryotic protein synthesis: In vitro and in vivo studies, Mycopathologia, 165, 37-49.

Kim, D. H.; Lee, Y. S.; Lee, Y. M.; Oh, S.; Yun, Y. P.; Yoo, H. S., 2007. Elevation of sphingoid base 1phosphate as a potential contributor to hepatotoxicity in fulmonisin b-1-exposed mice, Archives of Pharmacal Research, 30, 962-969.

Kim, D. H.; Yoo, H. S.; Lee, Y. M.; Kie, J. H.; Jang, S.; Oh, S., 2006. Elevation of sphinganine 1phosphate as a predictive biomarker for fumonisin exposure and toxicity in mice, J Toxicol Environ Health A, 69, 2071-2082.

Kim, M. S.; Lee, D. Y.; Wang, T.; Schroeder, J. J., 2001. Fumonisin b-1 induces apoptosis in Ilc-pk1 renal epithelial cells via a sphinganine- and calmodulin-dependent pathway, Toxicology and Applied Pharmacology, 176, 118-126.

Kim, M. S.; Schroeder, J. J., 2000. Fumonisin b-1 induces kidney cell apoptosis by a sphinganine- and calmodulin-dependent pathway, Faseb Journal, 14, A748-A748.

Kirkham, P. A.; Takamatsu, H. H.; Lam, E. W. F.; Parkhouse, R. M. E., 2000. Ligation of the wc1 receptor induces gamma delta $t$ cell growth arrest through fumonisin b1-sensitive increases in cellular ceramide, Journal of Immunology, 165, 3564-3570.

Klaric, M. S.; Pepeljnjak, S.; Domijan, A. M.; Petrik, J., 2007. Lipid peroxidation and glutathione levels in porcine kidney pk15 cells after individual and combined treatment with fumonisin b-1, beauvericin and ochratoxin a, Basic \& Clinical Pharmacology \& Toxicology, 100, 157-164.

Kodell, R. L.; Young, J. F.; Delongchamp, R. R.; Turturro, A.; Chen, J. J.; Gaylor, D. W.; Howard, P. C.; Zheng, Q., 2001. A mechanistic approach to modelling the risk of liver tumours in mice exposed to fumonisin b-1 in the diet, Food Additives and Contaminants, 18, 237-253.

Kouadio, J. H.; Mobio, T. A.; Baudrimont, I.; Moukha, S.; Dano, S. D.; Creppy, E. E., 2005. Comparative study of cytotoxicity and oxidative stress induced by deoxynivalenol, zearalenone or fumonisin b1 in human intestinal cell line caco-2, Toxicology, 213, 56-65.

Kovacevic, G.; Gregorovic, G.; Horvatin, K.; Krstanac, Z.; Domijan, A. M.; Zeljezic, D.; Peraica, M.; Kalafatic, M., 2006. Fumonisin b-1-induced apoptosis in rat liver: Morphometrical study, Toxicology Letters, 164, S252-S252.

Kroesen, B. J.; Pettus, B.; Luberto, C.; Busman, M.; Sietsma, H.; de Leij, L.; Hannun, Y. A., 2001. Induction of apoptosis through b-cell receptor cross-linking occurs via de novo generated c16ceramide and involves mitochondria, J Biol Chem, 276, 13606-13614.

Kwon, O. S.; Slikker, W.; Davies, D. L., 2000. Biochemical and morphological effects of fumonisin b-1 on primary cultures of rat cerebrum, Neurotoxicology and Teratology, 22, 565-572.

Lefrancois, S.; May, T.; Knight, C.; Bourbeau, D.; Morales, C. R., 2002. The lysosomal transport of prosaposin requires the conditional interaction of its highly conserved $d$ domain with sphingomyelin, J Biol Chem, 277, 17188-17199. 
Lessard, M.; Boudry, G.; Seve, B.; Oswald, I. P.; Lalles, J. P., 2009. Intestinal physiology and peptidase activity in male pigs are modulated by consumption of corn culture extracts containing fumonisins, J Nutr, 139, 1303-1307.

Li, W.; Riley, R. T.; Voss, K. A.; Norred, W. P., 2000. Role of proliferation in the toxicity of fumonisin b-1: Enhanced hepatotoxic response in the partially hepatectomized rat, Journal of Toxicology and Environmental Health-Part A, 60, 441-457.

Lipardi, C.; Nitsch, L.; Zurzolo, C., 2000. Detergent-insoluble gpi-anchored proteins are apically sorted in fischer rat thyroid cells, but interference with cholesterol or sphingolipids differentially affects detergent insolubility and apical sorting, Mol Biol Cell, 11, 531-542.

Liu, B. H.; Yu, F. Y.; Chan, M. H.; Yang, Y. L., 2002. The effects of mycotoxins, fumonisin b-1 and aflatoxin b-1, on primary swine alveolar macrophages, Toxicology and Applied Pharmacology, 180, 197-204.

Loiseau, N.; Debrauwer, L.; Sambou, T.; Bouhet, S.; Miller, J. D.; Martin, P. G.; Viadere, J. L.; Pinton, P.; Puel, O.; Pineau, T.; Tulliez, J.; Galtier, P.; Oswald, I. P., 2007. Fumonisin b-1 exposure and its selective effect on porcine jejunal segment: Sphingolipids, glycolipids and trans-epithelial passage disturbance, Biochemical Pharmacology, 74, 144-152.

Loiseau, N.; Polizzi, A.; Dupuy, A.; Therville, N.; Rakotonirainy, M.; Loy, J.; Viadere, J. L.; Cossalter, A. M.; Bailly, J. D.; Puel, O.; Kolf-Clauw, M.; Bertrand-Michel, J.; Levade, T.; Guillou, H.; Oswald, I. P., 2015. New insights into the organ-specific adverse effects of fumonisin b1: Comparison between lung and liver, Arch Toxicol, 89, 1619-1629.

Luongo, D.; Severino, L.; Bergamo, P.; De Luna, R.; Lucisano, A.; Rossi, M., 2006. Interactive effects of fumonisin b1 and alpha-zearalenol on proliferation and cytokine expression in jurkat $t$ cells, Toxicol In Vitro, 20, 1403-1410.

Mahmoodi, M.; Alizadeh, A. M.; Sohanaki, H.; Rezaei, N.; Amini-Najafi, F.; Khosravi, A. R.; Hosseini, S. K.; Safari, Z.; Hydarnasab, D.; Khori, V., 2012. Impact of fumonisin b1 on the production of inflammatory cytokines by gastric and colon cell lines, Iran J Allergy Asthma Immunol, 11, 165173.

Mancinetti, A.; Di Bartolomeo, S.; Spinedi, A., 2009. Long-chain ceramide produced in response to nhexanoylsphingosine does not induce apoptosis in chp-100 cells, Lipids, 44, 1039-1046.

Marasas, W. F. O.; Riley, R. T.; Hendricks, K. A.; Stevens, V. L.; Sadler, T. W.; Gelineau-van Waes, J.; Missmer, S. A.; Cabrera, J.; Torres, O.; Gelderblom, W. C. A.; Allegood, J.; Martinez, C.; Maddox, J.; Miller, J. D.; Starr, L.; Sullards, M. C.; Roman, A. V.; Voss, K. A.; Wang, E.; Merrill, A. H., 2004. Fumonisins disrupt sphingolipid metabolism, folate transport, and neural tube development in embryo culture and in vivo: A potential risk factor for human neural tube defects among populations consuming fumonisin-contaminated maize, Journal of Nutrition, 134, 711-716.

Marin, D. E.; Gouze, M. E.; Taranu, I.; Oswald, I. P., 2007. Fumonisin b1 alters cell cycle progression and interleukin-2 synthesis in swine peripheral blood mononuclear cells, Mol Nutr Food Res, 51, 1406-1412.

Marnewick, J. L.; van der Westhuizen, F. H.; Joubert, E.; Swanevelder, S.; Swart, P.; Gelderblom, W. C. A., 2009. Chemoprotective properties of rooibos (aspalathus linearis), honeybush (cyclopia intermedia) herbal and green and black (camellia sinensis) teas against cancer promotion induced by fumonisin b-1 in rat liver, Food and Chemical Toxicology, 47, 220-229.

Mary, V. S.; Theumer, M. G.; Arias, S. L.; Rubinstein, H. R., 2012. Reactive oxygen species sources and biomolecular oxidative damage induced by aflatoxin b1 and fumonisin b1 in rat spleen mononuclear cells, Toxicology, 302, 299-307.

Mary, V. S.; Valdehita, A.; Navas, J. M.; Rubinstein, H. R.; Fernandez-Cruz, M. L., 2015. Effects of aflatoxin $b-1$, fumonisin $b-1$ and their mixture on the aryl hydrocarbon receptor and cytochrome p450 1a induction, Food and Chemical Toxicology, 75, 104-111. 
Masini, E.; Giannini, L.; Nistri, S.; Cinci, L.; Mastroianni, R.; Xu, W.; Comhair, S. A. A.; Li, D.; Cuzzocrea, S.; Matuschak, G. M.; Salvemini, D., 2008. Ceramide: A key signaling molecule in a guinea pig model of allergic asthmatic response and airway inflammation, Journal of Pharmacology and Experimental Therapeutics, 324, 548-557.

Mathur, S.; Constable, P. D.; Eppley, R. M.; Tumbleson, M. E.; Smith, G. W.; Tranquilli, W. J.; Morin, D. E.; Haschek, W. M., 2001. Fumonisin b-1 increases serum sphinganine concentration but does not alter serum sphingosine concentration or induce cardiovascular changes in milk-fed calves, Toxicological Sciences, 60, 379-384.

Mathur, S.; Constable, P. D.; Eppley, R. M.; Waggoner, A. L.; Tumbleson, M. E.; Haschek, W. M., 2001. Fumonisin b-1 is hepatotoxic and nephrotoxic in milk-fed calves, Toxicological Sciences, 60, 385-396.

Mazumder, P. M.; Sasmal, D., 2008. Hepatotoxicity studies of some mycotoxins with special reference to hepatoprotection against mycotoxin induced liver damage, Indian Journal of Pharmaceutical Education and Research, 42, 141-146.

Meca, G.; Fernandez-Franzon, M.; Ritieni, A.; Font, G.; Ruiz, M. J.; Manes, J., 2010. Formation of fumonisin b-1-glucose reaction product, in vitro cytotoxicity, and lipid peroxidation on kidney cells, Journal of Agricultural and Food Chemistry, 58, 1359-1365.

Meca, G.; Ruiz, M. J.; Fernandez-Franzon, M.; Ritieni, A.; Manes, J., 2010. Isolation, purification, Ic$\mathrm{ms} / \mathrm{ms}$ characterization and reactive oxygen species induced by fumonisin b-1 in vero cells, Food and Chemical Toxicology, 48, 2891-2897.

Merrill, A. H., Jr.; Sullards, M. C.; Wang, E.; Voss, K. A.; Riley, R. T., 2001. Sphingolipid metabolism: Roles in signal transduction and disruption by fumonisins, Environ Health Perspect, 109 Suppl 2, 283-289.

Minervini, F.; Debellis, L.; Garbetta, A.; De Girolamo, A.; Schena, R.; Portincasa, P.; Visconti, A., 2014. Influence on functional parameters of intestinal tract induced by short-term exposure to fumonisins contaminated corn chyme samples, Food Chem Toxicol, 66, 166-172.

Minervini, F.; Fornelli, F.; Flynn, K. M., 2004. Toxicity and apoptosis induced by the mycotoxins nivalenol, deoxynivalenol and fumonisin b-1 in a human erythroleukemia cell line, Toxicology in Vitro, 18, 21-28.

Minervini, F.; Garbetta, A.; D'Antuono, I.; Cardinali, A.; Martino, N. A.; Debellis, L.; Visconti, A., 2014. Toxic mechanisms induced by fumonisin b-1 mycotoxin on human intestinal cell line, Archives of Environmental Contamination and Toxicology, 67, 115-123.

Minervini, F.; Lacalandra, G. M.; Filannino, A.; Garbetta, A.; Nicassio, M.; Dell'aquila, M. E.; Visconti, A., 2010. Toxic effects induced by mycotoxin fumonisin b1 on equine spermatozoa: Assessment of viability, sperm chromatin structure stability, ros production and motility, Toxicol In Vitro, 24, 2072-2078.

Mobio, T. A.; Tavan, E.; Baudrimont, I.; Anane, R.; Carratu, M. R.; Sanni, A.; Gbeassor, M. F.; Shier, T. W.; Narbonne, J. F.; Creppy, E. E., 2003. Comparative study of the toxic effects of fumonisin b1 in rat c6 glioma cells and p53-null mouse embryo fibroblasts, Toxicology, 183, 65-75.

Moon, W. S.; Kim, J. H.; Kang, M. J.; Lee, D. G., 2000. Early ultrastructural changes of apoptosis induced by fumonisin b1 in rat liver, Yonsei Med J, 41, 195-204.

Muller, S.; Dekant, W.; Mally, A., 2012. Fumonisin b-1 and the kidney: Modes of action for renal tumor formation by fumonisin b-1 in rodents, Food and Chemical Toxicology, 50, 3833-3846.

Myburg, R. B.; Needhi, N.; Chuturgoon, A. A., 2009. The ultrastructural effects and immunolocalisation of fumonisin b-1 on cultured oesophageal cancer cells (sno), South African Journal of Science, 105, 217-222. 
Nadjia, B.; Fatima, L. D., 2015. Beneficial effects of androctonus australis hector venom and its nontoxic fraction in the restoration of early hepatocyte-carcinogenesis induced by fb1 mycotoxin: Involvement of oxidative biomarkers, Exp Mol Pathol, 99, 198-206.

Nagy, B.; Chiu, S. M.; Separovic, D., 2000. Fumonisin b1 does not prevent apoptosis in a431 human epidermoid carcinoma cells after photosensitization with a silicon phthalocyanine, J Photochem Photobiol B, 57, 132-141.

Nogueira, T. C. A.; Graciano, M. F. R.; Anhe, G. F.; Curi, R.; Bordin, S.; Carpinelli, A. R., 2009. Shortterm modulation of extracellular signal-regulated kinase $1 / 2$ and stress-activated protein kinase/cjun nh2-terminal kinase in pancreatic islets by glucose and palmitate possible involvement of ceramide, Pancreas, 38, 585-592.

Norred, W. P.; Riley, R. T.; Meredith, F. I.; Poling, S. M.; Plattner, R. D., 2001. Instability of nacetylated fumonisin b1 (fa1) and the impact on inhibition of ceramide synthase in rat liver slices, Food Chem Toxicol, 39, 1071-1078.

Nour, A. M. A.; Ringot, D.; Gueant, J. L.; Chango, A., 2007. Folate receptor and human reduced folate carrier expression in hepg2 cell line exposed to fumonisin b-1 and folate deficiency, Carcinogenesis, 28, 2291-2297.

Odhav, B.; Adam, J. K.; Bhoola, K. D., 2008. Modulating effects of fumonisin b1 and ochratoxin a on leukocytes and messenger cytokines of the human immune system, International Immunopharmacology, 8, 799-809.

Osborne, C. D.; Noblet, G. P.; Enongene, E. N.; Bacon, C. W.; Riley, R. T.; Voss, K. A., 2002. Host resistance to trypanosoma cruzi infection is enhanced in mice fed fusarium verticillioides $(=\mathrm{f}$ moniliforme) culture material containing fumonisins, Food and Chemical Toxicology, 40, 17891798.

Osuchowski, M. F.; Edwards, G. L.; Sharma, R. P., 2005. Fumonisin b-1-induced neurodegeneration in mice after intracerebroventricular infusion is concurrent with disruption of sphingolipid metabolism and activation of proinflammatory signaling, Neurotoxicology, 26, 211-221.

Osuchowski, M. F.; He, Q. R.; Sharma, R. P., 2005. Endotoxin exposure alters brain and liver effects of fumonisin b-1 in balb/c mice: Implication of blood brain barrier, Food and Chemical Toxicology, 43, 1389-1397.

Osuchowski, M. F.; Sharma, R. P., 2005. Fumonisin b-1 induces necrotic cell death in bv-2 cells and murine cultured astrocytes and is antiproliferative in bv-2 cells while n2a cells and primary cortical neurons are resistant, Neurotoxicology, 26, 981-992.

Pak, S. M.; Park, N. Y.; Park, M. Y.; Kim, W. J.; Lee, J. H.; Oh, S.; Yoo, H. S.; Lee, Y. M., 2008. Fumonisin $b 1$ induces apoptosis in sphingosine 1-phosphate lyase-null f9 cells through increase of sphingolipids levels, Biomolecules \& Therapeutics, 16, 95-99.

Pallis, M.; Russell, N., 2000. P-glycoprotein plays a drug-efflux-independent role in augmenting cell survival in acute myeloblastic leukemia and is associated with modulation of a sphingomyelinceramide apoptotic pathway, Blood, 95, 2897-2904.

Pellanda, H.; Forges, T.; Bressenot, A.; Chango, A.; Bronowicki, J. P.; Gueant, J. L.; Namour, F., 2012. Fumonisin fb1 treatment acts synergistically with methyl donor deficiency during rat pregnancy to produce alterations of h3- and h4-histone methylation patterns in fetuses, Mol Nutr Food Res, 56, 976-985.

Pepeljnjak, S.; Petrik, J.; Klaric, M. S., 2005. Toxic effects of ustilago maydis and fumonisin b1 in rats, Acta Pharm, 55, 339-348.

Peraica, M.; Domijan, A. M.; Zeljezic, D.; Fuchs, R.; Zlender, V., 2006. Fumonisin b-1: Oxidative status and DNA damage in rats, Toxicology Letters, 164, S262-S263. 
Peraica, M.; Ljubanovic, D.; Zeljezic, D.; Domijan, A. M., 2007. The effect of single dose of fumonisin b-1 on oxidative stress, sphingolipid metabolism and DNA damage in rat kidney, Toxicology Letters, 172, S53-S53.

Pfohl-Leszkowicz, A.; Hadjeba-Medjdoub, K.; Peraica, M.; Manderville, R., 2014. Co-exposure of human kidney cells to two carcinogenic mycotoxins (ochratoxin a and fumonisin b1): Molecular mechanisms, Febs Journal, 281, 447-448.

Pocsfalvi, G.; Ritieni, A.; Randazzo, G.; Dobo, A.; Malorni, A., 2000. Interaction of fusarium mycotoxins, fusaproliferin and fumonisin b-1, with DNA studied by electrospray ionization mass spectrometry, Journal of Agricultural and Food Chemistry, 48, 5795-5801.

Poersch, A. B.; Trombetta, F.; Souto, N. S.; Lima, C. D.; Braga, A. C. M.; Dobrachinski, F.; Ribeiro, L. R.; Soares, F. A. A.; Fighera, M. R.; Royes, L. F. F.; Oliveira, M. S.; Furian, A. F., 2015. Fumonisin b1 facilitates seizures induced by pentylenetetrazol in mice, Neurotoxicology and Teratology, 51, 61-67.

Poersch, A. B.; Trombetta, F.; Braga, A. C. M.; Boeira, S. P.; Oliveira, M. S.; Dilkin, P.; Mallmann, C. A.; Fighera, M. R.; Royes, L. F. F.; Oliveira, M. S.; Furian, A. F., 2014. Involvement of oxidative stress in subacute toxicity induced by fumonisin b-1 in broiler chicks, Veterinary Microbiology, 174, 180-185.

Qian, G.; Tang, L.; Lin, S.; Xue, K. S.; Mitchell, N. J.; Su, J.; Gelderblom, W. C.; Riley, R. T.; Phillips, T. D.; Wang, J. S., 2016. Sequential dietary exposure to aflatoxin b1 and fumonisin b1 in f344 rats increases liver preneoplastic changes indicative of a synergistic interaction, Food Chem Toxicol, 95, 188-195.

Rabkin, S. W., 2002. Fumonisin blunts nitric oxide-induced and nitroprusside-induced cardiornyocyte death, Nitric Oxide-Biology and Chemistry, 7, 229-235.

Raiola, A.; Tenore, G. C.; Manyes, L.; Meca, G.; Ritieni, A., 2015. Risk analysis of main mycotoxins occurring in food for children: An overview, Food Chem Toxicol, 84, 169-180.

Ramljak, D.; Calvert, R. J.; Wiesenfeld, P. W.; Diwan, B. A.; Catipovic, B.; Marasas, W. F.; Victor, T. C.; Anderson, L. M.; Gelderblom, W. C., 2000. A potential mechanism for fumonisin b(1)-mediated hepatocarcinogenesis: Cyclin d1 stabilization associated with activation of akt and inhibition of gsk3beta activity, Carcinogenesis, 21, 1537-1546.

Reisinger, N.; Dohnal, I.; Nagl, V.; Schaumberger, S.; Schatzmayr, G.; Mayer, E., 2016. Fumonisin b-1 (fb1) induces lamellar separation and alters sphingolipid metabolism of in vitro cultured hoof explants, Toxins, 8.

Rentz, S. S.; Showker, J. L.; Meredith, F. I.; Riley, R. T., 2005. Inhibition of sphingolipid biosynthesis decreases phosphorylated erk2 in llc-pk1 cells, Food Chem Toxicol, 43, 123-131.

Ribeiro, D. H.; Ferreira, F. L.; da Silva, V. N.; Aquino, S.; Correa, B., 2010. Effects of aflatoxin b(1) and fumonisin $\mathrm{b}(1)$ on the viability and induction of apoptosis in rat primary hepatocytes, Int J Mol Sci, 11, 1944-1955.

Riedel, S.; Abel, S.; Burger, H. M.; van der Westhuizen, L.; Swanevelder, S.; Gelderblom, W. C. A., 2016. Differential modulation of the lipid metabolism as a model for cellular resistance to fumonisin b-1-induced cytotoxic effects in vitro, Prostaglandins Leukotrienes and Essential Fatty Acids, 109, 39-51.

Riley, R. T.; Torres, O.; Matute, J.; Gregory, S. G.; Ashley-Koch, A. E.; Showker, J. L.; Mitchell, T.; Voss, K. A.; Maddox, J. R.; Gelineau-van Waes, J. B., 2015. Evidence for fumonisin inhibition of ceramide synthase in humans consuming maize-based foods and living in high exposure communities in guatemala, Molecular Nutrition \& Food Research, 59, 2209-2224. 
Riley, R. T.; Voss, K. A., 2006. Differential sensitivity of rat kidney and liver to fumonisin toxicity: Organ-specific differences in toxin accumulation and sphingoid base metabolism, Toxicol Sci, 92, 335-345.

Romero, A.; Ares, I.; Ramos, E.; Castellano, V.; Martinez, M.; Martinez-Larranaga, M. R.; Anadon, A.; Martinez, M. A., 2016. Mycotoxins modify the barrier function of caco-2 cells through differential gene expression of specific claudin isoforms: Protective effect of illite mineral clay, Toxicology, 353-354, 21-33.

Rumora, L.; Domijan, A. M.; Grubisic, T. Z.; Peraica, M., 2007. Mycotoxin fumonisin b-1 alters cellular redox balance and signalling pathways in rat liver and kidney, Toxicology, 242, 31-38.

Raa, H.; Grimmer, S.; Schwudke, D.; Bergan, J.; Walchli, S.; Skotland, T.; Shevchenko, A.; Sandvig, K., 2009. Glycosphingolipid requirements for endosome-to-golgi transport of shiga toxin, Traffic, $10,868-882$.

Sadler, T. W.; Merrill, A. H.; Stevens, V. L.; Sullards, M. C.; Wang, E.; Wang, P., 2002. Prevention of fumonisin b1-induced neural tube defects by folic acid, Teratology, 66, 169-176.

Sancak, D.; Ozden, S., 2015. Global histone modifications in fumonisin b1 exposure in rat kidney epithelial cells, Toxicol In Vitro, 29, 1809-1815.

Schwerdt, G.; Konigs, M.; Holzinger, H.; Humpf, H. U.; Gekle, M., 2009. Effects of the mycotoxin fumonisin b-1 on cell death in human kidney cells and human lung fibroblasts in primary culture, Journal of Applied Toxicology, 29, 174-182.

Seefelder, W.; Humpf, H. U.; Schwerdt, G.; Freudinger, R.; Gekle, M., 2003. Induction of apoptosis in cultured human proximal tubule cells by fumonisins and fumonisin metabolites, Toxicol Appl Pharmacol, 192, 146-153.

Seegers, J. C.; Joubert, A. M.; Panzer, A.; Lottering, M. L.; Jordan, C. A.; Joubert, F.; Maree, J. L.; Bianchi, P.; de Kock, M.; Gelderblom, W. C. A., 2000. Fumonisin b-1 influenced the effects of arachidonic acid, prostaglandins e2 and a2 on cell cycle progression, apoptosis induction, tyrosineand cdc2-kinase activity in oesophageal cancer cells, Prostaglandins Leukotrienes and Essential Fatty Acids, 62, 75-84.

Seiferlein, M.; Humpf, H. U.; Voss, K. A.; Sullards, M. C.; Allegood, J. C.; Wang, E.; Merrill, A. H., Jr., 2007. Hydrolyzed fumonisins $\mathrm{hfb} 1 \mathrm{and} \mathrm{hfb} 2$ are acylated in vitro and in vivo by ceramide synthase to form cytotoxic n-acyl-metabolites, Mol Nutr Food Res, 51, 1120-1130.

Sharma, N.; He, Q.; Sharma, R. P., 2006. Amelioration of fumonisin b1 hepatotoxicity in mice by depletion of $t$ cells with anti-thy-1.2, Toxicology, 223, 191-201.

Sharma, N.; He, Q.; Sharma, R. P., 2004. Augmented fumonisin b1 toxicity in co-cultures: Evidence for crosstalk between macrophages and non-parenchymatous liver epithelial cells involving proinflammatory cytokines, Toxicology, 203, 239-251.

Sharma, N.; He, Q.; Sharma, R. P., 2004. Sphingosine kinase activity confers resistance to apoptosis by fumonisin b-1 in human embryonic kidney (hek-293) cells, Chemico-Biological Interactions, 151, $33-42$.

Sharma, N.; Suzuki, H.; He, Q. R.; Sharma, R. P., 2005. Tumor necrosis factor alpha-mediated activation of c-jun nh2-terminal kinase as a mechanism for fumonisin b-1 induced apoptosis in murine primary hepatocytes, Journal of Biochemical and Molecular Toxicology, 19, 359-367.

Sharma, R. P.; Bhandari, N.; He, Q. R.; Riley, R. T.; Voss, K. A., 2001. Decreased fumonisin hepatotoxicity in mice with a targeted deletion of tumor necrosis factor receptor 1 , Toxicology, 159, 69-79.

Sharma, R. P.; Bhandari, N.; Tsunoda, M.; Riley, R. T.; Voss, K. A., 2000. Fumonisin hepatotoxicity is reduced in mice carrying the human tumour necrosis factor alpha transgene, Arch Toxicol, 74, 238248. 
Sharma, R. P.; Bhandari, N.; Tsunoda, M.; Riley, R. T.; Voss, K. A.; Meredith, F. I., 2000. Fumonisin toxicity in a transgenic mouse model lacking the mdr1a/1b p-glycoprotein genes, Environ Toxicol Pharmacol, 8, 173-182.

Sharma, R. P.; Bhandari, N.; Riley, R. T.; Voss, K. A.; Meredith, F. I., 2000. Tolerance to fumonisin toxicity in a mouse strain lacking the p75 tumor necrosis factor receptor, Toxicology, 143, 183-194.

Sharma, R. P.; He, Q. R.; Johnson, V. J., 2003. Deletion of ifn-gamma reduces fumonisin-induced hepatotoxicity in mice via alterations in inflammatory cytokines and apoptotic factors, Journal of Interferon and Cytokine Research, 23, 13-23.

Sharma, R. P.; He, Q.; Johnson, V. J.; Voss, K. A., 2003. Increased expression of cd95-ligand and other apoptotic signaling factors by fumonisin $b 1$, a hepatotoxic mycotoxin, in livers of mice lacking tumor necrosis factor alpha, Cytokine, 24, 226-236.

Sharma, R. P.; He, Q. R.; Riley, R. T., 2005. Lupus-prone nzbwf1/j mice, defective in cytokine signaling, are resistant to fumonisin hepatotoxicity despite accumulation of liver sphinganine, Toxicology, 216, 59-71.

Sharma, R. P.; He, Q.; Johnson, V. J.; Suzuki, H., 2006. Mice lacking both tnf alpha receptors show increased constitutive expression of ifn gamma: A possible reason for lack of protection from fumonisin b-1 hepatotoxicity, Cytokine, 34, 260-270.

Sharma, R. P.; He, Q.; Meredith, F. I.; Riley, R. T.; Voss, K. A., 2002. Paradoxical role of tumor necrosis factor alpha in fumonisin-induced hepatotoxicity in mice, Toxicology, 180, 221-232.

Sharma, R. P.; He, Q. R.; Johnson, V. J.; Voss, K. A.; Riley, R. T., 2005. Targeted deletion of both tumor necrosis factor alpha receptors modulates various apoptotic pathways in mouse liver: Possible mechanism for a lack of resistance against fumonisin b-1 hepatotoxicity, Faseb Journal, 19, A554-A554.

Shen, X.; Si, Y.; Wang, Z.; Wang, J.; Guo, Y.; Zhang, X., 2016. Quercetin inhibits the growth of human gastric cancer stem cells by inducing mitochondrial-dependent apoptosis through the inhibition of pi3k/akt signaling, Int J Mol Med, 38, 619-626.

Smith, G. W.; Constable, P. D.; Eppley, R. M.; Tumbleson, M. E.; Gumprecht, L. A.; Haschek-Hock, W. M., 2000. Purified fumonisin b-1 decreases cardiovascular function but does not alter pulmonary capillary permeability in swine, Toxicological Sciences, 56, 240-249.

Smith, L. E.; Stoltzfus, R. J.; Prendergast, A., 2012. Food chain mycotoxin exposure, gut health, and impaired growth: A conceptual framework, Advances in Nutrition, 3, 526-531.

Soeda, S.; Iwata, K.; Hosoda, Y.; Shimeno, H., 2001. Daunorubicin attenuates tumor necrosis factoralpha-induced biosynthesis of plasminogen activator inhibitor-1 in human umbilical vein endothelial cells, Biochim Biophys Acta, 1538, 234-241.

Solfrizzo, M.; Carratu, M. R.; Avantaggiato, G.; Galvano, F.; Pietri, A.; Visconti, A., 2001. Ineffectiveness of activated carbon in reducing the alteration of sphingolipid metabolism in rats exposed to fumonisin-contaminated diets, Food Chem Toxicol, 39, 507-511.

Soriano, J. M.; Gonzalez, L.; Catala, A. I., 2005. Mechanism of action of sphingolipids and their metabolites in the toxicity of fumonisin b1, Prog Lipid Res, 44, 345-356.

Spotti, M.; Maas, R. F. M.; de Nijs, C. M.; Fink-Gremmels, J., 2000. Effect of fumonisin b-1 on rat hepatic p450 system, Environmental Toxicology and Pharmacology, 8, 197-204.

Stark, A. A., 2005. Threat assessment of mycotoxins as weapons: Molecular mechanisms of acute toxicity, J Food Prot, 68, 1285-1293.

Stockman-Juvala, H.; Mikkola, J.; Naarala, J.; Loikkanen,; Elovaara, E.; Savolainen, K., 2004. Oxidative stress and apoptosis in human $\mathrm{u}-118 \mathrm{mg}$ glioblastoma cells exposed to fumonisin b1, Toxicology and Applied Pharmacology, 197, 334-334. 
Stockmann-Juvala, H.; Alenius, H.; Savolainen, K., 2008. Effects of fumonisin b-1 on the expression of cytokines and chemokines in human dendritic cells, Food and Chemical Toxicology, 46, 1444-1451.

Stockmann-Juvala, H.; Mikkola, J.; Naarala, J.; Loikkanen, J.; Elovaara, E.; Savolainen, K., 2004. Fumonisin b1-induced toxicity and oxidative damage in u-118mg glioblastoma cells, Toxicology, 202, 173-183.

Stockmann-Juvala, H.; Mikkola, J.; Naarala, J.; Loikkanen, J.; Elovaara, E.; Savolainen, K., 2004. Oxidative stress induced by fumonisin b-1 in continuous human and rodent neural cell cultures, Free Radical Research, 38, 933-942.

Stockmann-Juvala, H.; Savolainen, K., 2008. A review of the toxic effects and mechanisms of action of fumonisin b-1, Human \& Experimental Toxicology, 27, 799-809.

Sun, L. H.; Lei, M. Y.; Zhang, N. Y.; Gao, X.; Li, C.; Krumm, C. S.; Qi, D. S., 2015. Individual and combined cytotoxic effects of aflatoxin $b-1$, zearalenone, deoxynivalenol and fumonisin $b-1$ on brl 3a rat liver cells, Toxicon, 95, 6-12.

Suzuki, H.; Riley, R. T.; Sharma, R. P., 2007. Inducible nitric oxide has protective effect on fumonisin b-1 hepatotoxicity in mice via modulation of sphingosine kinase, Toxicology, 229, 42-53.

Taranu, I.; Marin, D. E.; Burlacu, R.; Pinton, P.; Damian, V.; Oswald, I. P., 2010. Comparative aspects of in vitro proliferation of human and porcine lymphocytes exposed to mycotoxins, Archives of Animal Nutrition, 64, 383-393.

Taranu, I.; Marin, D. E.; Bouhet, S.; Pascale, F.; Bailly, J. D.; Miller, J. D.; Pinton, P.; Oswald, I. P., 2005. Mycotoxin fumonisin b-1 alters the cytokine profile and decreases the vaccinal antibody titer in pigs, Toxicological Sciences, 84, 301-307.

Tardieu, D.; Tran, S. T.; Auvergne, A.; Babile, R.; Benard, G.; Bailly, J. D.; Guerre, P., 2006. Effects of fumonisins on liver and kidney sphinganine and the sphinganine to sphingosine ratio during chronic exposure in ducks, Chem Biol Interact, 160, 51-60.

Theumer, M. G.; Lopez, A. G.; Masih, D. T.; Chulze, S. N.; Rubinstein, H. R., 2003. Immunobiological effects of afb1 and afb1-fb1 mixture in experimental subchronic mycotoxicoses in rats, Toxicology, $186,159-170$.

Theumer, M. G.; Lopez, A. G.; Masih, D. T.; Chulze, S. N.; Rubinstein, H. R., 2002. Immunobiological effects of fumonisin b1 in experimental subchronic mycotoxicoses in rats, Clin Diagn Lab Immunol, 9, 149-155.

Todorova, K.; Ivanov, I.; Georgieva, A.; Lazarova, S.; Milcheva, R.; Dimitrov, P.; Dimitrov, R.; Russev, R., 2015. Fumonisin b-1 cytotoxicity and subcellular localization in duck embryo cell line dec 99, Comptes Rendus De L Academie Bulgare Des Sciences, 68, 617-622.

Todorova, K. S.; Kril, A. I.; Dimitrov, P. S.; Gardeva, E. G.; Toshkova, R. A.; Tasheva, Y. R.; Petrichev, M. H.; Russev, R. V., 2011. Effect of fumonisin b1 on lymphatic organs in broiler chickens pathomorphology, Bulletin of the Veterinary Institute in Pulawy, 55, 801-805.

Torres, O.; Matute, J.; Gelineau-van Waes, J.; Maddox, J. R.; Gregory, S. G.; Ashley-Koch, A. E.; Showker, J. L.; Voss, K. A.; Riley, R. T., 2015. Human health implications from co-exposure to aflatoxins and fumonisins in maize-based foods in latin america: Guatemala as a case study, World Mycotoxin Journal, 8, 143-159.

Ueda, N.; Camargo, S. M. R.; Hong, X. M.; Basnakian, A. G.; Walker, P. D.; Shah, S. V., 2001. Role of ceramide synthase in oxidant injury to renal tubular epithelial cells, Journal of the American Society of Nephrology, 12, 2384-2391.

van der Westhuizen, L.; Gelderblom, W. C.; Shephard, G. S.; Swanevelder, S., 2004. Disruption of sphingolipid biosynthesis in hepatocyte nodules: Selective proliferative stimulus induced by fumonisin b1, Toxicology, 200, 69-75. 
van der Westhuizen, L.; Shephard, G. S.; van Schalkwyk, D. J., 2001. The effect of a single gavage dose of fumonisin b-1 on the sphinganine and sphingosine levels in vervet monkeys, Toxicon, 39, 273-281.

van der Westhuizen, L.; Shephard, G. S.; van Schalkwyk, D. J., 2001. The effect of a single gavage dose of fumonisin $b-2$ on the sphinganine and sphingosine concentrations in vervet monkeys, Food and Chemical Toxicology, 39, 455-459.

van der Westhuizen, L.; Shephard, G. S.; van Schalkwyk, D. J., 2001. The effect of repeated gavage doses of fumonisin b-1 on the sphinganine and sphingosine levels in vervet monkeys, Toxicon, 39, 969-972.

Voss, K. A.; Howard, P. C.; Riley, R. T.; Sharma, R. P.; Bucci, T. J.; Lorentzen, R. J., 2002. Carcinogenicity and mechanism of action of fumonisin b-1: A mycotoxin produced by fusarium moniliforme (= f-verticillioides), Cancer Detection and Prevention, 26, 1-9.

Voss, K. A.; Liu, J.; Anderson, S. P.; Dunn, C.; Miller, J. D.; Owen, J. R.; Riley, R. T.; Bacon, C. W.; Corton, J. C., 2006. Toxic effects of fumonisin in mouse liver are independent of the peroxisome proliferator-activated receptor alpha, Toxicol Sci, 89, 108-119.

Voss, K. A.; Riley, R. T.; Gelineau-van Waes, J., 2014. Fumonisin b-1 induced neural tube defects were not increased in $\mathrm{Im} / \mathrm{bc}$ mice fed folate-deficient diet, Molecular Nutrition \& Food Research, $58,1190-1198$.

Voss, K. A.; Riley, R. T.; Norred, W. P.; Bacon, C. W.; Meredith, F. I.; Howard, P. C.; Plattner, R. D.; Collins, T. F.; Hansen, D. K.; Porter, J. K., 2001. An overview of rodent toxicities: Liver and kidney effects of fumonisins and fusarium moniliforme, Environ Health Perspect, 109 Suppl 2, 259-266.

Voss, K. A.; Riley, R. T.; Snook, M. E.; Gelineau-van Waes, J., 2009. Reproductive and sphingolipid metabolic effects of fumonisin b-1 and its alkaline hydrolysis product in $1 \mathrm{~m} / \mathrm{bc}$ mice: Hydrolyzed fumonisin b-1 did not cause neural tube defects, Toxicological Sciences, 112, 459-467.

Voss, K. A.; Riley, R.; Dunn, C.; Corton, J. C., 2006. The role of tumor necrosis factor alpha and the peroxisome proliferator-activated receptor alpha in modulating the effects of fumonisin in mouse liver, Toxicology, 222, 165-174.

Voss, K. A.; Smith, G. W.; Haschek, W. M., 2007. Fumonisins: Toxicokinetics, mechanism of action and toxicity, Animal Feed Science and Technology, 137, 299-325.

Waes, J. G.; Starr, L.; Maddox, J.; Aleman, F.; Voss, K. A.; Wilberding, J.; Riley, R. T., 2005. Maternal fumonisin exposure and risk for neural tube defects: Mechanisms in an in vivo mouse model, Birth Defects Research Part a-Clinical and Molecular Teratology, 73, 487-497.

Wan, L. Y. M.; Allen, K. J.; Turner, P. C.; El-Nezami, H., 2014. Modulation of mucin mrna (muc5ac and muc5b) expression and protein production and secretion in caco-2/ht29-mtx co-cultures following exposure to individual and combined fusarium mycotoxins, Toxicological Sciences, 139, 83-98.

Wan, L. Y. M.; Woo, C. S. J.; Turner, P. C.; Wan, J. M. F.; El-Nezami, H., 2013. Individual and combined effects of fusarium toxins on the mrna expression of pro-inflammatory cytokines in swine jejunal epithelial cells, Toxicology Letters, 220, 238-246.

Wan, M. L. Y.; Woo, C. S. J.; Allen, K. J.; Turner, P. C.; El-Nezami, H., 2013. Modulation of porcine beta-defensins 1 and 2 upon individual and combined fusarium toxin exposure in a swine jejunal epithelial cell line, Applied and Environmental Microbiology, 79, 2225-2232.

Wang, S. K.; Liu, S.; Yang, L. G.; Shi, R. F.; Sun, G. J., 2013. Effect of fumonisin b-1 on the cell cycle of normal human liver cells, Molecular Medicine Reports, 7, 1970-1976.

Wang, S. K.; Wang, T. T.; Huang, G. L.; Shi, R. F.; Yang, L. G.; Sun, G. J., 2014. Stimulation of the proliferation of human normal esophageal epithelial cells by fumonisin b-1 and its mechanism, Experimental and Therapeutic Medicine, 7, 55-60. 
Wang, X.; Wu, Q. H.; Wan, D.; Liu, Q. Y.; Chen, D. M.; Liu, Z. L.; Martinez-Larranaga, M. R.; Martinez, M. A.; Anadon, A.; Yuan, Z. H., 2016. Fumonisins: Oxidative stress-mediated toxicity and metabolism in vivo and in vitro, Archives of Toxicology, 90, 81-101.

Weber, F.; Schwerdt, G.; Freudinger, R.; Gekle, M., 2003. Programmed cell death by interaction of ochratoxin a with other nephrotoxins, Mycotoxin Res, 19, 20-23.

Wen, J. K.; Mu, P. Q.; Deng, Y. Q., 2016. Mycotoxins: Cytotoxicity and biotransformation in animal cells, Toxicology Research, 5, 377-387.

Wentzel, C. A. G.; Riedel, S.; Burger, H.; Abel, S.; Liana, V.; Jeanine, M.; Marasas, W., 2006. Carcinogenesis by the fumonisins: Mechanisms, risk analyses and implications, Abstracts of Papers of the American Chemical Society, 232, 239-239.

Xing, F. Q.; Li, Z.; Sun, A. Z.; Xing, D., 2013. Reactive oxygen species promote chloroplast dysfunction and salicylic acid accumulation in fumonisin b1-induced cell death, Febs Letters, 587, 2164-2172.

Yao, Z. G.; Zhang, X. H.; Hua, F.; Wang, J.; Xing, X.; Wang, J. L.; Yan, X.; Xing, L. X., 2011. Effects of fumonisin b1 on hla class $\mathrm{i}$ antigen presentation and processing pathway in ges-1 cells in vitro, Hum Exp Toxicol, 30, 379-390.

Yin, S. T.; Guo, X.; Li, J. H.; Fan, L. H.; Hu, H. B., 2016. Fumonisin b1 induces autophagic cell death via activation of ern1-mapk8/9/10 pathway in monkey kidney marc-145 cells, Archives of Toxicology, 90, 985-996.

Yu, C. H.; Lee, Y. M.; Yun, Y. P.; Yoo, H. S., 2001. Differential effects of fumonisin b-1 on cell death in cultured cells: The significance of the elevated sphinganine, Archives of Pharmacal Research, 24, 136-143.

Yu, M. U.; Yoo, J. M.; Lee, Y. S.; Lee, Y. M.; Hong, J. T.; Oh, K. W.; Song, S.; Yun, Y. P.; Yoo, H. S.; Oh, S., 2004. Altered de novo sphingolipid biosynthesis is involved in the serum deprivationinduced cell death in Ilc-pk1 cells, J Toxicol Environ Health A, 67, 2085-2094.

Zhang, Y.; Jones, C.; Dickman, M. B., 2001. Identification of differentially expressed genes following treatment of monkey kidney cells with the mycotoxin fumonisin b-1, Food and Chemical Toxicology, 39, 45-53.

Zitomer, N. C.; Mitchell, T.; Voss, K. A.; Bondy, G. S.; Pruett, S. T.; Garnier-Amblard, E. C.; Liebeskind, L. S.; Park, H.; Wang, E.; Sullards, M. C.; Merrill, A. H.; Riley, R. T., 2009. Ceramide synthase inhibition by fumonisin b-1 causes accumulation of 1-deoxysphinganine a novel category of bioactive 1-deoxysphingoid bases and 1-deoxydihydroceramides biosynthesized by mammalian cell lines and animals, Journal of Biological Chemistry, 284, 4786-4795.

\section{Relevant references not retrieved in the literature searches for Area 3 MODE OF ACTION:}

Abdelnour, A. M.; Leridon, C.; Tessier, F.; Abdennebi-Najar, L.; Chang, A.; Ringot, D., 2011. Simultaneous determination of genomic DNA methylation and uracil misincorporation into DNA from cells exposed to fumonisin b1 and/or folate deficiency, Journal of Developmental Origins of Health and Disease, 2, S49-S49.

Albonico, M.; Schutz, L. F.; Caloni, F.; Cortinovis, C.; Spicer, L. J., 2016. Toxicological effects of fumonisin b1 alone and in combination with other fusariotoxins on bovine granulosa cells, Toxicon, 118, 47-53.

Bhandari, N.; Enongene, E. N.; Riley, R. T.; Meredith, F. I.; Sharma, R. P., 2002. Temporal expression of fumonisin $b$-1-induced tumor necrosis factor-alpha and interferon gamma in mice, Comparative Biochemistry and Physiology C-Toxicology \& Pharmacology, 131, 113-122. 
Bondy, G. S.; Barker, M. G.; Lombaert, G. A.; Armstrong, C. L.; Fernie, S. M.; Gurofsky, S.; Huzel, V.; Savard, M. E.; Curran, I. H. A., 2000. A comparison of clinical, histopathological and cell-cycle markers in rats receiving the fungal toxins fumonisin $b-1$ or fumonisin $b-1$ by intraperitoneal injection, Food and Chemical Toxicology, 38, 873-886.

Bracarense, A. P.; Lucioli, J.; Grenier, B.; Drociunas Pacheco, G.; Moll, W. D.; Schatzmayr, G.; Oswald, I. P., 2012. Chronic ingestion of deoxynivalenol and fumonisin, alone or in interaction, induces morphological and immunological changes in the intestine of piglets, $\mathrm{Br}$ J Nutr, 107, 1776-1786.

Caloni, F.; Albonico, M.; Schutz, L.; Pizzo, F.; Spicer, L. J., 2014. Differential effects of fumonisin b1 and zearalenone metabolites on estradiol and progesterone production in cultured bovine granulosa cells, Toxicology Letters, 229, S57-S57.

Dombrink-Kurtzman, M. A.; Gomez-Flores, R.; Weber, R. J., 2000. Activation of rat splenic macrophage and lymphocyte functions by fumonisin b-1, Immunopharmacology, 49, 401-409.

Fernandez-Surumay, G.; Osweiler, G. D.; Yaeger, M. J.; Hauck, C. C.; Hendrich, S.; Murphy, P. A., 2004. Glucose reaction with fumonisin b1 partially reduces its toxicity in swine, J Agric Food Chem, $52,7732-7739$.

Gbore, F. A., 2010. Brain and hypophyseal acetylcholinesterase activity of pubertal boars fed dietary fumonisin b1, J Anim Physiol Anim Nutr (Berl), 94, e123-129.

Gelderblom, W. C. A.; Galendo, D.; Abel, S.; Swanevelder, S.; Marasas, W. F. O.; Wild, C. P., 2001. Cancer initiation by fumonisin b-1 in rat liver - role of cell proliferation, Cancer Lett, 169, 127-137.

Halloy, D. J.; Gustin, P. G.; Bouhet, S.; Oswald, I. P., 2005. Oral exposure to culture material extract containing fumonisins predisposes swine to the development of pneumonitis caused by pasteurellamultocida, Toxicology, 213, 34-44.

Hecker, D. C.; Salzig, C.; Schrenk, D., 2008. Possible signalling pathways for the cancer promotion through fumonisin b-1, Naunyn-Schmiedebergs Archives of Pharmacology, 377, 73-73.

Kim, M. S.; Schroeder, J. J., 2001. Fumonisin b-1 reduces phosphorylation of mapk/erk and pkb/akt in Ilc-pk1 porcine kidney epithelial cells, Faseb Journal, 15, A600-A600.

Lalles, J. P.; Lessard, M.; Oswald, I. P.; David, J. C., 2010. Consumption of fumonisin b-1 for 9 days induces stress proteins along the gastrointestinal tract of pigs, Toxicon, 55, 244-249.

Lemmer, E. R.; Vessey, C. J.; Gelderblom, W. C. A.; Shephard, E. G.; Van Schalkwyk, D. J.; Van Wijk, R. A.; Marasas, W. F. O.; Kirsch, R. E.; Hall, P. D., 2004. Fumonisin b-1-induced hepatocellular and cholangiocellular tumors in male fischer 344 rats: Potentiating effects of 2-acetylaminofluorene on oval cell proliferation and neoplastic development in a discontinued feeding study, Carcinogenesis, $25,1257-1264$.

Loiseau, N.; Therville, N.; Levade, T.; Bertrand-Michel, J., 2010. Dual and opposite effects of fumonisin b1 on ceramide and sphingomyelin contents in piglet's lung and liver, NaunynSchmiedebergs Archives of Pharmacology, 382, 10-10.

Meli, R.; Ferrante, M. C.; Raso, G. M.; Cavaliere, M.; Di Carlo, R.; Lucisano, A., 2000. Effect of fumonisin b-1 on inducible nitric oxide synthase and cyclooxygenase-2 in Ips-stimulated j774a.1 cells, Life Sciences, 67, 2845-2853.

Mexia-Salazar, A. L.; Hernandez-Lopez, J.; Burgos-Hernandez, A.; Cortez-Rocha, M. O.; CastroLongoria, R.; Ezquerra-Brauer, J. M., 2008. Role of fumonisin b-1 on the immune system, histopathology, and muscle proteins of white shrimp (litopenaeus vannamei), Food Chemistry, 110, 471-479.

Mobio, T. A.; Anane, R.; Baudrimont, I.; Carratu, M. R.; Shier, T. W.; Dano, S. D.; Ueno, Y.; Creppy, E. E., 2000. Epigenetic properties of fumonisin b-1: Cell cycle arrest and DNA base modification in c6 glioma cells, Toxicology and Applied Pharmacology, 164, 91-96. 
Osuchowski, M. F.; Sharma, R. P., 2004. Intracerebral and subcutaneous application of fumonisin b-1 shows different modulatory effects upon liver homeostasis in balb/c mice, Faseb Journal, 18, A610A610.

Sakai, A.; Suzuki, C.; Masui, Y.; Kuramashi, A.; Takatori, K.; Tanaka, N., 2007. The activities of mycotoxins derived from fusarium and related substances in a short-term transformation assay using v-ha-ras-transfected balb/3t3 cells (bhas 42 cells), Mutat Res, 630, 103-111.

Sharma, R. P.; He, Q. R.; Johnson, V. J.; Voss, K. A., 2003. Increased hepatotoxicity of fumonisin b-1 in tumor necrosis factor aknockout mouse involves modulation of fas signaling, Faseb Journal, 17, A1040-A1040.

Stockmann-Juvala, H.; Savolainen, K., 2001. Caspase-3 activation and decreased levels of glutathione in mouse gt1-7 hypothalamic cells exposed to fumonisin b1, Toxicology, 164, 176-177.

Tachampa, K.; Takeda, M.; Khamdang, S.; Noshiro-Kofuji, R.; Tsuda, M.; Jariyawat, S.; Fukutomi, T.; Sophasan, S.; Anzai, N.; Endou, H., 2008. Interactions of organic anion transporters and organic cation transporters with mycotoxins, J Pharmacol Sci, 106, 435-443.

Zhang, Y.; Jones, C.; Dickman, M. B., 2001. Identification of differentially expressed genes following treatment of monkey kidney cells with the mycotoxin fumonisin $b(1)$, Food Chem Toxicol, 39, 4553.

Zomborszky, M. K.; Vetesi, F.; Repa, I.; Kovacs, F.; Bata, A.; Horn, P.; Toth, A.; Romvari, R., 2000. Experiment to determine limits of tolerance for fumonisin b1 in weaned piglets, J Vet Med B Infect Dis Vet Public Health, 47, 277-286. 


\section{AREA 4 IN VIVO TOXICITY}

Reference list with all relevant references identified for AREA 4: Data on toxicity in vivo (e.g. acute, subacute, subchronic, chronic toxicity; genotoxicity, carcinogenicity, toxicity to specific organs) in laboratory animals published in English since year 2000.

\section{Relevant references retrieved in the literature searches for Area 4 IN VIVO TOXICITY:}

Abdellatef, A. A.; Khalil, A. A., 2016. Ameliorated effects of lactobacillus delbrueckii subsp. Lactis dsm 20076 and pediococcus acidilactici nnrl b-5627 on fumonisin b1-induced hepatotoxicity and nephrotoxicity in rats, Asian Journal of Pharmaceutical Sciences, 11, 326-336.

Abde-Wahhab, M. A.; Hassan, A. M.; Amer, H. A.; Naguib, K. M., 2004. Prevention of fumonisinindnced maternal and developmental toxicity in rats by certain plant extracts, Journal of Applied Toxicology, 24, 469-474.

Alizadeh, A. M.; Mohammadghasemi, F.; Zendehdel, K.; Kamyabi-Moghaddam, Z.; Tavassoli, A.; Amini-Najafi, F.; Khosravi, A., 2015. Apoptotic and proliferative activity of mouse gastric mucosa following oral administration of fumonisin b1, Iran J Basic Med Sci, 18, 8-13.

Anonymous, 2001. Toxicology and carcinogenesis studies of fumonisin b1 (cas no. 116355-83-0) in f344/n rats and b6c3f1 mice (feed studies), 2001. Natl Toxicol Program Tech Rep Ser, 1-352.

Aranda, M.; Perez-Alzola, L.; Ellahuene, M.; Sepulveda, C., 2000. Assessment of in vitro mutagenicity in salmonella and in vivo genotoxicity in mice of the mycotoxin fumonisin b-1, Mutagenesis, 15, 469-471.

Banczerowski-Pelyhe, L.; Detari, L.; Vilagi, I.; Kukorelli, T., 2002. Nerve conduction velocity and spinal reflexes may change in rats after fumonisin b-1 exposure, Acta Biologica Hungarica, 53, 413-422.

Bhandari, N.; Enongene, E. N.; Riley, R. T.; Meredith, F. I.; Sharma, R. P., 2002. Temporal expression of fumonisin b-1-induced tumor necrosis factor-alpha and interferon gamma in mice, Comparative Biochemistry and Physiology C-Toxicology \& Pharmacology, 131, 113-122.

Bhandari, N.; He, Q. R.; Sharma, R. P., 2001. Gender-related differences in subacute fumonisin b-1 hepatotoxicity in balb/c mice, Toxicology, 165, 195-204.

Bondy, G.; Mehta, R.; Caldwell, D.; Coady, L.; Armstrong, C.; Savard, M.; Miller, J. D.; Chomyshyn, E.; Bronson, R.; Zitomer, N.; Riley, R. T., 2012. Effects of long term exposure to the mycotoxin fumonisin b-1 in p53 heterozygous and p53 homozygous transgenic mice, Food and Chemical Toxicology, 50, 3604-3613.

Bondy, G. S.; Armstrong, C. L.; Curran, I. H. A.; Barker, M. G.; Mehta, R., 2000. Retrospective evaluation of serum ornithine carbamyltransferase activity as an index of hepatotoxicity in toxicological studies with rats, Toxicology Letters, 114, 163-171.

Bondy, G. S.; Barker, M. G.; Lombaert, G. A.; Armstrong, C. L.; Fernie, S. M.; Gurofsky, S.; Huzel, V.; Savard, M. E.; Curran, I. H. A., 2000. A comparison of clinical, histopathological and cell-cycle markers in rats receiving the fungal toxins fumonisin $b-1$ or fumonisin $b-1$ by intraperitoneal injection, Food and Chemical Toxicology, 38, 873-886.

Bouhet, S.; Oswald, I. P., 2007. The intestine as a possible target for fumonisin toxicity, Mol Nutr Food Res, 51, 925-931.

Casado, J. M.; Theumer, M.; Masih, D. T.; Chulze, S.; Rubinstein, H. R., 2001. Experimental subchronic mycotoxicoses in mice: Individual and combined effects of dietary exposure to fumonisins and aflatoxin b1, Food Chem Toxicol, 39, 579-586.

Domijan, A. M., 2012. Fumonisin b-1: A neurotoxic mycotoxin, Arhiv Za Higijenu Rada I ToksikologijuArchives of Industrial Hygiene and Toxicology, 63, 531-544. 
Domijan, A. M.; Zeljezic, D.; Milic, M.; Peraica, M., 2007. Fumonisin b-1: Oxidative status and DNA damage in rats, Toxicology, 232, 163-169.

Domijan, A.; Zeljezic, D.; Peraica, M.; Kovacevic, G.; Gregorovic, G.; Krstanac, Z.; Horvatin, K.; Kalafatic, M., 2008. Early toxic effects of fumonisin b1 in rat liver, Hum Exp Toxicol, 27, 895-900.

Dragan, Y. P.; Bidlack, W. R.; Cohen, S. M.; Goldsworthy, T. L.; Hard, G. C.; Howard, P. C.; Riley, R. T.; Voss, K. A., 2001. Implications of apoptosis for toxicity, carcinogenicity, and risk assessment: Fumonisin b-1 as an example, Toxicological Sciences, 61, 6-17.

Dresden Osborne, C.; Pittman Noblet, G.; Enongene, E. N.; Bacon, C. W.; Riley, R. T.; Voss, K. A., 2002. Host resistance to trypanosoma cruzi infection is enhanced in mice fed fusarium verticillioides ( $=$ f. Moniliforme) culture material containing fumonisins, Food Chem Toxicol, 40, 1789-1798.

Ewuola, E. O., 2009. Organ traits and histopathology of rabbits fed varied levels of dietary fumonisin b-1, Journal of Animal Physiology and Animal Nutrition, 93, 726-731.

Ewuola, E. O.; Egbunike, G. N., 2010. Effects of dietary fumonisin b-1 on the onset of puberty, semen quality, fertility rates and testicular morphology in male rabbits, Reproduction, 139, 439-445.

Ewuola, E. O.; Egbunike, G. N., 2010. Gonadal and extra-gonadal sperm reserves and sperm production of pubertal rabbits fed dietary fumonisin b-1, Animal Reproduction Science, 119, 282286.

Ewuola, E. O.; Egbunike, G. N., 2008. Haematological and serum biochemical response of growing rabbit bucks fed dietary fumonisin b-1, African Journal of Biotechnology, 7, 4304-4309.

Ewuola, E. O.; Gbore, F. A.; Ogunlade, J. T.; Bandyopadhyay, R.; Niezen, J.; Egbunike, G. N., 2008. Physiological response of rabbit bucks to dietary fumonisin: Performance, haematology and serum biochemistry, Mycopathologia, 165, 99-104.

Gbore, F. A.; Yinusa, R. I.; Salleh, B., 2010. Evaluation of subchronic dietary fumonisin b-1 on nutrient digestibility and growth performance of rats, African Journal of Biotechnology, 9, 6442-6447.

Gbore, F. A.; Akele, O., 2010. Growth performance, haematology and serum biochemistry of female rabbits (oryctolagus cuniculus) fed dietary fumonisin, Veterinarski Arhiv, 80, 431-443.

Gelderblom, W. C.; Abel, S.; Smuts, C. M.; Marnewick, J.; Marasas, W. F.; Lemmer, E. R.; Ramljak, D., 2001. Fumonisin-induced hepatocarcinogenesis: Mechanisms related to cancer initiation and promotion, Environ Health Perspect, 109 Suppl 2, 291-300.

Gelderblom, W. C. A.; Lebepe-Mazur, S.; Snijman, P. W.; Abel, S.; Swanevelder, S.; Kriek, N. P. J.; Marasas, W. F. O., 2001. Toxicological effects in rats chronically fed low dietary levels of fumonisin b(1), Toxicology, 161, 39-51.

Gelderblom, W. C. A.; Rheeder, J. P.; Leggott, N.; Stockenstrom, S.; Humphreys, J.; Shephard, G. S.; Marasas, W. F. O., 2004. Fumonisin contamination of a corn sample associated with the induction of hepatocarcinogenesis in rats - role of dietary deficiencies, Food and Chemical Toxicology, 42, 471-479.

Gelderblom, W. C.; Galendo, D.; Abel, S.; Swanevelder, S.; Marasas, W. F.; Wild, C. P., 2001. Cancer initiation by fumonisin $b(1)$ in rat liver--role of cell proliferation, Cancer Lett, 169, 127-137.

Gelderblom, W. C.; Marasas, W. F.; Lebepe-Mazur, S.; Swanevelder, S.; Abel, S., 2008. Cancer initiating properties of fumonisin b1 in a short-term rat liver carcinogenesis assay, Toxicology, 250, 89-95.

Gelderblom, W. C.; Seier, J. V.; Snijman, P. W.; Van Schalkwyk, D. J.; Shephard, G. S.; Marasas, W. F., 2001. Toxicity of culture material of fusarium verticillioides strain mrc 826 to nonhuman primates, Environ Health Perspect, 109 Suppl 2, 267-276. 
Grenier, B.; Oswald, I. P., 2011. Mycotoxin co-contamination of food and feed: Meta-analysis of publications describing toxicological interactions, World Mycotoxin Journal, 4, 285-313.

Hahn, I.; Nagl, V.; Schwartz-Zimmermann, H. E.; Varga, E.; Schwarz, C.; Slavik, V.; Reisinger, N.; Malachova, A.; Cirlini, M.; Generotti, S.; Dall'Asta, C.; Krska, R.; Moll, W. D.; Berthiller, F., 2015. Effects of orally administered fumonisin $b-1(\mathrm{fb} 1)$, partially hydrolysed fb1, hydrolysed fb1 and n(1-deoxy-d-fructos-1-yl) fb1 on the sphingolipid metabolism in rats, Food and Chemical Toxicology, 76, 11-18.

Hard, G. C.; Howard, P. C.; Kovatch, R. M.; Bucci, T. J., 2001. Rat kidney pathology induced by chronic exposure to fumonisin b1 includes rare variants of renal tubule tumor, Toxicol Pathol, 29, 379-386.

Hassan, A. M.; Mohamed, S. R.; El-Nekeety, A. A.; Hassan, N. S.; Abdel-Wahhab, M. A., 2010. Aquilegia vulgaris $I$. Extract counteracts oxidative stress and cytotoxicity of fumonisin in rats, Toxicon, 56, 8-18.

He, Q. R.; Kim, H.; Sharma, R. P., 2005. Fumonisin b-1 hepatotoxicity in mice is attenuated by depletion of kupffer cells by gadolinium chloride, Toxicology, 207, 137-147.

Howard, P. C.; Couch, L. H.; Patton, R. E.; Eppley, R. M.; Doerge, D. R.; Churchwell, M. I.; Marques, M. M.; Okerberg, C. V., 2002. Comparison of the toxicity of several fumonisin derivatives in a 28day feeding study with female b6c3f(1) mice, Toxicol Appl Pharmacol, 185, 153-165.

Howard, P. C.; Eppley, R. M.; Stack, M. E.; Warbritton, A.; Voss, K. A.; Lorentzen, R. J.; Kovach, R. M.; Bucci, T. J., 2001. Fumonisin b1 carcinogenicity in a two-year feeding study using f344 rats and b6c3f1 mice, Environ Health Perspect, 109 Suppl 2, 277-282.

Howard, P. C.; Warbritton, A.; Voss, K. A.; Lorentzen, R. J.; Thurman, J. D.; Kovach, R. M.; Bucci, T. J., 2001. Compensatory regeneration as a mechanism for renal tubule carcinogenesis of fumonisin b1 in the f344/n/nctr br rat, Environ Health Perspect, 109 Suppl 2, 309-314.

Johnson, V. J.; Bhandari, N.; Sharma, R. P., 2001. Fumonisin b-1-induced immunosuppresion in balb/c mice is more pronounced in females than in males, Faseb Journal, 15, A566-A566.

Johnson, V. J.; Sharma, R. P., 2001. Gender-dependent immunosuppression following subacute exposure to fumonisin b-1, International Immunopharmacology, 1, 2023-2034.

Khalil, A. A.; Abou-Gabal, A. E.; Abdellatef, A. A.; Khalid, A. E., 2015. Protective role of probiotic lactic acid bacteria against dietary fumonisin b1-induced toxicity and DNA-fragmentation in spraguedawley rats, Prep Biochem Biotechnol, 45, 530-550.

Kim, D. H.; Lee, Y. S.; Lee, Y. M.; Oh, S.; Yun, Y. P.; Yoo, H. S., 2007. Elevation of sphingoid base 1phosphate as a potential contributor to hepatotoxicity in fulmonisin b-1-exposed mice, Archives of Pharmacal Research, 30, 962-969.

Kim, D. H.; Yoo, H. S.; Lee, Y. M.; Kie, J. H.; Jang, S.; Oh, S., 2006. Elevation of sphinganine 1phosphate as a predictive biomarker for fumonisin exposure and toxicity in mice, J Toxicol Environ Health A, 69, 2071-2082.

Kodell, R. L.; Turturro, A., 2004. Risk-assessment implications of mechanistic model's prediction of low-dose nonlinearity of liver tumor risk for mice fed fumonisin $b(1)$, Nonlinearity Biol Toxicol Med, 2, 35-43.

Kouadio, J. H.; Moukha, S.; Brou, K.; Gnakri, D., 2013. Lipid metabolism disorders, lymphocytes cells death, and renal toxicity induced by very low levels of deoxynivalenol and fumonisin b1 alone or in combination following 7 days oral administration to mice, Toxicol Int, 20, 218-223.

Lalles, J. P.; Lessard, M.; Oswald, I. P.; David, J. C., 2010. Consumption of fumonisin b-1 for 9 days induces stress proteins along the gastrointestinal tract of pigs, Toxicon, 55, 244-249. 
Lemmer, E. R.; Vessey, C. J.; Gelderblom, W. C. A.; Shephard, E. G.; Van Schalkwyk, D. J.; Van Wijk, R. A.; Marasas, W. F. O.; Kirsch, R. E.; Hall, P. D., 2004. Fumonisin b-1-induced hepatocellular and cholangiocellular tumors in male fischer 344 rats: Potentiating effects of 2-acetylaminofluorene on oval cell proliferation and neoplastic development in a discontinued feeding study, Carcinogenesis, 25, 1257-1264.

Lessard, M.; Boudry, G.; Seve, B.; Oswald, I. P.; Lalles, J. P., 2009. Intestinal physiology and peptidase activity in male pigs are modulated by consumption of corn culture extracts containing fumonisins, J Nutr, 139, 1303-1307.

Li, W.; Riley, R. T.; Voss, K. A.; Norred, W. P., 2000. Role of proliferation in the toxicity of fumonisin b-1: Enhanced hepatotoxic response in the partially hepatectomized rat, Journal of Toxicology and Environmental Health-Part A, 60, 441-457.

Liu, H. J.; Lu, Y.; Haynes, J. S.; Cunnick, J. E.; Murphy, P.; Hendrich, S., 2001. Reaction of fumonisin with glucose prevents promotion of hepatocarcinogenesis in female f344/n rats while maintaining normal hepatic sphinganine/sphingosine ratios, Journal of Agricultural and Food Chemistry, 49, 4113-4121.

Liu, Y.; Tang, L.; Lian, M.; McKean, C.; Wu, H.; Liu, H.; Theodorakis, C. W.; Kendall, R. J.; Wang, J., 2003. Comparative acute and combinative toxicity of aflatoxin b1 and fumonisin b1 in animals and human cells, Toxicological Sciences, 72, 188-188.

Marin, D. E.; Taranu, I.; Pascale, F.; Lionide, A.; Burlacu, R.; Bailly, J. D.; Oswald, I. P., 2006. Sexrelated differences in the immune response of weanling piglets exposed to low doses of fumonisin extract, $\mathrm{Br}$ J Nutr, 95, 1185-1192.

Mazumder, P. M.; Sasmal, A., 2007. Comparative assessment of the mycotoxins citrinin and fumonisins on the liver function and metabolism in mice, National Academy Science Letters-India, $30,177-181$.

Moon, W. S.; Kim, J. H.; Kang, M. J.; Lee, D. G., 2000. Early ultrastructural changes of apoptosis induced by fumonisin b1 in rat liver, Yonsei Med J, 41, 195-204.

Morsy, F. A.; Badawy, M. A.; Farrag, A. R. H., 2006. The protective effect of melatonin against fumonisin-induced renal damage in rats, International Journal of Toxicology, 25, 523-529.

Orsi, R. B.; Dilkin, P.; Xavier, J. G.; Aquino, S.; Rocha, L. O.; Correa, B., 2009. Acute toxicity of a single gavage dose of fumonisin b-1 in rabbits, Chemico-Biological Interactions, 179, 351-355.

Orsi, R. B.; Oliveira, C. A. F.; Dilkin, P.; Xavier, J. G.; Direito, G. M.; Correa, B., 2007. Effects of oral administration of aflatoxin b-1 and fumonisin b-1 in rabbits (oryctolagus cuniculus), ChemicoBiological Interactions, 170, 201-208.

Osborne, C. D.; Noblet, G. P.; Enongene, E. N.; Bacon, C. W.; Riley, R. T.; Voss, K. A., 2002. Host resistance to trypanosoma cruzi infection is enhanced in mice fed fusarium verticillioides $(=\mathrm{f}$ moniliforme) culture material containing fumonisins, Food and Chemical Toxicology, 40, 17891798.

Osuchowski, M. F.; He, Q.; Sharma, R. P., 2003. Fumonisin b-1 toxicity in the brain during coexisting lipopolysaccharide-related endotoxemia in balb/c mice, Toxicological Sciences, 72, 252-253.

Owen, J. R.; Plattner, R. D.; Rottinghaus, G. E.; Riley, R. T.; Tackett, R. L.; Voss, K. A., 2003. Subchronic toxicity in rats fed culture materials of fumonisin-producing and moniliformin-producing fungal isolates, Toxicological Sciences, 72, 253-253.

Peraica, M.; Ljubanovic, D.; Zeljezic, D.; Domijan, A. M., 2008. The effect of a single dose of fumonisin b-1 on rat kidney, Croatica Chemica Acta, 81, 119-124.

Peraica, M.; Ljubanovic, D.; Zeljezic, D.; Domijan, A. M., 2007. The effect of single dose of fumonisin b-1 on oxidative stress, sphingolipid metabolism and DNA damage in rat kidney, Toxicology Letters, 172, S53-S53. 
Piva, A.; Casadei, G.; Pagliuca, G.; Cabassi, E.; Galvano, F.; Solfrizzo, M.; Riley, R. T.; Diaz, D. E., 2005. Activated carbon does not prevent the toxicity of culture material containing fumonisin $b-1$ when fed to weanling piglets, Journal of Animal Science, 83, 1939-1947.

Poersch, A. B.; Trombetta, F.; Souto, N. S.; Lima, C. D.; Braga, A. C. M.; Dobrachinski, F.; Ribeiro, L. R.; Soares, F. A. A.; Fighera, M. R.; Royes, L. F. F.; Oliveira, M. S.; Furian, A. F., 2015. Fumonisin b1 facilitates seizures induced by pentylenetetrazol in mice, Neurotoxicology and Teratology, 51, 61-67.

Posa, R.; Magyar, T.; Stoev, S. D.; Glavits, R.; Donko, T.; Repa, I.; Kovacs, M., 2013. Use of computed tomography and histopathologic review for lung lesions produced by the interaction between mycoplasma hyopneumoniae and fumonisin mycotoxins in pigs, Vet Pathol, 50, 971-979.

Pozzi, C. R.; Correa, B.; Xavier, J. G.; Direito, G. M.; Orsi, R. B.; Matarazzo, S. V., 2001. Effects of prolonged oral administration of fumonisin b1 and aflatoxin b1 in rats, Mycopathologia, 151, 21-27.

Qian, G.; Tang, L.; Lin, S.; Xue, K. S.; Mitchell, N. J.; Su, J.; Gelderblom, W. C.; Riley, R. T.; Phillips, T. D.; Wang, J. S., 2016. Sequential dietary exposure to aflatoxin b1 and fumonisin b1 in f344 rats increases liver preneoplastic changes indicative of a synergistic interaction, Food Chem Toxicol, 95, 188-195.

Riley, R. T.; Voss, K. A., 2006. Differential sensitivity of rat kidney and liver to fumonisin toxicity: Organ-specific differences in toxin accumulation and sphingoid base metabolism, Toxicological Sciences, 92, 335-345.

Rossi, F.; Morlacchini, M.; Fusconi, G.; Pietri, A.; Piva, G., 2011. Effect of insertion of bt gene in corn and different fumonisin content on growth performance of weaned piglets, Italian Journal of Animal Science, 10, 95-100.

Segvic, M.; Pepeljnjak, S., 2003. Distribution and fumonisin b-1 production capacity of fusarium moniliforme isolated from corn in croatia, Periodicum Biologorum, 105, 275-279.

Sharma, R. P.; Bhandari, N.; Tsunoda, M.; Riley, R. T.; Voss, K. A., 2000. Fumonisin hepatotoxicity is reduced in mice carrying the human tumour necrosis factor alpha transgene, Arch Toxicol, 74, 238248.

Sharma, R. P.; Bhandari, N.; Tsunoda, M.; Riley, R. T.; Voss, K. A.; Meredith, F. I., 2000. Fumonisin toxicity in a transgenic mouse model lacking the mdr1a/1b p-glycoprotein genes, Environ Toxicol Pharmacol, 8, 173-182.

Sharma, R. P.; Bhandari, N.; Riley, R. T.; Voss, K. A.; Meredith, F. I., 2000. Tolerance to fumonisin toxicity in a mouse strain lacking the p75 tumor necrosis factor receptor, Toxicology, 143, 183-194.

Sharma, R. P.; He, Q. R.; Riley, R. T., 2005. Lupus-prone nzbwf1/j mice, defective in cytokine signaling, are resistant to fumonisin hepatotoxicity despite accumulation of liver sphinganine, Toxicology, 216, 59-71.

Sousa, F. C.; Schamber, C. R.; Amorin, S. S. S.; Natali, M. R. M., 2014. Effect of fumonisin-containing diet on the myenteric plexus of the jejunum in rats, Autonomic Neuroscience-Basic \& Clinical, 185, 93-99.

Spotti, M.; Maas, R. F. M.; de Nijs, C. M.; Fink-Gremmels, J., 2000. Effect of fumonisin b-1 on rat hepatic p450 system, Environmental Toxicology and Pharmacology, 8, 197-204.

Szabo, A.; Szabo-Fodor, J.; Febel, H.; Romvari, R.; Kovacs, M., 2014. Individual and combined haematotoxic effects of fumonisin b-1 and t-2 mycotoxins in rabbits, Food and Chemical Toxicology, 72, 257-264.

Theumer, M. G.; Canepa, M. C.; Lopez, A. G.; Mary, V. S.; Dambolena, J. S.; Rubinstein, H. R., 2010. Subchronic mycotoxicoses in wistar rats: Assessment of the in vivo and in vitro genotoxicity induced by fumonisins and aflatoxin b-1, and oxidative stress biomarkers status, Toxicology, 268, 104-110. 
Theumer, M. G.; Lopez, A. G.; Masih, D. T.; Chulze, S. N.; Rubinstein, H. R., 2002. Immunobiological effects of fumonisin b1 in experimental subchronic mycotoxicoses in rats, Clin Diagn Lab Immunol, 9, 149-155.

Voss, K. A.; Howard, P. C.; Riley, R. T.; Sharma, R. P.; Bucci, T. J.; Lorentzen, R. J., 2002. Carcinogenicity and mechanism of action of fumonisin b-1: A mycotoxin produced by fusarium moniliforme (= f-verticillioides), Cancer Detection and Prevention, 26, 1-9.

Voss, K. A.; Riley, R. T.; Gelineau-van Waes, J., 2014. Fumonisin b-1 induced neural tube defects were not increased in $\mathrm{Im} / \mathrm{bc}$ mice fed folate-deficient diet, Molecular Nutrition \& Food Research, $58,1190-1198$.

Voss, K. A.; Riley, R. T.; Norred, W. P.; Bacon, C. W.; Meredith, F. I.; Howard, P. C.; Plattner, R. D.; Collins, T. F.; Hansen, D. K.; Porter, J. K., 2001. An overview of rodent toxicities: Liver and kidney effects of fumonisins and fusarium moniliforme, Environ Health Perspect, 109 Suppl 2, 259-266.

Voss, K. A.; Riley, R. T.; Snook, M. E.; Gelineau-van Waes, J., 2009. Reproductive and sphingolipid metabolic effects of fumonisin b-1 and its alkaline hydrolysis product in $1 \mathrm{~m} / \mathrm{bc}$ mice: Hydrolyzed fumonisin b-1 did not cause neural tube defects, Toxicological Sciences, 112, 459-467.

Waes, J. G.; Starr, L.; Maddox, J.; Aleman, F.; Voss, K. A.; Wilberding, J.; Riley, R. T., 2005. Maternal fumonisin exposure and risk for neural tube defects: Mechanisms in an in vivo mouse model, Birth Defects Research Part a-Clinical and Molecular Teratology, 73, 487-497.

WHO (World Health Organization), 2011. Evaluation of certain food additives and contaminants, 2011. World Health Organ Tech Rep Ser, 1-136.

Relevant reference not retrieved in the literature searches for Area 4 IN VIVO TOXICITY:

Voss, K. A.; Gelineau-van Waes, J. B.; Riley, R. T., 2006. Fumonisins: Current research trends in developmental toxicology, Mycotoxin Res, 22, 61-69. 


\section{AREA 5 IN VITRO TOXICITY}

Reference list with all relevant references identified for AREA 5: Data on toxicity in vitro published in English since year 2000.

Relevant references retrieved in the literature searches for Area 5 IN VITRO TOXICITY:

Abdel Nour, A. M.; Ringot, D.; Gueant, J. L.; Chango, A., 2007. Folate receptor and human reduced folate carrier expression in hepg2 cell line exposed to fumonisin b1 and folate deficiency, Carcinogenesis, 28, 2291-2297.

Abou-Karam, M.; Abbas, H. K.; Shier, W. T., 2004. N-fatty acylation of hydrolyzed fumonisin b(1), but not of intact fumonisin $b(1)$, strongly enhances in vitro mammalian toxicity, Journal of ToxicologyToxin Reviews, 23, 123-151.

Alassane-Kpembi, I.; Schatzmayr, G.; Taranu, I.; Marin, D.; Puel, O.; Oswald, I. P., 2016. Mycotoxins co-contamination: Methodological aspects and biological relevance of combined toxicity studies, Crit Rev Food Sci Nutr, 0.

Aranda, M.; Perez-Alzola, L.; Ellahuene, M.; Sepulveda, C., 2000. Assessment of in vitro mutagenicity in salmonella and in vivo genotoxicity in mice of the mycotoxin fumonisin b-1, Mutagenesis, 15 , 469-471.

Baines, D.; Erb, S.; Lowe, R.; Turkington, K.; Sabau, E.; Kuldau, G.; Juba, J.; Masson, L.; Mazza, A.; Roberts, R., 2011. A prebiotic, celmanax, decreases escherichia coli 0157:H7 colonization of bovine cells and feed-associated cytotoxicity in vitro, BMC Res Notes, 4, 110.

Banczerowski-Pelyhe, I.; Vilagi, I.; Detari, L.; Doczi, J.; Kovacs, F.; Kukorelli, T., 2002. In vivo and in vitro electrophysiological monitoring of rat neocortical activity after dietary fumonisin exposure, Mycopathologia, 153, 149-156.

Basso, K.; Gomes, F.; Bracarense, A. P. L., 2013. Deoxynivanelol and fumonisin, alone or in combination, induce changes on intestinal junction complexes and in e- cadherin expression, Toxins, 5, 2341-2352.

Behm, C.; Follmann, W.; Degen, G. H., 2012. Cytotoxic potency of mycotoxins in cultures of v79 lung fibroblast cells, J Toxicol Environ Health A, 75, 1226-1231.

Bernabucci, U.; Colavecchia, L.; Danieli, P. P.; Basirico, L.; Lacetera, N.; Nardone, A.; Ronchi, B., 2011. Aflatoxin $b-1$ and fumonisin $b-1$ affect the oxidative status of bovine peripheral blood mononuclear cells, Toxicology in Vitro, 25, 684-691.

Bouhet, S.; Hourcade, E.; Loiseau, N.; Fikry, A.; Martinez, S.; Roselli, M.; Galtier, P.; Mengheri, E.; Oswald, I. P., 2004. The mycotoxin fumonisin b-1 alters the proliferation and the barrier function of porcine intestinal epithelial cells, Toxicological Sciences, 77, 165-171.

Bouhet, S.; Le Dorze, E.; Peres, S.; Fairbrother, J. M.; Oswald, I. P., 2006. Mycotoxin fumonisin b-1 selectively down-regulates the basal il-8 expression in pig intestine: In vivo and in vitro studies, Food and Chemical Toxicology, 44, 1768-1773.

Bouhet, S.; Oswald, I. P., 2005. The effects of mycotoxins, fungal food contaminants, on the intestinal epithelial cell-derived innate immune response, Veterinary Immunology and Immunopathology, 108, 199-209.

Caloni, F.; Albonico, M.; Schutz, L.; Pizzo, F.; Spicer, L. J., 2014. Differential effects of fumonisin b1 and zearalenone metabolites on estradiol and progesterone production in cultured bovine granulosa cells, Toxicology Letters, 229, S57-S57. 
Caloni, F.; Spotti, M.; Pompa, G.; Zucco, F.; Stammati, A.; De Angelis, I., 2002. Evaluation of fumonisin b-1 and its metabolites absorption and toxicity on intestinal cells line caco-2, Toxicon, 40, 1181-1188.

Caloni, F.; Stammati, A. L.; Raimondi, F.; De Angelis, I., 2005. In vitro study with caco-2 cells on fumonisin b-1: Aminopentol intestinal passage and role of p-glycoprotein, Veterinary Research Communications, 29, 285-287.

Cetin, Y.; Bullerman, L. B., 2005. Cytotoxicity of fusarium mycotoxins to mammalian cell cultures as determined by the mtt bioassay, Food Chem Toxicol, 43, 755-764.

Cheli, F.; Giromini, C.; Baldi, A., 2015. Mycotoxin mechanisms of action and health impact: 'In vitro' or 'in vivo' tests, that is the question, World Mycotoxin Journal, 8, 573-589.

Chen, X.; Murdoch, R.; Shafer, D. J.; Ajuwon, K. M.; Applegate, T. J., 2016. Cytotoxicity of various chemicals and mycotoxins in fresh primary duck embryonic fibroblasts: A comparison to hepg2 cells, J Appl Toxicol.

Chuturgoon, A.; Phulukdaree, A.; Moodley, D., 2014. Fumonisin b-1 induces global DNA hypomethylation and modulates cytochrome p-450 1b1 (cyp1b1) by repressing mir-27b in hepg2 cells, Toxicology Letters, 229, S147-S147.

Chuturgoon, A.; Phulukdaree, A.; Moodley, D., 2014. Fumonisin b-1 induces global DNA hypomethylation in hepg2 cells - an alternative mechanism of action, Toxicology, 315, 65-69.

Chuturgoon, A. A.; Phulukdaree, A.; Moodley, D., 2015. Fumonisin b-1 inhibits apoptosis in hepg2 cells by inducing birc-8/ilp-2, Toxicology Letters, 235, 67-74.

Chuturgoon, A. A.; Phulukdaree, A.; Moodley, D., 2014. Fumonisin b-1 modulates expression of human cytochrome p450 1 b1 in human hepatoma (hepg2) cells by repressing mir-27b, Toxicology Letters, 227, 50-55.

Clarke, R.; Connolly, L.; Frizzell, C.; Elliott, C. T., 2014. Cytotoxic assessment of the regulated, coexisting mycotoxins aflatoxin $b 1$, fumonisin $b 1$ and ochratoxin, in single, binary and tertiary mixtures, Toxicon, 90, 70-81.

Cortinovis, C.; Caloni, F.; Schreiber, N. B.; Spicer, L. J., 2014. Effects of fumonisin b-1 alone and combined with deoxynivalenol or zearalenone on porcine granulosa cell proliferation and steroid production, Theriogenology, 81, 1042-1049.

Cortinovis, C.; Caloni, F.; Schreiber, N.; Spicer, L. J., 2013. In vitro effects of fumonisin b-1 on porcine granulosa cell steroidogenesis and gene expression, Toxicology Letters, 221, S150-S150.

Creppy, E. E.; Chiarappa, P.; Baudrimont, I.; Borracci, P.; Moukha, S.; Carratu, M. R., 2004. Synergistic effects of fumonisin b1 and ochratoxin a: Are in vitro cytotoxicity data predictive of in vivo acute toxicity?, Toxicology, 201, 115-123.

De Angelis, I.; Frigge, G.; Raimondi, F.; Stammati, A.; Zucco, F.; Caloni, F., 2005. Absorption of fumonisin b-1 and aminopentol on an in vitro model of intestinal epithelium; the role of $\mathrm{p}$ glycoprotein, Toxicon, 45, 285-291.

De Lorenzi, L.; De Giovanni, A.; Malagutti, L.; Molteni, L.; Sciaraffia, F.; Tamburini, A.; Zannotti, M., 2005. Genotoxic activity of the fumonisin b1 mycotoxin in cultures of bovine lymphocytes, Italian Journal of Animal Science, 4, 395-402.

De Ruyck, K.; De Boevre, M.; Huybrechts, I.; De Saeger, S., 2015. Dietary mycotoxins, co-exposure, and carcinogenesis in humans: Short review, Mutat Res Rev Mutat Res, 766, 32-41.

Demirel, G.; Alpertunga, B.; Ozden, S., 2015. Role of fumonisin b1 on DNA methylation changes in rat kidney and liver cells, Pharm Biol, 53, 1302-1310.

Dombrink-Kurtzman, M. A., 2003. Fumonisin and beauvericin induce apoptosis in turkey peripheral blood lymphocytes, Mycopathologia, 156, 357-364. 
Dombrink-Kurtzman, M. A.; Gomez-Flores, R.; Weber, R. J., 2000. Activation of rat splenic macrophage and lymphocyte functions by fumonisin b-1, Immunopharmacology, 49, 401-409.

Domijan, A. M.; Abramov, A. Y., 2011. Fumonisin b-1 inhibits mitochondrial respiration and deregulates calcium homeostasis-implication to mechanism of cell toxicity, International Journal of Biochemistry \& Cell Biology, 43, 897-904.

Domijan, A. M.; Gajski, G.; Jovanovic, I. N.; Genic, M.; Garaj-Vrhovac, V., 2015. In vitro genotoxicity of mycotoxins ochratoxin a and fumonisin b-1 could be prevented by sodium copper chlorophyllin implication to their genotoxic mechanism, Food Chemistry, 170, 455-462.

Dresden-Osborne, C.; Noblet, G. P., 2002. Fumonisin b-1 affects viability and alters nitric oxide production of a murine macrophage cell line, International Immunopharmacology, 2, 1087-1093.

Ehrlich, V.; Darroudi, F.; Uhl, M.; Steinkellner, H.; Zsivkovits, M.; Knasmueller, S., 2002. Fumonisin b1 is genotoxic in human derived hepatoma (hepg2) cells, Mutagenesis, 17, 257-260.

Fernandez-Blanco, C.; Frizzell, C.; Shannon, M.; Ruiz, M. J.; Connolly, L., 2016. An in vitro investigation on the cytotoxic and nuclear receptor transcriptional activity of the mycotoxins fumonisin b1 and beauvericin, Toxicol Lett, 257, 1-10.

Ferrante, M. C.; Meli, R.; Raso, G. M.; Esposito, E.; Severino, L.; Di Carlo, G.; Lucisano, A., 2002. Effect of fumonisin b-1 on structure and function of macrophage plasma membrane, Toxicology Letters, 129, 181-187.

Fodor, J.; Meyer, K.; Gottschalk, C.; Mamet, R.; Kametler, L.; Bauer, J.; Horn, P.; Kovacs, F.; Kovacs, M., 2007. In vitro microbial metabolism of fumonisin b-1, Food Additives and Contaminants, 24, 416-420.

Fornelli, F.; Minervini, F.; Mule, G., 2004. Cytotoxicity induced by nivalenol, deoxynivalenol, and fumonisin b, in the sf-9 insect cell line, In Vitro Cellular \& Developmental Biology-Animal, 40, 166171.

Galvano, F.; Campisi, A.; Russo, A.; Galvano, G.; Palumbo, M.; Renis, M.; Barcellona, M. L.; PerezPolo, J. R.; Vanella, A., 2002. DNA damage in astrocytes exposed to fumonisin b-1, Neurochemical Research, 27, 345-351.

Galvano, F.; Russo, A.; Cardile, V.; Galvano, G.; Vanella, A.; Renis, M., 2002. DNA damage in human fibroblasts exposed to fumonisin b-1, Food and Chemical Toxicology, 40, 25-31.

Garbetta, A.; Debellis, L.; De Girolamo, A.; Schena, R.; Visconti, A.; Minervini, F., 2015. Dosedependent lipid peroxidation induction on ex vivo intestine tracts exposed to chyme samples from fumonisins contaminated corn samples, Toxicol In Vitro, 29, 1140-1145.

Gopee, N. V.; He, Q. R.; Sharma, R. P., 2003. Fumonisin b-1-induced apoptosis is associated with delayed inhibition of protein kinase $c$, nuclear factor-kappa $\mathrm{b}$ and tumor necrosis factor alpha in llcpk1 cells, Chemico-Biological Interactions, 146, 131-145.

Gopee, N. V.; Sharma, R. P., 2004. Selective and transient activation of protein kinase c alpha by fumonisin b-1, a ceramide synthase inhibitor mycotoxin, in cultured porcine renal cells, Life Sciences, 74, 1541-1559.

Gopee, N. V.; Sharma, R. P., 2003. Sphingoid bases and their phosphates: Transient activation and delayed repression of protein kinase $\mathrm{c}$ isoforms and their possible involvement in fumonisin $\mathrm{b}-1$ cytotoxicity, Toxicology, 187, 239-250.

Grenier, B.; Applegate, T. J., 2013. Modulation of intestinal functions following mycotoxin ingestion: Meta-analysis of published experiments in animals, Toxins, 5, 396-430.

Gutleb, A. C.; Morrison, E.; Murk, A. J., 2002. Cytotoxicity assays for mycotoxins produced by fusarium strains: A review, Environmental Toxicology and Pharmacology, 11, 309-320. 
Harrer, H.; Laviad, E. L.; Humpf, H. U.; Futerman, A. H., 2013. Identification of n-acyl-fumonisin b1 as new cytotoxic metabolites of fumonisin mycotoxins, Mol Nutr Food Res, 57, 516-522.

He, Q. R.; Riley, R. T.; Sharma, R. P., 2002. Pharmacological antagonism of fumonisin b-1 cytotoxicity in porcine renal epithelial cells (Ilc-pk1): A model for reducing fumonisin-induced nephrotoxicity in vivo, Pharmacology \& Toxicology, 90, 268-277.

Hecker, D. C.; Schrenk, D., 2007. Cytotoxic and apoptotic effects of fumonisin b, in cultured rat hepatocytes, Toxicology Letters, 172, S45-S46.

Jackson, L. S.; Jablonski, J.; Bullerman, L. B.; Bianchini, A.; Hanna, M. A.; Voss, K. A.; Hollub, A. D.; Ryu, D., 2011. Reduction of fumonisin b-1 in corn grits by twin-screw extrusion, Journal of Food Science, 76, T150-T155.

Jebali, A.; Ardakani, S. A. Y.; Shandadi, H.; Zadeh, M. H. B.; Hekmatimoghaddam, S., 2015. Modification of nanocellulose by poly-lysine can inhibit the effect of fumonisin b1 on mouse liver cells, Colloids and Surfaces B-Biointerfaces, 126, 437-443.

Johnson, V. J.; He, Q. R.; Kim, S. H.; Kanti, A.; Sharma, R. P., 2003. Increased susceptibility of renal epithelial cells to tnf alpha-induced apoptosis following treatment with fumonisin b-1, ChemicoBiological Interactions, 145, 297-309.

Jones, C.; Ciacci-Zanella, J. R.; Zhang, Y. G.; Henderson, G.; Dickman, M., 2001. Analysis of fumonisin b-1-induced apoptosis, Environmental Health Perspectives, 109, 315-320.

Karuna, R.; Sashidhar, R. B., 2008. The mycotoxin fumonisin b-1 inhibits eukaryotic protein synthesis: In vitro and in vivo studies, Mycopathologia, 165, 37-49.

Keck, B. B.; Bodine, A. B., 2006. The effects of fumonisin b-1 on viability and mitogenic response of avian immune cells, Poultry Science, 85, 1020-1024.

Kim, B.; Ejaz, S.; Chekarova, I.; Sukura, A.; Ashraf, M.; Lim, C. W., 2008. Cytotoxicity of fumonisin $\mathrm{b}(1)$ in spheroid and monolayer cultures of rat hepatocytes, Drug Chem Toxicol, 31, 339-352.

Kim, M. S.; Lee, D. Y.; Wang, T.; Schroeder, J. J., 2001. Fumonisin b-1 induces apoptosis in llc-pk1 renal epithelial cells via a sphinganine- and calmodulin-dependent pathway, Toxicology and Applied Pharmacology, 176, 118-126.

Klaric, M. S.; Pepeljnjak, S.; Rumora, L.; Ljubanovic, D., 2006. Cytotoxic and apoptotic effects of fumonisin b-1, beauvericin and ochratoxin a on porcine kidney pk-15 cells, Toxicology Letters, 164, S59-S60.

Klaric, M. S.; Pepeljnjak, S.; Rozgaj, R., 2008. Genotoxicity of fumonisin b(1), beauvericin and ochratoxin a in porcine kidney pk15 cells: Effects of individual and combined treatment, Croatica Chemica Acta, 81, 139-146.

Klaric, M. S.; Pepeljnjak, S.; Domijan, A. M.; Petrik, J., 2007. Lipid peroxidation and glutathione levels in porcine kidney pk15 cells after individual and combined treatment with fumonisin b-1, beauvericin and ochratoxin a, Basic \& Clinical Pharmacology \& Toxicology, 100, 157-164.

Klaric, M. S.; Rumora, L.; Ljubanovic, D.; Pepeljnjak, S., 2008. Cytotoxicity and apoptosis induced by fumonisin $b(1)$, beauvericin and ochratoxin a in porcine kidney pk15 cells: Effects of individual and combined treatment, Arch Toxicol, 82, 247-255.

Kouadio, J. H.; Dano, S. D.; Moukha, S.; Mobio, T. A.; Creppy, E. E., 2007. Effects of combinations of fusarium mycotoxins on the inhibition of macromolecular synthesis, malondialdehyde levels, DNA methylation and fragmentation, and viability in caco-2 cells, Toxicon, 49, 306-317.

Kouadio, J. H.; Mobio, T. A.; Baudrimont, I.; Moukha, S.; Dano, S. D.; Creppy, E. E., 2005. Comparative study of cytotoxicity and oxidative stress induced by deoxynivalenol, zearalenone or fumonisin b1 in human intestinal cell line caco-2, Toxicology, 213, 56-65. 
Kwon, O. S.; Slikker, W.; Davies, D. L., 2000. Biochemical and morphological effects of fumonisin b-1 on primary cultures of rat cerebrum, Neurotoxicology and Teratology, 22, 565-572.

Lee, Y. M.; Min, J. K.; Kihara, A.; Oh, S. K.; Lee, E. Y.; Yoo, H. S.; Choi, C. H.; Kim, T. J.; Igarashi, Y., 2004. Accumulation of dihydrosphingosine 1-phosphate in mammalian cells induces apoptosis and functions as a biomarker for fumonisin b-1 cytotoxicity, Chemistry and Physics of Lipids, 130, 5050.

Lei, M. Y.; Zhang, N. Y.; Qi, D. S., 2013. In vitro investigation of individual and combined cytotoxic effects of aflatoxin b1 and other selected mycotoxins on the cell line porcine kidney 15, Experimental and Toxicologic Pathology, 65, 1149-1157.

Lemke, S. L.; Ottinger, S. E.; Ake, C. A.; Mayura, K.; McDonald, T.; Phillips, T. D., 2000. Deamination of fumonisin b-1 and biological assessment of reaction-product toxicity in vitro, Abstracts of Papers of the American Chemical Society, 219, U29-U29.

Lerda, D.; Bistoni, B.; Peralta, N.; Ychari, S.; Vazquez, M.; Bosio, G., 2005. Fumonisins in foods from cordoba (argentina), presence, and genotoxicity, Food and Chemical Toxicology, 43, 691-698.

Liu, B. H.; Yu, F. Y.; Chan, M. H.; Yang, Y. L., 2002. The effects of mycotoxins, fumonisin b-1 and aflatoxin b-1, on primary swine alveolar macrophages, Toxicology and Applied Pharmacology, 180, 197-204.

Loiseau, N.; Debrauwer, L.; Sambou, T.; Bouhet, S.; Miller, J. D.; Martin, P. G.; Viadere, J. L.; Pinton, P.; Puel, O.; Pineau, T.; Tulliez, J.; Galtier, P.; Oswald, I. P., 2007. Fumonisin b-1 exposure and its selective effect on porcine jejunal segment: Sphingolipids, glycolipids and trans-epithelial passage disturbance, Biochemical Pharmacology, 74, 144-152.

Luongo, D.; De Luna, R.; Russo, R.; Severino, L., 2008. Effects of four fusarium toxins (fumonisin $b(1)$, alpha-zearalenol, nivalenol and deoxynivalenol) on porcine whole-blood cellular proliferation, Toxicon, 52, 156-162.

Luongo, D.; Severino, L.; Bergamo, P.; De Luna, R.; Lucisano, A.; Rossi, M., 2006. Interactive effects of fumonisin b1 and alpha-zearalenol on proliferation and cytokine expression in jurkat $t$ cells, Toxicol In Vitro, 20, 1403-1410.

Maenetje, P. W.; de Villiers, N.; Dutton, M. F., 2008. The use of isolated human lymphocytes in mycotoxin cytotoxicity testing, Int J Mol Sci, 9, 1515-1526.

Mahmoodi, M.; Alizadeh, A. M.; Sohanaki, H.; Rezaei, N.; Amini-Najafi, F.; Khosravi, A. R.; Hosseini, S. K.; Safari, Z.; Hydarnasab, D.; Khori, V., 2012. Impact of fumonisin b1 on the production of inflammatory cytokines by gastric and colon cell lines, Iran J Allergy Asthma Immunol, 11, 165173.

Makun, H. A.; Dutton, M. F.; Mwanza, M.; Njobeh, P. B., 2011. Mycotoxins profiling of the culture material of fusarium verticillioides (sacc.) nirenberg culture (cabi-imi 392668) isolated from rice in niger state, nigeria and its cytotoxic effects on human lymphocytes comparatively to those of some mycotoxin standards, African Journal of Biotechnology, 10, 12031-12038.

Marin, D. E.; Gouze, M. E.; Taranu, I.; Oswald, I. P., 2007. Fumonisin b1 alters cell cycle progression and interleukin-2 synthesis in swine peripheral blood mononuclear cells, Mol Nutr Food Res, 51, 1406-1412.

Mary, V. S.; Theumer, M. G.; Arias, S. L.; Rubinstein, H. R., 2012. Reactive oxygen species sources and biomolecular oxidative damage induced by aflatoxin b1 and fumonisin b1 in rat spleen mononuclear cells, Toxicology, 302, 299-307.

McKean, C.; Tang, L.; Tang, M.; Billam, M.; Wang, Z.; Theodorakis, C. W.; Kendall, R. J.; Wang, J. S., 2006. Comparative acute and combinative toxicity of aflatoxin b-1 and fumonisin b- 1 in animals and human cells, Food and Chemical Toxicology, 44, 868-876. 
Meca, G.; Fernandez-Franzon, M.; Ritieni, A.; Font, G.; Ruiz, M. J.; Manes, J., 2010. Formation of fumonisin b-1-glucose reaction product, in vitro cytotoxicity, and lipid peroxidation on kidney cells, Journal of Agricultural and Food Chemistry, 58, 1359-1365.

Meca, G.; Ruiz, M. J.; Fernandez-Franzon, M.; Ritieni, A.; Manes, J., 2010. Isolation, purification, Ic$\mathrm{ms} / \mathrm{ms}$ characterization and reactive oxygen species induced by fumonisin b-1 in vero cells, Food and Chemical Toxicology, 48, 2891-2897.

Meky, F. A.; Hardie, L. J.; Evans, S. W.; Wild, C. P., 2001. Deoxynivalenol-induced immunomodulation of human lymphocyte proliferation and cytokine production, Food Chem Toxicol, 39, 827-836.

Meli, R.; Ferrante, M. C.; Raso, G. M.; Cavaliere, M.; Di Carlo, R.; Lucisano, A., 2000. Effect of fumonisin b- 1 on inducible nitric oxide synthase and cyclooxygenase-2 in Ips-stimulated j774a.1 cells, Life Sciences, 67, 2845-2853.

Minervini, F.; Debellis, L.; Garbetta, A.; De Girolamo, A.; Schena, R.; Portincasa, P.; Visconti, A., 2014. Influence on functional parameters of intestinal tract induced by short-term exposure to fumonisins contaminated corn chyme samples, Food Chem Toxicol, 66, 166-172.

Minervini, F.; Fornelli, F.; Flynn, K. M., 2004. Toxicity and apoptosis induced by the mycotoxins nivalenol, deoxynivalenol and fumonisin b-1 in a human erythroleukemia cell line, Toxicology in Vitro, 18, 21-28.

Minervini, F.; Garbetta, A.; D'Antuono, I.; Cardinali, A.; Martino, N. A.; Debellis, L.; Visconti, A., 2014. Toxic mechanisms induced by fumonisin b-1 mycotoxin on human intestinal cell line, Archives of Environmental Contamination and Toxicology, 67, 115-123.

Minervini, F.; Lacalandra, G. M.; Filannino, A.; Garbetta, A.; Nicassio, M.; Dell'aquila, M. E.; Visconti, A., 2010. Toxic effects induced by mycotoxin fumonisin b1 on equine spermatozoa: Assessment of viability, sperm chromatin structure stability, ros production and motility, Toxicol In Vitro, 24, 2072-2078.

Mobio, T. A.; Baudrimont, I.; Sanni, A.; Shier, T. W.; Saboureau, D.; Dano, S. D.; Ueno, Y.; Steyn, P. S.; Creppy, E. E., 2000. Prevention by vitamin e of DNA fragmentation and apoptosis induced by fumonisin b1 in c6 glioma cells, Arch Toxicol, 74, 112-119.

Mobio, T. A.; Tavan, E.; Baudrimont, I.; Anane, R.; Carratu, M. R.; Sanni, A.; Gbeassor, M. F.; Shier, T. W.; Narbonne, J. F.; Creppy, E. E., 2003. Comparative study of the toxic effects of fumonisin b1 in rat c6 glioma cells and p53-null mouse embryo fibroblasts, Toxicology, 183, 65-75.

Mobio, T. A.; Anane, R.; Baudrimont, I.; Carratu, M. R.; Shier, T. W.; Dano, S. D.; Ueno, Y.; Creppy, E. E., 2000. Epigenetic properties of fumonisin b-1: Cell cycle arrest and DNA base modification in c6 glioma cells, Toxicology and Applied Pharmacology, 164, 91-96.

Mokoena, M. P.; Chelule, P. K.; Gqaleni, N., 2005. Reduction of fumonisin b1 and zearalenone by lactic acid bacteria in fermented maize meal, J Food Prot, 68, 2095-2099.

Mwanza, M.; Kametler, L.; Bonai, A.; Rajli, V.; Kovacs, M.; Dutton, M. F., 2009. The cytotoxic effect of fumonisin b1 and ochratoxin a on human and pig lymphocytes using the methyl thiazol tetrazolium (mtt) assay, Mycotoxin Res, 25, 233-238.

Myburg, R. B.; Dutton, M. F.; Chuturgoon, A. A., 2002. Cytotoxicity of fumonisin b-1, diethylnitrosamine, and catechol on the sno esophageal cancer cell line, Environmental Health Perspectives, 110, 813-815.

Myburg, R. B.; Needhi, N.; Chuturgoon, A. A., 2009. The ultrastructural effects and immunolocalisation of fumonisin b-1 on cultured oesophageal cancer cells (sno), South African Journal of Science, 105, 217-222.

Odhav, B.; Adam, J. K.; Bhoola, K. D., 2008. Modulating effects of fumonisin b1 and ochratoxin a on leukocytes and messenger cytokines of the human immune system, International Immunopharmacology, 8, 799-809. 
Osuchowski, M. F.; Sharma, R. P., 2005. Fumonisin b-1 causes necrotic cell death in bv-2 and murine cultured astrocytes and inhibits proliferation in bv-2 cells but n2a and primary cortical neurons are not affected, Faseb Journal, 19, A1078-A1078.

Osuchowski, M. F.; Sharma, R. P., 2005. Fumonisin b-1 induces necrotic cell death in bv-2 cells and murine cultured astrocytes and is antiproliferative in bv-2 cells while n2a cells and primary cortical neurons are resistant, Neurotoxicology, 26, 981-992.

Pak, S. M.; Park, N. Y.; Park, M. Y.; Kim, W. J.; Lee, J. H.; Oh, S.; Yoo, H. S.; Lee, Y. M., 2008. Fumonisin b1 induces apoptosis in sphingosine 1-phosphate lyase-null f9 cells through increase of sphingolipids levels, Biomolecules \& Therapeutics, 16, 95-99.

Ribeiro, D. H.; Ferreira, F. L.; da Silva, V. N.; Aquino, S.; Correa, B., 2010. Effects of aflatoxin b(1) and fumonisin $\mathrm{b}(1)$ on the viability and induction of apoptosis in rat primary hepatocytes, Int J Mol Sci, 11, 1944-1955.

Riedel, S.; Abel, S.; Burger, H. M.; van der Westhuizen, L.; Swanevelder, S.; Gelderblom, W. C. A., 2016. Differential modulation of the lipid metabolism as a model for cellular resistance to fumonisin b-1-induced cytotoxic effects in vitro, Prostaglandins Leukotrienes and Essential Fatty Acids, 109, 39-51.

Rumora, L.; Kovacic, S.; Rozgaj, R.; Cepelak, I.; Pepeljnjak, S.; Grubisic, T. Z., 2002. Cytotoxic and genotoxic effects of fumonisin b-1 on rabbit kidney rk13 cell line, Archives of Toxicology, 76, 5561.

Sadler, T. W.; Merrill, A. H.; Stevens, V. L.; Sullards, M. C.; Wang, E.; Wang, P., 2002. Prevention of fumonisin b1-induced neural tube defects by folic acid, Teratology, 66, 169-176.

Sakai, A.; Suzuki, C.; Masui, Y.; Kurarnashi, A.; Takatori, K.; Tanaka, N., 2007. Activities of mycotoxins derived from fusarium and related substances in a short-term transformation assay using v-ha-ras-transfected balb/3t3 cells (bhas 42 cells), Mutation Research-Genetic Toxicology and Environmental Mutagenesis, 630, 103-111.

Schwerdt, G.; Konigs, M.; Holzinger, H.; Humpf, H. U.; Gekle, M., 2009. Effects of the mycotoxin fumonisin b-1 on cell death in human kidney cells and human lung fibroblasts in primary culture, Journal of Applied Toxicology, 29, 174-182.

Seefelder, W.; Humpf, H. U.; Schwerdt, G.; Freudinger, R.; Gekle, M., 2003. Induction of apoptosis in cultured human proximal tubule cells by fumonisins and fumonisin metabolites, Toxicol Appl Pharmacol, 192, 146-153.

Severino, L.; Russo, R.; Luongo, D.; De Luna, R.; Ciarcia, R.; Rossi, M., 2008. Immune effects of four fusarium-toxins (fb1, zea, niv, don) on the proliferation of jurkat cells and porcine lymphocytes: In vitro study, Vet Res Commun, 32 Suppl 1, S311-313.

Sharma, N.; He, Q.; Sharma, R. P., 2004. Augmented fumonisin b1 toxicity in co-cultures: Evidence for crosstalk between macrophages and non-parenchymatous liver epithelial cells involving proinflammatory cytokines, Toxicology, 203, 239-251.

Sharma, N.; He, Q.; Sharma, R. P., 2003. Interactions between macrophages and nonparenchymatous liver cells in response to fumonisin treament in vitro, Toxicological Sciences, 72, 253-253.

Sharma, N.; He, Q.; Sharma, R. P., 2004. Sphingosine kinase activity confers resistance to apoptosis by fumonisin b1 in human embryonic kidney (hek-293) cells, Chem Biol Interact, 151, 33-42.

Sharma, N.; Suzuki, H.; He, Q. R.; Sharma, R. P., 2005. Tumor necrosis factor alpha-mediated activation of c-jun nh2-terminal kinase as a mechanism for fumonisin b-1 induced apoptosis in murine primary hepatocytes, Journal of Biochemical and Molecular Toxicology, 19, 359-367.

Stockmann-Juvala, H.; Alenius, H.; Savolainen, K., 2008. Effects of fumonisin b(1) on the expression of cytokines and chemokines in human dendritic cells, Food Chem Toxicol, 46, 1444-1451. 
Stockmann-Juvala, H.; Mikkola, J.; Naarala, J.; Loikkanen, J.; Elovaara, E.; Savolainen, K., 2004. Fumonisin b-1-induced toxicity and oxidative damage in u-118mg glioblastoma cells, Toxicology, 202, 173-183.

Stockmann-Juvala, H.; Mikkola, J.; Naarala, J.; Loikkanen, J.; Elovaara, E.; Savolainen, K., 2004. Oxidative stress induced by fumonisin b-1 in continuous human and rodent neural cell cultures, Free Radical Research, 38, 933-942.

Stockmann-Juvala, H.; Naarala, J.; Loikkanen, J.; Vahakangas, K.; Savolainen, K., 2006. Fumonisin b1-induced apoptosis in neuroblastoma, glioblastoma and hypothalamic cell lines, Toxicology, 225, 234-241.

Sun, L. H.; Lei, M. Y.; Zhang, N. Y.; Gao, X.; Li, C.; Krumm, C. S.; Qi, D. S., 2015. Individual and combined cytotoxic effects of aflatoxin b-1, zearalenone, deoxynivalenol and fumonisin b-1 on brl 3a rat liver cells, Toxicon, 95, 6-12.

Tachampa, K.; Takeda, M.; Khamdang, S.; Noshiro-Kofuji, R.; Tsuda, M.; Jariyawat, S.; Fukutomi, T.; Sophasan, S.; Anzai, N.; Endou, H., 2008. Interactions of organic anion transporters and organic cation transporters with mycotoxins, J Pharmacol Sci, 106, 435-443.

Tajima, O.; Schoen, E. D.; Feron, V. K.; Groten, J. P., 2002. Statistically designed experiments in a tiered approach to screen mixtures of fusarium mycotoxins for possible interactions, Food and Chemical Toxicology, 40, 685-695.

Taranu, I.; Marin, D. E.; Burlacu, R.; Pinton, P.; Damian, V.; Oswald, I. P., 2010. Comparative aspects of in vitro proliferation of human and porcine lymphocytes exposed to mycotoxins, Archives of Animal Nutrition, 64, 383-393.

Theumer, M. G.; Canepa, M. C.; Lopez, A. G.; Mary, V. S.; Dambolena, J. S.; Rubinstein, H. R., 2010. Subchronic mycotoxicoses in wistar rats: Assessment of the in vivo and in vitro genotoxicity induced by fumonisins and aflatoxin b-1, and oxidative stress biomarkers status, Toxicology, 268, 104-110.

Theumer, M. G.; Lopez, A. G.; Masih, D. T.; Chulze, S. N.; Rubinstein, H. R., 2002. Immunobiological effects of fumonisin b1 in experimental subchronic mycotoxicoses in rats, Clin Diagn Lab Immunol, 9, 149-155.

Todorova, K.; Ivanov, I.; Georgieva, A.; Lazarova, S.; Milcheva, R.; Dimitrov, P.; Dimitrov, R.; Russev, R., 2015. Fumonisin b-1 cytotoxicity and subcellular localization in duck embryo cell line dec 99, Comptes Rendus De L Academie Bulgare Des Sciences, 68, 617-622.

Wan, L. Y. M.; Allen, K. J.; Turner, P. C.; El-Nezami, H., 2014. Modulation of mucin mrna (muc5ac and muc5b) expression and protein production and secretion in caco-2/ht29-mtx co-cultures following exposure to individual and combined fusarium mycotoxins, Toxicological Sciences, 139, 83-98.

Wan, L. Y. M.; Woo, C. S. J.; Turner, P. C.; Wan, J. M. F.; El-Nezami, H., 2013. Individual and combined effects of fusarium toxins on the mrna expression of pro-inflammatory cytokines in swine jejunal epithelial cells, Toxicology Letters, 220, 238-246.

Wan, M. L. Y.; Woo, C. S. J.; Allen, K. J.; Turner, P. C.; El-Nezami, H., 2013. Modulation of porcine beta-defensins 1 and 2 upon individual and combined fusarium toxin exposure in a swine jejunal epithelial cell line, Applied and Environmental Microbiology, 79, 2225-2232.

Wang, S. K.; Wang, T. T.; Huang, G. L.; Shi, R. F.; Yang, L. G.; Sun, G. J., 2014. Stimulation of the proliferation of human normal esophageal epithelial cells by fumonisin b-1 and its mechanism, Experimental and Therapeutic Medicine, 7, 55-60.

Wen, J. K.; Mu, P. Q.; Deng, Y. Q., 2016. Mycotoxins: Cytotoxicity and biotransformation in animal cells, Toxicology Research, 5, 377-387. 
Yu, C. H.; Lee, Y. M.; Yun, Y. P.; Yoo, H. S., 2001. Differential effects of fumonisin b-1 on cell death in cultured cells: The significance of the elevated sphinganine, Archives of Pharmacal Research, 24, 136-143.

Yu, M. U.; Yoo, J. M.; Lee, Y. S.; Lee, Y. M.; Hong, J. T.; Oh, K. W.; Song, S.; Yun, Y. P.; Yoo, H. S.; Oh, S., 2004. Altered de novo sphingolipid biosynthesis is involved in the serum deprivationinduced cell death in Ilc-pk1 cells, J Toxicol Environ Health A, 67, 2085-2094.

\section{Relevant references not retrieved in the literature searches for Area 5 IN VITRO TOXICITY:}

Anadon, A.; Martinez, M. A.; Ares, I.; Ramos, E.; Castellano, V.; Martinez, M.; Martinez-Larranaga, M. R.; Romero, A., 2014. The food contaminants aflatoxin b-1, fumonisin b-1, ocratoxina, t-2 toxin and deoxynivalenol decrease intestinal barrier permeability in human caco-2 cells. Protector role of clay additives, Toxicology Letters, 229, S170-S170.

Gardner, N. M.; Riley, R. T.; Showker, J. L.; Voss, K. A.; Sachs, A. J.; Maddox, J. R.; Gelineau-van Waes, J. B., 2016. Elevated nuclear sphingoid base-1-phosphates and decreased histone deacetylase activity after fumonisin b1 treatment in mouse embryonic fibroblasts, Toxicology and Applied Pharmacology, 298, 56-65.

Gopee, N. V.; Sharma, R. P., 2004. The mycotoxin fumonisin b1 transiently activates nuclear factorkappab, tumor necrosis factor alpha and caspase 3 via protein kinase calpha-dependent pathway in porcine renal epithelial cells, Cell Biol Toxicol, 20, 197-212.

Gopee, N. V.; Sharma, R. P., 2003. Tumor necrosis factor-alpha induction in fumonisin b-1-treated porcine renal epithelial cells is mediated via activation of protein kinase c-alpha and nuclear factorkappa b, Toxicological Sciences, 72, 254-254.

He, Q.; Riley, R. T.; Sharma, R. P., 2001. Fumonisin-induced tumor necrosis factor-alpha expression in a porcine kidney cell line is independent of sphingoid base accumulation induced by ceramide synthase inhibition, Toxicol Appl Pharmacol, 174, 69-77.

Kim, M. S.; Schroeder, J. J., 2001. Fumonisin b-1 reduces phosphorylation of mapk/erk and pkb/akt in Ilc-pk1 porcine kidney epithelial cells, Faseb Journal, 15, A600-A600.

Pizzamiglio, V.; Grilli, E.; Fabbri, L.; Piva, A.; Westrom, B., 2006. No absorption of ochratoxin a and fumonisin b1 in rat small intestine detected with ussing diffusion chamber, Journal of Animal Science, 84, 342-342.

Wan, L. Y.; Turner, P. C.; El-Nezami, H., 2013. Individual and combined cytotoxic effects of fusarium toxins (deoxynivalenol, nivalenol, zearalenone and fumonisins b1) on swine jejunal epithelial cells, Food Chem Toxicol, 57, 276-283.

Zhang, Y.; Jones, C.; Dickman, M. B., 2001. Identification of differentially expressed genes following treatment of monkey kidney cells with the mycotoxin fumonisin $b(1)$, Food Chem Toxicol, 39, 4553. 


\section{AREA 6 OBSERVATIONS IN HUMANS}

Reference list with all relevant references identified for AREA 6: Data on observations in humans (e.g. epidemiological studies, case reports, intervention studies) published in English since year 2000.

Relevant references retrieved in the literature searches for Area 6 OBSERVATIONS IN HUMANS:

Abnet, C. C.; Borkowf, C. B.; Qiao, Y. L.; Albert, P. S.; Wang, E.; Merrill, A. H., Jr.; Mark, S. D.; Dong, Z. W.; Taylor, P. R.; Dawsey, S. M., 2001. Sphingolipids as biomarkers of fumonisin exposure and risk of esophageal squamous cell carcinoma in china, Cancer Causes Control, 12, 821-828.

Alizadeh, A. M.; Roshandel, G.; Roudbarmohammadi, S.; Roudbary, M.; Sohanaki, H.; Ghiasian, S. A.; Taherkhani, A.; Semnani, S.; Aghasi, M., 2012. Fumonisin b1 contamination of cereals and risk of esophageal cancer in a high risk area in northeastern iran, Asian Pacific Journal of Cancer Prevention, 13, 2625-2628.

Anonymous, 2012. Mycotoxins and human health, 2012. IARC Sci Publ, 87-104.

Antonissen, G.; Martel, A.; Pasmans, F.; Ducatelle, R.; Verbrugghe, E.; Vandenbroucke, V.; Li, S. J.; Haesebrouck, F.; Van Immerseel, F.; Croubels, S., 2014. The impact of fusarium mycotoxins on human and animal host susceptibility to infectious diseases, Toxins, 6, 430-452.

Chen, J.; Jia, Z.; Song, J.; Yuan, Y.; Zhang, L., 2015. Fumonisins in china: Update on occurrence, epidemiology, exposure and regulation, Quality Assurance and Safety of Crops \& Foods, 7, 63-72.

Dutton, M. F., 2009. The african fusarium/maize disease, Mycotoxin Res, 25, 29-39.

Ediage, E. N.; Di Mavungu, J. D.; Song, S. Q.; Sioen, I.; De Saeger, S., 2013. Multimycotoxin analysis in urines to assess infant exposure: A case study in cameroon, Environment International, 57-58, 50-59.

Gelineau-van Waes J, Starr L,Maddox J,Aleman F,Voss KA,Wilberding J and Riley RT, 2005. .Maternal fumonisin exposure and neural tube defects: Folate and tetrahydrobiopterin prevention of oxidative stress. Birth Defects Research Part a-Clinical and Molecular Teratology, 73, 303-303.

Kimanya, M. E.; De Meulenaer, B.; Kolsteren, P. W., 2009. The correlation between fumonisins exposure and growth retardation among infants in rombo, tanzania, Annals of Nutrition and Metabolism, 55, 614-614.

Kimanya, M. E.; De Meulenaer, B.; Roberfroid, D.; Lachat, C.; Kolsteren, P., 2010. Fumonisin exposure through maize in complementary foods is inversely associated with linear growth of infants in tanzania, Mol Nutr Food Res, 54, 1659-1667.

Lombard, M. J., 2014. Mycotoxin exposure and infant and young child growth in africa: What do we know?, Ann Nutr Metab, 64 Suppl 2, 42-52.

Magoha, H.; Kimanya, M.; De Meulenaer, B.; Roberfroid, D.; Lachat, C.; Kolsteren, P., 2016. Risk of dietary exposure to aflatoxins and fumonisins in infants less than 6 months of age in rombo, northern tanzania, Matern Child Nutr, 12, 516-527.

Marasas, W. F. O.; Riley, R. T.; Hendricks, K. A.; Stevens, V. L.; Sadler, T. W.; Gelineau-van Waes, J.; Missmer, S. A.; Cabrera, J.; Torres, O.; Gelderblom, W. C. A.; Allegood, J.; Martinez, C.; Maddox, J.; Miller, J. D.; Starr, L.; Sullards, M. C.; Roman, A. V.; Voss, K. A.; Wang, E.; Merrill, A. H., 2004. Fumonisins disrupt sphingolipid metabolism, folate transport, and neural tube development in embryo culture and in vivo: A potential risk factor for human neural tube defects among populations consuming fumonisin-contaminated maize, Journal of Nutrition, 134, 711-716.

Missmer, S. A.; Suarez, L.; Felkner, M.; Wang, E.; Merrill, A. H., Jr.; Rothman, K. J.; Hendricks, K. A., 2006. Exposure to fumonisins and the occurrence of neural tube defects along the texas-mexico border, Environ Health Perspect, 114, 237-241. 
Peraica, M.; Domijan, A. M., 2001. Contamination of food with mycotoxins and human health, Arh Hig Rada Toksikol, 52, 23-35.

Peraica, M.; Richter, D.; Rasic, D., 2014. Mycotoxicoses in children, Arhiv Za Higijenu Rada I Toksikologiju-Archives of Industrial Hygiene and Toxicology, 65, 347-363.

Persson, E. C.; Sewram, V.; Evans, A. A.; London, W. T.; Volkwyn, Y.; Shen, Y. J.; Van Zyl, J. A.; Chen, G.; Lin, W. Y.; Shephard, G. S.; Taylor, P. R.; Fan, J. H.; Dawsey, S. M.; Qiao, Y. L.; McGlynn, K. A.; Abnet, C. C., 2012. Fumonisin b-1 and risk of hepatocellular carcinoma in two chinese cohorts, Food and Chemical Toxicology, 50, 679-683.

Richard, J. L., 2007. Some major mycotoxins and their mycotoxicoses - an overview, International Journal of Food Microbiology, 119, 3-10.

Riley, R. T.; Torres, O.; Matute, J.; Gregory, S. G.; Ashley-Koch, A. E.; Showker, J. L.; Mitchell, T.; Voss, K. A.; Maddox, J. R.; Gelineau-van Waes, J. B., 2015. Evidence for fumonisin inhibition of ceramide synthase in humans consuming maize-based foods and living in high exposure communities in guatemala, Mol Nutr Food Res, 59, 2209-2224.

Shirima, C. P.; Kimanya, M. E.; Routledge, M. N.; Srey, C.; Kinabo, J. L.; Humpf, H. U.; Wild, C. P.; Tu, Y. K.; Gong, Y. Y., 2015. A prospective study of growth and biomarkers of exposure to aflatoxin and fumonisin during early childhood in tanzania, Environ Health Perspect, 123, 173-178.

Shirima, ; Tu, Y. K., 2015. A prospective study of growth and biomarkers of exposure to aflatoxin and fumonisin during early childhood in tanzania (vol 123, pg 173, 2015), Environmental Health Perspectives, 123, A32-A32.

Smith, L. E.; Prendergast, A. J.; Turner, P. C.; Mbuya, M. N. N.; Mutasa, K.; Kembo, G.; Stoltzfus, R. J.; Sanitation Hyg Infant Nutr, Efficac, 2015. The potential role of mycotoxins as a contributor to stunting in the shine trial, Clinical Infectious Diseases, 61, S733-S737.

Smith, L. E.; Stoltzfus, R. J.; Prendergast, A., 2012. Food chain mycotoxin exposure, gut health, and impaired growth: A conceptual framework, Adv Nutr, 3, 526-531.

Suarez, L.; Felkner, M.; Brender, J. D.; Canfield, M.; Zhu, H. P.; Hendricks, K. A., 2012. Neural tube defects on the texas-mexico border: What we've learned in the 20 years since the brownsville cluster, Birth Defects Research Part a-Clinical and Molecular Teratology, 94, 882-892.

Sun, G.; Wang, S.; Hu, X.; Su, J.; Zhang, Y.; Xie, Y.; Zhang, H.; Tang, L.; Wang, J. S., 2011. Cocontamination of aflatoxin $b-1$ and fumonisin $b-1$ in food and human dietary exposure in three areas of china, Food Additives and Contaminants Part a-Chemistry Analysis Control Exposure \& Risk Assessment, 28, 461-470.

Torres, A. M.; Ramirez, M. L.; Arroyo, M.; Chulze, S. N.; Magan, N., 2003. Potential use of antioxidants for control of growth and fumonisin production by fusarium verticillioides and fusarium proliferatum on whole maize grain, Int J Food Microbiol, 83, 319-324.

van der Westhuizen, L.; Shephard, G. S.; Rheeder, J. P.; Burger, H. M., 2010. Individual fumonisin exposure and sphingoid base levels in rural populations consuming maize in south africa, Food Chem Toxicol, 48, 1698-1703.

van Waes, J. G.; Maddox, J.; Ashley-Koch, A.; Gregory, S.; de Matute, O. T.; Voss, K. A.; Riley, R. T., 2011. Evaluating human exposure to fumonisins in guatemala and its possible role as a contributing factor to neural tube defects, Phytopathology, 101, S222-S222.

Wild, C. P.; Gong, Y. Y., 2010. Mycotoxins and human disease: A largely ignored global health issue, Carcinogenesis, 31, 71-82.

Wu, F.; Groopman, J. D.; Pestka, J. J. 2014. Public health impacts of foodborne mycotoxins. in M. P.; Klaenhammer Doyle, T. R. (ed.), Annual review of food science and technology, vol 5. 
Xu, L.; Cal, Q. S.; Tang, L. L.; Hu, X.; Sun, G. J.; Wang, J. S., 2009. Dietary fumonisin b1 exposure and human esophageal cancer risk in huaian, china: Use of urinary free fumonisin b1 as biomarker of exposure, Cancer Research, 69.

Xu, L.; Cai, Q.; Tang, L.; Wang, S.; Hu, X.; Su, J.; Sun, G.; Wang, J. S., 2010. Evaluation of fumonisin biomarkers in a cross-sectional study with two high-risk populations in china, Food Addit Contam Part A Chem Anal Control Expo Risk Assess, 27, 1161-1169.

Relevant references not retrieved in the literature searches for Area 6 OBSERVATIONS IN HUMANS:

Ahangarkani, F.; Rouhi, S.; Azizi, I. G., 2014. A review on incidence and toxicity of fumonisins, Toxin Reviews, 33, 95-100.

Fokunang, C. N.; Tembe-Fokunang, E. A.; Tomkins, P.; Barkwan, S., 2006. Global impact of mycotoxins on human and animal health management, Outlook on Agriculture, 35, 247-253.

Raghavender, C. R.; Reddy, B. N., 2009. Human and animal disease outbreaks in india due to mycotoxins other than aflatoxins, World Mycotoxin Journal, 2, 23-30.

Reddy, B.; Raghavender, C., 2008. Outbreaks of fusarial-toxicoses in india, Cereal Research Communications, 36, 321-325.

Reddy, K. R. N.; Salleh, B.; Saad, B.; Abbas, H. K.; Abel, C. A.; Shier, W. T., 2010. An overview of mycotoxin contamination in foods and its implications for human health, Toxin Reviews, 29, 3-26.

Waes, J. G. V.; Maddox, J.; Rainey, M.; Gardner, N.; Sachs, A.; Voss, K.; Riley, R. T., 2012. Tortillas and toxins: Gene-environment interactions in fumonisin-induced neural tube defects, International Journal of Developmental Neuroscience, 30, 636-636. 


\section{AREA 7 TOXICITY IN FARM ANIMALS}

Reference list with all relevant references identified for AREA 7: Data on adverse effects in farm and companion animals (studies in the different species e.g. ruminants, pigs, poultry, rabbits, fish, cats, dogs etc.) published since year 1980.

Abeni, F.; Migliorati, L.; Terzano, G. M.; Capelletti, M.; Gallo, A.; Masoero, F.; Pirlo, G., 2014. Effects of two different blends of naturally mycotoxin-contaminated maize meal on growth and metabolic profile in replacement heifers, Animal, 8, 1667-1676.

Abidin, Z.; Khatoon, A.; Numan, M., 2011. Mycotoxins in broilers: Pathological alterations induced by aflatoxins and ochratoxins, diagnosis and determination, treatment and control of mycotoxicosis, Worlds Poultry Science Journal, 67, 485-496.

Akare, S.; Hsiao, S. H.; Volmer, P.; Wallig, M.; Haschek, W., 2008. Fumonisin induced pulmonary edema in swine: A case report, Toxicologic Pathology, 36, 163-164.

Anonymous, 2012. Effects in food-producing animals, 2012. IARC Sci Publ, 59-85.

Antonissen, G.; Croubels, S.; Pasmans, F.; Ducatelle, R.; Eeckhaut, V.; Devreese, M.; Verlinden, M.; Haesebrouck, F.; Eeckhout, M.; De Saeger, S.; Antlinger, B.; Novak, B.; Martel, A.; Van Immerseel, F., 2015. Fumonisins affect the intestinal microbial homeostasis in broiler chickens, predisposing to necrotic enteritis, Veterinary Research, 46.

Antonissen, G.; Martel, A.; Pasmans, F.; Ducatelle, R.; Verbrugghe, E.; Vandenbroucke, V.; Li, S. J.; Haesebrouck, F.; Van Immerseel, F.; Croubels, S., 2014. The impact of fusarium mycotoxins on human and animal host susceptibility to infectious diseases, Toxins, 6, 430-452.

Antonissen, G.; Van Immerseel, F.; Pasmans, F.; Ducatelle, R.; Janssens, G. P.; De Baere, S.; Mountzouris, K. C.; Su, S.; Wong, E. A.; De Meulenaer, B.; Verlinden, M.; Devreese, M.; Haesebrouck, F.; Novak, B.; Dohnal, I.; Martel, A.; Croubels, S., 2015. Mycotoxins deoxynivalenol and fumonisins alter the extrinsic component of intestinal barrier in broiler chickens, J Agric Food Chem, 63, 10846-10855.

Asrani, R. K.; Katoch, R. C.; Gupta, V. K.; Deshmukh, S.; Jindal, N.; Ledoux, D. R.; Rottinghaus, G. E.; Singh, S. P., 2006. Effects of feeding fusarium verticillioides (formerly fusarium moniliforme) culture material containing known levels of fumonisin $b(1)$ in japanese quail (coturnix coturnix japonica), Poultry Science, 85, 1129-1135.

Atef, A. H.; Mogda, K. M.; Samira, A. M. S.; Randa, A. H., 2010. Mycological, biochemical and histopathological studies on acute fusariotoxicosis in sheep, Life Science Journal-Acta Zhengzhou University Overseas Edition, 7, 49-57.

Bailly, J. D.; Benard, G.; Jouglar, J. Y.; Durand, S.; Guerre, P., 2001. Toxicity of fusarium moniliforme culture material containing known levels of fumonisin b1 in ducks, Toxicology, 163, 11-22.

Baker, D. C.; Rottinghaus, G. E., 1999. Chronic experimental fumonisin intoxication of calves, Journal of Veterinary Diagnostic Investigation, 11, 289-292.

Bane, D. P.; Neumann, E. J.; Hall, W. F.; Harlin, K. S.; Slife, R. L., 1992. Relationship between fumonisin contamination of feed and mystery swine disease. A case-control study, Mycopathologia, 117, 121-124.

Becker, B. A.; Pace, L.; Rottinghaus, G. E.; Shelby, R.; Misfeldt, M.; Ross, P. F., 1995. Effects of feeding fumonisin b1 in lactating sows and their suckling pigs, Am J Vet Res, 56, 1253-1258.

Benlasher, E.; Geng, X.; Nguyen, N. T.; Tardieu, D.; Bailly, J. D.; Auvergne, A.; Guerre, P., 2012. Comparative effects of fumonisins on sphingolipid metabolism and toxicity in ducks and turkeys, Avian Dis, 56, 120-127. 
Bermudez, A. J.; Ledoux, D. R.; Turk, J. R.; Rottinghaus, G. E., 1996. The chronic effects of fusarium moniliforme culture material, containing known levels of fumonisin b1, in turkeys, Avian Dis, 40, 231-235.

Bermudez, A. J.; Ledoux, D. R.; Rottinghaus, G. E., 1995. Effects of fusarium moniliforme culture material containing known levels of fumonisin b1 in ducklings, Avian Dis, 39, 879-886.

Bermudez, A. J.; Ledoux, D. R.; Rottinghaus, G. E.; Bennett, G. A., 1997. The individual and combined effects of the fusarium mycotoxins moniliformin and fumonisin b1 in turkeys, Avian Dis, 41, 304311.

Binkerd, K. A.; Scott, D. H.; Everson, R. J.; Sullivan, J. M.; Robinson, F. R., 1993. Fumonisin contamination of the 1991 indiana corn crop and its effects on horses, Journal of Veterinary Diagnostic Investigation, 5, 653-655.

Bracarense, A. P.; Lucioli, J.; Grenier, B.; Drociunas Pacheco, G.; Moll, W. D.; Schatzmayr, G.; Oswald, I. P., 2012. Chronic ingestion of deoxynivalenol and fumonisin, alone or in interaction, induces morphological and immunological changes in the intestine of piglets, $\mathrm{Br}$ J Nutr, 107, 1776-1786.

Broomhead, J. N.; Ledoux, D. R.; Bermudez, A. J.; Rottinghaus, G. E., 2002. Chronic effects of fumonisin b1 in broilers and turkeys fed dietary treatments to market age, Poult Sci, 81, 56-61.

Brown, D. W.; McCoy, C. P.; Rottinghaus, G. E., 1994. Experimental feeding of fusarium moniliforme culture material containing fumonisin b1 to channel catfish, ictalurus punctatus, J Vet Diagn Invest, 6, 123-124.

Brown, T. P.; Rottinghaus, G. E.; Williams, M. E., 1992. Fumonisin mycotoxicosis in broilers: Performance and pathology, Avian Dis, 36, 450-454.

Burel, C.; Tanguy, M.; Guerre, P.; Boilletot, E.; Cariolet, R.; Queguiner, M.; Postollec, G.; Pinton, P.; Salvat, G.; Oswald, I. P.; Fravalo, P., 2013. Effect of low dose of fumonisins on pig health: Immune status, intestinal microbiota and sensitivity to salmonella, Toxins, 5, 841-864.

Butkeraitis, P.; Oliveira, C. A.; Ledoux, D. R.; Ogido, R.; Albuquerque, R.; Rosmaninho, J. F.; Rottinghaus, G. E., 2004. Effect of dietary fumonisin b1 on laying japanese quail, Br Poult Sci, 45, 798-801.

Caloni, F.; Cortinovis, C., 2010. Effects of fusariotoxins in the equine species, Veterinary Journal, 186, 157-161.

Carlson, D. B.; Williams, D. E.; Spitsbergen, J. M.; Ross, P. F.; Bacon, C. W.; Meredith, F. I.; Riley, R. T., 2001. Fumonisin b1 promotes aflatoxin b1 and n-methyl-n'-nitro-nitrosoguanidine-initiated liver tumors in rainbow trout, Toxicol Appl Pharmacol, 172, 29-36.

Casteel, S. W.; Turk, J. R.; Rottinghaus, G. E., 1994. Chronic effects of dietary fumonisin on the heart and pulmonary vasculature of swine, Fundamental and Applied Toxicology, 23, 518-524.

Casteel, S. W.; Turk, J. R.; Cowart, R. P.; Rottinghaus, G. E., 1993. Chronic toxicity of fumonisin in weanling pigs, Journal of Veterinary Diagnostic Investigation, 5, 413-417.

Cavret, S.; Lecoeur, S., 2006. Fusariotoxicosis, Annales De Medecine Veterinaire, 150, 43-55.

Cavret, S.; Lecoeur, S., 2006. Fusariotoxin transfer in animal, Food and Chemical Toxicology, 44, 444453.

Cheng, Y. H.; Ding, S. T.; Chang, M. H., 2006. Effect of fumonisins on macrophage immune functions and gene expression of cytokines in broilers, Archives of Animal Nutrition, 60, 267-276.

Christley, R. M.; Begg, A. P.; Hutchins, D. R.; Hodgson, D. R.; Bryden, W. L., 1993. Leukoencephalomalacia in horses, Aust Vet J, 70, 225-226.

Colvin, B. M.; Cooley, A. J.; Beaver, R. W., 1993. Fumonisin toxicosis in swine: Clinical and pathologic findings, J Vet Diagn Invest, 5, 232-241. 
Colvin, B. M.; Harrison, L. R., 1992. Fumonisin-induced pulmonary edema and hydrothorax in swine, Mycopathologia, 117, 79-82.

Conkova, E.; Laciakova, A.; Kovac, G.; Seidel, H., 2003. Fusarial toxins and their role in animal diseases, Veterinary Journal, 165, 214-220.

Constable, P. D.; Smith, G. W.; Haschek, W. M., 1999. Effect of fumonisin on left ventricular afterload in swine, Faseb Journal, 13, A93-A93.

Constable, P. D.; Smith, G. W.; Rottinghaus, G. E.; Tumbleson, M. E.; Haschek, W. M., 2003. Fumonisin-induced blockade of ceramide synthase in sphingolipid biosynthetic pathway alters aortic input impedance spectrum of pigs, American Journal of Physiology-Heart and Circulatory Physiology, 284, H2034-H2044.

Constable, P. D.; Smith, G. W.; Rottinghaus, G. E.; Haschek, W. M., 2000. Ingestion of fumonisin b1containing culture material decreases cardiac contractility and mechanical efficiency in swine, Toxicology and Applied Pharmacology, 162, 151-160.

Constable, P. D.; Waggoner, A. L.; Tumbleson, M. E.; Smith, G. W.; Foreman, J. H.; Eppley, R. M.; Haschek, W. M., 2002. Sphingolipid alterations following intravenous fumonisin b-1 administration to horses: Correlation with neurotoxicity, Faseb Journal, 16, A887-A887.

Cortinovis, C.; Pizzo, F.; Spicer, L. J.; Caloni, F., 2013. Fusarium mycotoxins: Effects on reproductive function in domestic animals--a review, Theriogenology, 80, 557-564.

De Liguoro, M.; Petterino, C.; Mezzalira, G.; Tenti, S.; Ravarotto, L., 2004. Field observations in pigs exposed to fumonisin b1 contaminated feed, Veterinary and Human Toxicology, 46, 303-305.

Del Bianchi, M.; Oliveira, C. A.; Albuquerque, R.; Guerra, J. L.; Correa, B., 2005. Effects of prolonged oral administration of aflatoxin b1 and fumonisin b1 in broiler chickens, Poult Sci, 84, 1835-1840.

Dersjant-Li, Y.; Verstegen, M. W.; Gerrits, W. J., 2003. The impact of low concentrations of aflatoxin, deoxynivalenol or fumonisin in diets on growing pigs and poultry, Nutr Res Rev, 16, 223-239.

Deshmukh, S.; Asrani, R. K.; Jindal, N.; Ledoux, D. R.; Rottinghaus, G. E.; Sharma, M.; Singh, S. P., 2005. Effects of fusarium moniliforme culture material containing known levels of fumonisin b1 on progress of salmonella gallinarum infection in japanese quail: Clinical signs and hematologic studies, Avian Dis, 49, 274-280.

Deshmukh, S.; Asrani, R. K.; Ledoux, D. R.; Jindal, N.; Bermudez, A. J.; Rottinghaus, G. E.; Sharma, M.; Singh, S. P., 2005. Individual and combined effects of fusarium moniliforme culture material, containing known levels of fumonisin $b(1)$, and salmonella gallinarum infection on liver of japanese quail, Avian Diseases, 49, 592-600.

Deshmukh, S.; Asrani, R. K.; Ledoux, D. R.; Rottinghaus, G. E.; Bermudez, A. J.; Gupta, V. K., 2007. Pathologic changes in extrahepatic organs and agglutinin response to salmonella gallinarum infection in japanese quail fed fusarium verticillioides culture material containing known levels of fumonisin b1, Avian Dis, 51, 705-712.

Devreese, M.; De Backer, P.; Croubels, S., 2013. Overview of the most important mycotoxins for the pig and poultry husbandry, Vlaams Diergeneeskundig Tijdschrift, 82, 171-180.

Devriendt, B.; Gallois, M.; Verdonck, F.; Wache, Y.; Bimczok, D.; Oswald, I. P.; Goddeeris, B. M.; Cox, $E ., 2009$. The food contaminant fumonisin $b(1)$ reduces the maturation of porcine cd11r1(+) intestinal antigen presenting cells and antigen-specific immune responses, leading to a prolonged intestinal etec infection, Vet Res, 40, 40.

Diaz, C. T.; Sogbe, E.; Ascanio, E.; Hernandez, M., 2001. Ocratoxin a and fumonisin b1 natural interaction in pigs. Clinical and pathological study, Revista Cientifica-Facultad De Ciencias Veterinarias, 11, 314-321. 
Diaz, G. J.; Boermans, H. J., 1994. Fumonisin toxicosis in domestic animals: A review, Vet Hum Toxicol, 36, 548-555.

Dilkin, P.; Zorzete, P.; Mallmann, C. A.; Gomes, J. D.; Utiyama, C. E.; Oetting, L. L.; Correa, B., 2003. Toxicological effects of chronic low doses of aflatoxin $b(1)$ and fumonisin $b(1)$-containing fusarium moniliforme culture material in weaned piglets, Food Chem Toxicol, 41, 1345-1353.

D'Mello, J. P. F.; Placinta, C. M.; Macdonald, A. M. C., 1999. Fusarium mycotoxins: A review of global implications for animal health, welfare and productivity, Animal Feed Science and Technology, 80, 183-205.

Dombrink-Kurtzman, M. A.; Javed, T.; Bennett, G. A.; Richard, J. L.; Cote, L. M.; Buck, W. B., 1993. Lymphocyte cytotoxicity and erythrocytic abnormalities induced in broiler chicks by fumonisins b1 and b2 and moniliformin from fusarium proliferatum, Mycopathologia, 124, 47-54.

dos Santos, C. E. P.; de Souto, F. S. M.; Santurio, J. M.; Marques, L. C., 2013. Leukoencephalomacia in equidae of the eastern region of mato grosso, brazil, Acta Scientiae Veterinariae, 41.

Edrington, T. S.; Kamps-Holtzapple, C. A.; Harvey, R. B.; Kubena, L. F.; Elissalde, M. H.; Rottinghaus, G. E., 1995. Acute hepatic and renal toxicity in lambs dosed with fumonisin-containing culture material, J Anim Sci, 73, 508-515.

Espada, Y.; Ruiz de Gopegui, R.; Cuadradas, C.; Cabanes, F. J., 1994. Fumonisin mycotoxicosis in broilers. Weights and serum chemistry modifications, Avian Dis, 38, 454-460.

Espada, Y.; Ruiz de Gopegui, R.; Cuadradas, C.; Cabanes, F. J., 1997. Fumonisin mycotoxicosis in broilers: Plasma proteins and coagulation modifications, Avian Dis, 41, 73-79.

Ewuola, E. O., 2009. Organ traits and histopathology of rabbits fed varied levels of dietary fumonisin b(1), J Anim Physiol Anim Nutr (Berl), 93, 726-731.

Ewuola, E. O.; Egbunike, G. N., 2010. Gonadal and extra-gonadal sperm reserves and sperm production of pubertal rabbits fed dietary fumonisin b1, Anim Reprod Sci, 119, 282-286.

Ewuola, E. O.; Egbunike, G. N., 2008. Haematological and serum biochemical response of growing rabbit bucks fed dietary fumonisin b-1, African Journal of Biotechnology, 7, 4304-4309.

Ewuola, E. O.; Gbore, F. A.; Ogunlade, J. T.; Bandyopadhyay, R.; Niezen, J.; Egbunike, G. N., 2008. Physiological response of rabbit bucks to dietary fumonisin: Performance, haematology and serum biochemistry, Mycopathologia, 165, 99-104.

Fazekas, B., 1999. Fusariotoxicoses in swine, Magyar Allatorvosok Lapja, 121, 340-343.

Fazekas, B., 1997. Rectifying remarks to the article "experimental fumonisin mycotoxicosis in swine", Magyar Allatorvosok Lapja, 119, 767-768.

Fazekas, B.; Bajmocy, E.; Glavits, R.; Fenyvesi, A., 1997. Experimental fumonisin mycotoxicosis of swine, Magyar Allatorvosok Lapja, 119, 10-14.

Fazekas, B.; Bajmocy, E.; Glavits, R.; Fenyvesi, A.; Tanyi, J., 1998. Fumonisin b1 contamination of maize and experimental acute fumonisin toxicosis in pigs, Zentralbl Veterinarmed $B, 45,171-181$.

Fazekas, B.; Bajmocy, E.; Glavits, R.; Fenyvesi, A., 1997. Fumonisine mycotoxicoses in hungary. Leukoencephalomalacia in horses, fattening pulmonary oedema in pigs, Magyar Allatorvosok Lapja, $119,137-139$.

Fazekas, B.; Bajmocy, E., 1996. Occurrence of the equine leukoencephalomalacia (elem) caused by fumonisin-b-1 mycotoxin in hungary, Magyar Allatorvosok Lapja, 51, 484-487.

Fazekas, B.; Molnar, T.; Ivanics, E.; Abonyi, T.; Glavits, R., 2011. Animal health significance of fusariotoxins in swine and poultry. 2. Main mycotoxicoses in swine and poultry, Magyar Allatorvosok Lapja, 133, 267-279. 
Fernandez-Surumay, G.; Osweiler, G. D.; Yaeger, M. J.; Rottinghaus, G. E.; Hendrich, S.; Buckley, L. K.; Murphy, P. A., 2005. Fumonisin b-glucose reaction products are less toxic when fed to swine, Journal of Agricultural and Food Chemistry, 53, 4264-4271.

Ficken, M. D.; Cummings, T. S.; Wages, D. P., 1993. Cerebral encephalomalacia in commercial turkeys, Avian Diseases, 37, 917-922.

Floss, J. L.; Casteel, S. W.; Johnson, G. C.; Rottinghaus, G. E.; Krause, G. F., 1994. Development toxicity of fumonisin in syrian hamsters, Mycopathologia, 128, 33-38.

Floss, J. L.; Casteel, S. W.; Johnson, G. C.; Rottinghaus, G. E.; Krause, G. F., 1994. Developmental toxicity in hamsters of an aqueous extract of fusarium moniliforme culture material containing known quantities of fumonisin b1, Vet Hum Toxicol, 36, 5-10.

Fodor, J.; Balogh, K.; Weber, M.; Miklos, M.; Kametler, L.; Posa, R.; Mamet, R.; Bauer, J.; Horn, P.; Kovacs, F.; Kovacs, M., 2008. Absorption, distribution and elimination of fumonisin $b(1)$ metabolites in weaned piglets, Food Addit Contam Part A Chem Anal Control Expo Risk Assess, 25, 88-96.

Fodor, J.; Bauer, J.; Horn, P.; Kovacs, F.; Kovacs, M., 2005. Effect of different dietary fumonisin b-1 exposure on the toxin content of porcine tissues, Italian Journal of Animal Science, 4, 73-78.

Fokunang, C. N.; Tembe-Fokunang, E. A.; Tomkins, P.; Barkwan, S., 2006. Global impact of mycotoxins on human and animal health management, Outlook on Agriculture, 35, 247-253.

Foreman, J. H.; Constable, P. D.; Waggoner, A. L.; Levy, M.; Eppley, R. M.; Smith, G. W.; Tumbleson, M. E.; Haschek, W. M., 2004. Neurologic abnormalities and cerebrospinal fluid changes in horses administered fumonisin b1 intravenously, J Vet Intern Med, 18, 223-230.

Gabor, S., 2001. Toxicoses of horses. Review article. 2. Toxic plants, mycotoxins, Magyar Allatorvosok Lapja, 123, 585-595.

Gallo, A.; Giuberti, G.; Frisvad, J. C.; Bertuzzi, T.; Nielsen, K. F., 2015. Review on mycotoxin issues in ruminants: Occurrence in forages, effects of mycotoxin ingestion on health status and animal performance and practical strategies to counteract their negative effects, Toxins, 7, 3057-3111.

Galtier, P., 1998. Biological fate of mycotoxins in animals, Revue De Medecine Veterinaire, 149, 549554.

Garcia-Morales, M. H.; Perez-Velazquez, M.; Gonzalez-Felix, M. L.; Burgos-Hernandez, A.; CortezRocha, M. O.; Bringas-Alvarado, L.; Ezquerra-Brauer, J. M., 2015. Effects of fumonisin b-1containing feed on the muscle proteins and ice-storage life of white shrimp (litopenaeus vannamei), Journal of Aquatic Food Product Technology, 24, 340-353.

Gbore, F. A., 2010. Brain and hypophyseal acetylcholinesterase activity of pubertal boars fed dietary fumonisin b1, J Anim Physiol Anim Nutr (Berl), 94, e123-129.

Gbore, F. A., 2009. Growth performance and puberty attainment in growing pigs fed dietary fumonisin b(1), J Anim Physiol Anim Nutr (Berl), 93, 761-767.

Gbore, F. A., 2009. Reproductive organ weights and semen quality of pubertal boars fed dietary fumonisin b1, Animal, 3, 1133-1137.

Gbore, F. A.; Egbunike, G. N., 2008. Testicular and epididymal sperm reserves and sperm production of pubertal boars fed dietary fumonisin b(1), Anim Reprod Sci, 105, 392-397.

Gbore, F. A.; Adewole, A. M.; Oginni, O.; Oguntolu, M. F.; Bada, A. M.; Akele, O., 2010. Growth performance, haematology and serum biochemistry of african catfish (clarias gariepinus) fingerlings fed graded levels of dietary fumonisin b1, Mycotoxin Res, 26, 221-227.

Gbore, F. A.; Akele, O., 2010. Growth performance, haematology and serum biochemistry of female rabbits (oryctolagus cuniculus) fed dietary fumonisin, Veterinarski Arhiv, 80, 431-443. 
Giannitti, F.; Diab, S. S.; Pacin, A. M.; Barrandeguy, M.; Larrere, C.; Ortega, J.; Uzal, F. A., 2011. Equine leukoencephalomalacia (elem) due to fumonisins b1 and b2 in argentina, Pesquisa Veterinaria Brasileira, 31, 407-412.

Gilchrist, D. G.; Wang, H.; Bostock, R. M., 1995. Sphingosine-related mycotoxins in plant and animal diseases, Canadian Journal of Botany-Revue Canadienne De Botanique, 73, S459-S467.

Girish, C. K.; Smith, T. K., 2008. Impact of feed-borne mycotoxins on avian cell-mediated and humoral immune responses, World Mycotoxin Journal, 1, 105-121.

Glavits, R.; Palfi, V.; Toth, A., 2005. Cholesterol granuloma (plexus cholesteatoma) in a horse - case report, Magyar Allatorvosok Lapja, 127, 259-262.

Goel, S.; Lenz, S. D.; Lumlertdacha, S.; Lovell, R. T.; Shelby, R. A.; Li, M.; Riley, R. T.; Kemppainen, B. W., 1994. Sphingolipid levels in catfish consuming fusarium-moniliforme corn culture material containing fumonisins, Aquatic Toxicology, 30, 285-294.

Goel, S.; Schumacher, J.; Lenz, S. D.; Kemppainen, B. W., 1996. Effects of fusarium moniliforme isolates on tissue and serum sphingolipid concentrations in horses, Veterinary and Human Toxicology, 38, 265-270.

Grenier, B.; Bracarense, A. P.; Schwartz, H. E.; Lucioli, J.; Cossalter, A. M.; Moll, W. D.; Schatzmayr, G.; Oswald, I. P., 2013. Biotransformation approaches to alleviate the effects induced by fusarium mycotoxins in swine, J Agric Food Chem, 61, 6711-6719.

Grenier, B.; Bracarense, A. P.; Schwartz, H. E.; Trumel, C.; Cossalter, A. M.; Schatzmayr, G.; KolfClauw, M.; Moll, W. D.; Oswald, I. P., 2012. The low intestinal and hepatic toxicity of hydrolyzed fumonisin $b(1)$ correlates with its inability to alter the metabolism of sphingolipids, Biochem Pharmacol, 83, 1465-1473.

Grenier, B.; Loureiro-Bracarense, A. P.; Lucioli, J.; Pacheco, G. D.; Cossalter, A. M.; Moll, W. D.; Schatzmayr, G.; Oswald, I. P., 2011. Individual and combined effects of subclinical doses of deoxynivalenol and fumonisins in piglets, Molecular Nutrition \& Food Research, 55, 761-771.

Grenier, B.; Schwartz-Zimmermann, H. E.; Caha, S.; Moll, W. D.; Schatzmayr, G.; Applegate, T. J., 2015. Dose-dependent effects on sphingoid bases and cytokines in chickens fed diets prepared with fusarium verticillioides culture material containing fumonisins, Toxins, 7, 1253-1272.

Grimes, J. L.; Eleazer, T. H.; Hill, J. E., 1993. Paralysis of undetermined origin in bobwhite quail, Avian Diseases, 37, 582-584.

Gumprecht, L. A.; Beasley, V. R.; Weigel, R. M.; Parker, H. M.; Tumbleson, M. E.; Bacon, C. W.; Meredith, F. I.; Haschek, W. M., 1998. Development of fumonisin-induced hepatotoxicity and pulmonary edema in orally dosed swine: Morphological and biochemical alterations, Toxicologic Pathology, 26, 777-788.

Gumprecht, L. A.; Marcucci, A.; Weigel, R. M.; Vesonder, R. F.; Riley, R. T.; Showker, J. L.; Beasley, V. R.; Haschek, W. M., 1995. Effects of intravenous fumonisin b1 in rabbits: Nephrotoxicity and sphingolipid alterations, Nat Toxins, 3, 395-403.

Gurung, N. K.; Rankins, D. L.; Shelby, R. A.; Goel, S., 1998. Effects of fumonisin b(1)-contaminated feeds on weanling angora goats, Journal of Animal Science, 76, 2863-2870.

Guzman, R. E.; Bailey, K.; Casteel, S. W.; Turk, J.; Rottinghaus, G., 1997. Dietary fusarium moniliforme culture material induces in vitro tumor necrosis factor-alpha like activity in the sera of swine, Immunopharmacology and Immunotoxicology, 19, 279-289.

Guzman, R. E.; Casteel, S. W.; Rottinghaus, G. E.; Turk, J. R., 1997. Chronic consumption of fumonisins derived from fusarium moniliforme culture material: Clinical and pathologic effects in swine, Journal of Veterinary Diagnostic Investigation, 9, 216-218. 
Hall, J. O.; Javed, T.; Bennett, G. A.; Richard, J. L.; Dombrink-Kurtzman, M. A.; Cote, L. M.; Buck, W. B., 1995. Serum vitamin a (retinol) reduction in broiler chicks on feed amended with fusarium proliferatum culture material or fumonisin b1 and moniliformin, J Vet Diagn Invest, 7, 416-418.

Halloy, D. J.; Gustin, P. G.; Bouhet, S.; Oswald, I. P., 2005. Oral exposure to culture material extract containing fumonisins predisposes swine to the development of pneumonitis caused by pasteurella multocida, Toxicology, 213, 34-44.

Hammer, P.; Bluthgen, A.; Walte, H. G., 1996. Carry-over of fumonisin b-1 into the milk of lactating cows, Milchwissenschaft-Milk Science International, 51, 691-695.

Harrison, L. R.; Colvin, B. M.; Greene, J. T.; Newman, L. E.; Cole, J. R., Jr., 1990. Pulmonary edema and hydrothorax in swine produced by fumonisin $\mathrm{b} 1$, a toxic metabolite of fusarium moniliforme, $\mathrm{J}$ Vet Diagn Invest, 2, 217-221.

Harvey, B.; Edrington, T. S.; Kubena, L. F.; Rottinghaus, G. E.; Turk, J. R.; Genovese, K. J.; Ziprin, R. L.; Nisbet, D. J., 2002. Toxicity of fumonisin from fusarium verticillioides culture material and moniliformin from fusarium fujikuroi culture material when fed singly and in combination to growing barrows, J Food Prot, 65, 373-377.

Harvey, R. A.; Kubena, L. F.; Rottinghaus, G. E.; Turk, J. R.; Buckley, S. A., 1997. Effects of fumonisin and moniliformin from culture materials to growing swine, Cereal Research Communications, 25, 415-417.

Harvey, R. B.; Edrington, T. S.; Kubena, L. F.; Elissalde, M. H.; Casper, H. H.; Rottinghaus, G. E.; Turk, J. R., 1996. Effects of dietary fumonisin b1-containing culture material, deoxynivalenolcontaminated wheat, or their combination on growing barrows, Am J Vet Res, 57, 1790-1794.

Harvey, R. B.; Edrington, T. S.; Kubena, L. F.; Elissalde, M. H.; Rottinghaus, G. E., 1995. Influence of aflatoxin and fumonisin b1-containing culture material on growing barrows, Am J Vet Res, 56, 1668-1672.

Haschek, W. M.; Gumprecht, L. A.; Smith, G.; Tumbleson, M. E.; Constable, P. D., 2001. Fumonisin toxicosis in swine: An overview of porcine pulmonary edema and current perspectives, Environmental Health Perspectives, 109, 251-257.

Haschek, W. M.; Motelin, G.; Ness, D. K.; Harlin, K. S.; Hall, W. F.; Vesonder, R. F.; Peterson, R. E.; Beasley, V. R., 1992. Characterization of fumonisin toxicity in orally and intravenously dosed swine, Mycopathologia, 117, 83-96.

Haschek, W. M.; Waggoner, A. L.; Hsiao, S.; Smith, G. W.; Tumbleson, M. E.; Eppley, R. M.; Foreman, J. H.; Constable, P. D., 2003. Clinicopathologic characterization of fumonisin b-1 (fb1) induced hepato, nephro-and neuro-toxicity in horses, Toxicological Sciences, 72, 252-252.

Henry, M. H.; Wyatt, R. D., 2001. The toxicity of fumonisin b1, b2, and b3, individually and in combination, in chicken embryos, Poult Sci, 80, 401-407.

Henry, M. H.; Wyatt, R. D.; Fletchert, O. J., 2000. The toxicity of purified fumonisin b1 in broiler chicks, Poult Sci, 79, 1378-1384.

Hussein, H. S.; Brasel, J. M., 2001. Toxicity, metabolism, and impact of mycotoxins on humans and animals, Toxicology, 167, 101-134.

Idahor, K. O.; Egbunike, G. N., 2012. Fertility potential of rabbit bucks fed maize-based diets containing graded levels of fumonisin b-1, World Rabbit Science, 20, 81-88.

Javed, T.; Bunte, R. M.; Dombrink-Kurtzman, M. A.; Richard, J. L.; Bennett, G. A.; Cote, L. M.; Buck, W. B., 2005. Comparative pathologic changes in broiler chicks on feed amended with fusarium proliferatum culture material or purified fumonisin b1 and moniliformin, Mycopathologia, 159, 553564. 
Javed, T.; Bennett, G. A.; Richard, J. L.; Dombrink-Kurtzman, M. A.; Cote, L. M.; Buck, W. B., 1993. Mortality in broiler chicks on feed amended with fusarium proliferatum culture material or with purified fumonisin b1 and moniliformin, Mycopathologia, 123, 171-184.

Javed, T.; Dombrink-Kurtzman, M. A.; Richard, J. L.; Bennett, G. A.; Cote, L. M.; Buck, W. B., 1995. Serohematologic alterations in broiler chicks on feed amended with fusarium proliferatum culture material on fumonisin b1 and moniliformin, J Vet Diagn Invest, 7, 520-526.

Jiang, S. Z.; Li, Z.; Wang, G. Y.; Yang, Z. B.; Yang, W. R.; Zhang, G. G.; Wu, Y. B., 2014. Effects of fusarium mycotoxins with yeast cell wall absorbent on hematology, serum biochemistry, and oxidative stress in broiler chickens, Journal of Applied Poultry Research, 23, 165-173.

Jovanovic, M.; Trailovic, D.; Kukolj, V.; Nesic, S.; Marinkovic, D.; Nedeljkovic-Trailovic, J.; Strajn, B. J.; Milicevic, D., 2015. An outbreak of fumonisin toxicosis in horses in serbia, World Mycotoxin Journal, 8, 387-391.

Kellerman, T. S.; Marasas, W. F.; Thiel, P. G.; Gelderblom, W. C.; Cawood, M.; Coetzer, J. A., 1990. Leukoencephalomalacia in two horses induced by oral dosing of fumonisin b1, Onderstepoort J Vet Res, 57, 269-275.

Kostro, K.; Bednarek, D.; Aleksiewicz, R.; Jarosz, L.; Lisiecka, U.; Zmuda, A.; Wojtaszczyk, P., 2010. Serum amyloid a concentrations and lysozyme bacteriolytic activity in the serum of sheep with natural zearalenosis, Bulletin of the Veterinary Institute in Pulawy, 54, 383-388.

Kovacic, S.; Pepeljnjak, S.; Petrinec, Z.; Klaric, M. S., 2009. Fumonisin b1 neurotoxicity in young carp (cyprinus carpio I.), Arh Hig Rada Toksikol, 60, 419-426.

Kubena, L. F.; Edrington, T. S.; Kamps-Holtzapple, C.; Harvey, R. B.; Elissalde, M. H.; Rottinghaus, G. E., 1995. Effects of feeding fumonisin b1 present in fusarium moniliforme culture material and aflatoxin singly and in combination to turkey poults, Poult Sci, 74, 1295-1303.

Kubena, L. F.; Edrington, T. S.; Harvey, R. B.; Phillips, T. D.; Sarr, A. B.; Rottinghaus, G. E., 1997. Individual and combined effects of fumonisin b1 present in fusarium moniliforme culture material and diacetoxyscirpenol or ochratoxin a in turkey poults, Poult Sci, 76, 256-264.

Kubena, L. F.; Edrington, T. S.; Harvey, R. B.; Buckley, S. A.; Phillips, T. D.; Rottinghaus, G. E.; Casper, H. H., 1997. Individual and combined effects of fumonisin b1 present in fusarium moniliforme culture material and t-2 toxin or deoxynivalenol in broiler chicks, Poult Sci, 76, 12391247.

Kubena, L. F.; Edrington, T. S.; Kamps-Holtzapple, C.; Harvey, R. B.; Elissalde, M. H.; Rottinghaus, G. E., 1995. Influence of fumonisin b1, present in fusarium moniliforme culture material, and t-2 toxin on turkey poults, Poult Sci, 74, 306-313.

Kubena, L. F.; Harvey, R. B.; Buckley, S. A.; Bailey, R. H.; Rottinghaus, G. E., 1999. Effects of longterm feeding of diets containing moniliformin, supplied by fusarium fujikuroi culture material, and fumonisin, supplied by fusarium moniliforme culture material, to laying hens, Poultry Science, 78, 1499-1505.

Kupper, J.; Naegeli, H.; Eser, M. W., 2010. Common poisonings in the horse, Praktische Tierarzt, 91, 492-498.

LaBorde, J. B.; Terry, K. K.; Howard, P. C.; Chen, J. J.; Collins, T. F.; Shackelford, M. E.; Hansen, D. K., 1997. Lack of embryotoxicity of fumonisin b1 in new zealand white rabbits, Fundam Appl Toxicol, 40, 120-128.

Lalles, J. P.; Lessard, M.; Oswald, I. P.; David, J. C., 2010. Consumption of fumonisin b1 for 9 days induces stress proteins along the gastrointestinal tract of pigs, Toxicon, 55, 244-249.

Ledoux, D. R.; Bermudez, A. J.; Rottinghaus, G. E., 1996. Effects of feeding fusarium moniliforme culture material, containing known levels of fumonisin b1, in the young turkey poult, Poult Sci, 75 , 1472-1478. 
Ledoux, D. R.; Bermudez, A. J.; Rottinghaus, G. E.; Broomhead, J.; Bennett, G. A., 1995. Effects of feeding fusarium-fujikuroi culture material, containing known levels of moniliformin, in young broiler chicks, Poultry Science, 74, 297-305.

Ledoux, D. R.; Brown, T. P.; Weibking, T. S.; Rottinghaus, G. E., 1992. Fumonisin toxicity in broiler chicks, Journal of Veterinary Diagnostic Investigation, 4, 330-333.

Ledoux, D. R.; Broomhead, J. N.; Bermudez, A. J.; Rottinghaus, G. E., 2003. Individual and combined effects of the fusarium mycotoxins fumonisin b1 and moniliformin in broiler chicks, Avian Dis, 47, 1368-1375.

Leitgeb, R.; Lew, H.; Wetscherek, W.; Bohm, J.; Quinz, A., 1999. Influence of fusariotoxins on growing and slaughtering perfomance of broilers, Bodenkultur, 50, 57-66.

Leitgeb, R.; Lew, H.; Khidr, R.; Bohm, J.; Zollitsch, W.; Wagner, E., 2000. Influence of fusarium toxins on growth and carcass characteristics of turkeys, Bodenkultur, 51, 171-178.

Leslie, J. F.; Marasas, W. F.; Shephard, G. S.; Sydenham, E. W.; Stockenstrom, S.; Thiel, P. G., 1996. Duckling toxicity and the production of fumonisin and moniliformin by isolates in the a and $e$ mating populations of gibberella fujikuroi (fusarium moniliforme), Appl Environ Microbiol, 62, 11821187.

Lessard, M.; Boudry, G.; Seve, B.; Oswald, I. P.; Lalles, J. P., 2009. Intestinal physiology and peptidase activity in male pigs are modulated by consumption of corn culture extracts containing fumonisins, Journal of Nutrition, 139, 1303-1307.

Li, Y. C.; Ledoux, D. R.; Bermudez, A. J.; Fritsche, K. L.; Rottinghaus, G. E., 1999. Effects of fumonisin $\mathrm{b}(1)$ on selected immune responses in broiler chicks, Poultry Science, 78, 1275-1282.

Li, Y. C.; Ledoux, D. R.; Bermudez, A. J.; Fritsche, K. L.; Rottinghaus, G. E., 2000. The individual and combined effects of fumonisin $b(1)$ and moniliformin on performance and selected immune parameters in turkey poults, Poultry Science, 79, 871-878.

Lumlertdacha, S.; Lovell, R. T.; Shelby, R. A.; Lenz, S. D.; Kemppainen, B. W., 1995. Growth, hematology, and histopathology of channel catfish, ictalurus-punctatus, fed toxins from fusariummoniliforme, Aquaculture, 130, 201-218.

Manning, B. B.; Abbas, H. K., 2012. The effect of fusarium mycotoxins deoxynivalenol, fumonisin, and moniliformin from contaminated moldy grains on aquaculture fish, Toxin Reviews, 31, 11-15.

Marasas, W. F., 1995. Fumonisins: Their implications for human and animal health, Nat Toxins, 3, 193-198; discussion 221.

Marasas, W. F.; Kellerman, T. S.; Gelderblom, W. C.; Coetzer, J. A.; Thiel, P. G.; van der Lugt, J. J., 1988. Leukoencephalomalacia in a horse induced by fumonisin b1 isolated from fusarium moniliforme, Onderstepoort J Vet Res, 55, 197-203.

Marin, D. E.; Taranu, I.; Pascale, F.; Lionide, A.; Burlacu, R.; Bailly, J. D.; Oswald, I. P., 2006. Sexrelated differences in the immune response of weanling piglets exposed to low doses of fumonisin extract, British Journal of Nutrition, 95, 1185-1192.

Masching, S.; Naehrer, K.; Schwartz-Zimmermann, H. E.; Sarandan, M.; Schaumberger, S.; Dohnal, I.; Nagl, V.; Schatzmayr, D., 2016. Gastrointestinal degradation of fumonisin b(1) by carboxylesterase fumd prevents fumonisin induced alteration of sphingolipid metabolism in turkey and swine, Toxins (Basel), 8.

Mathur, S.; Constable, P. D.; Eppley, R. M.; Tumbleson, M. E.; Smith, G. W.; Tranquilli, W. J.; Morin, D. E.; Haschek, W. M., 2001. Fumonisin b(1) increases serum sphinganine concentration but does not alter serum sphingosine concentration or induce cardiovascular changes in milk-fed calves, Toxicol Sci, 60, 379-384. 
Mathur, S.; Constable, P. D.; Eppley, R. M.; Waggoner, A. L.; Tumbleson, M. E.; Haschek, W. M., 2001. Fumonisin $b(1)$ is hepatotoxic and nephrotoxic in milk-fed calves, Toxicol Sci, 60, 385-396.

Matteri, R. L.; Becker, B. A.; Pace, L.; Rottinghaus, G. E., 1994. Effects of thermal environment and maternal exposure to fumonisin b1 on luteinizing-hormone secretion in preweaning gilts, Biology of Reproduction, 50, 68-68.

Meissonnier, G. M.; Oswald, I. P.; Galtier, P., 2005. Aflatoxicosis in swine - a bibliographic review of clinical cases and experimental data, Revue De Medecine Veterinaire, 156, 591-605.

Melinda, K.; Judit, F.; Meyer, K.; Mohr, K.; Bauer, J.; Imre, R.; Ferenc, V.; Peter, H.; Ferenc, K., 2004. Residue formation of fumonisin $b-1$ in porcine tissues after feeding diet of high toxin concentration, Magyar Allatorvosok Lapja, 126, 146-154.

Meredith, F. I.; Riley, R. T.; Bacon, C. W.; Showker, J. L.; Williams, D.; Carlson, D., 1997. Dietary levels of fumonisin $\mathrm{fb} 1$ in feed correlated with sphingoid base elevation in rainbow trout liver and kidney tissue, Abstracts of Papers of the American Chemical Society, 213, 80-AGFD.

Meredith, F. I.; Riley, R. T.; Bacon, C. W.; Williams, D. E.; Carlson, D. B., 1998. Extraction, quantification, and biological availability of fumonisin b1 incorporated into the oregon test diet and fed to rainbow trout, J Food Prot, 61, 1034-1038.

Mexia-Salazar, A. L.; Hernandez-Lopez, J.; Burgos-Hernandez, A.; Cortez-Rocha, M. O.; CastroLongoria, R.; Ezquerra-Brauer, J. M., 2008. Role of fumonisin b1 on the immune system, histopathology, and muscle proteins of white shrimp (litopenaeus vannamei), Food Chem, 110, 471-479.

Morgan, M. K.; Bursian, S. J.; Schroeder, J. J.; Aulerich, R. J., 1997. Dietary fumonisins disrupt sphingolipid metabolism in mink and increase the free sphinganine to sphingosine ratio in urine but not in hair, Faseb Journal, 11, 3395-3395.

Morgan, M. K.; Schroeder, J. J.; Rottinghaus, G. E.; Powell, D. C.; Bursian, S. J.; Aulerich, R. J., 1997. Dietary fumonisins disrupt sphingolipid metabolism in mink and increase the free sphinganine to sphingosine ratio in urine but not in hair, Veterinary and Human Toxicology, 39, 334-336.

Morgavi, D. P.; Riley, R. T., 2007. An historical overview of field disease outbreaks known or suspected to be caused by consumption of feeds contaminated with fusarium toxins, Animal Feed Science and Technology, 137, 201-212.

Motelin, G. K.; Haschek, W. M.; Ness, D. K.; Hall, W. F.; Harlin, K. S.; Schaeffer, D. J.; Beasley, V. R., 1994. Temporal and dose-response features in swine fed corn screenings contaminated with fumonisin mycotoxins, Mycopathologia, 126, 27-40.

Muller, G.; Kielstein, P.; Rosner, H.; Kohler, H.; Berndt, A.; Heller, M., 2000. Do mycotoxins impair immune and defense reactions in pigs?, Praktische Tierarzt, 81, 932-+.

Muller, G.; Kielstein, P.; Rosner, H.; Berndt, A.; Heller, M.; Kohler, H., 1999. Studies on the influence of combined administration of ochratoxin a, fumonisin b1, deoxynivalenol and t2 toxin on immune and defence reactions in weaner pigs, Mycoses, 42, 485-493.

Nagaraj, R. Y.; Wu, W. D.; Vesonder, R. F., 1994. Toxicity of corn culture material of fusarium proliferatum m-7176 and nutritional intervention in chicks, Poult Sci, 73, 617-626.

Ogido, R.; Oliveira, C. A.; Ledoux, D. R.; Rottinghaus, G. E.; Correa, B.; Butkeraitis, P.; Reis, T. A.; Goncales, E.; Albuquerque, R., 2004. Effects of prolonged administration of aflatoxin b1 and fumonisin b1 in laying japanese quail, Poult Sci, 83, 1953-1958.

Oliveira, E. M.; Tanure, Cbgs; Castejon, F. V.; Castro, Rmad; Rocha, F. R. T.; Carvalho, F. B.; Andrade, M. A.; Stringhini, J. H., 2015. Performance and nutrient metabolizability in broilers fed diets containing corn contaminated with fumonisin b1 and esterified glucomannan, Brazilian Journal of Poultry Science, 17, 313-318. 
Orsi, R. B.; Oliveira, C. A.; Dilkin, P.; Xavier, J. G.; Direito, G. M.; Correa, B., 2007. Effects of oral administration of aflatoxin b1 and fumonisin b1 in rabbits (oryctolagus cuniculus), Chem Biol Interact, 170, 201-208.

Oswald, I. P.; Desautels, C.; Laffitte, J.; Fournout, S.; Peres, S. Y.; Odin, M.; Le Bars, P.; Le Bars, J.; Fairbrother, J. M., 2003. Mycotoxin fumonisin b1 increases intestinal colonization by pathogenic escherichia coli in pigs, Appl Environ Microbiol, 69, 5870-5874.

Osweiler, G. D., 2001. Mycotoxins, Veterinary Clinics of North America-Equine Practice, 17, 547-+.

Osweiler, G. D.; Kehrli, M. E.; Stabel, J. R.; Thurston, J. R.; Ross, P. F.; Wilson, T. M., 1993. Effects of fumonisin-contaminated corn screenings on growth and health of feeder calves, Journal of Animal Science, 71, 459-466.

Osweiler, G. D.; Ross, P. F.; Wilson, T. M.; Nelson, P. E.; Witte, S. T.; Carson, T. L.; Rice, L. G.; Nelson, H. A., 1992. Characterization of an epizootic of pulmonary edema in swine associated with fumonisin in corn screenings, J Vet Diagn Invest, 4, 53-59.

Penner, J. D.; Casteel, S. W.; Pittman, L., Jr.; Rottinghaus, G. E.; Wyatt, R. D., 1998. Developmental toxicity of purified fumonisin b1 in pregnant syrian hamsters, J Appl Toxicol, 18, 197-203.

Pepeljnjak, S.; Petrinec, Z.; Kovacic, S.; Segvic, M., 2003. Screening toxicity study in young carp (cyprinus carpio I.) on feed amended with fumonisin b1, Mycopathologia, 156, 139-145.

Petrinec, Z.; Pepeljnjak, S.; Kovacic, S.; Krznaric, A., 2004. Fumonisin b1 causes multiple lesions in common carp (cyprinus carpio), Dtsch Tierarztl Wochenschr, 111, 358-363.

Piramanayagam, S.; George, V. T., 2002. Effect of dietary fumonisin mycotoxin on the growth rate of broiler chicken, Indian Veterinary Journal, 79, 1022-1025.

Piramanayagam, S.; George, V. T., 2001. Subacute toxicity of 'fumonisin' in broiler chicks - changes in some biochemical parameters, Indian Veterinary Journal, 78, 27-29.

Piva, A.; Casadei, G.; Pagliuca, G.; Cabassi, E.; Galvano, F.; Solfrizzo, M.; Riley, R. T.; Diaz, D. E., 2005. Activated carbon does not prevent the toxicity of culture material containing fumonisin b1 when fed to weanling piglets, J Anim Sci, 83, 1939-1947.

Plumlee, K. H.; Galey, F. D., 1994. Neurotoxic mycotoxins: A review of fungal toxins that cause neurological disease in large animals, J Vet Intern Med, 8, 49-54.

Poersch, A. B.; Trombetta, F.; Braga, A. C. M.; Boeira, S. P.; Oliveira, M. S.; Dilkin, P.; Mallmann, C. A.; Fighera, M. R.; Royes, L. F. F.; Oliveira, M. S.; Furian, A. F., 2014. Involvement of oxidative stress in subacute toxicity induced by fumonisin b-1 in broiler chicks, Veterinary Microbiology, 174, 180-185.

Posa, R.; Donko, T.; Bogner, P.; Kovacs, M.; Repa, I.; Magyar, T., 2011. Interaction of bordetella bronchiseptica, pasteurella multocida, and fumonisin b1 in the porcine respiratory tract as studied by computed tomography, Canadian Journal of Veterinary Research-Revue Canadienne De Recherche Veterinaire, 75, 176-182.

Posa, R.; Kovacs, M.; Donko, T.; Szabo-Fodor, J.; Mondok, J.; Bogner, P.; Repa, I.; Magyar, T., 2009. Effect of mycoplasma hyopneumoniae and fumonisin b-1 toxin on the lung in pigs, Italian Journal of Animal Science, 8, 172-174.

Posa, R.; Magyar, T.; Stoev, S. D.; Glavits, R.; Donko, T.; Repa, I.; Kovacs, M., 2013. Use of computed tomography and histopathologic review for lung lesions produced by the interaction between mycoplasma hyopneumoniae and fumonisin mycotoxins in pigs, Veterinary Pathology, 50, 971-979.

Posa, R.; Stoev, S.; Kovacs, M.; Donko, T.; Repa, I.; Magyar, T., 2016. A comparative pathological finding in pigs exposed to fumonisin b1 and/or mycoplasma hyopneumoniae, Toxicol Ind Health, $32,998-1012$. 
Powell, D. C.; Bursian, S. J.; Bush, C. R.; Render, J. A.; Rottinghaus, G. E.; Aulerich, R. J., 1996. Effects of dietary exposure to fumonisins from fusarium moniliforme culture material $(\mathrm{m}-1325)$ on the reproductive performance of female mink, Archives of Environmental Contamination and Toxicology, 31, 286-292.

Prathapkumar, S. H.; Rao, V. S.; Paramkishan, R. J.; Bhat, R. V., 1997. Disease outbreak in laying hens arising from the consumption of fumonisin-contaminated food, British Poultry Science, 38, 475-479.

Prelusky, D. B.; Miller, J. D.; Trenholm, H. L., 1996. Disposition of 14c-derived residues in tissues of pigs fed radiolabelled fumonisin b1, Food Addit Contam, 13, 155-162.

Prelusky, D. B.; Savard, M. E.; Trenholm, H. L., 1995. Pilot study on the plasma pharmacokinetics of fumonisin b1 in cows following a single dose by oral gavage or intravenous administration, Nat Toxins, 3, 389-394.

Prelusky, D. B.; Trenholm, H. L.; Rotter, B. A.; Miller, J. D.; Savard, M. E.; Yeung, J. M.; Scott, P. M., 1996. Biological fate of fumonisin b1 in food-producing animals, Adv Exp Med Biol, 392, 265-278.

Prelusky, D. B.; Trenholm, H. L.; Savard, M. E., 1994. Pharmacokinetic fate of 14c-labelled fumonisin b1 in swine, Nat Toxins, 2, 73-80.

Qureshi, M. A.; Garlich, J. D.; Hagler, W. M.; Weinstock, D., 1995. Fusarium proliferatum culture material alters several production and immune performance parameters in white leghorn chickens, Immunopharmacology and Immunotoxicology, 17, 791-804.

Raghavender, C. R.; Reddy, B. N., 2009. Human and animal disease outbreaks in india due to mycotoxins other than aflatoxins, World Mycotoxin Journal, 2, 23-30.

Ramos, C. M.; Martinez, E. M.; Carrasco, A. C.; Puente, J. H. L.; Quezada, F.; Perez, J. T.; Oswald, I. P.; Elvira, S. M., 2010. Experimental trial of the effect of fumonisin b-1 and the prrs virus in swine, Journal of Animal and Veterinary Advances, 9, 1301-1310.

Rauber, R. H.; Dilkin, P.; Mallmann, A. O.; Marchioro, A.; Mallmann, C. A.; Borsoi, A.; Nascimento, V. P., 2012. Individual and combined effects of salmonella typhimurium lipopolysaccharide and fumonisin b1 in broiler chickens, Poult Sci, 91, 2785-2791.

Rauber, R. H.; Oliveira, M. S.; Mallmann, A. O.; Dilkin, P.; Mallmann, C. A.; Giacomini, L. Z.; Nascimento, V. P., 2013. Effects of fumonisin b-1 on selected biological responses and performance of broiler chickens, Pesquisa Veterinaria Brasileira, 33, 1081-1086.

Raynal, M.; Bailly, J. D.; Benard, G.; Guerre, P., 2001. Effects of fumonisin b1 present in fusarium moniliforme culture material on drug metabolising enzyme activities in ducks, Toxicology Letters, 121, 179-190.

Razzazi-Fazeli, E.; Bohm, J.; Adler, A.; Zentek, J., 2003. Fusarium mycotoxins and their significance in animal husbandry, Wiener Tierarztliche Monatsschrift, 90, 202-210.

Restum, J. C.; Bursian, S. J.; Millerick, M.; Render, J. A.; Merrill, A. H., Jr.; Wang, E.; Rottinghaus, G. E.; Aulerich, R. J., 1995. Chronic toxicity of fumonisins from fusarium moniliforme culture material (m-1325) to mink, Arch Environ Contam Toxicol, 29, 545-550.

Riet-Correa, F.; Rivero, R.; Odriozola, E.; Adrien Mde, L.; Medeiros, R. M.; Schild, A. L., 2013. Mycotoxicoses of ruminants and horses, J Vet Diagn Invest, 25, 692-708.

Riley, R. T.; An, N. H.; Showker, J. L.; Yoo, H. S.; Norred, W. P.; Chamberlain, W. J.; Wang, E.; Merrill, A. H.; Motelin, G.; Beasley, V. R.; Haschek, W. M., 1993. Alteration of tissue and serum sphinganine to sphingosine ratio - an early biomarker of exposure to fumonisin-containing feeds in pigs, Toxicology and Applied Pharmacology, 118, 105-112.

Riley, R. T.; An, N. H.; Showker, J. L.; Yoo, H. S.; Norred, W. P.; Chamberlain, W. J.; Wang, E.; Merrill, A. H., Jr.; Motelin, G.; Beasley, V. R.; et al.,, 1993. Alteration of tissue and serum 
sphinganine to sphingosine ratio: An early biomarker of exposure to fumonisin-containing feeds in pigs, Toxicol Appl Pharmacol, 118, 105-112.

Riley, R. T.; Showker, J. L.; Owens, D. L.; Ross, P. F., 1997. Disruption of sphingolipid metabolism and induction of equine leukoencephalomalacia by fusarium proliferatum culture material containing fumonisin $b(2)$ or $b(3)$, Environ Toxicol Pharmacol, 3, 221-228.

Riley, R. T.; Voss, K. A.; Norred, W. P.; Sharma, R. P.; Wang, E.; Merrill, A. H., 1998. Fumonisins: Mechanism of mycotoxicity, Revue De Medecine Veterinaire, 149, 617-626.

Rosiles, M. R.; Bautista, J.; Fuentes, V. O.; Ross, F., 1998. An outbreak of equine leukoencephalomalacia at oaxaca, mexico, associated with fumonisin b1, Journal of Veterinary Medicine Series a-Physiology Pathology Clinical Medicine, 45, 299-302.

Ross, P. F., 1995. Effects of fumonisins in domestic livestock, Abstracts of Papers of the American Chemical Society, 209, 60-AGFD.

Ross, P. F.; Ledet, A. E.; Owens, D. L.; Rice, L. G.; Nelson, H. A.; Osweiler, G. D.; Wilson, T. M., 1993. Experimental equine leukoencephalomalacia, toxic hepatosis, and encephalopathy caused by corn naturally contaminated with fumonisins, Journal of Veterinary Diagnostic Investigation, 5, 69-74.

Ross, P. F.; Ledet, A. E.; Owens, D. L., 1993. Experimental equine leukoencephalomalacia, toxic hepatosis, and encephalopathy caused by corn naturally contaminated with fumonisins (vol 5, pg 72, 1993), Journal of Veterinary Diagnostic Investigation, 5, 504-504.

Ross, P. F.; Nelson, P. E.; Owens, D. L.; Rice, L. G.; Nelson, H. A.; Wilson, T. M., 1994. Fumonisin b2 in cultured fusarium proliferatum, m-6104, causes equine leukoencephalomalacia, J Vet Diagn Invest, 6, 263-265.

Ross, P. F.; Nelson, P. E.; Richard, J. L.; Osweiler, G. D.; Rice, L. G.; Plattner, R. D.; Wilson, T. M., 1990. Production of fumonisins by fusarium moniliforme and fusarium proliferatum isolates associated with equine leukoencephalomalacia and a pulmonary edema syndrome in swine, Appl Environ Microbiol, 56, 3225-3226.

Ross, P. F.; Rice, L. G.; Plattner, R. D.; Osweiler, G. D.; Wilson, T. M.; Owens, D. L.; Nelson, H. A.; Richard, J. L., 1991. Concentrations of fumonisin b1 in feeds associated with animal health problems, Mycopathologia, 114, 129-135.

Ross, P. F.; Rice, L. G.; Reagor, J. C.; Osweiler, G. D.; Wilson, T. M.; Nelson, H. A.; Owens, D. L.; Plattner, R. D.; Harlin, K. A.; Richard, J. L.; et al.,, 1991. Fumonisin b1 concentrations in feeds from 45 confirmed equine leukoencephalomalacia cases, J Vet Diagn Invest, 3, 238-241.

Ross, P. F.; Rice, L. G.; Osweiler, G. D.; Nelson, P. E.; Richard, J. L.; Wilson, T. M., 1992. A review and update of animal toxicoses associated with fumonisin-contaminated feeds and production of fumonisins by fusarium isolates, Mycopathologia, 117, 109-114.

Rossi, F.; Morlacchini, M.; Fusconi, G.; Pietri, A.; Piva, G., 2011. Effect of insertion of bt gene in corn and different fumonisin content on growth performance of weaned piglets, Italian Journal of Animal Science, 10, 95-100.

Rotter, B. A.; Prelusky, D. B.; Fortin, A.; Miller, J. D.; Savard, M. E., 1997. Impact of pure fumonisin b1 on various metabolic parameters and carcass quality of growing-finishing swine - preliminary findings, Canadian Journal of Animal Science, 77, 465-470.

Rotter, B. A.; Thompson, B. K.; Prelusky, D. B.; Trenholm, H. L.; Stewart, B.; Miller, J. D.; Savard, M. E., 1996. Response of growing swine to dietary exposure to pure fumonisin b1 during an eightweek period: Growth and clinical parameters, Nat Toxins, 4, 42-50.

Sandmeyer, L. S.; Vujanovic, V.; Petrie, L.; Campbell, J. R.; Bauer, B. S.; Allen, A. L.; Grahn, B. H., 2015. Optic neuropathy in a herd of beef cattle in alberta associated with consumption of moldy corn, Canadian Veterinary Journal-Revue Veterinaire Canadienne, 56, 249-256. 
Satheesh, K.; Ahmed, M. N.; Srilatha, C.; Rao, T. C. S., 2004. Effects of fumonisin-b-1 toxicity on serum bio-chemistry in broiler chicken, Indian Veterinary Journal, 81, 1097-1099.

Satheesh, K.; Ahmed, M. N.; Srilatha, C. H.; Rao, Tscs, 2005. Histopathological evaluation of fumonisin b-1 toxicity in broiler chicken, Indian Veterinary Journal, 82, 1141-1144.

Scaff, R. M. C.; Scussel, V. M., 2008. Ultra-structural and histochemical analysis of channel catfish (ictalurus punctatus) liver treated with fumonisin b-1, Brazilian Archives of Biology and Technology, 51, 333-344.

Schatzmayr, G.; Streit, E., 2013. Global occurrence of mycotoxins in the food and feed chain: Facts and figures, World Mycotoxin Journal, 6, 213-222.

Schumacher, J.; Mullen, J.; Shelby, R.; Lenz, S.; Ruffin, D. C.; Kemppainen, B. W., 1995. An investigation of the role of fusarium moniliforme in duodenitis/proximal jejunitis of horses, Vet Hum Toxicol, 37, 39-45.

Sharma, D.; Asrani, R. K.; Ledoux, D. R.; Jindal, N.; Rottinghaus, G. E.; Gupta, V. K., 2008. Individual and combined effects of fumonisin $b(1)$ and moniliformin on clinicopathological and cell-mediated immune response in japanese quail, Poultry Science, 87, 1039-1051.

Siloto, E. V.; Oliveira, E. F.; Sartori, J. R.; Fascina, V. B.; Martins, B. A.; Ledoux, D. R.; Rottinghaus, G. E.; Sartori, D. R., 2013. Lipid metabolism of commercial layers fed diets containing aflatoxin, fumonisin, and a binder, Poult Sci, 92, 2077-2083.

Smith, G. W.; Constable, P. D.; Foreman, J. H.; Eppley, R. M.; Waggoner, A. L.; Tumbleson, M. E.; Haschek, W. M., 2002. Cardiovascular changes associated with intravenous administration of fumonisin b1 in horses, Am J Vet Res, 63, 538-545.

Smith, G. W.; Constable, P. D.; Bacon, C. W.; Meredith, F. I.; Haschek, W. M., 1996. Cardiovascular effects of fumonisins in swine, Fundamental and Applied Toxicology, 31, 169-172.

Smith, G. W.; Constable, P. D.; Haschek, W. M., 1996. Cardiovascular responses to short-term fumonisin exposure in swine, Fundamental and Applied Toxicology, 33, 140-148.

Smith, G. W.; Constable, P. D.; Smith, A. R.; Bacon, C. W.; Meredith, F. I.; Wollenberg, G. K.; Haschek, W. M., 1996. Effects of fumonisin-containing culture material on pulmonary clearance in swine, American Journal of Veterinary Research, 57, 1233-1238.

Smith, G. W.; Constable, P. D.; Tumbleson, M. E.; Haschek, W. M., 1997. Fumonisins are negative inotropic and chronotropic agents in swine, Faseb Journal, 11, 2894-2894.

Smith, G. W.; Constable, P. D.; Eppley, R. M.; Tumbleson, M. E.; Gumprecht, L. A.; Haschek-Hock, W. M., 2000. Purified fumonisin $b(1)$ decreases cardiovascular function but does not alter pulmonary capillary permeability in swine, Toxicol Sci, 56, 240-249.

Smith, G. W.; Constable, P. D.; Tumbleson, M. E.; Rottinghaus, G. E.; Haschek, W. M., 1999. Sequence of cardiovascular changes leading to pulmonary edema in swine fed culture material containing fumonisin, American Journal of Veterinary Research, 60, 1292-1300.

Smith, G. W.; Constable, P. D.; Tumbleson, M. E.; Haschek, W. M., 1999. Sequence of cardiovascular changes leading to pulmonary edema in swine fed fumonisin, Faseb Journal, 13, A154-A154.

Souto, Pcmc; Ramalho, L. N. Z.; Ramalho, F. S.; Gregorio, M. C.; Bordin, K.; Cossalter, A. M.; Oswald, I. P.; Oliveira, C. A. F., 2015. Weight gain, feed consumption and histology of organs from piglets fed rations containing low levels of fumonisin b-1, Pesquisa Veterinaria Brasileira, 35, 451-455.

Step, D. L., 1993. Equine leukoencephalomalacia - discussion, Equine Practice, 15, 24-\&.

Stoev, S. D.; Gundasheva, D.; Zarkov, I.; Mircheva, T.; Zapryanova, D.; Denev, S.; Mitev, Y.; Daskalov, H.; Dutton, M.; Mwanza, M.; Schneider, Y. J., 2012. Experimental mycotoxic nephropathy in pigs provoked by a mouldy diet containing ochratoxin a and fumonisin b1, Experimental and Toxicologic Pathology, 64, 733-741. 
Sydenham, E. W.; Marasas, W. F. O.; Shephard, G. S.; Thiel, P. G.; Hirooka, E. Y., 1992. Fumonisin concentrations in brazilian feeds associated with field outbreaks of confirmed and suspected animal mycotoxicoses, Journal of Agricultural and Food Chemistry, 40, 994-997.

Szabo, A.; Szabo-Fodor, J.; Febel, H.; Romvari, R.; Kovacs, M., 2014. Individual and combined haematotoxic effects of fumonisin $\mathrm{b}(1)$ and $\mathrm{t}-2$ mycotoxins in rabbits, Food Chem Toxicol, 72, 257264.

Taranu, I.; Marin, D. E.; Bouhet, S.; Pascale, F.; Bailly, J. D.; Miller, J. D.; Pinton, P.; Oswald, I. P., 2005. Mycotoxin fumonisin b1 alters the cytokine profile and decreases the vaccinal antibody titer in pigs, Toxicol Sci, 84, 301-307.

Tardieu, D.; Bailly, J. D.; Skiba, F.; Metayer, J. P.; Grosjean, F.; Guerre, P., 2007. Chronic toxicity of fumonisins in turkeys, Poultry Science, 86, 1887-1893.

Tardieu, D.; Bailly, J. D.; Benard, G.; Tran, T. S.; Guerre, P., 2004. Toxicity of maize containing known levels of fumonisin b1 during force-feeding of ducks, Poultry Science, 83, 1287-1293.

Tardieu, D.; Tran, S. T.; Auvergne, A.; Babile, R.; Benard, G.; Bailly, J. D.; Guerre, P., 2006. Effects of fumonisins on liver and kidney sphinganine and the sphinganine to sphingosine ratio during chronic exposure in ducks, Chemico-Biological Interactions, 160, 51-60.

Tessari, E. N. C.; Kobashigawa, E.; Cardoso, Alsp; Ledoux, D. R.; Rottinghaus, G. E.; Oliveira, C. A. F., 2010. Effects of aflatoxin b-1 and fumonisin b-1 on blood biochemical parameters in broilers, Toxins, 2, 453-460.

Tessari, E. N.; Oliveira, C. A.; Cardoso, A. L.; Ledoux, D. R.; Rottinghaus, G. E., 2006. Effects of aflatoxin b1 and fumonisin b1 on body weight, antibody titres and histology of broiler chicks, $\mathrm{Br}$ Poult Sci, 47, 357-364.

Thibault, N.; Burgat, V.; Guerre, P., 1997. Fumonisins: Properties, sources and toxicity, Revue De Medecine Veterinaire, 148, 369-388.

Thiel, P. G.; Shephard, G. S.; Sydenham, E. W.; Marasas, W. F. O.; Nelson, P. E.; Wilson, T. M., 1991. Levels of fumonisin-b1 and fumonisin-b2 in feeds associated with confirmed cases of equine leukoencephalomalacia, Journal of Agricultural and Food Chemistry, 39, 109-111.

Todorova, K.; Dimitrov, P.; Toshkova, R.; Lazarova, S.; Gardeva, E.; Yossifova, L.; Andonova-Lilova, B.; Milcheva, R.; Russev, R., 2014. Influence of fumonisin b-1 and deoxynivalenol on the immune system of chickens after application in quantities, naturally presented in fodders, Comptes Rendus De L Academie Bulgare Des Sciences, 67, 139-144.

Todorova, K. S.; Kril, A. I.; Dimitrov, P. S.; Gardeva, E. G.; Toshkova, R. A.; Tasheva, Y. R.; Petrichev, M. H.; Russev, R. V., 2011. Effect of fumonisin b1 on lymphatic organs in broiler chickens pathomorphology, Bulletin of the Veterinary Institute in Pulawy, 55, 801-805.

Tornyos, G.; Kovacs, M.; Rusvai, M.; Horn, P.; Fodor, J.; Kovacs, F., 2003. Effect of dietary fumonisin b1 on certain immune parameters of weaned pigs, Acta Vet Hung, 51, 171-179.

Tran, S. T.; Auvergne, A.; Benard, G.; Bailly, J. D.; Tardieu, D.; Babile, R.; Guerre, P., 2005. Chronic effects of fumonisin b1 on ducks, Poult Sci, 84, 22-28.

Tuan, N. A.; Manning, B. B.; Lovell, R. T.; Rottinghaus, G. E., 2003. Responses of nile tilapia (oreochromis niloticus) fed diets containing different concentrations of moniliformin or fumonisin b1, Aquaculture, 217, 515-528.

Uhlinger, C., 1997. Leukoencephalomalacia, Veterinary Clinics of North America-Equine Practice, 13, 13-\&.

Vesonder, R. F.; Wu, W., 1998. Correlation of moniliformin, but not fumonisin b1 levels, in culture materials of fusarium isolates to acute death in ducklings, Poult Sci, 77, 67-72. 
Vetesi, F., 1999. Pathological aspects of selected swine respiratory disorders, Magyar Allatorvosok Lapja, 121, 467-475.

Voss, K. A.; Smith, G. W.; Haschek, W. M., 2007. Fumonisins: Toxicokinetics, mechanism of action and toxicity, Animal Feed Science and Technology, 137, 299-325.

Vudathala, D. K.; Prelusky, D. B.; Ayroud, M.; Trenholm, H. L.; Miller, J. D., 1994. Pharmacokinetic fate and pathological effects of 14c-fumonisin b1 in laying hens, Nat Toxins, 2, 81-88.

Wang, E.; Ross, P. F.; Wilson, T. M.; Riley, R. T.; Merrill, A. H., Jr., 1992. Increases in serum sphingosine and sphinganine and decreases in complex sphingolipids in ponies given feed containing fumonisins, mycotoxins produced by fusarium moniliforme, J Nutr, 122, 1706-1716.

Weibking, T. S.; Ledoux, D. R.; Bermudez, A. J.; Turk, J. R.; Rottinghaus, G. E.; Wang, E.; Merrill, A. $\mathrm{H}$. , Jr., 1993. Effects of feeding fusarium moniliforme culture material, containing known levels of fumonisin b1, on the young broiler chick, Poult Sci, 72, 456-466.

Weibking, T. S.; Ledoux, D. R.; Brown, T. P.; Rottinghaus, G. E., 1993. Fumonisin toxicity in turkey poults, Journal of Veterinary Diagnostic Investigation, 5, 75-83.

Weibking, T. S.; Ledoux, D. R.; Bermudez, A. J.; Rottinghaus, G. E., 1994. Individual and combined effects of feeding fusarium moniliforme culture material, containing known levels of fumonisin b1, and aflatoxin b1 in the young turkey poult, Poult Sci, 73, 1517-1525.

Wilkins, P. A.; Vaala, W. E.; Zivotofsky, D.; Twitchell, E. D., 1994. A herd outbreak of equine leukoencephalomalacia, Cornell Vet, 84, 53-59.

Wilson, T. M.; Nelson, P. E.; Marasas, W. F.; Thiel, P. G.; Shephard, G. S.; Sydenham, E. W.; Nelson, H. A.; Ross, P. F., 1990. A mycological evaluation and in vivo toxicity evaluation of feed from 41 farms with equine leukoencephalomalacia, J Vet Diagn Invest, 2, 352-354.

Wilson, T. M.; Ross, P. F.; Owens, D. L.; Rice, L. G.; Green, S. A.; Jenkins, S. J.; Nelson, H. A., 1992. Experimental reproduction of elem. A study to determine the minimum toxic dose in ponies, Mycopathologia, 117, 115-120.

Wilson, T. M.; Ross, P. F.; Rice, L. G.; Osweiler, G. D.; Nelson, H. A.; Owens, D. L.; Plattner, R. D.; Reggiardo, C.; Noon, T. H.; Pickrell, J. W., 1990. Fumonisin b1 levels associated with an epizootic of equine leukoencephalomalacia, J Vet Diagn Invest, 2, 213-216.

Wilson, T. M.; Ross, P. F.; Nelson, P. E., 1991. Fumonisin mycotoxins and equine leukoencephalomalacia, Journal of the American Veterinary Medical Association, 198, 1104-1105.

Wu, W.; Jerome, D.; Nagaraj, R., 1994. Increased redness in turkey breast muscle induced by fusarial culture materials, Poultry Science, 73, 331-335.

Wu, W.; Li, G.; Liu, T.; Vesonder, R. R., 1995. The effect of fumonisin b1 on isolated chondrocytes and on bone formation, Poult Sci, 74, 1431-1436.

Yildirim, M.; Manning, B. B.; Lovell, R. T.; Grizzle, J. M.; Rottinghaus, G. E., 2000. Toxicity of moniliformin and fumonisin b-1 fed singly and in combination in diets for young channel catfish ictalurus punctatus, Journal of the World Aquaculture Society, 31, 599-608.

Zomborszky, M. K.; Vetesi, F.; Repa, I.; Kovacs, F.; Bata, A.; Horn, P.; Toth, A.; Romvari, R., 2000. Experiment to determine limits of tolerance for fumonisin b1 in weaned piglets, Journal of Veterinary Medicine Series B-Infectious Diseases and Veterinary Public Health, 47, 277-286.

Zomborszky, M. K.; Vetesi, F.; Horn, P.; Kovacs, F., 1997. Investigation into the effect of toxins produced by fusarium moniliforme in pigs - ii. Examination of perinatal toxicosis in pregnant sows and newborn piglets - preliminary publication, Magyar Allatorvosok Lapja, 119, 763-764.

Zomborszky-Kovacs, M.; Kovacs, F.; Vetesi, F.; Repa, I.; Tornyos, G.; Toth, A., 2002. Investigations into the time- and dose-dependent effect of fumonisin b-1 in order to determine tolerable limit values in pigs, Livestock Production Science, 76, 251-256. 
Zomborszky-Kovacs, M.; Vetesi, F.; Horn, P.; Repa, I.; Kovacs, F., 2002. Effects of prolonged exposure to low-dose fumonisin b1 in pigs, J Vet Med B Infect Dis Vet Public Health, 49, 197-201.

Zomborszky-Kovacs, M.; Vetesi, F.; Kovacs, F.; Bata, A.; Toth, A.; Tornyos, G., 2000. Preliminary communication: Examination of the harmful effect to fetuses of fumonisin $\mathrm{b}(1)$ in pregnant sows, Teratog Carcinog Mutagen, 20, 293-299. 


\section{AREA 8 OCCURRENCE IN FOOD}

Reference list with all relevant references identified for AREA 8: Data on occurrence in food published in English since year 2000.

\section{Relevant references retrieved in the literature searches for Area 8 OCCURRENCE IN FOOD:}

Abbas, H. K.; Cartwright, R. D.; Xie, W. P.; Shier, W. T., 2006. Aflatoxin and fumonisin contamination of corn (maize, zea mays) hybrids in arkansas, Crop Protection, 25, 1-9.

Abbas, H. K.; Williams, W. P.; Windham, G. L.; Pringle, H. C.; Xie, W. P.; Shier, W. T., 2002. Aflatoxin and fumonisin contamination of commercial corn (zea mays) hybrids in mississippi, Journal of Agricultural and Food Chemistry, 50, 5246-5254.

Abbas, H. K.; Zablotowicz, R. M.; Shier, W. T.; Johnson, B. J.; Phillips, N. A.; Weaver, M. A.; Abel, C. A.; Bruns, H. A., 2015. Aflatoxin and fumonisin in corn (zea mays) infected by common smut ustilago maydis, Plant Disease, 99, 1236-1240.

Abia, W. A.; Warth, B.; Sulyok, M.; Krska, R.; Tchana, A. N.; Njobeh, P. B.; Dutton, M. F.; Moundipa, P. F., 2013. Determination of multi-mycotoxin occurrence in cereals, nuts and their products in cameroon by liquid chromatography tandem mass spectrometry (Ic-ms/ms), Food Control, 31, 438453.

Abrunhosa, L.; Calado, T.; Venancio, A., 2011. Incidence of fumonisin b-2 production by aspergillus niger in portuguese wine regions, Journal of Agricultural and Food Chemistry, 59, 7514-7518.

Abrunhosa, L.; Morales, H.; Soares, C.; Calado, T.; Vila-Cha, A. S.; Pereira, M.; Venancio, A., 2016. A review of mycotoxins in food and feed products in portugal and estimation of probable daily intakes, Crit Rev Food Sci Nutr, 56, 249-265.

Adejumo, T. O.; Hettwer, U.; Karlovsky, P., 2007. Survey of maize from south-western nigeria for zearalenone, alpha- and beta-zearalenols, fumonisin b-1 and enniatins produced by fusarium species, Food Additives and Contaminants, 24, 993-1000.

Adetunji, M.; Atanda, O.; Ezekiel, C. N.; Sulyok, M.; Warth, B.; Beltran, E.; Krska, R.; Obadina, O.; Bakare, A.; Chilaka, C. A., 2014. Fungal and bacterial metabolites of stored maize (zea mays, I.) from five agro-ecological zones of nigeria, Mycotoxin Res, 30, 89-102.

Afolabi, C. G.; Bandyopadhyay, R.; Leslie, J. F.; Ekpo, E. J. A., 2006. Effect of sorting on incidence and occurrence of fumonisins and fusarium verticillioides on maize from nigeria, Journal of Food Protection, 69, 2019-2023.

Afolabi, C. G.; Ojiambo, P. S.; Ekpo, E. J. A.; Menkir, A.; Bandyopadhyay, R., 2007. Evaluation of maize inbred lines for resistance to fusarium ear rot and fumonisin accumulation in grain in tropical africa, Plant Disease, 91, 279-286.

Afsah-Hejri, L.; Jinap, S.; Hajeb, P.; Radu, S.; Shakibazadeh, S., 2013. A review on mycotoxins in food and feed: Malaysia case study, Comprehensive Reviews in Food Science and Food Safety, 12, 629651.

Aguin, O.; Cao, A.; Pintos, C.; Santiago, R.; Mansilla, P.; Butron, A., 2014. Occurrence of fusarium species in maize kernels grown in northwestern spain, Plant Pathology, 63, 946-951.

Alakonya, A. E.; Monda, E. O.; Ajanga, S., 2009. Fumonisin b-1 and aflatoxin b-1 levels in kenyan maize, Journal of Plant Pathology, 91, 459-464.

Alemu, T.; Birhanu, G.; Azerefgne, F.; Skinnes, H., 2008. Evidence for mycotoxin contamination of maize in southern ethiopia: The need for further multidisciplinary research, Cereal Research Communications, 36, 337-339. 
Alexa, E.; Pop, G.; Sumalan, R. M.; Radulov, I.; Poiana, M.; Tulcan, C., 2011. Fusarium species and fusarium mycotoxins in cereals from west romania: Preliminary survey, Commun Agric Appl Biol Sci, 76, 661-666.

Alghuthaymi, M. A.; Bahkali, A. H., 2015. Toxigenic profiles and trinucleotide repeat diversity of fusarium species isolated from banana fruits, Biotechnol Biotechnol Equip, 29, 324-330.

Alizadeh, A. M.; Roshandel, G.; Roudbarmohammadi, S.; Roudbary, M.; Sohanaki, H.; Ghiasian, S. A.; Taherkhani, A.; Semnani, S.; Aghasi, M., 2012. Fumonisin b1 contamination of cereals and risk of esophageal cancer in a high risk area in northeastern iran, Asian Pacific Journal of Cancer Prevention, 13, 2625-2628.

Almeida, A. P.; Correa, B.; Mallozzi, M. A. B.; Sawazaki, E.; Soares, L. M. V., 2000. Mycoflora and aflatoxin/fumonisin production by fungal isolates from freshly harvested corn hybrids, Brazilian Journal of Microbiology, 31, 321-326.

Al-Taher, F.; Banaszewski, K.; Jackson, L.; Zweigenbaum, J.; Ryu, D.; Cappozzo, J., 2013. Rapid method for the determination of multiple mycotoxins in wines and beers by $\mathrm{Ic}-\mathrm{ms} / \mathrm{ms}$ using a stable isotope dilution assay, J Agric Food Chem, 61, 2378-2384.

Altiparmak, G.; Tunali, B., 2009. Incidence of fusarium species and levels of fumonisin b-1 in corn in the samsun province of turkey, Phytoprotection, 90, 97-106.

Al-Zuaagi, K. S.; Moslem, M. A.; Hadi, S.; Rabbani, M., 2013. Molecular procedures for detection of mycotoxegenic fungi in wheat supplies in saudi arabia, Journal of Pure and Applied Microbiology, 7, 53-62.

Am, P.; Le, B.; Sl, R.; Hhl, G., 2001. Mycoflora and mycotoxins natural occurrence in corn from entre rios province, argentina, Mycotoxin Res, 17, 39-44.

Amadi, J. E.; Adeniyi, D. O., 2009. Mycotoxin production by fungi isolated from stored grains, African Journal of Biotechnology, 8, 1219-1221.

Amato, B.; Pfohl, K.; Tonti, S.; Nipoti, P.; Dastjerdi, R.; Pisi, A.; Karlovsky, P.; Prodi, A., 2015. Fusarium proliferatum and fumonisin b1 co-occur with fusarium species causing fusarium head blight in durum wheat in italy, Journal of Applied Botany and Food Quality, 88, 228-233.

Anderson, G. P.; Kowtha, V. A.; Taitt, C. R., 2010. Detection of fumonisin b1 and ochratoxin a in grain products using microsphere-based fluid array immunoassays, Toxins (Basel), 2, 297-309.

Anfossi, L.; Calderara, M.; Baggiani, C.; Giovannoli, C.; Arletti, E.; Giraudi, G., 2010. Development and application of a quantitative lateral flow immunoassay for fumonisins in maize, Anal Chim Acta, 682, 104-109.

Anonymous, 2012. Fungi producing significant mycotoxins, 2012. IARC Sci Publ, 1-30.

Anonymous, 2012. Sampling and sample preparation methods for determining concentrations of mycotoxins in foods and feeds, 2012. IARC Sci Publ, 39-51.

Anukul, N.; Vangnai, K.; Mahakarnchanakul, W., 2013. Significance of regulation limits in mycotoxin contamination in asia and risk management programs at the national level, Journal of Food and Drug Analysis, 21, 227-241.

Aoyama, K.; Nakajima, M.; Tabata, S.; Ishikuro, E.; Tanaka, T.; Norizuki, H.; Itoh, Y.; Fujita, K.; Kai, S.; Tsutsumi, T.; Takahashi, M.; Tanaka, H.; Iizuka, S.; Ogiso, M.; Maeda, M.; Yamaguchi, S.; Sugiyama, K.; Sugita-Konishi, Y.; Kumagai, S., 2010. Four-year surveillance for ochratoxin a and fumonisins in retail foods in japan, J Food Prot, 73, 344-352.

Aprodu, I.; Banu, I., 2015. Co-occurrence of fumonisins and $\mathrm{t}-2$ toxins in milling maize fractions under industrial conditions, Cyta-Journal of Food, 13, 102-106.

Arici, M.; Daglioglu, O.; Gumus, T.; Daglioglu, F., 2004. Occurrence of fumonisin in processed and low processed corn-based products in turkey, Acta Alimentaria, 33, 325-328. 
Arino, A.; Estopanan, G.; Juan, T.; Herrera, A., 2007. Estimation of dietary intakes of fumonisins b-1 and b-2 from conventional and organic corn, Food Control, 18, 1058-1062.

Arino, A.; Juan, T.; Estopanan, G.; Gonzalez-Cabo, J. F., 2007. Natural occurrence of fusarium species, fumonisin production by toxigenic strains, and concentrations of fumonisins $b-1$ and $b-2$ in conventional and organic maize grown in spain, Journal of Food Protection, 70, 151-156.

Arroyo-Manzanares, N.; Huertas-Perez, J. F.; Gamiz-Gracia, L.; Garcia-Campana, A. M., 2013. A new approach in sample treatment combined with uhplc-ms/ms for the determination of multiclass mycotoxins in edible nuts and seeds, Talanta, 115, 61-67.

Arroyo-Manzanares, N.; Huertas-Perez, J. F.; Gamiz-Gracia, L.; Garcia-Campana, A. M., 2015. Simple and efficient methodology to determine mycotoxins in cereal syrups, Food Chem, 177, 274-279.

Arroyo-Manzanares, N.; Huertas-Perez, J. E.; Garcia-Campana, A. M.; Gamiz-Gracia, L., 2014. Simple methodology for the determination of mycotoxins in pseudocereals, spelt and rice, Food Control, $36,94-101$.

Ashiq, S., 2015. Natural occurrence of mycotoxins in food and feed: Pakistan perspective, Comprehensive Reviews in Food Science and Food Safety, 14, 159-175.

Atanasova-Penichon, V.; Barreau, C.; Richard-Forget, F., 2016. Antioxidant secondary metabolites in cereals: Potential involvement in resistance to fusarium and mycotoxin accumulation, Front Microbiol, 7, 566.

Atanda, S. A.; Pessu, P. O.; Agoda, S.; Isong, I. U.; Adekalu, O. A.; Echendu, M. A.; Falade, T. C., 2011. Fungi and mycotoxins in stored foods, African Journal of Microbiology Research, 5, 43734382.

Ates, E.; Mittendorf, K.; Stroka, J.; Senyuva, H., 2013. Determination of fusarium mycotoxins in wheat, maize and animal feed using on-line clean-up with high resolution mass spectrometry, Food Addit Contam Part A Chem Anal Control Expo Risk Assess, 30, 156-165.

Atukwase, A.; Kaaya, A. N.; Muyanja, C., 2012. Dynamics of fusarium and fumonisins in maize during storage - a case of the traditional storage structures commonly used in uganda, Food Control, 26, 200-205.

Atukwase, A.; Kaaya, A. N.; Muyanja, C., 2009. Factors associated with fumonisin contamination of maize in uganda, Journal of the Science of Food and Agriculture, 89, 2393-2398.

Avantaggiato, G.; De la Campa, R.; Miller, J. D.; Visconti, A., 2003. Effects of muffin processing on fumonisins from c-14-labeled toxins produced in cultured corn kernels, Journal of Food Protection, $66,1873-1878$.

Ayalew, A.; Fehrmann, H.; Lepschy, J.; Beck, R.; Abate, D., 2006. Natural occurrence of mycotoxins in staple cereals from ethiopia, Mycopathologia, 162, 57-63.

Azaiez, I.; Font, G.; Manes, J.; Fernandez-Franzon, M., 2015. Survey of mycotoxins in dates and dried fruits from tunisian and spanish markets, Food Control, 51, 340-346.

Azizi, I. G.; Rouhi, S., 2013. The comparison of total fumonisin and total aflatoxin levels in biscuit and cookie samples in babol city, northern iran, Iranian Journal of Public Health, 42, 422-427.

Bakker, G. J. I.; Sizoo, E. A.; Jekel, A. A.; Pereboom-de Fauw, Dpkh; Schothorst, R. C.; van Egmond, H. P., 2009. Determination of mean daily intakes of aflatoxin b-1, aflatoxin $m-1$, ochratoxin a, trichothecenes and fumonisins in 24-hour diets of children in the netherlands, World Mycotoxin Journal, 2, 451-459.

Bankole, S.; Schollenberger, M.; Drochner, W., 2006. Mycotoxins in food systems in sub saharan africa: A review, Mycotoxin Res, 22, 163-169. 
Bansal, J.; Pantazopoulos, P.; Tam, J.; Cavlovic, P.; Kwong, K.; Turcotte, A. M.; Lau, B. P. Y.; Scott, P. M., 2011. Surveys of rice sold in canada for aflatoxins, ochratoxin a and fumonisins, Food Additives and Contaminants Part a-Chemistry Analysis Control Exposure \& Risk Assessment, 28, 767-774.

Barna-Vetro, I.; Szabo, E.; Fazekas, B.; Solti, L., 2000. Development of a sensitive elisa for the determination of fumonisin b-1 in cereals, Journal of Agricultural and Food Chemistry, 48, 28212825.

Barros, G.; Magnoli, C.; Reynoso, M. M.; Ramirez, M. L.; Farnochi, M. C.; Torres, A.; Dalcero, M.; Sequeira, J.; Rubinstein, C.; Chulze, S., 2009. Fungal and mycotoxin contamination in bt maize and non-bt maize grown in argentina, World Mycotoxin Journal, 2, 53-60.

Battilani, P.; Pietri, A.; Barbano, C.; Scandolara, A.; Bertuzzi, T.; Marocco, A., 2008. Logistic regression modeling of cropping systems to predict fumonisin contamination in maize, J Agric Food Chem, 56, 10433-10438.

Becker-Algeri, T. A.; Castagnaro, D.; de Bortoli, K.; de Souza, C.; Drunkler, D. A.; Badiale-Furlong, E., 2016. Mycotoxins in bovine milk and dairy products: A review, J Food Sci, 81, R544-552.

Becker-Algeri, T. A.; Heidtmann-Bemvenuti, R.; Hackbart, H. C. D.; Badiale-Furlong, E., 2013. Thermal treatments and their effects on the fumonisin b-1 level in rice, Food Control, 34, 488-493.

Belajova, E.; Rauova, D., 2010. Single laboratory-validated hplc methods for determination of ochratoxin a, fumonisin b1 and b2, zearalenone and deoxynivalenol in cereals and cereal-based foods, Journal of Food and Nutrition Research, 49, 57-68.

Beltran, E.; Ibanez, M.; Portoles, T.; Ripolles, C.; Sancho, J. V.; Yusa, V.; Marin, S.; Hernandez, F., 2013. Development of sensitive and rapid analytical methodology for food analysis of 18 mycotoxins included in a total diet study, Anal Chim Acta, 783, 39-48.

Berardo, N.; Lanzanova, C.; Locatelli, S.; Lagana, P.; Verderio, A.; Motto, M., 2011. Levels of total fumonisins in maize samples from italy during 2006-2008, Food Addit Contam Part B Surveill, 4, 116-124.

Berthiller, F.; Crews, C.; Dall'Asta, C.; De Saeger, S.; Haesaert, G.; Karlovsky, P.; Oswald, I. P.; Seefelder, W.; Speijers, G.; Stroka, J., 2013. Masked mycotoxins: A review, Molecular Nutrition \& Food Research, 57, 165-186.

Bertuzzi, T.; Mulazzi, A.; Rastelli, S.; Pietri, A., 2016. Hidden fumonisins: Simple and innovative extractions for their determination in maize and derived products, Food Analytical Methods, 9, 1970-1979.

Bertuzzi, T.; Rastelli, S.; Mulazzi, A.; Donadini, G.; Pietri, A., 2011. Mycotoxin occurrence in beer produced in several european countries, Food Control, 22, 2059-2064.

Bezuidenhout, C. C.; Prinsloo, M.; Van der Walt, A. M., 2006. Multiplex pcr-based detection of potential fumonisin-producing fusarium in traditional african vegetables, Environ Toxicol, 21, 360366.

Bian, Y. N.; Huang, X. Y.; Ren, J. C., 2016. Sensitive and homogenous immunoassay of fumonisin in foods using single molecule fluorescence correlation spectroscopy, Analytical Methods, 8, 13331338.

Bittencourt, A. B. F.; Oliveira, C. A. F.; Dilkin, P.; Correa, B., 2005. Mycotoxin occurrence in corn meal and flour traded in sao paulo, brazil, Food Control, 16, 117-120.

Blesa, J.; Molto, J. C.; El Akhdari, S.; Manes, J.; Zinedine, A., 2014. Simultaneous determination of fusarium mycotoxins in wheat grain from morocco by liquid chromatography coupled to triple quadrupole mass spectrometry, Food Control, 46, 1-5. 
Bluhm, B. H.; Flaherty, J. E.; Cousin, M. A.; Woloshuk, C. P., 2002. Multiplex polymerase chain reaction assay for the differential detection of trichothecene- and fumonisin-producing species of fusarium in cornmeal, J Food Prot, 65, 1955-1961.

Bolduan, C.; Montes, J. M.; Dhillon, B. S.; Mirdita, V.; Melchinger, A. E., 2009. Determination of mycotoxin concentration by elisa and near-infrared spectroscopy in fusarium-inoculated maize, Cereal Research Communications, 37, 521-529.

Bolechova, M.; Benesova, K.; Belakova, S.; Caslavsky, J.; Pospichalova, M.; Mikulikova, R., 2015. Determination of seventeen mycotoxins in barley and malt in the czech republic, Food Control, 47, 108-113.

Boonzaaijer, G.; van Osenbruggen, W. A.; Kleinnijenhuis, A. J.; van Dongen, W. D., 2008. An exploratory investigation of several mycotoxins and their natural occurrence in flavour ingredients and spices, using a multi-mycotoxin lc-ms/ms method, World Mycotoxin Journal, 1, 167-174.

Bordin, K.; Rosim, R. E.; Neeff, D. V.; Rottinghaus, G. E.; Oliveira, C. A. F., 2014. Assessment of dietary intake of fumonisin b-1 in sao paulo, brazil, Food Chemistry, 155, 174-178.

Bordin, K.; Rottinghaus, G. E.; Landers, B. R.; Ledoux, D. R.; Kobashigawa, E.; Corassin, C. H.; Oliveira, C. A. F., 2015. Evaluation of fumonisin exposure by determination of fumonisin b-1 in human hair and in brazilian corn products, Food Control, 53, 67-71.

Boutigny, A. L.; Beukes, I.; Small, I.; Zuhlke, S.; Spiteller, M.; Van Rensburg, B. J.; Flett, B.; Viljoen, A., 2012. Quantitative detection of fusarium pathogens and their mycotoxins in south african maize, Plant Pathology, 61, 522-531.

Boutsiadou-Theurillat, X.; Meier, P.; Richard, C., 2014. Development and in-house validation of a rapid Ic-ms/ms method for the semi-quantification of eleven mycotoxins in maize samples, Chimia (Aarau), 68, 716-720.

Broggi, L. E.; Pacin, A. M.; Gasparovic, A.; Sacchi, C.; Rothermel, A.; Gallay, A.; Resnik, S., 2007. Natural occurrence of aflatoxins, deoxynivalenol, fumonisins and zearalenone in maize from entre rios province, argentina, Mycotoxin Res, 23, 59-64.

Broggi, L. E.; Resnik, S. L.; Pacin, A. M.; Gonzalez, H. H. L.; Cano, G.; Taglieri, D., 2002. Distribution of fumonisins in dry-milled corn fractions in argentina, Food Additives and Contaminants, 19, 465469.

Bryla, M.; Jedrzejczak, R.; Roszko, M.; Szymczyk, K.; Obiedzinski, M. W.; Sekul, J.; Rzepkowska, M., 2013. Application of molecularly imprinted polymers to determine $b-1, b-2$, and $b-3$ fumonisins in cereal products, Journal of Separation Science, 36, 578-584.

Bryla, M.; Roszko, M.; Szymczyk, K.; Jedrzejczak, R.; Slowik, E.; Obiedzinski, M. W., 2014. Effect of baking on reduction of free and hidden fumonisins in gluten-free bread, J Agric Food Chem, 62, 10341-10347.

Bryla, M.; Roszko, M.; Szymczyk, K.; Jedrzejczak, R.; Obiedzinski, M. W., 2016. Fumonisins and their masked forms in maize products, Food Control, 59, 619-627.

Bryla, M.; Roszko, M.; Szymczyk, K.; Jedrzejczak, R.; Obiedzinski, M. W.; Sekul, J., 2013. Fumonisins in plant-origin food and fodder - a review, Food Additives and Contaminants Part a-Chemistry Analysis Control Exposure \& Risk Assessment, 30, 1626-1640.

Bryla, M.; Szymczyk, K.; Jedrzejczak, R.; Obiedzinski, M. W., 2015. Free and hidden fumonisins in various fractions of maize dry milled under model conditions, Lwt-Food Science and Technology, 64, 171-176.

Bullerman, L. B.; Ryu, D.; Jackson, L. S. 2002. Stability of fumonisins in food processing. in J. W.; Trucksess DeVries, M. W.; Jackson, L. S. (ed.), Mycotoxins and food safety. 
Burns, T. D.; Snook, M. E.; Riley, R. T.; Voss, K. A., 2008. Fumonisin concentrations and in vivo toxicity of nixtamalized fusarium verticillioides culture material: Evidence for fumonisin-matrix interactions, Food Chem Toxicol, 46, 2841-2848.

Busman, M.; Desjardins, A. E.; Proctor, R. H., 2012. Analysis of fumonisin contamination and the presence of fusarium in wheat with kernel black point disease in the united states, Food Addit Contam Part A Chem Anal Control Expo Risk Assess, 29, 1092-1100.

Caldas, E. D.; Jardim, A. N. O., 2012. Exposure to toxic chemicals in the diet: Is the brazilian population at risk?, Journal of Exposure Science and Environmental Epidemiology, 22, 1-15.

Caldas, E. D.; Silva, A. C. S., 2007. Mycotoxins in corn-based food products consumed in brazil: An exposure assessment for fumonisins, Journal of Agricultural and Food Chemistry, 55, 7974-7980.

Camargos, S. M.; Soares, L. M. V.; Sawazaki, E.; Bolonhezi, D.; Castro, J. L.; Bortolleto, N., 2002. Accumulation of fumonisins $b(1)$ and $b(2)$ in freshly harvested brazilian commercial maize at three locations during two nonconsecutive seasons, Mycopathologia, 155, 219-228.

Candlish, A.; Aidoo, K.; Smith, J.; Pearson, S., 2000. A limited survey of aflatoxins and fumonisins in retail maizebased products in the uk using immunoassay detection, Mycotoxin Res, 16, 2-8.

Cano-Sancho, G.; Ramos, A. J.; Marin, S.; Sanchis, V., 2012. Occurrence of fumonisins in catalonia (spain) and an exposure assessment of specific population groups, Food Addit Contam Part A Chem Anal Control Expo Risk Assess, 29, 799-808.

Cano-Sancho, G.; Ramos, A. J.; Marin, S.; Sanchis, V., 2012. Presence and co-occurrence of aflatoxins, deoxynivalenol, fumonisins and zearalenone in gluten-free and ethnic foods, Food Control, 26, 282-286.

Capriotti, A. L.; Cavaliere, C.; Foglia, P.; Samperi, R.; Stampachiacchiere, S.; Ventura, S.; Lagana, A., 2014. Multiclass analysis of mycotoxins in biscuits by high performance liquid chromatographytandem mass spectrometry. Comparison of different extraction procedures, J Chromatogr A, 1343, 69-78.

Casado, M. R.; Parsons, D. J.; Magan, N.; Weightman, R. M.; Battilani, P.; Pietri, A., 2010. A short geostatistical study of the three-dimensional spatial structure of fumonisins in stored maize, World Mycotoxin Journal, 3, 95-103.

Castegnaro, M.; Tozlovanu, M.; Wild, C.; Molinie, A.; Sylla, A.; Pfohl-Leszkowicz, A., 2006. Advantages and drawbacks of immunoaffinity columns in analysis of mycotoxins in food, Mol Nutr Food Res, 50, 480-487.

Castells, M.; Marin, S.; Sanchis, V.; Ramos, A. J., 2008. Distribution of fumonisins and aflatoxins in corn fractions during industrial cornflake processing, Int J Food Microbiol, 123, 81-87.

Castells, M.; Marin, S.; Sanchis, V.; Ramos, A. J., 2005. Fate of mycotoxins in cereals during extrusion cooking: A review, Food Addit Contam, 22, 150-157.

Castelo, M. M.; Jackson, L. S.; Hanna, M. A.; Reynolds, B. H.; Bullerman, L. B., 2001. Loss of fuminosin $b(1)$ in extruded and baked corn-based foods with sugars, Journal of Food Science, 66, 416-421.

Castoria, R.; Lima, G.; Ferracane, R.; Ritieni, A., 2005. Occurrence of mycotoxin in farro samples from southern italy, J Food Prot, 68, 416-420.

Cavaliere, C.; Foglia, P.; Guarino, C.; Motto, M.; Nazzari, M.; Samperi, R.; Lagana, A.; Berardo, N., 2007. Mycotoxins produced by fusarium genus in maize: Determination by screening and confirmatory methods based on liquid chromatography tandem mass spectrometry, Food Chemistry, 105, 700-710. 
Cendoya, E.; Monge, M. P.; Palacios, S. A.; Chiacchiera, S. M.; Torres, A. M.; Farnochi, M. C.; Ramirez, M. L., 2014. Fumonisin occurrence in naturally contaminated wheat grain harvested in argentina, Food Control, 37, 56-61.

Chang, S.; Carneiro-Leao, M. P.; de Oliveira, B. F.; Souza-Motta, C.; Lima, N.; Santos, C.; de Oliveira, N. T., 2016. Polyphasic approach including maldi-tof $\mathrm{ms} / \mathrm{ms}$ analysis for identification and characterisation of fusarium verticillioides in brazilian corn kernels, Toxins (Basel), 8.

Chehri, K.; Jahromi, S. T.; Reddy, K. R. N.; Abbasi, S.; Salleh, B., 2010. Occurrence of fusarium spp. And fumonisins in stored wheat grains marketed in iran, Toxins, 2, 2816-2823.

Chelule, P. K.; Gqaleni, N.; Dutton, M. F.; Chuturgoon, A. A., 2001. Exposure of rural and urban populations in kwazulu natal, south africa, to fumonisin $b(1)$ in maize, Environ Health Perspect, 109, 253-256.

Chelule, P. K.; Mbongwa, H. P.; Carries, S.; Gqaleni, N., 2010. Lactic acid fermentation improves the quality of amahewu, a traditional south african maize-based porridge, Food Chemistry, 122, 656661.

Chen, J.; Jia, Z.; Song, J.; Yuan, Y.; Zhang, L., 2015. Fumonisins in china: Update on occurrence, epidemiology, exposure and regulation, Quality Assurance and Safety of Crops \& Foods, 7, 63-72.

Chilaka, C. A.; De Kock, S.; Phoku, J. Z.; Mwanza, M.; Egbuta, M. A.; Dutton, M. F., 2012. Fungal and mycotoxin contamination of south african commercial maize, Journal of Food Agriculture \& Environment, 10, 296-303.

Chiotta, M. L.; Susca, A.; Stea, G.; Mule, G.; Perrone, G.; Logrieco, A.; Chulze, S. N., 2011. Phylogenetic characterization and ochratoxin a--fumonisin profile of black aspergillus isolated from grapes in argentina, Int J Food Microbiol, 149, 171-176.

Christofidou, M.; Kafouris, D.; Christodoulou, M.; Stefani, D.; Christoforou, E.; Nafti, G.; Christou, E.; Aletrari, M.; Ioannou-Kakouri, E., 2015. Occurrence, surveillance, and control of mycotoxins in food in cyprus for the years 2004-2013, Food and Agricultural Immunology, 26, 880-895.

Chulze, S. N., 2010. Strategies to reduce mycotoxin levels in maize during storage: A review, Food Addit Contam Part A Chem Anal Control Expo Risk Assess, 27, 651-657.

Chulze, S. N.; Palazzini, J. M.; Torres, A. M.; Barros, G.; Ponsone, M. L.; Geisen, R.; Schmidt-Heydt, M.; Kohl, J., 2015. Biological control as a strategy to reduce the impact of mycotoxins in peanuts, grapes and cereals in argentina, Food Addit Contam Part A Chem Anal Control Expo Risk Assess, $32,471-479$.

Chung, S. H.; Cho, T. Y.; Oh, K. S.; Kim, D. S.; Hong, M. K., 2008. Fumonisin contamination in corn and processed corn products commercialized in korea, Cereal Research Communications, 36, 353355.

Cirillo, T.; Ritieni, A.; Visone, M.; Cocchieri, R. A., 2003. Evaluation of conventional and organic italian foodstuffs for deoxynivalenol and fumonisins b-1 and b-2, Journal of Agricultural and Food Chemistry, 51, 8128-8131.

Cirillo, T.; Ritieni, A.; Galvano, F.; Cocchieri, R. A., 2003. Natural co-occurrence of deoxynivalenol and fumonisins $b(1)$ and $b(2)$ in italian marketed foodstuffs, Food Additives and Contaminants Part aChemistry Analysis Control Exposure \& Risk Assessment, 20, 566-571.

Clarke, R.; Connolly, L.; Frizzell, C.; Elliott, C. T., 2015. Challenging conventional risk assessment with respect to human exposure to multiple food contaminants in food: A case study using maize, Toxicol Lett, 238, 54-64.

Coronel, M. B.; Vicente, S.; Resnik, S. L.; Aizamora, S. M.; Pacin, A., 2016. Fumonisins in maize and gluten meal analysed in argentinean wet milling industrial plants by elisa compared with hplc-fld method, Food Control, 67, 285-291. 
Covarelli, L.; Beccari, G.; Salvi, S., 2011. Infection by mycotoxigenic fungal species and mycotoxin contamination of maize grain in umbria, central italy, Food Chem Toxicol, 49, 2365-2369.

Covarelli, L.; Stifano, S.; Beccari, G.; Raggi, L.; Lattanzio, V. M. T.; Albertini, E., 2012. Characterization of fusarium verticillioides strains isolated from maize in italy: Fumonisin production, pathogenicity and genetic variability, Food Microbiology, 31, 17-24.

Cumagun, C. J. R.; Ramos, J. S.; Dimaano, A. O.; Munaut, F.; Van Hove, F., 2009. Genetic characteristics of fusarium verticillioides from corn in the philippines, Journal of General Plant Pathology, 75, 405-412.

Czembor, E.; Stepien, L.; Waskiewicz, A., 2015. Effect of environmental factors on fusarium species and associated mycotoxins in maize grain grown in poland, PLoS One, 10, e0133644.

da Silva, J. B.; Dilkin, P.; Fonseca, H.; Correa, B., 2004. Production of aflatoxins by aspergillus flavus and of fumonisins by fusarium species isolated from brazilian sorghum, Brazilian Journal of Microbiology, 35, 182-186.

da Silva, J. B.; Pozzi, C. R.; Mallozzi, M. A. B.; Ortega, E. M.; Correa, B., 2000. Mycoflora and occurrence of aflatoxin b-1 and fumonisin b-1 during storage of brazilian sorghum, Journal of Agricultural and Food Chemistry, 48, 4352-4356.

Dall'Asta, C.; Falavigna, C.; Galaverna, G.; Dossena, A.; Marchelli, R., 2010. In vitro digestion assay for determination of hidden fumonisins in maize, J Agric Food Chem, 58, 12042-12047.

Dall'Asta, C.; Galaverna, G.; Mangia, M.; Sforza, S.; Dossena, A.; Marchelli, R., 2009. Free and bound fumonisins in gluten-free food products, Mol Nutr Food Res, 53, 492-499.

Dall'Asta, C.; Galaverna, G.; Aureli, G.; Dossena, A.; Marchelli, R., 2008. A Ic/ms/ms method for the simultaneous quantification of free and masked fumonisins in maize and maize-based products, World Mycotoxin Journal, 1, 237-246.

Dall'Asta, C.; Mangia, M.; Berthiller, F.; Molinelli, A.; Sulyok, M.; Schuhmacher, R.; Krska, R.; Galaverna, G.; Dossena, A.; Marchelli, R., 2009. Difficulties in fumonisin determination: The issue of hidden fumonisins, Anal Bioanal Chem, 395, 1335-1345.

Dambolena, J. S.; Zunino, M. P.; Lopez, A. G.; Rubinstein, H. R.; Zygadlo, J. A.; Mwangi, J. W.; Thoithi, G. N.; Kibwage, I. O.; Mwalukumbi, J. M.; Kariuki, S. T., 2010. Essential oils composition of ocimum basilicum I. And ocimum gratissimum I. From kenya and their inhibitory effects on growth and fumonisin production by fusarium verticillioides, Innovative Food Science \& Emerging Technologies, 11, 410-414.

D'Arco, G.; Fernandez-Franzon, M.; Font, G.; Damiani, P.; Manes, J., 2008. Analysis of fumonisins b-1, b-2 and b-3 in corn-based baby food by pressurized liquid extraction and liquid chromatography/tandem mass spectrometry, Journal of Chromatography A, 1209, 188-194.

D'Arco, G.; Fernandez-Franzon, M.; Font, G.; Damiani, P.; Manes, J., 2009. Survey of fumonisins b-1, b-2 and b-3 in conventional and organic retail corn products in spain and italy and estimated dietary exposure, Food Additives \& Contaminants Part B-Surveillance, 2, 146-153.

Darwish, W. S.; Ikenaka, Y.; Nakayama, S. M. M.; Ishizuka, M., 2014. An overview on mycotoxin contamination of foods in africa, Journal of Veterinary Medical Science, 76, 789-797.

Daskaya-Dikmen, C.; Heperkan, D., 2013. Fumonisin production of black aspergilli in vitro, fumonisin and ochratoxin a production in figs of positive strains and their growth assessment, Toxin Reviews, 32, 10-17.

Dawlatana, M.; Coker, R. D.; Nagler, M. J.; Wild, C. P.; Hassan, M. S.; Blunden, G., 2002. The occurrence of mycotoxins in key commodities in bangladesh: Surveillance results from 1993 to 1995, J Nat Toxins, 11, 379-386. 
de Castro, Mfpm; Shephard, G. S.; Sewram, V.; Vicente, E.; Mendonca, T. A.; Jordan, A. C., 2004. Fumonisins in brazilian corn-based foods for infant consumption, Food Additives and Contaminants Part a-Chemistry Analysis Control Exposure \& Risk Assessment, 21, 693-699.

de Galarreta, J. I. R.; Butron, A.; Ortiz-Barredo, A.; Malvar, R. A.; Ordas, A.; Landa, A.; Revilla, P., 2015. Mycotoxins in maize grains grown in organic and conventional agriculture, Food Control, 52, 98-102.

De Girolamo, A.; Lattanzio, V. M. T.; Schena, R.; Visconti, A.; Pascale, M., 2014. Use of liquid chromatography-high-resolution mass spectrometry for isolation and characterization of hydrolyzed fumonisins and relevant analysis in maize-based products, Journal of Mass Spectrometry, 49, 297305.

De Girolamo, A.; Pascale, M.; Visconti, A., 2011. Comparison of methods and optimisation of the analysis of fumonisins $b(1)$ and $b(2)$ in masa flour, an alkaline cooked corn product, Food Addit Contam Part A Chem Anal Control Expo Risk Assess, 28, 667-675.

De Girolamo, A.; Pereboom-de Fauw, D.; Sizoo, E.; van Egmond, H. P.; Gambacorta, L.; Bouten, K.; Stroka, J.; Visconti, A.; Solfrizzo, M., 2010. Determination of fumonisins b-1 and b-2 in maizebased baby food products by hplc with fluorimetric detection after immunoaffinity column clean-up, World Mycotoxin Journal, 3, 135-146.

De Girolamo, A.; Solfrizzo, M.; von Holst, C.; Visconti, A., 2001. Comparison of different extraction and clean-up procedures for the determination of fumonisins in maize and maize-based food products, Food Addit Contam, 18, 59-67.

De Girolamo, A.; Solfrizzo, M.; Lattanzio, V. M. T.; Stroka, J.; Alldrick, A.; van Egmond, H. P.; Visconti, A., 2013. Critical evaluation of lc-ms-based methods for simultaneous determination of deoxynivalenol, ochratoxin a, zearalenone, aflatoxins, fumonisins and t-2/ht-2 toxins in maize, World Mycotoxin Journal, 6, 317-334.

De Girolamo, A.; Solfrizzo, M.; Visconti, A., 2001. Effect of processing on fumonisin concentration in corn flakes, J Food Prot, 64, 701-705.

De La Campa, R.; Miller, J. D.; Hendricks, K., 2004. Fumonisin in tortillas produced in small-scale facilities and effect of traditional masa production methods on this mycotoxin, J Agric Food Chem, $52,4432-4437$.

De Ruyck, K.; De Boevre, M.; Huybrechts, I.; De Saeger, S., 2015. Dietary mycotoxins, co-exposure, and carcinogenesis in humans: Short review, Mutat Res Rev Mutat Res, 766, 32-41.

De Saeger, S.; Sibanda, L.; Paepens, C.; Lobeau, M.; Delmulle, B.; Barna-Vetro, I.; Van Peteghem, C., 2006. Novel developments in rapid mycotoxin detection, Mycotoxin Res, 22, 100-104.

De Smet, D.; Dubruel, P.; Van Peteghem, C.; Schacht, E.; De Saeger, S., 2009. Molecularly imprinted solid-phase extraction of fumonisin $b$ analogues in bell pepper, rice and corn flakes, Food Addit Contam Part A Chem Anal Control Expo Risk Assess, 26, 874-884.

Deepa, N.; Adkar-Purushothama, C. R.; Sreenivasa, M. Y., 2016. Nested pcr method for early detection of fumonisin producing fusarium verticillioides in pure cultures, cereal samples and plant parts, Food Biotechnology, 30, 18-29.

Demir, C.; Simsek, O.; Arici, M., 2010. Incidence of fusarium verticillioides and levels of fumonisin b-1 and b-2 in corn in turkey, Food Science and Biotechnology, 19, 1103-1106.

Desjardins, A. E.; Busman, M., 2006. Mycotoxins in developing countries: A case study of maize in nepal, Mycotoxin Res, 22, 92-95.

Desjardins, A. E.; Busman, M.; Proctor, R. H.; Stessman, R., 2007. Wheat kernel black point and fumonisin contamination by fusarium proliferatum, Food Addit Contam, 24, 1131-1137. 
Desjardins, A. E.; Manandhar, H. K.; Plattner, R. D.; Manandhar, G. G.; Poling, S. M.; Maragos, C. M., 2000. Fusarium species from nepalese rice and production of mycotoxins and gibberellic acid by selected species, Appl Environ Microbiol, 66, 1020-1025.

Desjardins, A. E.; Manandhar, G.; Plattner, R. D.; Maragos, C. M.; Shrestha, K.; McCormick, S. P., 2000. Occurrence of fusarium species and mycotoxins in nepalese maize and wheat and the effect of traditional processing methods on mycotoxin levels, J Agric Food Chem, 48, 1377-1383.

Desmarchelier, A.; Oberson, J. M.; Tella, P.; Gremaud, E.; Seefelder, W.; Mottier, P., 2010. Development and comparison of two multiresidue methods for the analysis of 17 mycotoxins in cereals by liquid chromatography electrospray ionization tandem mass spectrometry, J Agric Food Chem, 58, 7510-7519.

Di Mavungu, J. D.; Monbaliu, S.; Scippo, M. L.; Maghuin-Rogister, G.; Schneider, Y. J.; Larondelle, Y.; Callebaut, A.; Robbens, J.; Van Peteghem, C.; De Saeger, S., 2009. Lc-ms/ms multi-analyte method for mycotoxin determination in food supplements, Food Additives and Contaminants Part a-Chemistry Analysis Control Exposure \& Risk Assessment, 26, 885-895.

Di Nardo, F.; Anfossi, L.; Giovannoli, C.; Passini, C.; Goftman, V. V.; Goryacheva, I. Y.; Baggiani, C., 2016. A fluorescent immunochromatographic strip test using quantum dots for fumonisins detection, Talanta, 150, 463-468.

Diaz-Gomez, J.; Marin, S.; Capell, T.; Sanchis, V.; Ramos, A. J., 2016. The impact of bacillus thuringiensis technology on the occurrence of fumonisins and other mycotoxins in maize, World Mycotoxin Journal, 9, 475-486.

Dissanayake, Mlmc; Tanaka, S.; Ito, S., 2009. Fumonisin b-1 production by fusarium proliferatum strains isolated from allium fistulosum plants and seeds in japan, Letters in Applied Microbiology, 48, 598-604.

Divakara, S. T.; Santosh, P.; Aiyaz, M.; Ramana, M. V.; Hariprasad, P.; Nayaka, S. C.; Niranjana, S. R., 2014. Molecular identification and characterization of fusarium spp. Associated with sorghum seeds, J Sci Food Agric, 94, 1132-1139.

Dombrink-Kurtzman, M. A.; Dvorak, T. J.; Barron, M. E.; Rooney, L. W., 2000. Effect of nixtamalization (alkaline cooking) on fumonisin-contaminated corn for production of masa and tortillas, J Agric Food Chem, 48, 5781-5786.

Dombrink-Kurtzman, M. A.; Rooney, L. W. 2002. Effect of nixtamalization on fumonisin-contaminated corn for production of tortillas. in T. C.; Ho Lee, C. T. (ed.), Bioactive compounds in foods: Effects of processing and storage.

Domijan, A. M.; Peraica, M.; Jurjevic, Z.; Ivic, D.; Cvjetkovic, B., 2005. Fumonisin b-1, fumonisin b-2, zearalenone and ochratoxin a contamination of maize in croatia, Food Additives and Contaminants, $22,677-680$.

Domijan, A. M.; Peraica, M.; Cvjetkovic, B.; Turcin, S.; Jurjevic, Z.; Ivic, D., 2005. Mould contamination and co-occurrence of mycotoxins in maize grain in croatia, Acta Pharm, 55, 349356.

dos Reis, T. A.; Zorzete, P.; Pozzi, C. R.; da Silva, V. N.; Ortega, E.; Correa, B., 2010. Mycoflora and fumonisin contamination in brazilian sorghum from sowing to harvest, Journal of the Science of Food and Agriculture, 90, 1445-1451.

D'Ovidio, K. L.; Trucksess, M. W.; Devries, J. W.; Bean, G., 2007. Effects of irradiation on fungi and famonisin $b(1)$ in corn, and of microwave-popping on fumonisins in popcorn, Food Additives and Contaminants Part a-Chemistry Analysis Control Exposure \& Risk Assessment, 24, 735-743.

Duan, C.; Qin, Z.; Yang, Z.; Li, W.; Sun, S.; Zhu, Z.; Wang, X., 2016. Identification of pathogenic fusarium spp. Causing maize ear rot and potential mycotoxin production in china, Toxins (Basel), 8.

Dutton, M. F., 2009. The african fusarium/maize disease, Mycotoxin Res, 25, 29-39. 
Dvorak, N. J.; Riley, R. T.; Harris, M.; McGregor, J. A., 2008. Fumonisin mycotoxin contamination of corn-based foods consumed by potentially pregnant women in southern california, J Reprod Med, $53,672-676$.

Ediage, E. N.; Di Mavungu, J. D.; Goryacheva, I. Y.; Van Peteghem, C.; De Saeger, S., 2012. Multiplex flow-through immunoassay formats for screening of mycotoxins in a variety of food matrices, Anal Bioanal Chem, 403, 265-278.

Ediage, E. N.; Di Mavungu, J. D.; Monbaliu, S.; Van Peteghem, C.; De Saeger, S., 2011. A validated multianalyte Ic-ms/ms method for quantification of 25 mycotoxins in cassava flour, peanut cake and maize samples, J Agric Food Chem, 59, 5173-5180.

Ediage, E. N.; Hell, K.; De Saeger, S., 2014. A comprehensive study to explore differences in mycotoxin patterns from agro-ecological regions through maize, peanut, and cassava products: $\mathrm{A}$ case study, cameroon, J Agric Food Chem, 62, 4789-4797.

Ediage, E. N.; Van Poucke, C.; De Saeger, S., 2015. A multi-analyte Ic-ms/ms method for the analysis of 23 mycotoxins in different sorghum varieties: The forgotten sample matrix, Food Chemistry, $177,397-404$.

Egbuta, M. A.; Chilaka, C. A.; Phoku, J. Z.; Mwanza, M.; Dutton, M. F., 2013. Co-contamination of nigerian cocoa and cocoa-based powder beverages destined for human consumption by mycotoxins, Studies on Ethno-Medicine, 7, 187-194.

Eller, M.; Holland, J.; Payne, G., 2008. Breeding for improved resistance to fumonisin contamination in maize, Toxin Reviews, 27, 371-389.

El-Sayed, Amaa; Soher, E. A.; Sahab, A. F., 2003. Occurrence of certain mycotoxins in corn and cornbased products and thermostability of fumonisin b(1) during processing, Nahrung-Food, 47, 222225.

Engelhardt, G.; Barthel, J.; Sparrer, D., 2006. Fusarium mycotoxins and ochratoxin a in cereals and cereal products - results from the bavarian health and food safety authority in 2004, Molecular Nutrition \& Food Research, 50, 401-405.

Escobar, J.; Loran, S.; Gimenez, I.; Ferruz, E.; Herrera, M.; Herrera, A.; Arino, A., 2013. Occurrence and exposure assessment of fusarium mycotoxins in maize germ, refined corn oil and margarine, Food Chem Toxicol, 62, 514-520.

Ezekiel, C. N.; Abia, W. A.; Ogara, I. M.; Sulyok, M.; Warth, B.; Krska, R., 2015. Fate of mycotoxins in two popular traditional cereal-based beverages (kunu-zaki and pito) from rural nigeria, Lwt-Food Science and Technology, 60, 137-141.

Ezekiel, C. N.; Warth, B.; Ogara, I. M.; Abia, W. A.; Ezekiel, V. C.; Atehnkeng, J.; Sulyok, M.; Turner, P. C.; Tayo, G. O.; Krska, R.; Bandyopadhyay, R., 2014. Mycotoxin exposure in rural residents in northern nigeria: A pilot study using multi-urinary biomarkers, Environ Int, 66, 138-145.

Ezquerra, A.; Vidal, J. C.; Bonel, L.; Castillo, J. R., 2015. A validated multi-channel electrochemical immunoassay for rapid fumonisin b1 determination in cereal samples, Analytical Methods, 7, 37423749.

Faberi, A.; Foglia, P.; Pastorini, E.; Samperi, R.; Lagana, A., 2005. Determination of type b fumonisin mycotoxins in maize and maize-based products by liquid chromatography/tandem mass spectrometry using a qqqlinear ion trap mass spectrometer, Rapid Commun Mass Spectrom, 19, 275-282.

Fabregat-Cabello, N.; Zomer, P.; Sancho, J. V.; Roig-Navarro, A. F.; Mol, H. G. J., 2016. Comparison of approaches to deal with matrix effects in Ic-ms/ms based determinations of mycotoxins in food and feed, World Mycotoxin Journal, 9, 149-161. 
Falavigna, C.; Cirlini, M.; Galaverna, G.; Sforza, S.; Dossena, A.; Dall'Asta, C., 2012. Lc/esi-ms/ms analysis outlines the different fumonisin patterns produced by $\mathrm{f}$. Verticillioides in culture media and in maize kernels, J Mass Spectrom, 47, 1170-1176.

Falavigna, C.; Cirlini, M.; Galaverna, G.; Dall'Asta, C., 2012. Masked fumonisins in processed food: Cooccurrence of hidden and bound forms and their stability under digestive conditions, World Mycotoxin Journal, 5, 325-334.

Falavigna, C.; Dall'Asta, C.; Decontardi, S.; Galaverna, G.; Battilani, P., 2014. A true scale study of the maize chain with focus on free and hidden fumonisins and related fungi, World Mycotoxin Journal, 7, 297-304.

Falavigna, C.; Lazzaro, I.; Galaverna, G.; Battilani, P.; Dall'Asta, C., 2013. Fatty acid esters of fumonisins: First evidence of their presence in maize, Food Addit Contam Part A Chem Anal Control Expo Risk Assess, 30, 1606-1613.

Fandohan, P.; Ahouansou, R.; Houssou, P.; Hell, K.; Marasas, W. F. O.; Wingfield, M. J., 2006. Impact of mechanical shelling and dehulling on fusarium infection and fumonisin contamination in maize, Food Additives and Contaminants Part a-Chemistry Analysis Control Exposure \& Risk Assessment, $23,415-421$.

Fandohan, P.; Gnonlonfin, B.; Hell, K.; Marasas, W. F. O.; Wingfield, M. J., 2006. Impact of indigenous storage systems and insect infestation on the contamination of maize with fumonisins, African Journal of Biotechnology, 5, 546-552.

Fandohan, P.; Gnonlonfin, B.; Hell, K.; Marasas, W. F. O.; Wingfield, M. J., 2005. Natural occurrence of fusarium and subsequent famonisin contamination in preharvest and stored maize in benin, west africa, International Journal of Food Microbiology, 99, 173-183.

Fandohan, P.; Zoumenou, D.; Hounhouigan, D. J.; Marasas, W. F. O.; Wingfield, M. J.; Hell, K., 2005. Fate of aflatoxins and fumonisins during the processing of maize into food products in benin, International Journal of Food Microbiology, 98, 249-259.

Federico, F. J.; Funes, G. J.; Salas, M. P.; Resnik, S. L., 2010. Natural occurrence of fumonisins in corn puff in argentina, Mycotoxin Res, 26, 273-278.

Feng, Y. Z.; Lu, X. H.; Tao, B.; Pang, M. H.; Liu, Y. C.; Dong, J. G., 2011. Natural occurrence of fumonisins $b-1$ and $b-2$ in corn from three main production provinces in china, Journal of Food Protection, 74, 1374-1378.

Fernandes, P. J.; Barros, N.; Santo, J. L.; Camara, J. S., 2015. High-throughput analytical strategy based on modified quechers extraction and dispersive solid-phase extraction clean-up followed by liquid chromatography-triple-quadrupole tandem mass spectrometry for quantification of multiclass mycotoxins in cereals, Food Analytical Methods, 8, 841-856.

Ferre, F. S., 2016. Worldwide occurrence of mycotoxins in rice, Food Control, 62, 291-298.

Firrao, G.; Torelli, E.; Gobbi, E.; Raranciuc, S.; Bianchi, G.; Locci, R., 2010. Prediction of milled maize fumonisin contamination by multispectral image analysis, Journal of Cereal Science, 52, 327-330.

Flores-Flores, M. E.; Lizarraga, E.; de Cerain, A. L.; Gonzalez-Penas, E., 2015. Presence of mycotoxins in animal milk: A review, Food Control, 53, 163-176.

Folcher, L.; Delos, M.; Marengue, E.; Jarry, M.; Weissenberger, A.; Eychenne, N.; Regnault-Roger, C., 2010. Lower mycotoxin levels in bt maize grain, Agronomy for Sustainable Development, 30, 711719.

Fotso, J.; Leslie, J. F.; Smith, J. S., 2002. Production of beauvericin, moniliformin, fusaproliferin, and fumonisins b-1, b-2, and b-3 by fifteen ex-type strains of fusarium species, Applied and Environmental Microbiology, 68, 5195-5197. 
Fox, G.; Manley, M., 2014. Applications of single kernel conventional and hyperspectral imaging near infrared spectroscopy in cereals, J Sci Food Agric, 94, 174-179.

Frenich, A. G.; Vidal, J. L. M.; Romero-Gonzalez, R.; Aguilera-Luiz, M. D., 2009. Simple and highthroughput method for the multimycotoxin analysis in cereals and related foods by ultra-high performance liquid chromatography/tandem mass spectrometry, Food Chemistry, 117, 705-712.

Froment, A.; Gautier, P.; Nussbaumer, A.; Griffiths, A., 2011. Forecast of mycotoxins levels in soft wheat, durum wheat and maize before harvesting with qualimstre(a (r)), Journal Fur Verbraucherschutz Und Lebensmittelsicherheit-Journal of Consumer Protection and Food Safety, 6, 277-281.

Fu, M.; Li, R. J.; Guo, C. C.; Pang, M. H.; Liu, Y. C.; Dong, J. G., 2015. Natural incidence of fusarium species and fumonisins $b-1$ and $b-2$ associated with maize kernels from nine provinces in china in 2012, Food Additives and Contaminants Part a-Chemistry Analysis Control Exposure \& Risk Assessment, 32, 503-511.

Fumero, M.; Reynoso, M.; Chulze, S., 2015. Fusarium temperatum and fusarium subglutinans isolated from maize in argentina, International Journal of Food Microbiology, 199, 86-92.

Galaverna, G.; Dall'asta, C.; Mangia, M. A.; Dossena, A.; Marchelli, R., 2009. Masked mycotoxins: An emerging issue for food safety, Czech Journal of Food Sciences, 27, S89-S92.

Galvano, F.; Piva, A.; Ritieni, A.; Galvano, G., 2001. Dietary strategies to counteract the effects of mycotoxins: A review, J Food Prot, 64, 120-131.

Gamanya, R.; Sibanda, L., 2001. Survey of fusarium moniliforme (f-verticillioides) and production of fumonisin b-1 in cereal grains and oilseeds in zimbabwe, International Journal of Food Microbiology, 71, 145-149.

Garcia, L. P.; Savi, G. D.; Santos, K.; Scussel, V. M., 2016. Fumonisins and fungi in dry soybeans (glycine max I.) for human consumption, Food Addit Contam Part B Surveill, 9, 79-84.

Garcia-Cela, E.; Crespo-Sempere, A.; Gil-Serna, J.; Porqueres, A.; Marin, S., 2015. Fungal diversity, incidence and mycotoxin contamination in grapes from two agro-climatic spanish regions with emphasis on aspergillus species, J Sci Food Agric, 95, 1716-1729.

Garcia-Fonseca, S.; Rubio, S., 2016. Restricted access supramolecular solvents for removal of matrixinduced ionization effects in mass spectrometry: Application to the determination of fusarium toxins in cereals, Talanta, 148, 370-379.

Garcia-Moraleja, A.; Font, G.; Manes, J.; Ferrer, E., 2015. Analysis of mycotoxins in coffee and risk assessment in spanish adolescents and adults, Food Chem Toxicol, 86, 225-233.

Garcia-Moraleja, A.; Font, G.; Manes, J.; Ferrer, E., 2015. Development of a new method for the simultaneous determination of 21 mycotoxins in coffee beverages by liquid chromatography tandem mass spectrometry, Food Research International, 72, 247-255.

Garcia-Moraleja, A.; Font, G.; Manes, J.; Ferrer, E., 2015. Simultaneous determination of mycotoxin in commercial coffee, Food Control, 57, 282-292.

Garrido, C. E.; Pezzani, C. H.; Pacin, A., 2012. Mycotoxins occurrence in argentina's maize (zea mays I.), from 1999 to 2010, Food Control, 25, 660-665.

Gaspardo, B.; Del Zotto, S.; Torelli, E.; Cividino, S. R.; Firrao, G.; Della Riccia, G.; Stefanon, B., 2012. A rapid method for detection of fumonisins $b-1$ and $b-2$ in corn meal using fourier transform near infrared (ft-nir) spectroscopy implemented with integrating sphere, Food Chemistry, 135, 16081612.

Gazzotti, T.; Lugoboni, B.; Zironi, E.; Barbarossa, A.; Serraino, A.; Pagliuca, G., 2009. Determination of fumonisin b1 in bovine milk by lc-ms/ms, Food Control, 20, 1171-1174. 
Geary, P. A.; Chen, G. Y.; Kimanya, M. E.; Shirima, C. P.; Oplatowska-Stachowiak, M.; Elliott, C. T.; Routledge, M. N.; Gong, Y. Y., 2016. Determination of multi-mycotoxin occurrence in maize based porridges from selected regions of tanzania by liquid chromatography tandem mass spectrometry (Ic-ms/ms), a longitudinal study, Food Control, 68, 337-343.

Gelderblom, W. C. A.; Rheeder, J. P.; Leggott, N.; Stockenstrom, S.; Humphreys, J.; Shephard, G. S.; Marasas, W. F. O., 2004. Fumonisin contamination of a corn sample associated with the induction of hepatocarcinogenesis in rats - role of dietary deficiencies, Food and Chemical Toxicology, 42, 471-479.

Generotti, S.; Cirlini, M.; Dall'Asta, C.; Suman, M., 2015. Influence of the industrial process from caryopsis to cornmeal semolina on levels of fumonisins and their masked forms, Food Control, 48, 170-174.

Ghali, R.; Ghorbel, H.; Hedilli, A., 2009. Fumonisin determination in tunisian foods and feeds. Elisa and hplc methods comparison, J Agric Food Chem, 57, 3955-3960.

Gherbawy, Y.; Elhariry, H.; Kocsube, S.; Bahobial, A.; El Deeb, B.; Altalhi, A.; Varga, J.; Vagvolgyi, C., 2015. Molecular characterization of black aspergillus species from onion and their potential for ochratoxin a and fumonisin b2 production, Foodborne Pathogens and Disease, 12, 414-423.

Ghiasian, S. A.; Maghsood, A. H.; Yazdanpanah, H.; Shephard, G. S.; Van der Westhuizen, L.; Vismer, H. F.; Rheeder, J. P.; Marasas, W. F. O., 2006. Incidence of fusarium verticillioides and levels of fumonisins in corn from main production areas in iran, Journal of Agricultural and Food Chemistry, 54, 6118-6122.

Ghiasian, S. A.; Rezayat, S. M.; Kord-Bacheh, P.; Maghsood, A. H.; Yazdanpanah, H.; Shephard, G. S.; van der Westhuizen, L.; Vismer, H. F.; Marasas, W. F. O., 2005. Fumonisin production by fusarium species isolated from freshly harvested corn in iran, Mycopathologia, 159, 31-40.

Ghiasian, S. A.; Aghamirian, M. R.; Maghsood, A. H.; Shephard, G. S.; van der Westhuizen, L., 2009. Occurrence of fumonisins in maize imported into iran during 2001-2002, Mycotoxin Res, 25, 25-28.

Giorni, P.; Dall'Asta, C.; Gregori, R.; Cirlini, M.; Galaverna, G.; Battilani, P., 2015. Starch and thermal treatment, important factors in changing detectable fumonisins in maize post-harvest, Journal of Cereal Science, 61, 78-85.

Gnonlonfin, G. J.; Hell, K.; Fandohan, P.; Siame, A. B., 2008. Mycoflora and natural occurrence of aflatoxins and fumonisin b1 in cassava and yam chips from benin, west africa, Int J Food Microbiol, $122,140-147$.

Goertz, A.; Zuehlke, S.; Spiteller, M.; Steiner, U.; Dehne, H. W.; Waalwijk, C.; de Vries, I.; Oerke, E. C., 2010. Fusarium species and mycotoxin profiles on commercial maize hybrids in germany, European Journal of Plant Pathology, 128, 101-111.

Golinski, P.; Waskiewicz, A.; Gromadzka, K., 2009. Mycotoxins and mycotoxicoses under climatic conditions of poland, Pol J Vet Sci, 12, 581-588.

Gong, H. Z.; Ji, R.; Li, Y. X.; Zhang, H. Y.; Li, B.; Zhao, Y.; Sun, L.; Yu, F.; Yang, J., 2009. Occurrence of fumonisin b-1 in corn from the main corn-producing areas of china, Mycopathologia, 167, 31-36.

Grenier, B.; Oswald, I. P., 2011. Mycotoxin co-contamination of food and feed: Meta-analysis of publications describing toxicological interactions, World Mycotoxin Journal, 4, 285-313.

Guo, C.; Liu, Y.; Jiang, Y.; Li, R.; Pang, M.; Liu, Y.; Dong, J., 2016. Fusarium species identification and fumonisin production in maize kernels from shandong province, china, from 2012 to 2014, Food Addit Contam Part B Surveill, 9, 203-209.

Gutema, T.; Munimbazi, C.; Bullerman, L. B., 2000. Occurrence of fumonisins and moniliformin in corn and corn-based food products of u.S. Origin, J Food Prot, 63, 1732-1737. 
Hammond, B. G.; Campbell, K. W.; Pilcher, C. D.; Degooyer, T. A.; Robinson, A. E.; McMillen, B. L.; Spangler, S. M.; Riordan, S. G.; Rice, L. G.; Richard, J. L., 2004. Lower fumonisin mycotoxin levels in the grain of bt corn grown in the united states in 2000-2002, J Agric Food Chem, 52, 1390-1397.

Han, Z.; Tangni, E. K.; Huybrechts, B.; Munaut, F.; Scauflaire, J.; Wu, A.; Callebaut, A., 2014. Screening survey of co-production of fusaric acid, fusarin c, and fumonisins $b-1, b-2$ and $b-3$ by fusarium strains grown in maize grains, Mycotoxin Research, 30, 231-240.

He, Q. H.; Xu, Y.; Wang, D.; Kang, M.; Huang, Z. B.; Li, Y. P., 2012. Simultaneous multiresidue determination of mycotoxins in cereal samples by polyvinylidene fluoride membrane based dot immunoassay, Food Chemistry, 134, 507-512.

Hennigen, M. R.; Sanchez, S.; Di Benedetto, N. M.; Longhi, A.; Torroba, J. E.; Soares, L. M. V., 2000. Fumonisin levels in commercial corn products in buenos aires, argentina, Food Additives and Contaminants Part a-Chemistry Analysis Control Exposure \& Risk Assessment, 17, 55-58.

Heperkan, D.; Guler, F. K.; Oktay, H. I., 2012. Mycoflora and natural occurrence of aflatoxin, cyclopiazonic acid, fumonisin and ochratoxin a in dried figs, Food Addit Contam Part A Chem Anal Control Expo Risk Assess, 29, 277-286.

Heperkan, D.; Moretti, A.; Dikmen, C. D.; Logrieco, A. F., 2012. Toxigenic fungi and mycotoxin associated with figs in the mediterranean area, Phytopathologia Mediterranea, 51, 119-130.

Herrera, M.; Conchello, P.; Juan, T.; Estopanan, G.; Herrera, A.; Arino, A., 2010. Fumonisins concentrations in maize as affected by physico-chemical, environmental and agronomical conditions, Maydica, 55, 121-126.

Hickert, S.; Gerding, J.; Ncube, E.; Hubner, F.; Flett, B.; Cramer, B.; Humpf, H. U., 2015. A new approach using micro hplc-ms/ms for multi-mycotoxin analysis in maize samples, Mycotoxin Res, 31, 109-115.

Hinojo, M. J.; Llorens, A.; Mateo, R.; Patino, B.; Gonzalez-Jaen, M. T.; Jimenez, M., 2004. Utility of the polymerase chain reaction-restriction fragment length polymorphisms of the intergenic spacer region of the rdna for characterizing gibberella fujikuroi isolates, Syst Appl Microbiol, 27, 681-688.

Ho, J. A. A.; Durst, R. A., 2003. Detection of fumonisin b1: Comparison of flow-injection liposome immunoanalysis with high-performance liquid chromatography, Analytical Biochemistry, 312, 7-13.

Houssou, P. A.; Ahohuendo, B. C.; Fandohan, P.; Kpodo, K.; Hounhouigan, D. J.; Jakobsen, M., 2009. Natural infection of cowpea (vigna unguiculata (I.) walp.) by toxigenic fungi and mycotoxin contamination in benin, west africa, Journal of Stored Products Research, 45, 40-44.

Hove, M.; Van Poucke, C.; Njumbe-Ediage, E.; Nyanga, L. K.; De Saeger, S., 2016. Review on the natural co-occurrence of afb1 and fb1 in maize and the combined toxicity of afb1 and fb1, Food Control, 59, 675-682.

Haas, D.; Pfeifer, B.; Reiterich, C.; Partenheimer, R.; Reck, B.; Buzina, W., 2013. Identification and quantification of fungi and mycotoxins from pu-erh tea, Int J Food Microbiol, 166, 316-322.

Irzykowska, L.; Bocianowski, J.; Waskiewicz, A.; Weber, Z.; Karolewski, Z.; Golinski, P.; Kostecki, M.; Irzykowski, W., 2012. Genetic variation of fusarium oxysporum isolates forming fumonisin b-1 and moniliformin, Journal of Applied Genetics, 53, 237-247.

Isaacson, C., 2005. The change of the staple diet of black south africans from sorghum to maize (corn) is the cause of the epidemic of squamous carcinoma of the oesophagus, Med Hypotheses, $64,658-660$.

Ivic, D.; Domijan, A. M.; Peraica, M.; Cvjetkovic, B., 2009. Fumonisin b-1 and zearalenone contamination of wheat in croatia and influence of fungicide treatments, Phytoprotection, 90, 3134. 
Ivic, D.; Kovacevik, B.; Vasilj, V.; Idzakovic, N., 2011. Occurrence of potentially toxigenic fusarium verticillioides and low fumonisin b-1 content on barley grain in bosnia and herzegovina, Journal of Applied Botany and Food Quality-Angewandte Botanik, 84, 121-124.

Izzati, Mzna; Hasmida, W. I. W., 2011. Isolation of microfungi from malay traditional vegetables and secondary metabolites produced by fusarium species, Sains Malaysiana, 40, 437-444.

Jackson, L. S.; Jablonski, J.; Bullerman, L. B.; Bianchini, A.; Hanna, M. A.; Voss, K. A.; Hollub, A. D.; Ryu, D., 2011. Reduction of fumonisin b-1 in corn grits by twin-screw extrusion, Journal of Food Science, 76, T150-T155.

Jackson, L. S.; Voss, K. A.; Ryu, D., 2012. Effects of different extrusion conditions on the chemical and toxicological fate of fumonisin b-1 in maize: A short review, World Mycotoxin Journal, 5, 251-260.

Jaksic, S.; Abramovic, B.; Jajic, I.; Balos, M. Z.; Mihaljev, Z.; Despotovic, V.; Sojic, D., 2012. Cooccurrence of fumonisins and deoxynivalenol in wheat and maize harvested in serbia, Bull Environ Contam Toxicol, 89, 615-619.

Jaksic, S.; Zivkov-Balos, M.; Mihaljev, Z.; Masic, Z.; Jajic, I.; Banic, N.; Abramovic, B., 2015. Extraction without organic solvents in the determination of fumonisins $b-1, b-2$, and $b-3$ in maize by hplc-fld and elisa tests, Food Analytical Methods, 8, 1446-1455.

Jestoi, M.; Kokkonen, M.; Uhlig, S., 2009. What about the 'other' fusarium mycotoxins?, World Mycotoxin Journal, 2, 181-192.

Jettanajit, A.; Nhujak, T., 2016. Determination of mycotoxins in brown rice using quechers sample preparation and uhplc-ms-ms, J Chromatogr Sci, 54, 720-729.

Jodra, A.; Lopez, M. A.; Escarpa, A., 2015. Disposable and reliable electrochemical magnetoimmunosensor for fumonisins simplified determination in maize-based foodstuffs, Biosens Bioelectron, 64, 633-638.

Joshi, S.; Segarra-Fas, A.; Peters, J.; Zuilhof, H.; van Beek, T. A.; Nielen, M. W. F., 2016. Multiplex surface plasmon resonance biosensing and its transferability towards imaging nanoplasmonics for detection of mycotoxins in barley, Analyst, 141, 1307-1318.

Juan, C.; Covarelli, L.; Beccari, G.; Colasante, V.; Manes, J., 2016. Simultaneous analysis of twenty-six mycotoxins in durum wheat grain from italy, Food Control, 62, 322-329.

Jung, S. Y.; Choe, B. C.; Choi, E. J.; Jeong, H. J.; Hwang, Y. S.; Shin, G. Y.; Kim, J. H., 2015. Survey of mycotoxins in commonly consumed korean grain products using an Ic-ms/ms multimycotoxin method in combination with immunoaffinity clean-up, Food Science and Biotechnology, 24, 11931199.

Jurjevic, Z.; Solfrizzo, M.; Cvjetkovic, B.; De Girolamo, A.; Visconti, A., 2002. Occurrence of beauvericin in corn from croatia, Food Technology and Biotechnology, 40, 91-94.

Kabak, B.; Dobson, A. D. W.; Var, I., 2006. Strategies to prevent mycotoxin contamination of food and animal feed: A review, Critical Reviews in Food Science and Nutrition, 46, 593-619.

Kadir, M. K. A.; Tothill, I. E., 2010. Development of an electrochemical immunosensor for fumonisins detection in foods, Toxins, 2, 382-398.

Kamala, A.; Kimanya, M.; Haesaert, G.; Tiisekwa, B.; Madege, R.; Degraeve, S.; Cyprian, C.; De Meulenaer, B., 2016. Local post-harvest practices associated with aflatoxin and fumonisin contamination of maize in three agro ecological zones of tanzania, Food Addit Contam Part A Chem Anal Control Expo Risk Assess, 33, 551-559.

Kanetis, L.; Testempasis, S.; Goulas, V.; Samuel, S.; Myresiotis, C.; Karaoglanidis, G. S., 2015. Identification and mycotoxigenic capacity of fungi associated with pre- and postharvest fruit rots of pomegranates in greece and cyprus, Int J Food Microbiol, 208, 84-92. 
Kankolongo, M. A.; Hell, K.; Nawa, I. N., 2009. Assessment for fungal, mycotoxin and insect spoilage in maize stored for human consumption in zambia, Journal of the Science of Food and Agriculture, 89, 1366-1375.

Karbancioglu-Guler, F.; Heperkan, D., 2009. Natural occurrence of fumonisin b-1 in dried figs as an unexpected hazard, Food and Chemical Toxicology, 47, 289-292.

Karimla, A.; Ortiz, J.; Kimanya, M.; Haesaert, G.; Donoso, S.; Tiisekwa, B.; De Meulenaer, B., 2015. Multiple mycotoxin co-occurrence in maize grown in three agro-ecological zones of tanzania, Food Control, 54, 208-215.

Karolewski, Z.; Waskiewicz, A.; Irzykowska, L.; Bocianowski, J.; Kostecki, M.; Golinski, P.; Knaflewski, M.; Weber, Z., 2011. Fungi presence and their mycotoxin distribution in asparagus spears, Polish Journal of Environmental Studies, 20, 911-918.

Kaushik, G., 2015. Effect of processing on mycotoxin content in grains, Crit Rev Food Sci Nutr, 55, 1672-1683.

Kawashima, L. M.; Vieira, A. P.; Soares, L. M. V., 2007. Famonisin b(1) and ochratoxin a in beers made in brazil, Ciencia E Tecnologia De Alimentos, 27, 317-323.

Kaya, S. B.; Tosun, H., 2013. Occurence of total aflatoxin, ochratoxin a and fumonisin in some organic foods, Journal of Pure and Applied Microbiology, 7, 2925-2932.

Kayode, O. F.; Sulyok, M.; Fapohunda, S. O.; Ezekiel, C. N.; Krska, R.; Oguntona, C. R. B., 2013. Mycotoxins and fungal metabolites in groundnut- and maize-based snacks from nigeria, Food Additives \& Contaminants Part B-Surveillance, 6, 294-300.

Khayoon, W. S.; Saad, B.; Salleh, B.; Ismail, N. A.; Manaf, N. H. A.; Latiff, A. A., 2010. A reversed phase high performance liquid chromatography method for the determination of fumonisins $b-1$ and b-2 in food and feed using monolithic column and positive confirmation by liquid chromatography/tandem mass spectrometry, Analytica Chimica Acta, 679, 91-97.

Khosravi, A. R.; Shokri, H.; Zaboli, F., 2013. Grain-borne mycoflora and fumonisin b1 from freshharvested and stored rice in northern iran, Jundishapur Journal of Microbiology, 6.

Kim, E. K.; Scott, P. M.; Lau, B. P. Y.; Lewis, D. A., 2002. Extraction of fumonisins b-1, and b-2 from white rice flour and their stability in white rice flour, cornstarch, cornmeal, and glucose, Journal of Agricultural and Food Chemistry, 50, 3614-3620.

Kim, E. K.; Scott, P. M.; Lau, B. P. Y., 2003. Hidden fumonisin in corn flakes, Food Additives and Contaminants Part a-Chemistry Analysis Control Exposure \& Risk Assessment, 20, 161-169.

Kim, E. K.; Shon, D. H.; Chung, S. H.; Kim, Y. B., 2002. Survey for fumonisin b-1 in korean corn-based food products, Food Additives and Contaminants, 19, 459-464.

Kim, N. Y.; Lee, I.; Ji, G. E., 2014. Reliable and simple detection of ochratoxin and fumonisin production in black aspergillus, J Food Prot, 77, 653-658.

Kimanya, M.; De Meulenaer, B.; Tiisekwa, B.; Ndomondo-Sigonda, M.; Kolsteren, P., 2008. Human exposure to fumonisins from home grown maize in tanzania, World Mycotoxin Journal, 1, 307-313.

Kimanya, M. E.; De Meulenaer, B.; Tiisekwa, B.; Ndomondo-Sigonda, M.; Devlieghere, F.; Van Camp, J.; Kolsteren, P., 2008. Co-occurrence of fumonisins with aflatoxins in home-stored maize for human consumption in rural villages of tanzania, Food Addit Contam Part A Chem Anal Control Expo Risk Assess, 25, 1353-1364.

Kimanya, M. E.; De Meulenaer, B.; Roberfroid, D.; Lachat, C.; Kolsteren, P., 2010. Fumonisin exposure through maize in complementary foods is inversely associated with linear growth of infants in tanzania, Mol Nutr Food Res, 54, 1659-1667. 
Kirincic, S.; Skrjanc, B.; Kos, N.; Kozolc, B.; Pirnat, N.; Tavcar-Kalcher, G., 2015. Mycotoxins in cereals and cereal products in slovenia - official control of foods in the years 2008-2012, Food Control, 50, 157-165.

Klaric, M. S.; Cvetnic, Z.; Pepeljnjak, S.; Kosalec, I., 2009. Co-occurrence of aflatoxins, ochratoxin a, fumonisins, and zearalenone in cereals and feed, determined by competitive direct enzyme-linked immunosorbent assay and thin-layer chromatography, Arh Hig Rada Toksikol, 60, 427-434.

Kleinschmidt, C. E.; Clements, M. J.; Maragos, C. M.; Pataky, J. K.; White, D. G., 2005. Evaluation of food-grade dent corn hybrids for severity of fusarium ear rot and fumonisin accumulation in grain, Plant Disease, 89, 291-297.

Knudsen, P. B.; Mogensen, J. M.; Larsen, T. O.; Nielsen, K. F., 2011. Occurrence of furnonisins b-2 and b-4 in retail raisins, Journal of Agricultural and Food Chemistry, 59, 772-776.

Kokkonen, M. K.; Jestoi, M. N., 2009. A multi-compound Ic-ms/ms method for the screening of mycotoxins in grains, Food Analytical Methods, 2, 128-140.

Kong, D. Z.; Liu, L. Q.; Song, S. S.; Suryoprabowo, S.; Li, A. K.; Kuang, H.; Wang, L. B.; Xu, C. L., 2016. A gold nanoparticle-based semi-quantitative and quantitative ultrasensitive paper sensor for the detection of twenty mycotoxins, Nanoscale, 8, 5245-5253.

Kong, W.; Xie, T.; Li, J.; Wei, J.; Qiu, F.; Qi, A.; Zheng, Y.; Yang, M., 2012. Analysis of fumonisins b1 and b2 in spices and aromatic and medicinal herbs by hplc-fld with on-line post-column derivatization and positive confirmation by lc-ms/ms, Analyst, 137, 3166-3174.

Konietzny, U.; Greiner, R., 2003. The application of pcr in the detection of mycotoxigenic fungi in foods, Brazilian Journal of Microbiology, 34, 283-300.

Kos, J.; Hajnal, E. J.; Skrinjar, M.; Misan, A.; Mandic, A.; Jovanov, P.; Milovanovic, I., 2014. Presence of fusarium toxins in maize from autonomous province of vojvodina, serbia, Food Control, 46, 98101.

Kosoglu, I.; Aksoy, U.; Pehlivan, R., 2011. Fumonisin b-1 and b-2 occurrence in dried fig fruits (ficus carica I.) under meander valley's climatic conditions and relationship with fruit quality, Food Additives and Contaminants Part a-Chemistry Analysis Control Exposure \& Risk Assessment, 28, 1569-1577.

Kouadio, J. H.; Lattanzio, V. M.; Ouattara, D.; Kouakou, B.; Visconti, A., 2014. Assessment of mycotoxin exposure in cote d'ivoire (ivory coast) through multi-biomarker analysis and possible correlation with food consumption patterns, Toxicol Int, 21, 248-257.

Kpodo, K.; Thrane, U.; Hald, B., 2000. Fusaria and fumonisins in maize from ghana and their cooccurrence with aflatoxins, Int J Food Microbiol, 61, 147-157.

Krska, R.; Becalski, A.; Braekevelt, E.; Koerner, T.; Cao, X. L.; Dabeka, R.; Godefroy, S.; Lau, B.; Moisey, J.; Rawn, D. F. K.; Scott, P. M.; Wang, Z. W.; Forsyth, D., 2012. Challenges and trends in the determination of selected chemical contaminants and allergens in food, Analytical and Bioanalytical Chemistry, 402, 139-162.

Krynitsky, A. J.; Trucksess, M. W.; Wong, J. W.; Zhang, K., 2016. Perspective on advancing fda regulatory monitoring for mycotoxins in foods using liquid chromatography and mass spectrometry (review), J AOAC Int.

Kulisek, E. S.; Hazebroek, J. P., 2000. Comparison of extraction buffers for the detection of fumonisin b-1 in corn by immunoassay and high-performance liquid chromatography, Journal of Agricultural and Food Chemistry, 48, 65-69.

Kumagai, S.; Nakajima, M.; Tabata, S.; Ishikuro, E.; Tanaka, T.; Norizuki, H.; Itoh, Y.; Aoyama, K.; Fujita, K.; Kai, S.; Sato, T.; Saito, S.; Yoshiike, N.; Sugita-Konishi, Y., 2008. Aflatoxin and ochratoxin a contamination of retail foods and intake of these mycotoxins in japan, Food Addit Contam Part A Chem Anal Control Expo Risk Assess, 25, 1101-1106. 
Kumar, V.; Basu, M. S.; Rajendran, T. P., 2008. Mycotoxin research and mycoflora in some commercially important agricultural commodities, Crop Protection, 27, 891-905.

Kumi, J.; Mitchell, N. J.; Asare, G. A.; Dotse, E.; Kwaa, F.; Phillips, T. D.; Ankrah, N. A., 2014. Aflatoxins and fumonisins contamination of home-made food (weanimix) from cereal-legume blends for children, Ghana Med J, 48, 121-126.

Kushiro, M.; Zheng, Y. Z.; Nagara, R.; Nakagawa, H.; Nagashima, H., 2009. Limited surveillance of fumonisins in brown rice and wheat harvested in japan, Journal of Food Protection, 72, 1327-1331.

Lanza, F. E.; Zambolim, L.; da Costa, R. V.; Queiroz, V. A. V.; Cota, L. V.; da Silva, D. D.; de Souza, A. G. C.; Figueiredo, J. E. F., 2014. Prevalence of fumonisin-producing fusarium species in brazilian corn grains, Crop Protection, 65, 232-237.

Lattanzio, V. M. T.; Ciasca, B.; Powers, S.; Visconti, A., 2014. Improved method for the simultaneous determination of aflatoxins, ochratoxin a and fusarium toxins in cereals and derived products by liquid chromatography-tandem mass spectrometry after multi-toxin immunoaffinity clean up, Journal of Chromatography A, 1354, 139-143.

Lattanzio, V. M. T.; Nivarlet, N.; Lippolis, V.; Della Gatta, S.; Huet, A. C.; Delahaut, P.; Granier, B.; Visconti, A., 2012. Multiplex dipstick immunoassay for semi-quantitative determination of fusarium mycotoxins in cereals, Analytica Chimica Acta, 718, 99-108.

Lattanzio, V. M. T.; von Holst, C.; Visconti, A., 2014. Collaborative study for evaluating performances of a multiplex dipstick immunoassay for fusarium mycotoxin screening in wheat and maize, Quality Assurance and Safety of Crops \& Foods, 6, 299-307.

Lawrence, J. F.; Menard, C.; Yeung, J.; Ben Rejeb, S., 2000. Evaluation of silica- and sepharose-based immunoaffinity sorbents for sample cleanup in determination of fumonisins b-1 and b-2 in corn products, Journal of Aoac International, 83, 597-603.

Lee, K. M.; Herrman, T. J., 2016. Determination and prediction of fumonisin contamination in maize by surface-enhanced raman spectroscopy (sers), Food and Bioprocess Technology, 9, 588-603.

Lefyedi, M. L.; Marais, G. J.; Dutton, M. F.; Taylor, J. R. N., 2005. The microbial contamination, toxicity and quality of turned and unturned outdoor floor malted sorghum, Journal of the Institute of Brewing, 111, 190-196.

Leggieri, M. C.; Bertuzzi, T.; Pietri, A.; Battilani, P., 2015. Mycotoxin occurrence in maize produced in northern italy over the years 2009-2011: Focus on the role of crop related factors, Phytopathologia Mediterranea, 54, 212-221.

Lehner, S. M.; Neumann, N. K. N.; Sulyok, M.; Lemmens, M.; Krska, R.; Schuhmacher, R., 2011. Evaluation of Ic-high-resolution $\mathrm{ft}$-orbitrap ms for the quantification of selected mycotoxins and the simultaneous screening of fungal metabolites in food, Food Additives and Contaminants Part aChemistry Analysis Control Exposure \& Risk Assessment, 28, 1457-1468.

Levasseur-Garcia, C.; Bailly, S.; Kleiber, D.; Bailly, J. D., 2015. Assessing risk of fumonisin contamination in maize using near-infrared spectroscopy, Journal of Chemistry.

Levasseur-Garcia, C.; Kleiber, D., 2015. A method for the allotment of maize contaminated by toxins, Journal of near Infrared Spectroscopy, 23, 255-265.

Li, C. L.; Wen, K.; Mi, T. J.; Zhang, X. Y.; Zhang, H. Y.; Zhang, S. X.; Shen, J. Z.; Wang, Z. H., 2016. A universal multi-wavelength fluorescence polarization immunoassay for multiplexed detection of mycotoxins in maize, Biosensors \& Bioelectronics, 79, 258-265.

Li, C.; Mi, T.; Conti, G. O.; Yu, Q.; Wen, K.; Shen, J.; Ferrante, M.; Wang, Z., 2015. Development of a screening fluorescence polarization immunoassay for the simultaneous detection of fumonisins $b(1)$ and b(2) in maize, J Agric Food Chem, 63, 4940-4946. 
Li, C.; Wu, Y. L.; Yang, T.; Huang-Fu, W. G., 2012. Rapid determination of fumonisins b-1 and b-2 in corn by liquid chromatography-tandem mass spectrometry with ultrasonic extraction, Journal of Chromatographic Science, 50, 57-63.

Li, F.; Jiang, D.; Zheng, F.; Chen, J.; Li, W., 2015. Fumonisins $b(1), b(2)$ and $b(3)$ in corn products, wheat flour and corn oil marketed in shandong province of china, Food Addit Contam Part B Surveill, 8, 169-174.

Li, F. Q.; Yoshizawa, T.; Kawamura, O.; Luo, X. Y.; Li, Y. W., 2001. Aflatoxins and fumonisins in corn from the high-incidence area for human hepatocellular carcinoma in guangxi, china, J Agric Food Chem, 49, 4122-4126.

Li, L.; Xia, L. R.; Zhao, Y. F.; Wang, H. Y., 2016. Development of immune-affinity 96 spots monolith array for multiple mycotoxins detection in food samples, J Chromatogr B Analyt Technol Biomed Life Sci, 1029-1030, 72-80.

Li, R. J.; Guo, C. C.; Zhang, Q. G.; Pang, M. H.; Liu, Y. C.; Dong, J. G., 2015. Fumonisins b-1 and b-2 in maize harvested in hebei province, china, during 2011-2013, Food Additives \& Contaminants Part B-Surveillance, 8, 1-6.

Li, R. J.; Tao, B.; Pang, M. H.; Liu, Y. C.; Dong, J. G., 2015. Natural occurrence of fumonisins b-1 and b-2 in maize from three main maize-producing provinces in china, Food Control, 50, 838-842.

Li, W.; Herrman, T. J.; Dai, S. Y., 2010. Rapid determination of fumonisins in corn-based products by liquid chromatography/tandem mass spectrometry, J AOAC Int, 93, 1472-1481.

Li, X.; Li, P. W.; Zhang, Q.; Zhang, Z. W.; Li, R.; Zhang, W.; Ding, X. X.; Chen, X. M.; Tang, X. Q., 2013. A sensitive immunoaffinity column-linked indirect competitive elisa for ochratoxin a in cereal and oil products based on a new monoclonal antibody, Food Analytical Methods, 6, 1433-1440.

Li, Y. S.; Zhou, Y.; Lu, S. Y.; Guo, D. J.; Ren, H. L.; Meng, X. M.; Zhi, B. H.; Lin, C.; Wang, Z.; Li, X. B.; Liu, Z. S., 2012. Development of a one-step test strip for rapid screening of fumonisins b1, b2 and b3 in maize, Food Control, 24, 72-77.

Liao, C. D.; Wong, J. W.; Zhang, K.; Hayward, D. G.; Lee, N. S.; Trucksess, M. W., 2013. Multimycotoxin analysis of finished grain and nut products using high-performance liquid chromatography-triple-quadrupole mass spectrometry, J Agric Food Chem, 61, 4771-4782.

Liao, C. D.; Wong, J. W.; Zhang, K.; Yang, P.; Wittenberg, J. B.; Trucksess, M. W.; Hayward, D. G.; Lee, N. S.; Chang, J. S., 2015. Multi-mycotoxin analysis of finished grain and nut products using ultrahigh-performance liquid chromatography and positive electrospray ionization-quadrupole orbital ion trap high-resolution mass spectrometry, ] Agric Food Chem, 63, 8314-8332.

Lim, C. W.; Yoshinari, T.; Layne, J.; Chan, S. H., 2015. Multi-mycotoxin screening reveals separate occurrence of aflatoxins and ochratoxin a in asian rice, J Agric Food Chem, 63, 3104-3113.

Lin, X.; Guo, X., 2016. Advances in biosensors, chemosensors and assays for the determination of fusarium mycotoxins, Toxins (Basel), 8.

Ling, S.; Wang, R.; Gu, X.; Wen, C.; Chen, L.; Chen, Z.; Chen, Q. A.; Xiao, S.; Yang, Y.; Zhuang, Z.; Wang, S., 2015. Rapid detection of fumonisin b1 using a colloidal gold immunoassay strip test in corn samples, Toxicon, 108, 210-215.

Lino, C. M.; Silva, L. J. G.; Pena, A. L. S.; Silveira, M. I., 2006. Determination of fumonisins b1 and b2 in portuguese maize and maize-based samples by hplc with fluorescence detection, Analytical and Bioanalytical Chemistry, 384, 1214-1220.

Lino, C. M.; Silva, L. J. G.; Pena, A.; Fernandez, M.; Manes, J., 2007. Occurrence of fumonisins b-1 and b-2 in broa, typical portuguese maize bread, International Journal of Food Microbiology, 118, $79-82$. 
Liu, C. L.; Liu, F. M.; Xu, W. N.; Kofoet, A.; Humpf, H. U.; Jiang, S. R., 2005. Occurrence of fumonisins b-1 and b-2 in asparagus from shandong province, p.R. China, Food Additives and Contaminants, 22, 673-676.

Liu, C. L.; Xu, W. N.; Liu, F. M.; Jiang, S. R., 2007. Fumonisins production by fusarium proliferatum strains isolated from asparagus crown, Mycopathologia, 164, 127-134.

Liu, F. M.; Chen, P. C.; Fu, Y. M.; Shih, D. Y. C., 2005. Determination of fumonisin b-1 and b-2 in corn products, Journal of Food and Drug Analysis, 13, 273-278.

Liu, Y. P.; Yang, L. X.; Yang, N. J.; Dong, B.; Cao, L. L.; Wang, K.; Yang, L. X., 2012. Occurrence of fumonisins and aflatoxins in cereals from markets of hebei province of china, Food Addit Contam Part B Surveill, 5, 208-211.

Lo Magro, S.; Campaniello, M.; Nardiello, D.; Muscarella, M., 2011. Assessment of fumonisins b-1 and b-2 levels in commercial maize-based food products by liquid chromatography with fluorimetric detection and postcolumn chemical derivatization, Journal of Food Science, 76, T1-T4.

Logrieco, A.; Bottalico, A.; Mule, G.; Moretti, A.; Perrone, G., 2003. Epidemiology of toxigenic fungi and their associated mycotoxins for some mediterranean crops, European Journal of Plant Pathology, 109, 645-667.

Logrieco, A.; Ferracane, R.; Haidukowsky, M.; Cozzi, G.; Visconti, A.; Ritieni, A., 2009. Fumonisin b(2) production by aspergillus niger from grapes and natural occurrence in must, Food Addit Contam Part A Chem Anal Control Expo Risk Assess, 26, 1495-1500.

Logrieco, A.; Ferracane, R.; Visconti, A.; Ritieni, A., 2010. Natural occurrence of fumonisin b2 in red wine from italy, Food Addit Contam Part A Chem Anal Control Expo Risk Assess, 27, 1136-1141.

Logrieco, A. F.; Ferracane, R.; Cozzi, G.; Haidukowsky, M.; Susca, A.; Mule, G.; Ritieni, A., 2011. Fumonisin $b-2$ by aspergillus niger in the grape-wine chain: An additional potential mycotoxicological risk, Annals of Microbiology, 61, 1-3.

Logrieco, A. F.; Haidukowski, M.; Susca, A.; Mule, G.; Munkvold, G. P.; Moretti, A., 2014. Aspergillus section nigri as contributor of fumonisin b-2 contamination in maize, Food Additives and Contaminants Part a-Chemistry Analysis Control Exposure \& Risk Assessment, 31, 149-155.

Logrieco, A.; Mule, G.; Moretti, A.; Bottalico, A., 2002. Toxigenic fusarium species and mycotoxins associated with maize ear rot in europe, European Journal of Plant Pathology, 108, 597-609.

Lombaert, G. A.; Pellaers, P.; Roscoe, V.; Mankotia, M.; Neil, R.; Scott, P. M., 2003. Mycotoxins in infant cereal foods from the canadian retail market, Food Addit Contam, 20, 494-504.

Lopez, P.; de Rijk, T.; Sprong, R. C.; Mengelers, M. J. B.; Castenmiller, J. J. M.; Alewijn, M., 2016. A mycotoxin-dedicated total diet study in the netherlands in 2013: Part ii - occurrence, World Mycotoxin Journal, 9, 89-108.

Luzardo, O. P.; Bernal-Suarez Mdel, M.; Camacho, M.; Henriquez-Hernandez, L. A.; Boada, L. D.; RialBerriel, C.; Almeida-Gonzalez, M.; Zumbado, M.; Diaz-Diaz, R., 2016. Estimated exposure to eu regulated mycotoxins and risk characterization of aflatoxin-induced hepatic toxicity through the consumption of the toasted cereal flour called "gofio", a traditional food of the canary islands (spain), Food Chem Toxicol, 93, 73-81.

Ma, L. Y.; Xu, W. T.; He, X. Y.; Huang, K. L.; Wang, Y.; Luo, Y. B., 2013. Determination of fumonisins b1 and b2 in chinese rice wine by hplc using aqc precolumn derivatisation, Journal of the Science of Food and Agriculture, 93, 1128-1133.

Machinski, M.; Soares, L. M. V., 2000. Fumonisins b-1 and b-2 in brazilian corn-based food products, Food Additives and Contaminants, 17, 875-879. 
Madbouly, A. K.; Ibrahim, M. I. M.; Sehab, A. F.; Abdel-Wahhab, M. A., 2012. Co-occurrence of mycoflora, aflatoxins and fumonisins in maize and rice seeds from markets of different districts in cairo, egypt, Food Additives \& Contaminants Part B-Surveillance, 5, 112-120.

Maenetje, P. W.; Dutton, M. F., 2007. The incidence of fungi and mycotoxins in south african barley and barley products, J Environ Sci Health B, 42, 229-236.

Magoha, H.; De Meulenaer, B.; Kimanya, M.; Hipolite, D.; Lachat, C.; Kolsteren, P., 2014. Fumonisin b1 contamination in breast milk and its exposure in infants under 6 months of age in rombo, northern tanzania, Food Chem Toxicol, 74, 112-116.

Magoha, H.; Kimanya, M.; De Meulenaer, B.; Roberfroid, D.; Lachat, C.; Kolsteren, P., 2016. Risk of dietary exposure to aflatoxins and fumonisins in infants less than 6 months of age in rombo, northern tanzania, Matern Child Nutr, 12, 516-527.

Maheshwar, P. K.; Janardhana, G. R., 2010. Natural occurrence of toxigenic fusarium proliferatum on paddy (oryza sativa I.) in karnataka, india, Trop Life Sci Res, 21, 1-10.

Mahnine, N.; Meca, G.; Fernandez-Franzon, M.; Manes, J.; Zinedine, A., 2012. Occurrence of fumonisins b1, b2 and b3 in breakfast and infant cereals from morocco, Phytopathologia Mediterranea, 51, 193-197.

Makun, H. A.; Dutton, M. F.; Njobeh, P. B.; Phoku, J. Z.; Yah, C. S., 2011. Incidence, phylogeny and mycotoxigenic potentials of fungi isolated from rice in niger state, nigeria, Journal of Food Safety, 31, 334-349.

Makun, H. A.; Dutton, M. F.; Njobeh, P. B.; Mwanza, M.; Kabiru, A. Y., 2011. Natural multi-occurrence of mycotoxins in rice from niger state, nigeria, Mycotoxin Res, 27, 97-104.

Malhotra, B. D.; Srivastava, S.; Ali, M. A.; Singh, C., 2014. Nanomaterial-based biosensors for food toxin detection, Appl Biochem Biotechnol, 174, 880-896.

Manjula, K.; Hell, K.; Fandohan, P.; Abass, A.; Bandyopadhyay, R., 2009. Aflatoxin and fumonisin contamination of cassava products and maize grain from markets in tanzania and republic of the congo, Toxin Reviews, 28, 63-69.

Manova, R.; Mladenova, R., 2009. Incidence of zearalenone and fumonisins in bulgarian cereal production, Food Control, 20, 362-365.

Maragos, C. M.; Busman, M., 2010. Rapid and advanced tools for mycotoxin analysis: A review, Food Addit Contam Part A Chem Anal Control Expo Risk Assess, 27, 688-700.

Maragos, C. M.; Jolley, M. E.; Plattner, R. D.; Nasir, M. S., 2001. Fluorescence polarization as a means for determination of fumonisins in maize, J Agric Food Chem, 49, 596-602.

Marasas, W. F., 2001. Discovery and occurrence of the fumonisins: A historical perspective, Environ Health Perspect, 109 Suppl 2, 239-243.

Marin, S.; Ramos, A. J.; Vazquez, C.; Sanchis, V., 2007. Contamination of pine nuts by fumonisin produced by strains of fusarium proliferatum isolated from pinus pinea, Lett Appl Microbiol, 44, 6872.

Marin, S.; Ramos, A. J.; Cano-Sancho, G.; Sanchis, V., 2013. Mycotoxins: Occurrence, toxicology, and exposure assessment, Food Chem Toxicol, 60, 218-237.

Marschik, S.; Hepperle, J.; Lauber, U.; Schnaufer, R.; Maier, S.; Kuhn, C.; Schwab-Bohnert, G., 2013. Extracting fumonisins from maize: Efficiency of different extraction solvents in multi-mycotoxin analytics, Mycotoxin Res, 29, 119-129.

Martins, F. A.; Ferreira, F. M. D.; Ferreira, F. D.; Bando, E.; Nerilo, S. B.; Hirooka, E. Y.; Machinski, M., 2012. Daily intake estimates of fumonisins in corn-based food products in the population of parana, brazil, Food Control, 26, 614-618. 
Martins, H. M.; Almeida, I.; Marques, M. F.; Guerra, M. M., 2008. Fumonisins and deoxynivalenol in corn-based food products in portugal, Food and Chemical Toxicology, 46, 2585-2587.

Martins, M. L.; Martins, H. M.; Bernardo, F., 2001. Fumonisins b-1 and b-2 in black tea and medicinal plants, Journal of Food Protection, 64, 1268-1270.

Martos, P. A.; Thompson, W.; Diaz, G. J., 2010. Multiresidue mycotoxin analysis in wheat, barley, oats, rye and maize grain by high-performance liquid chromatography-tandem mass spectrometry, World Mycotoxin Journal, 3, 205-223.

Mashinini, K.; Dutton, M. F., 2006. The incidence of fungi and mycotoxins in south africa wheat and wheat-based products, J Environ Sci Health B, 41, 285-296.

Massi, F. P.; Sartori, D.; Ferranti Lde, S.; Iamanaka, B. T.; Taniwaki, M. H.; Vieira, M. L.; Fungaro, M. $H .$, 2016. Data on the presence or absence of genes encoding essential proteins for ochratoxin and fumonisin biosynthesis in aspergillus niger and aspergillus welwitschiae, Data Brief, 7, 704-708.

Massi, F. P.; Sartori, D.; Ferranti, L. D.; Iamanaka, B. T.; Taniwaki, M. H.; Vieira, M. L. C.; Fungaro, M. H. P., 2016. Prospecting for the incidence of genes involved in ochratoxin and fumonisin biosynthesis in brazilian strains of aspergillus niger and aspergillus welwitschiae, International Journal of Food Microbiology, 221, 19-28.

Mateo, J. J.; Jimenez, M., 2000. Trichothecenes and fumonisins produced in autoclaved tiger nuts by strains of fusarium sporotrichioides and fusarium moniliforme, Food Microbiology, 17, 167-176.

Mateo, J. J.; Mateo, R.; Jimenez, M., 2001. Determination of fumonisins b1 and b2 produced by isolates of gibberella fujikuroi complex in corn and rice, Food Science and Technology International, 7, 231-236.

Matsuo, Y.; Takahara, K.; Sago, Y.; Kushiro, M.; Nagashima, H.; Nakagawa, H., 2015. Detection of n(1-deoxy-d-fructos-1-yl) fumonisins b-2 and b-3 in corn by high-resolution Ic-orbitrap ms, Toxins, 7, 3700-3714.

Matumba, L.; Sulyok, M.; Monjerezi, M.; Biswick, T.; Krska, R., 2015. Fungal metabolites diversity in maize and associated human dietary exposures relate to micro-climatic patterns in malawi, World Mycotoxin Journal, 8, 269-282.

Matumba, L.; Van Poucke, C.; Ediage, E. N.; Jacobs, B.; De Saeger, S., 2015. Effectiveness of hand sorting, flotation/washing, dehulling and combinations thereof on the decontamination of mycotoxin-contaminated white maize, Food Additives and Contaminants Part a-Chemistry Analysis Control Exposure \& Risk Assessment, 32, 960-969.

Matumba, L.; Van Poucke, C.; Biswick, T.; Monjerezi, M.; Mwatseteza, J.; De Saeger, S., 2014. A limited survey of mycotoxins in traditional. Maize based opaque beers in malawi, Food Control, 36, 253-256.

Mayer, S.; Twaruzek, M.; Blajet-Kosicka, A.; Grajewski, J., 2016. Occupational exposure to mould and microbial metabolites during onion sorting-insights into an overlooked workplace, Environmental Monitoring and Assessment, 188.

Mazumder, P. M.; Sasmal, D., 2001. Mycotoxins - limits and regulations, Anc Sci Life, 20, 1-19.

Mazzani, C.; Borges, O.; Luzon, O.; Barrientos, V.; Quijada, P., 2001. Occurrence of fusarium moniliforme and fumonisins in kernels of maize hybrids in venezuela, Brazilian Journal of Microbiology, 32, 345-349.

Mbugua, S. K.; Gathumbi, J. K., 2004. The contamination of kenyan lager beers with fusarium mycotoxins, Journal of the Institute of Brewing, 110, 227-229.

Medina, A.; Valle-Algarra, F. M.; Mateo, R.; Gimeno-Adelantado, J. V.; Mateo, F.; Jimenez, M., 2006. Survey of the mycobiota of spanish malting barley and evaluation of the mycotoxin producing potential of species of alternaria, aspergillus and fusarium, Int J Food Microbiol, 108, 196-203. 
Medina-Martinez, M. S.; Martinez, A. J., 2000. Mold occurrence and aflatoxin b-1 and fumonisin b-1 determination in corn samples in venezuela, Journal of Agricultural and Food Chemistry, 48, 28332836.

Meirelles, P. G.; Ono, M. A.; Ohe, M. C. T.; Maroneze, D. M.; Itano, E. N.; Garcia, G. T.; Sugiura, Y.; Ueno, Y.; Hirooka, E. Y.; Ono, E. Y. S., 2006. Detection of fusarium sp contamination in corn by enzyme-linked immunosorbent assay, Food and Agricultural Immunology, 17, 79-89.

Meister, U., 2001. Investigations on the change of fumonisin content of maize during hydrothermal treatment of maize. Analysis by means of hplc methods and elisa, European Food Research and Technology, 213, 187-193.

Meister, U.; Springer, M., 2004. Mycotoxins in cereals and cereal products - occurrence and changes during processing, Journal of Applied Botany and Food Quality-Angewandte Botanik, 78, 168-173.

Mendes, G. D. L.; dos Reis, T. A.; Correa, B.; Badiale-Furlong, E., 2015. Mycobiota and occurrence of fumonisin b-1 in wheat harvested in southern brazil, Ciencia Rural, 45, 1050-1057.

Mikusova, P.; Ritieni, A.; Santini, A.; Juhasova, G.; Srobarova, A., 2010. Contamination by moulds of grape berries in slovakia, Food Addit Contam Part A Chem Anal Control Expo Risk Assess, 27, 738747.

Mikusova, P.; Sulyok, M.; Santini, A.; Srobarova, A., 2014. Aspergillus spp. And their secondary metabolite production in grape berries from slovakia, Phytopathologia Mediterranea, 53, 311-317.

Mikusova, P.; Srobarova, A.; Sulyok, M.; Santini, A., 2013. Fusarium fungi and associated metabolites presence on grapes from slovakia, Mycotoxin Res, 29, 97-102.

Milani, J.; Maleki, G., 2014. Effects of processing on mycotoxin stability in cereals, J Sci Food Agric, 94, 2372-2375.

Miller, J. D., 2001. Factors that affect the occurrence of fumonisin, Environ Health Perspect, 109 Suppl 2, 321-324.

Mirasoli, M.; Buragina, A.; Dolci, L. S.; Simoni, P.; Anfossi, L.; Giraudi, G.; Roda, A., 2012. Chemiluminescence-based biosensor for fumonisins quantitative detection in maize samples, Biosens Bioelectron, 32, 283-287.

Mirete, S.; Patino, B.; Vazquez, C.; Jimenez, M.; Hinojo, M. J.; Soldevilla, C.; Gonzalez-Jaen, M. T., 2003. Fumonisin production by gibberella fujikuroi strains from pinus species, Int J Food Microbiol, $89,213-221$.

Mngqawa, P.; Shephard, G. S.; Green, I. R.; Ngobeni, S. H.; de Rijk, T. C.; Katerere, D. R., 2016. Mycotoxin contamination of home-grown maize in rural northern south africa (limpopo and mpumalanga provinces), Food Addit Contam Part B Surveill, 9, 38-45.

Mogensen, J. M.; Frisvad, J. C.; Thrane, U.; Nielsen, K. F., 2010. Production of fumonisin b-2 and b-4 by aspergillus niger on grapes and raisins, Journal of Agricultural and Food Chemistry, 58, 954958.

Mogensen, J. M.; Larsen, T. O.; Nielsen, K. F., 2010. Widespread occurrence of the mycotoxin fumonisin b-2 in wine, Journal of Agricultural and Food Chemistry, 58, 4853-4857.

Mogensen, J. M.; Sorensen, S. M.; Sulyok, M.; van der Westhuizen, L.; Shephard, G. S.; Frisvad, J. C.; Thrane, U.; Krska, R.; Nielsen, K. F., 2011. Single-kernel analysis of fumonisins and other fungal metabolites in maize from south african subsistence farmers, Food Addit Contam Part A Chem Anal Control Expo Risk Assess, 28, 1724-1734.

Mohamed, A. M.; Abeer, R. M. A., 2016. Molecular identification and genetic variation of toxigenic and atoxigenic fusarium verticillioides and its toxin-contaminated maize grains, Research Journal of Biotechnology, 11, 53-59. 
Mohammadi, A.; Shams-Ghahfarokhi, M.; Nazarian-Firouzabadi, F.; Kachuei, R.; Gholami-Shabanid, M.; Razzaghi-Abyaneh, M., 2016. Giberella fujikuroi species complex isolated from maize and wheat in iran: Distribution, molecular identification and fumonisin b-1 in vitro biosynthesis, Journal of the Science of Food and Agriculture, 96, 1333-1340.

Molinie, A.; Faucet, V.; Castegnaro, P.; Pfohl-Leszkowicz, A., 2005. Analysis of some breakfast cereals on the french market for their contents of ochratoxin a, citrinin and fumonisin b-1: Development of a method for simultaneous extraction of ochratoxin a and citrinin, Food Chemistry, 92, 391-400.

Moller, T. E.; Gustavsson, H. F., 2000. Determination of fumonisins b-1 and b-2 in various maize products by a combined sax $+\mathrm{c}-18$ column and immunoaffinity column, Journal of Aoac International, 83, 99-103.

Monbaliu, S.; Van Poucke, C.; Van Peteghem, C.; Van Poucke, K.; Heungens, K.; De Saeger, S., 2009. Development of a multi-mycotoxin liquid chromatography/tandem mass spectrometry method for sweet pepper analysis, Rapid Commun Mass Spectrom, 23, 3-11.

Monbaliu, S.; Van Poucke, K.; Heungens, K.; Van Peteghem, C.; De Saeger, S., 2010. Production and migration of mycotoxins in sweet pepper analyzed by multimycotoxin Ic-ms/ms, J Agric Food Chem, 58, 10475-10479.

Monbaliu, S.; Wu, A.; Zhang, D.; Van Peteghem, C.; De Saeger, S., 2010. Multimycotoxin uplc-ms/ms for tea, herbal infusions and the derived drinkable products, J Agric Food Chem, 58, 12664-12671.

Moreno, E. C.; Garcia, G. T.; Ono, M. A.; Vizoni, E.; Kawamura, O.; Hirooka, E. Y.; Ono, E. Y. S., 2009. Co-occurrence of mycotoxins in corn samples from the northern region of parana state, brazil, Food Chemistry, 116, 220-226.

Moretti, A.; Ferracane, L.; Somma, S.; Ricci, V.; Mule, G.; Susca, A.; Ritieni, A.; Logrieco, A. F., 2010. Identification, mycotoxin risk and pathogenicity of fusarium species associated with fig endosepsis in apulia, italy, Food Addit Contam Part A Chem Anal Control Expo Risk Assess, 27, 718-728.

Moretti, A.; Susca, A.; Mule, G.; Logrieco, A. F.; Proctor, R. H., 2013. Molecular biodiversity of mycotoxigenic fungi that threaten food safety, Int J Food Microbiol, 167, 57-66.

Motta, E. L.; Scott, P. M., 2009. Bioaccessibility of total bound fumonisin from corn flakes, Mycotoxin Res, 25, 229-232.

Motta, E. L.; Scott, P. M., 2007. Effect ofin vitro digestion on fumonisin b1 in corn flakes, Mycotoxin Res, 23, 166-172.

Mudili, V.; Siddaih, C. N.; Nagesh, M.; Garapati, P.; Kumar, K. N.; Murali, H. S.; Mattila, T. Y.; Batra, H. V., 2014. Mould incidence and mycotoxin contamination in freshly harvested maize kernels originated from india, Journal of the Science of Food and Agriculture, 94, 2674-2683.

Mukanga, M.; Derera, J.; Tongoona, P.; Laing, M. D., 2010. A survey of pre-harvest ear rot diseases of maize and associated mycotoxins in south and central zambia, Int J Food Microbiol, 141, 213221.

Munitz, M. S.; Resnik, S. L.; Pacin, A.; Salas, P. M.; Gonzalez, H. H. L.; Montti, M. I. T.; Drunday, V.; Guillin, E. A., 2014. Mycotoxigenic potential of fungi isolated from freshly harvested argentinean blueberries, Mycotoxin Research, 30, 221-229.

Muscarella, M.; Magro, S. L.; Nardiello, D.; Palermo, C.; Centonze, D., 2011. Determination of fumonisins $b(1)$ and $b(2)$ in maize food products by a new analytical method based on highperformance liquid chromatography and fluorimetric detection with post-column derivatization, Methods Mol Biol, 739, 187-194.

Muscarella, M.; Magroa, S. L.; Nardiello, D.; Palermo, C.; Centonze, D., 2008. Development of a new analytical method for the determination of fumonisins b- 1 and $b-2$ in food products based on high performance liquid chromatography and fluorimetric detection with post-column derivatization, Journal of Chromatography A, 1203, 88-93. 
Mutiga, S. K.; Hoffmann, V.; Harvey, J. W.; Milgroom, M. G.; Nelson, R. J., 2015. Assessment of aflatoxin and fumonisin contamination of maize in western kenya, Phytopathology, 105, 12501261.

Mutiga, S. K.; Were, V.; Hoffmann, V.; Harvey, J. W.; Milgroom, M. G.; Nelson, R. J., 2014. Extent and drivers of mycotoxin contamination: Inferences from a survey of kenyan maize mills, Phytopathology, 104, 1221-1231.

Nagaraj, D.; Adkar-Purushothama, C. R.; Yanjarappa, S. M., 2016. Multiplex pcr for the early detection of fumonisin producing fusarium verticillioides, Food Bioscience, 13, 84-88.

Nardiello, D.; Lo Magro, S.; Iammarino, M.; Palermo, C.; Muscarella, M.; Centonze, D., 2014. Recent advances in the post-column derivatization for the determination of mycotoxins in food products and feed materials by liquid chromatography and fluorescence detection, Current Analytical Chemistry, 10, 355-365.

Nayaka, S. C.; Shankar, A. C. U.; Niranjana, S. R.; Wulff, E. G.; Mortensen, C. N.; Prakash, H. S., 2010. Detection and quantification of fumonisins from fusarium verticillioides in maize grown in southern india, World Journal of Microbiology \& Biotechnology, 26, 71-78.

Nazari, F.; Sulyok, M.; Yazdanpanah, H.; Kobarfard, F.; Krska, R., 2014. A survey of mycotoxins in domestic rice in iran by liquid chromatography tandem mass spectrometry, Toxicol Mech Methods, 24, 37-41.

Ncube, E.; Flett, B. C.; Waalwijk, C.; Viljoen, A., 2011. Fusarium spp. And levels of fumonisins in maize produced by subsistence farmers in south africa, South African Journal of Science, 107, 3339.

Ndube, N.; van der Westhuizen, L.; Green, I. R.; Shephard, G. S., 2011. Hplc determination of fumonisin mycotoxins in maize: A comparative study of naphthalene-2,3-dicarboxaldehyde and ophthaldialdehyde derivatization reagents for fluorescence and diode array detection, J Chromatogr B Analyt Technol Biomed Life Sci, 879, 2239-2243.

Ngoko, Z.; Marasas, W. F. O.; Rheeder, J. P.; Shephard, G. S.; Wingfield, M. J.; Cardwell, K. F., 2001. Fungal infection and mycotoxin contamination of maize in the humid forest and the western highlands of cameroon, Phytoparasitica, 29, 352-360.

Nielsen, K. F.; Mogensen, J. M.; Johansen, M.; Larsen, T. O.; Frisvad, J. C., 2009. Review of secondary metabolites and mycotoxins from the aspergillus niger group, Anal Bioanal Chem, 395, $1225-1242$.

Nielsen, K. F.; Ngemela, A. F.; Jensen, L. B.; de Medeiros, L. S.; Rasmussen, P. H., 2015. Uhplc$\mathrm{ms} / \mathrm{ms}$ determination of ochratoxin a and fumonisins in coffee using quechers extraction combined with mixed-mode spe purification, J Agric Food Chem, 63, 1029-1034.

Nikiema, P. N.; Worrillow, L.; Traore, A. S.; Wild, C. P.; Turner, P. C., 2004. Fumonisin contamination of maize in burkina faso, west africa, Food Addit Contam, 21, 865-870.

Njobeh, P. B.; Dutton, M. F.; Koch, S. H.; Chuturgoon, A. A.; Stoev, S. D.; Mosonik, J. S., 2010. Simultaneous occurrence of mycotoxins in human food commodities from cameroon, Mycotoxin Res, 26, 47-57.

Nkwe, D. O.; Taylor, J. E.; Siame, B. A., 2005. Fungi, aflatoxins, fumonisin b-1 and zearalenone contaminating sorghum-based traditional malt, wort and beer in botswana, Mycopathologia, 160, 177-186.

Noonim, P.; Mahakarnchanakul, W.; Nielsen, K. F.; Frisvad, J. C.; Samson, R. A., 2009. Fumonisin b2 production by aspergillus niger in thai coffee beans, Food Addit Contam Part A Chem Anal Control Expo Risk Assess, 26, 94-100. 
Numanoglu, E.; Uygun, U.; Koksel, H.; Solfrizzo, M., 2010. Stability of fusarium toxins during traditional turkish maize bread production, Quality Assurance and Safety of Crops \& Foods, 2, 8492.

Nuryono, ; Noviandi, C. T.; Bohm, J.; Agus, A.; Wedhastri, S.; Maryudani, Y. B.; Razzazi-Fazeli, E., 2004. Occurrence of fumonisins (b1, b 2, b 3) in maize-based food and feed samples from indonesia, Mycotoxin Res, 20, 2-9.

Nuryono, ; Noviandi, C. T.; Agus, A.; Wedhastri, S.; Maryudani, Y. B.; Bohm, J.; Razzazi, E., 2002. A survey of fumonisins (b1, b2, b3) in indonesian corn-based food and feed samples, Mycotoxin Res, 18 Suppl 2, 117-120.

Oh, K. S.; Scott, P. M.; Chung, S. H., 2009. Incomplete recoveries of fumonisins present in naturally contaminated corn foods from an immunoaffinity column, J AOAC Int, 92, 496-501.

Oles, C. J.; Trucksess, M. W., 2010. Determination of fumonisin b-1 in botanical roots by liquid chromatography with fluorescence detection: Single-laboratory validation, Journal of Aoac International, 93, 1155-1160.

Oliveira, M. S.; Diel, A. C. L.; Rauber, R. H.; Fontoura, F. P.; Mallmann, A.; Dilkin, P.; Mallmann, C. A., 2015. Free and hidden fumonisins in brazilian raw maize samples, Food Control, 53, 217-221.

Omurtag, G. Z., 2001. Determination of fumonisin b-1 and b-2 in corn and corn-based products in turkey by high-performance liquid chromatography, Journal of Food Protection, 64, 1072-1075.

Omurtag, G. Z.; Yazicioglu, D., 2004. Determination of fumonisins b-1 and b-2 in herbal tea and medicinal plants in turkey by high-performance liquid chromatography, Journal of Food Protection, $67,1782-1786$.

Ono, E. Y. S.; Biazon, L.; da Silva, M.; Vizoni, E.; Sugiura, Y.; Ueno, Y.; Hirooka, E. Y., 2006. Fumonisins in corn: Correlation with fusarium sp count, damaged kernels, protein and lipid content, Brazilian Archives of Biology and Technology, 49, 63-71.

Ono, E. Y. S.; da Silva, M.; Hashimoto, E. H.; Vizoni, E.; Kawamura, O.; Sugiura, Y.; Hirooka, E. Y., 2008. Mycotoxicological quality evaluation of corn samples used by processing industries in the northern region of parana state, brazil, Food Additives and Contaminants Part a-Chemistry Analysis Control Exposure \& Risk Assessment, 25, 1392-1399.

Ono, E. Y. S.; Kawamura, O.; Ono, M. A.; Ueno, Y.; Hirooka, E. Y., 2000. A comparative study of indirect competitive elisa and hplc for fumonisin detection in corn of the state of parana, brazil, Food and Agricultural Immunology, 12, 5-14.

Ono, E. Y. S.; Moreno, E. C.; Ono, M. A.; Rossi, C. N.; Saito, G. H.; Vizoni, E.; Sugiura, Y.; Hirooka, E. Y., 2011. Effect of cropping systems and crop successions on fumonisin levels in corn from northern parana state, brazil, European Journal of Plant Pathology, 131, 653-660.

Ono, E. Y. S.; Ono, M. A.; Funo, F. Y.; Medina, A. E.; Oliveira, Tcrm; Kawamura, O.; Ueno, Y.; Hirooka, E. Y., 2001. Evaluation of fumonisin-aflatoxin co-occurrence in brazilian corn hybrids by elisa, Food Additives and Contaminants Part a-Chemistry Analysis Control Exposure \& Risk Assessment, 18, 719-729.

Ono, E. Y. S.; Silva, M.; Ono, M. A.; Vizoni, E.; Garcia, G. T.; Kawamura, O.; Sabino, M.; Sugiura, Y.; Hirooka, E. Y., 2008. Implication of pre-drying steps with natural fumonisin contamination levels in freshly harvested corn, World Mycotoxin Journal, 1, 341-347.

Ono, E. Y. S.; Sasaki, E. Y.; Hashimoto, E. H.; Hara, L. N.; Correa, B.; Itano, E. N.; Sugiura, T.; Ueno, Y.; Hirooka, E. Y., 2002. Post-harvest storage of corn: Effect of beginning moisture content on mycoflora and fumonisin contamination, Food Additives and Contaminants Part a-Chemistry Analysis Control Exposure \& Risk Assessment, 19, 1081-1090. 
Orsi, R. B.; Correa, B.; Possi, C. R.; Schammass, E. A.; Nogueira, J. R.; Dias, S. M. C.; Malozzi, M. A. B., 2000. Mycoflora and occurrence of fumonisins in freshly harvested and stored hybrid maize, Journal of Stored Products Research, 36, 75-87.

Ortiz, J.; Van Camp, J.; Mestdagh, F.; Donoso, S.; De Meulenaer, B., 2013. Mycotoxin co-occurrence in rice, oat flakes and wheat noodles used as staple foods in ecuador, Food Addit Contam Part A Chem Anal Control Expo Risk Assess, 30, 2165-2176.

Oswald, S.; Karsunke, X.; Dietrich, R.; Martlbauer, E.; Niessner, R.; Knopp, D., 2013. Automated regenerable microarray-based immunoassay for rapid parallel quantification of mycotoxins in cereals, Analytical and Bioanalytical Chemistry, 405, 6405-6415.

Oueslati, S.; Romero-Gonzalez, R.; Lasram, S.; Frenich, A. G.; Vidal, J. L. M., 2012. Multi-mycotoxin determination in cereals and derived products marketed in tunisia using ultra-high performance liquid chromatography coupled to triple quadrupole mass spectrometry, Food and Chemical Toxicology, 50, 2376-2381.

Ouf, S. A.; Mohamed, A. A. H.; El-Sayed, W. S., 2016. Fungal decontamination of fleshy fruit water washes by double atmospheric pressure cold plasma, Clean-Soil Air Water, 44.

Pacin, A. M.; Boca, R. T.; Gonzalez, H. H.; Resnik, S. L.; Burak, R.; Broccoli, A. M.; de Souza, J. C., 2002. Natural occurrence of mycotoxins and mycoflora of argentinien popcorn, Mycotoxin Res, 18, 90-96.

Paepens, C.; De Saeger, S.; Van Poucke, C.; Dumoulin, F.; Van Calenbergh, S.; Van Peteghem, C., 2005. Development of a liquid chromatography/tandem mass spectrometry method for the quantification of fumonisin b1, b2 and b3 in cornflakes, Rapid Commun Mass Spectrom, 19, 20212029.

Paepens, C.; De Saeger, S.; Sibanda, L.; Barna-Vetro, I.; Anselme, M.; Larondelle, Y.; Van Peteghem, C., 2005. Evaluation of fumonisin contamination in cornflakes on the belgian market by "flowthrough" assay screening and Ic-ms/ms analyses, J Agric Food Chem, 53, 7337-7343.

Paepens, C.; De Saeger, S.; Sibanda, L.; Barna-Vetro, I.; Leglise, I.; Van Hove, F.; Van Peteghem, C., 2004. A flow-through enzyme immunoassay for the screening of fumonisins in maize, Analytica Chimica Acta, 523, 229-235.

Palacios, S. A.; Ramirez, M. L.; Zalazar, M. C.; Farnochi, M. C.; Zappacosta, D.; Chiacchiera, S. M.; Reynoso, M. M.; Chulze, S. N.; Torres, A. M., 2011. Occurrence of fusarium spp. And fumonisin in durum wheat grains, Journal of Agricultural and Food Chemistry, 59, 12264-12269.

Palacios, S. A.; Susca, A.; Haidukowski, M.; Stea, G.; Cendoya, E.; Ramirez, M. L.; Chulze, S. N.; Farnochi, M. C.; Moretti, A.; Torres, A. M., 2015. Genetic variability and fumonisin production by fusarium proliferatum isolated from durum wheat grains in argentina, Int J Food Microbiol, 201, 35-41.

Palencia, E. R.; Hinton, D. M.; Bacon, C. W., 2010. The black aspergillus species of maize and peanuts and their potential for mycotoxin production, Toxins (Basel), 2, 399-416.

Palencia, E. R.; Mitchell, T. R.; Snook, M. E.; Glenn, A. E.; Gold, S.; Hinton, D. M.; Riley, R. T.; Bacon, C. W., 2014. Analyses of black aspergillus species of peanut and maize for ochratoxins and fumonisins, J Food Prot, 77, 805-813.

Palencia, E.; Torres, O.; Hagler, W.; Meredith, F. I.; Williams, L. D.; Riley, R. T., 2003. Total fumonisins are reduced in tortillas using the traditional nixtamalization method of mayan communities, J Nutr, 133, 3200-3203.

Palumbo, J. D.; O'Keeffe, T. L., 2013. Distribution and mycotoxigenic potential of aspergillus section nigri species in naturally contaminated almonds, J Food Prot, 76, 702-706. 
Palumbo, J. D.; O'Keeffe, T. L.; McGarvey, J. A., 2011. Incidence of fumonisin b-2 production within aspergillus section nigri populations isolated from california raisins, Journal of Food Protection, 74, 672-675.

Papst, C.; Utz, H. F.; Melchinger, A. E.; Eder, J.; Magg, T.; Klein, D.; Bohn, M., 2005. Mycotoxins produced by fusarium spp. In isogenic bt vs. Non-bt maize hybrids under european corn borer pressure, Agronomy Journal, 97, 219-224.

Parikka, P.; Hakala, K.; Tiilikkala, K., 2012. Expected shifts in fusarium species' composition on cereal grain in northern europe due to climatic change, Food Addit Contam Part A Chem Anal Control Expo Risk Assess, 29, 1543-1555.

Park, J. W.; Kim, E. K.; Shon, D. H.; Kim, Y. B., 2002. Natural co-occurrence of aflatoxin b-1, fumonisin b-1 and ochratoxin a in barley and corn foods from korea, Food Additives and Contaminants, 19, 1073-1080.

Park, J. W.; Scott, P. M.; Lau, B. P. Y.; Lewis, D. A., 2004. Analysis of heat-processed corn foods for fumonisins and bound fumonisins, Food Additives and Contaminants Part a-Chemistry Analysis Control Exposure \& Risk Assessment, 21, 1168-1178.

Park, J. W.; Scott, P. M.; Lau, B. P. Y., 2013. Analysis of n-fatty acyl fumonisins in alkali-processed corn foods, Food Science and Biotechnology, 22, 147-152.

Pascual, C. B.; Barcos, A. K. S.; Mandap, J. A. L.; Ocampo, E. T. M., 2016. Fumonisin-producing fusarium species causing ear rot of corn in the philippines, Philippine Journal of Crop Science, 41 , 12-21.

Paterson, R. R. M.; Lima, N.; Taniwaki, M. H., 2014. Coffee, mycotoxins and climate change, Food Research International, 61, 1-15.

Peluque, E.; Neres, N. B.; Michelin, E. C.; Reis, T. A.; Rosim, R. E.; Oliveira, C. A. F.; Sousa, R. L. M.; Correa, B.; Fernandes, A. M., 2014. Fumonisin b-1 in cereal mixtures marketed in brazil, Food Additives \& Contaminants Part B-Surveillance, 7, 46-48.

Peraica, M.; Domijan, A. M.; Miletic-Medved, M.; Fuchs, R., 2008. The involvement of mycotoxins in the development of endemic nephropathy, Wien Klin Wochenschr, 120, 402-407.

Peraica, M.; Flajs, D.; Domijan, A. M.; Ivic, D.; Cvjetkovic, B., 2010. Ochratoxin a contamination of food from croatia, Toxins (Basel), 2, 2098-2105.

Pereyra, M. L.; Rosa, C. A. R.; Dalcero, A. M.; Cavaglieri, L. R., 2011. Mycobiota and mycotoxins in malted barley and brewer's spent grain from argentinean breweries, Letters in Applied Microbiology, 53, 649-655.

Perrone, G.; De Girolamo, A.; Sarigiannis, Y.; Haidukowski, M. E.; Visconti, A., 2013. Occurrence of ochratoxin a, fumonisin b-2 and black aspergilli in raisins from western greece regions in relation to environmental and geographical factors, Food Additives and Contaminants Part a-Chemistry Analysis Control Exposure \& Risk Assessment, 30, 1339-1347.

Peters, J.; Cardall, A.; Haasnoot, W.; Nielen, M. W. F., 2014. 6-plex microsphere immunoassay with imaging planar array detection for mycotoxins in barley, Analyst, 139, 3968-3976.

Petersen, A.; Thorup, I., 2001. Preliminary evaluation of fumonisins by the nordic countries and occurrence of fumonisins ( $\mathrm{fb} 1$ and $\mathrm{fb} 2$ ) in corn-based foods on the danish market, Food Addit Contam, 18, 221-226.

Petrarca, M. H.; Rossi, E. A.; de Sylos, C. M., 2016. In-house method validation, estimating measurement uncertainty and the occurrence of fumonisin b-1 in samples of brazilian commercial rice, Food Control, 59, 439-446.

Petrarca, M. H.; Rodrigues, M. I.; Rossi, E. A.; de Sylos, C. M., 2014. Optimisation of a sample preparation method for the determination of fumonisin b-1 in rice, Food Chemistry, 158, 270-277. 
Phoku, J. Z.; Dutton, M. F.; Njobeh, P. B.; Mwanza, M.; Egbuta, M. A.; Chilaka, C. A., 2012. Fusarium infection of maize and maize-based products and exposure of a rural population to fumonisin $b-1$ in limpopo province, south africa, Food Additives and Contaminants Part a-Chemistry Analysis Control Exposure \& Risk Assessment, 29, 1743-1751.

Phuong, N. H.; Thieu, N. Q.; Ogle, B.; Pettersson, H., 2015. Aflatoxins, fumonisins and zearalenone contamination of maize in the southeastern and central highlands provinces of vietnam, Agriculture-Basel, 5, 1195-1203.

Piacentini, K. C.; Savi, G. D.; Pereira, M. E. V.; Scussel, V. M., 2015. Fungi and the natural occurrence of deoxynivalenol and fumonisins in malting barley (hordeum vulgare I.), Food Chemistry, 187, 204-209.

Piacentini, K. C.; Savi, G. D.; Olivo, G.; Scussel, V. M., 2015. Quality and occurrence of deoxynivalenol and fumonisins in craft beer, Food Control, 50, 925-929.

Pietri, A.; Battilani, P.; Gualla, A.; Bertuzzi, T., 2012. Mycotoxin levels in maize produced in northern italy in 2008 as influenced by growing location and fao class of hybrid, World Mycotoxin Journal, 5, 409-418.

Pietri, A.; Bertuzzi, T.; Pallaroni, L.; Piva, G., 2004. Occurrence of mycotoxins and ergosterol in maize harvested over 5 years in northern italy, Food Addit Contam, 21, 479-487.

Pietri, A.; Bertuzzi, T., 2012. Simple phosphate buffer extraction for the determination of fumonisins in masa, maize, and derived products, Food Analytical Methods, 5, 1088-1096.

Pietri, A.; Bertuzzi, T.; Agosti, B.; Donadini, G., 2010. Transfer of aflatoxin b1 and fumonisin b1 from naturally contaminated raw materials to beer during an industrial brewing process, Food Addit Contam Part A Chem Anal Control Expo Risk Assess, 27, 1431-1439.

Pietri, A.; Zanetti, M.; Bertuzzi, T., 2009. Distribution of aflatoxins and fumonisins in dry-milled maize fractions, Food Addit Contam Part A Chem Anal Control Expo Risk Assess, 26, 372-380.

Pitt, J. I.; Taniwaki, M. H.; Cole, M. B., 2013. Mycotoxin production in major crops as influenced by growing, harvesting, storage and processing, with emphasis on the achievement of food safety objectives, Food Control, 32, 205-215.

Pleadin, J.; Persi, N.; Mitak, M.; Zadravec, M.; Sokolovic, M.; Vulic, A.; Jaki, V.; Brstilo, M., 2012. The natural occurrence of $\mathrm{t}-2$ toxin and fumonisins in maize samples in croatia, Bull Environ Contam Toxicol, 88, 863-866.

Pleadin, J.; Vahcic, N.; Persi, N.; Sevelj, D.; Markov, K.; Frece, J., 2013. Fusarium mycotoxins' occurrence in cereals harvested from croatian fields, Food Control, 32, 49-54.

Preis, R. A.; Vargas, E. A., 2000. A method for determining fumonisin b-1 in corn using immunoaffinity column clean-up and thin layer chromatography/densitometry, Food Additives and Contaminants, $17,463-468$.

Probst, C.; Bandyopadhyay, R.; Cotty, P. J., 2014. Diversity of aflatoxin-producing fungi and their impact on food safety in sub-saharan africa, Int J Food Microbiol, 174, 113-122.

Qi, T. Y. F.; Renaud, J. B.; McDowell, T.; Seifert, K. A.; Yeung, K. K. C.; Sumarah, M. W., 2016. Diversity of mycotoxin-producing black aspergilli in canadian vineyards, Journal of Agricultural and Food Chemistry, 64, 1583-1589.

Quan, Y.; Zhang, Y.; Wang, S.; Lee, N.; Kennedy, I. R., 2006. A rapid and sensitive chemiluminescence enzyme-linked immunosorbent assay for the determination of fumonisin b-1 in food samples, Analytica Chimica Acta, 580, 1-8.

Queiroz, V. A. V.; Alves, G. L. D.; da Conceicao, R. R. P.; Guimaraes, L. J. M.; Mendes, S. M.; Ribeiro, P. E. D.; da Costa, R. V., 2012. Occurrence of fumonisins and zearalenone in maize stored in family farm in minas gerais, brazil, Food Control, 28, 83-86. 
Rai, M.; Jogee, P. S.; Ingle, A. P., 2015. Emerging nanotechnology for detection of mycotoxins in food and feed, Int J Food Sci Nutr, 66, 363-370.

Raiola, A.; Tenore, G. C.; Manyes, L.; Meca, G.; Ritieni, A., 2015. Risk analysis of main mycotoxins occurring in food for children: An overview, Food Chem Toxicol, 84, 169-180.

Ramana, M. V.; Balakrishna, K.; Murali, H. C. S.; Batra, H. V., 2011. Multiplex pcr-based strategy to detect contamination with mycotoxigenic fusarium species in rice and fingermillet collected from southern india, Journal of the Science of Food and Agriculture, 91, 1666-1673.

Rao, K. N.; Reddy, B. V.; Girisham, S.; Reddy, S. M., 2008. Natural incidence of fusarial mycotoxins, Proceedings of the National Academy of Sciences India Section B-Biological Sciences, 78, 164-168.

Reddy, K. R. N.; Reddy, C. S.; Abbas, H. K.; Abel, C. A.; Muralidharan, K., 2008. Mycotoxigenic fungi, mycotoxins, and management of rice grains, Toxin Reviews, 27, 287-317.

Reddy, K. R. N.; Salleh, B.; Saad, B.; Abbas, H. K.; Abel, C. A.; Shier, W. T., 2010. An overview of mycotoxin contamination in foods and its implications for human health, Toxin Reviews, 29, 3-26.

Reinhold, L.; Reinhardt, K., 2011. Mycotoxins in foods in lower saxony (germany): Results of official control analyses performed in 2009, Mycotoxin Res, 27, 137-143.

Reinholds, I.; Pugajeva, I.; Bartkevics, V., 2016. A reliable screening of mycotoxins and pesticide residues in paprika using ultra-high performance liquid chromatography coupled to high resolution orbitrap mass spectrometry, Food Control, 60, 683-689.

Ren, Y.; Zhang, Y.; Lai, S.; Han, Z.; Wu, Y., 2011. Simultaneous determination of fumonisins b1, b2 and b3 contaminants in maize by ultra high-performance liquid chromatography tandem mass spectrometry, Anal Chim Acta, 692, 138-145.

Reyes-Velazquez, W. P.; Figueroa-Gomez, R. M.; Barberis, M.; Reynoso, M. M.; Rojo, F. G.; Chulze, S. N.; Torres, A. M., 2011. Fusarium species (section liseola) occurrence and natural incidence of beauvericin, fusaproliferin and fumonisins in maize hybrids harvested in mexico, Mycotoxin Res, $27,187-194$.

Rheeder, J. P.; Van der Westhuizen, L.; Imrie, G.; Shephard, G. S., 2016. Fusarium species and fumonisins in subsistence maize in the former transkei region, south africa: A multi-year study in rural villages, Food Addit Contam Part B Surveill, 9, 176-184.

Rocha, L. D.; Reis, G. M.; da Silva, V. N.; Braghini, R.; Teixeira, M. M. G.; Correa, B., 2011. Molecular characterization and fumonisin production by fusarium verticillioides isolated from corn grains of different geographic origins in brazil, International Journal of Food Microbiology, 145, 9-21.

Rocha, L. O.; Barroso, V. M.; Andrade, L. J.; Pereira, G. H. A.; Ferreira-Castro, F. L.; Duarte, A. P.; Michelotto, M. D.; Correa, B., 2016. Fum gene expression profile and fumonisin production by fusarium verticillioides inoculated in bt and non-bt maize, Frontiers in Microbiology, 6.

Rocha, L. O.; Nakai, V. K.; Braghini, R.; Reis, T. A.; Kobashigawa, E.; Correa, B., 2009. Mycoflora and co-occurrence of fumonisins and aflatoxins in freshly harvested corn in different regions of brazil, Int J Mol Sci, 10, 5090-5103.

Rofiat, A. S.; Fanelli, F.; Atanda, O.; Sulyok, M.; Cozzi, G.; Bavaro, S.; Krska, R.; Logrieco, A. F.; Ezekiel, C. N., 2015. Fungal and bacterial metabolites associated with natural contamination of locally processed rice (oryza sativa I.) in nigeria, Food Addit Contam Part A Chem Anal Control Expo Risk Assess, 32, 950-959.

Roger, D. D., 2011. Deoxynivanol (don) and fumonisins b-1 (fb1) in artisanal sorghum opaque beer brewed in north cameroon, African Journal of Microbiology Research, 5, 1565-1567.

Romero-Gonzalez, R.; Vidal, J. L. M.; Aguilera-Luiz, M. M.; Frenich, A. G., 2009. Application of conventional solid-phase extraction for multimycotoxin analysis in beers by ultrahigh-performance 
liquid chromatography-tandem mass spectrometry, Journal of Agricultural and Food Chemistry, 57, 9385-9392.

Roohi, S.; Azizi, I. G.; Hashemi, M., 2012. Fumonisin contamination based on flour quality used in bakeries and confectioneries in qaemshahr (city of the northern iran), African Journal of Microbiology Research, 6, 1815-1818.

Roscoe, V.; Lombaert, G. A.; Huzel, V.; Neumann, G.; Melietio, J.; Kitchen, D.; Kotello, S.; Krakalovich, T.; Trelka, R.; Scott, P. M., 2008. Mycotoxins in breakfast cereals from the canadian retail market: A 3-year survey, Food Addit Contam Part A Chem Anal Control Expo Risk Assess, 25, 347-355.

Royer, D.; Humpf, H. U.; Guy, P. A., 2004. Quantitative analysis of fusarium mycotoxins in maize using accelerated solvent extraction before liquid chromatography atmospheric pressure chemical ionization tandem mass spectrometry, Food Additives and Contaminants, 21, 678-692.

Rubert, J.; Manes, J.; James, K. J.; Soler, C., 2011. Application of hybrid linear ion trap-high resolution mass spectrometry to the analysis of mycotoxins in beer, Food Addit Contam Part A Chem Anal Control Expo Risk Assess, 28, 1438-1446.

Rubert, J.; Soler, C.; Manes, J., 2012. Application of an hplc-ms/ms method for mycotoxin analysis in commercial baby foods, Food Chemistry, 133, 176-183.

Rubert, J.; Soler, C.; Marin, R.; James, K. J.; Manes, J., 2013. Mass spectrometry strategies for mycotoxins analysis in european beers, Food Control, 30, 122-128.

Rubert, J.; Soler, C.; Manes, J., 2012. Occurrence of fourteen mycotoxins in tiger-nuts, Food Control, $25,374-379$.

Rubert, J.; Soriano, J. M.; Manes, J.; Soler, C., 2013. Occurrence of fumonisins in organic and conventional cereal-based products commercialized in france, germany and spain, Food Chem Toxicol, 56, 387-391.

Salem, N. M.; Ahmad, R., 2010. Mycotoxins in food from jordan: Preliminary survey, Food Control, 21, 1099-1103.

Sampietro, D. A.; Marin, P.; Iglesias, J.; Presello, D. A.; Vattuone, M. A.; Catalan, C. A. N.; Jaen, M. T. G., 2010. A molecular based strategy for rapid diagnosis of toxigenic fusarium species associated to cereal grains from argentina, Fungal Biology, 114, 74-81.

Sanchez-Rangel, D.; SanJuan-Badillo, A.; Plasencia, J., 2005. Fumonisin production by fusarium verficillioides strains isolated from maize in mexico and development of a polymerase chain reaction to detect potential toxigenic strains in grains, Journal of Agricultural and Food Chemistry, $53,8565-8571$.

Sangare-Tigori, B.; Moukha, S.; Kouadio, H. J.; Betbeder, A. M.; Dano, D. S.; Creppy, E. E., 2006. Cooccurrence of aflatoxin $b-1$, fumonisin $b-1$, ochratoxin a and zearalenone in cereals and peanuts from cote d'ivoire, Food Additives and Contaminants, 23, 1000-1007.

Santini, A.; Ferracane, R.; Meca, G.; Ritieni, A., 2009. Overview of analytical methods for beauvericin and fusaproliferin in food matrices, Anal Bioanal Chem, 395, 1253-1260.

Sapsford, K. E.; Ngundi, M. M.; Moore, M. H.; Lassman, M. E.; Shriver-Lake, L. C.; Taitt, C. R.; Ligler, F. S., 2006. Rapid detection of foodborne contaminants using an array biosensor, Sensors and Actuators B-Chemical, 113, 599-607.

Savi, G. D.; Piacentini, K. C.; Marchi, D.; Scussel, V. M., 2016. Fumonisins b-1 and b-2 in the cornmilling process and corn-based products, and evaluation of estimated daily intake, Food Additives and Contaminants Part a-Chemistry Analysis Control Exposure \& Risk Assessment, 33, 339-345. 
Scaff, R. M. C.; Scussell, V. M., 2004. Fumonisins $b(1)$ and $b(2)$ in corn-based products commercialized in the state of santa catarina - southern brazil, Brazilian Archives of Biology and Technology, 47, 911-919.

Schjoth, J. E.; Visconti, A.; Sundheim, L., 2009. Fumonisins in maize in relation to climate, planting time and hybrids in two agroecological zones in zambia, Mycopathologia, 167, 209-219.

Schothorst, R. C.; van Egmond, H. P., 2004. Report from scoop task 3.2.10 "collection of occurrence data of fusarium toxins in food and assessment of dietary intake by the population of eu member states" - subtask: Trichothecenes, Toxicology Letters, 153, 133-143.

Schaafsma, A. W.; Tamburic-Illincic, L.; Reid, L. M., 2006. Fumonisin b-1 accumulation and severity of fusarium ear rot and gibberella ear rot in food-grade corn hybrids in ontario after inoculation according to two methods, Canadian Journal of Plant Pathology-Revue Canadienne De Phytopathologie, 28, 548-557.

Scott, P. M., 2012. Recent research on fumonisins: A review, Food Addit Contam Part A Chem Anal Control Expo Risk Assess, 29, 242-248.

Scruggs, A. C.; Quesada-Ocampo, L. M., 2016. Etiology and epidemiological conditions promoting fusarium root rot in sweetpotato, Phytopathology, 106, 909-919.

Scudamore, K. A., 2008. Fate of fusarium mycotoxins in the cereal industry: Recent uk studies, World Mycotoxin Journal, 1, 315-323.

Scudamore, K. A.; Patel, S., 2008. The fate of deoxynivalenol and fumonisins in wheat and maize during commercial breakfast cereal production, World Mycotoxin Journal, 1, 437-448.

Scudamore, K. A.; Patel, S., 2009. Fusarium mycotoxins in milling streams from the commercial milling of maize imported to the uk, and relevance to current legislation, Food Addit Contam Part A Chem Anal Control Expo Risk Assess, 26, 744-753.

Scudamore, K. A.; Patel, S., 2009. Occurrence of fusarium mycotoxins in maize imported into the uk, 2004-2007, Food Addit Contam Part A Chem Anal Control Expo Risk Assess, 26, 363-371.

Scudamore, K. A.; Patel, S., 2000. Survey for aflatoxins, ochratoxin a, zearalenone and fumonisins in maize imported into the united kingdom, Food Addit Contam, 17, 407-416.

Scudamore, K. A.; Scriven, F.; Patel, S., 2009. Fusarium mycotoxins in the food chain: Maize-based snack foods, World Mycotoxin Journal, 2, 441-450.

Scussel, V. M.; Savi, G. D.; Costas, L. L. F.; Xavier, J. J. M.; Manfio, D.; Bittencourt, K. O.; Aguiar, K.; Stein, S. M., 2014. Fumonisins in corn (zea mays I.) from southern brazil, Food Additives \& Contaminants Part B-Surveillance, 7, 151-155.

Seefelder, W.; Gossmann, M.; Humpf, H. U., 2002. Analysis of fumonisin b-1 in fusarium proliferatuminfected asparagus spears and garlic bulbs from germany by liquid chromatography - electrospray ionization mass spectrometry, Journal of Agricultural and Food Chemistry, 50, 2778-2781.

Seefelder, W.; Hartl, M.; Humpf, H. U., 2001. Determination of n-(carboxymethyl)fumonisin b-1 in corn products by liquid chromatography/electrospray ionization-mass spectrometry, Journal of Agricultural and Food Chemistry, 49, 2146-2151.

Seefelder, W.; Knecht, A.; Gobetamann, M.; Kleta, S.; Buttner, C.; Humpf, H. U., 2004. Occurrence of fumonisins in asparagus (asparagus officinalis I.) and garlic (allium sativum I.) from germany, Mycotoxin Res, 20, 29-30.

Segvic, M.; Pepeljnjak, S., 2003. Distribution and fumonisin b-1 production capacity of fusarium moniliforme isolated from corn in croatia, Periodicum Biologorum, 105, 275-279.

Selvaraj, J. N.; Wang, Y.; Zhou, L.; Zhao, Y. J.; Xing, F. G.; Dai, X. F.; Liu, Y., 2015. Recent mycotoxin survey data and advanced mycotoxin detection techniques reported from china: A review, Food 
Additives and Contaminants Part a-Chemistry Analysis Control Exposure \& Risk Assessment, 32, 440-452.

Selvaraj, J. N.; Zhou, L.; Wang, Y.; Zhao, Y. J.; Xing, F. G.; Dai, X. F.; Liu, Y., 2015. Mycotoxin detection - recent trends at global level, Journal of Integrative Agriculture, 14, 2265-2281.

Senyuva, H.; Gilbert, J.; Ozcan, S.; Gurel, N., 2008. Rapid Ic and Ic/ms for routine analysis of mycotoxins in foods, World Mycotoxin Journal, 1, 229-235.

Senyuva, H. Z.; Gilbert, J.; Stroka, J., 2010. Determination of fumonisins b-1 and b-2 in corn by Ic/ms with immunoaffinity column cleanup: Interlaboratory study, Journal of Aoac International, 93, 611621.

Senyuva, H. Z.; Gilbert, J., 2008. Identification of fumonisin b-2, ht-2 toxin, patulin, and zearalenone in dried figs by liquid chromatography-time-of-flight mass spectrometry and liquid chromatography-mass spectrometry, Journal of Food Protection, 71, 1500-1504.

Senyuva, H. Z.; Ozcan, S.; Cimen, D.; Gilbert, J., 2008. Determination of fumonisins b-1 and b2 in corn by liquid chromatography/mass spectrometry with immunoaffinity column cleanup: Singlelaboratory method validation, Journal of Aoac International, 91, 598-606.

Seo, E.; Yoon, Y.; Kim, K.; Shim, W. B.; Kuzmina, N.; Oh, K. S.; Lee, J. O.; Kim, D. S.; Suh, J.; Lee, S. H.; Chung, K. H.; Chung, D. H., 2009. Fumonisins b-1 and b-2 in agricultural products consumed in south korea: An exposure assessment, Journal of Food Protection, 72, 436-440.

Sewram, V.; Shepard, G. S.; Marasas, W. F. O.; de Castro, Mfpm, 2003. Improving extraction of fumonisin mycotoxins from brazilian corn-based infant foods, Journal of Food Protection, 66, 854859.

Sewram, V.; Shephard, G. S.; van der Merwe, L.; Jacobs, T. V., 2006. Mycotoxin contamination of dietary and medicinal wild plants in the eastern cape province of south africa, J Agric Food Chem, 54, 5688-5693.

Sforza, S.; Dall'asta, C.; Marchelli, R., 2006. Recent advances in mycotoxin determination in food and feed by hyphenated chromatographic techniques/mass spectrometry, Mass Spectrom Rev, 25, 5476.

Shala-Mayrhofer, V.; Varga, E.; Marjakaj, R.; Berthiller, F.; Musolli, A.; Berisha, D.; Kelmendi, B.; Lemmens, M., 2013. Investigations on fusarium spp. And their mycotoxins causing fusarium ear rot of maize in kosovo, Food Addit Contam Part B Surveill, 6, 237-243.

Shale, K.; Mukamugema, J.; Lues, R. J.; Venter, P., 2012. Toxicity profile of commercially produced indigenous banana beer, Food Addit Contam Part A Chem Anal Control Expo Risk Assess, 29, 13001306.

Sharma, M., 2007. Detection of hydrolyzed fumonisins $b-1$ and $b-2$ by use of high performance liquid chromatography in sorghum, Asian Journal of Chemistry, 19, 499-504.

Sharma, M.; Montes, R.; Marques, C.; Bravo, L. L.; Flores, M. H. E., 2007. Incidence and quantification of fumonisins b-1 and b-2 at harvest stage in sorghum, Asian Journal of Chemistry, $19,396-400$.

Sheng, Y. J.; Jiang, W. X.; De Saeger, S.; Shen, J. Z.; Zhang, S. X.; Wang, Z. H., 2012. Development of a sensitive enzyme-linked immunosorbent assay for the detection of fumonisin b-1 in maize, Toxicon, 60, 1245-1250.

Shephard, G. S.; Burger, H. M.; Gambacorta, L.; Krska, R.; Powers, S. P.; Rheeder, J. P.; Solfrizzo, M.; Sulyok, M.; Visconti, A.; Warth, B.; van der Westhuizen, L., 2013. Mycological analysis and multimycotoxins in maize from rural subsistence farmers in the former transkei, south africa, J Agric Food Chem, 61, 8232-8240. 
Shephard, G. S.; Leggott, N. L.; Stockenstrom, S.; Somdyala, N. I. M.; Marasas, W. F. O., 2002. Preparation of south african maize porridge: Effect on fumonisin mycotoxin levels, South African Journal of Science, 98, 393-396.

Shephard, G. S.; Marasas, W. F. O.; Yazdanpanah, H.; Rahimian, H.; Safavi, N.; Zarghi, A.; Shafaati, A.; Rasekh, H. R., 2002. Fumonisin b-1 in maize harvested in iran during 1999, Food Additives and Contaminants, 19, 676-679.

Shephard, G. S.; Marasas, W. F. O.; Leggott, N. L.; Yazdanpanah, H.; Rahimian, H.; Safavi, N., 2000. Natural occurrence of fumonisins in corn from iran, Journal of Agricultural and Food Chemistry, 48, 1860-1864.

Shephard, G. S.; Rheeder, J. P.; van der Westhuizen, L., 2012. Effect of the traditional cooking practice on fumonisin content of maize porridge consumed in the former transkei region of south africa, World Mycotoxin Journal, 5, 405-407.

Shephard, G. S.; Van der Westhuizen, L.; Gatyeni, P. A.; Katerere, D. R.; Marasas, W. F. O., 2005. Do fumonisin mycotoxins occur in wheat?, Journal of Agricultural and Food Chemistry, 53, 9293-9296.

Shephard, G. S.; van der Westhuizen, L.; Gatyeni, P. M.; Somdyala, N. I. M.; Burger, H. M.; Marasas, W. F. O., 2005. Fumonisin mycotoxins in traditional xhosa maize beer in south africa, Journal of Agricultural and Food Chemistry, 53, 9634-9637.

Shephard, G. S.; van der Westhuizen, L.; Sewram, V.; van Zyl, J.; Rheeder, J. P., 2011. Occurrence of the c-series fumonisins in maize from the former transkei region of south africa, Food Addit Contam Part A Chem Anal Control Expo Risk Assess, 28, 1712-1716.

Shier, W. T.; Tiefel, P. A.; Abbas, H. K. 2000. Current research on mycotoxins: Fumonisins. in A. T.; Gaffield Tu, W. (ed.), Natural and selected synthetic toxins: Biological implications.

Shiu, C. M.; Wang, J. J.; Yu, F. Y., 2010. Sensitive enzyme-linked immunosorbent assay and rapid one-step immunochromatographic strip for fumonisin b1 in grain-based food and feed samples, J Sci Food Agric, 90, 1020-1026.

Shu, M.; Xu, Y.; Liu, X.; Li, Y. P.; He, Q. H.; Tu, Z.; Fu, J. H.; Gee, S. J.; Hammock, B. D., 2016. Antiidiotypic nanobody-alkaline phosphatase fusion proteins: Development of a one-step competitive enzyme immunoassay for fumonisin b-1 detection in cereal, Analytica Chimica Acta, 924, 53-59.

Silva, L.; Fernandez-Franzon, M.; Font, G.; Pena, A.; Silveira, I.; Lino, C.; Manes, J., 2009. Analysis of fumonisins in corn-based food by liquid chromatography with fluorescence and mass spectrometry detectors, Food Chemistry, 112, 1031-1037.

Silva, L. J.; Lino, C. M.; Pena, A.; Molto, J. C., 2007. Occurrence of fumonisins b1 and b2 in portuguese maize and maize-based foods intended for human consumption, Food Addit Contam, 24, 381-390.

Skrbic, B.; Zivancev, J.; Godula, M., 2014. Multimycotoxin analysis of crude extracts of nuts with ultrahigh performance liquid chromatography/tandem mass spectrometry, Journal of Food Composition and Analysis, 34, 171-177.

Skrbic, B.; Zivancev, J.; Durisic-Mladenovic, N.; Godula, M., 2012. Principal mycotoxins in wheat flour from the serbian market: Levels and assessment of the exposure by wheat-based products, Food Control, 25, 389-396.

Smith, M. C.; Madec, S.; Coton, E.; Hymery, N., 2016. Natural co-occurrence of mycotoxins in foods and feeds and their in vitro combined toxicological effects, Toxins (Basel), 8.

Soares, C.; Calado, T.; Venancio, A., 2013. Mycotoxin production by aspergillus niger aggregate strains isolated from harvested maize in three portuguese regions, Rev Iberoam Micol, 30, 9-13.

Soleimany, F.; Jinap, S.; Abas, F., 2012. Determination of mycotoxins in cereals by liquid chromatography tandem mass spectrometry, Food Chemistry, 130, 1055-1060. 
Soleimany, F.; Jinap, S.; Rahmani, A.; Khatib, A., 2011. Simultaneous detection of 12 mycotoxins in cereals using rp-hplc-pda-fld with phred and a post-column derivatization system, Food Addit Contam Part A Chem Anal Control Expo Risk Assess, 28, 494-501.

Soleimany, F.; Jinap, S.; Faridah, A.; Khatib, A., 2012. A uplc-ms/ms for simultaneous determination of aflatoxins, ochratoxin a, zearalenone, don, fumonisins, t-2 toxin and ht-2 toxin, in cereals, Food Control, 25, 647-653.

Solfrizzo, M.; De Girolamo, A.; Gambacorta, L.; Visconti, A.; Stroka, J.; van Egmond, H. P., 2011. Determination of fumonisins $b-1$ and $b-2$ in corn-based foods for infants and young children by lc with immunoaffinity column cleanup: Interlaboratory validation study, Journal of Aoac International, 94, 900-908.

Solfrizzo, M.; De Girolamo, A.; Visconti, A., 2001. Determination of fumonisins b-1 and b-2 in cornflakes by high performance liquid chromatography and immunoaffinity clean-up, Food Additives and Contaminants, 18, 227-235.

Solfrizzo, M.; De Girolamo, A.; Lattanzio, V. M. T.; Visconti, A.; Stroka, J.; Alldrick, A.; van Egmond, H. P., 2013. Results of a proficiency test for multi-mycotoxin determination in maize by using methods based on Ic-ms/(ms), Quality Assurance and Safety of Crops \& Foods, 5, 15-48.

Somma, S.; Perrone, G.; Logrieco, A. F., 2012. Diversity of black aspergilli and mycotoxin risks in grape, wine and dried vine fruits, Phytopathologia Mediterranea, 51, 131-147.

Somorin, Y. M.; Bertuzzi, T.; Battilani, P.; Pietri, A., 2012. Aflatoxin and fumonisin contamination of yam flour from markets in nigeria, Food Control, 25, 53-58.

Sorensen, L. K.; Elbaek, T. H., 2005. Determination of mycotoxins in bovine milk by liquid chromatography tandem mass spectrometry, J Chromatogr B Analyt Technol Biomed Life Sci, 820, 183-196.

Soriano, J. M.; Dragacci, S., 2004. Intake, decontamination and legislation of fumonisins in foods, Food Research International, 37, 367-374.

Soriano, J. M.; Dragacci, S., 2004. Occurrence of fumonisins in foods, Food Research International, 37, 985-1000.

Spanjer, M. C.; Rensen, P. M.; Scholten, J. M., 2008. Lc-ms/ms multi-method for mycotoxins after single extraction, with validation data for peanut, pistachio, wheat, maize, cornflakes, raisins and figs, Food Addit Contam Part A Chem Anal Control Expo Risk Assess, 25, 472-489.

Sreenivasa, M. Y.; Dass, R. S.; Raj, A. P. C.; Janardhana, G. R., 2008. Pcr method for the detection of genus fusarium and fumonisin-producing isolates from freshly harvested sorghum grains grown in karnataka, india, Journal of Food Safety, 28, 236-247.

Sreenivasa, M. Y.; Jaen, M. T. G.; Dass, R. S.; Raj, A. P. C.; Janardhana, G. R., 2008. A pcr-based assay for the detection and differentiation of potential fumonisin-producing fusarium verticillioides isolated from indian maize kernels, Food Biotechnology, 22, 160-170.

Srobarova, A.; Moretti, A.; Ferracane, R.; Ritieni, A.; Logrieco, A., 2002. Toxigenic fusarium species of liseola section in pre-harvest maize ear rot, and associated mycotoxins in slovakia, European Journal of Plant Pathology, 108, 299-306.

Stankovic, S.; Levic, J.; Ivanovic, D.; Krnjaja, V.; Stankovic, G.; Tancic, S., 2012. Fumonisin b-1 and its co-occurrence with other fusariotoxins in naturally-contaminated wheat grain, Food Control, 23, 384-388.

Stankovic, S.; Levic, J.; Petrovic, T.; Logrieco, A.; Moretti, A., 2007. Pathogenicity and mycotoxin production by fusarium proliferatum isolated from onion and garlic in serbia, European Journal of Plant Pathology, 118, 165-172. 
Stepien, L.; Chelkowski, J., 2010. Fusarium head blight of wheat: Pathogenic species and their mycotoxins, World Mycotoxin Journal, 3, 107-119.

Stepien, L.; Koczyk, G.; Waskiewicz, A., 2013. Diversity of fusarium species and mycotoxins contaminating pineapple, J Appl Genet, 54, 367-380.

Stepien, L.; Koczyk, G.; Waskiewicz, A., 2011. Genetic and phenotypic variation of fusarium proliferatum isolates from different host species, J Appl Genet, 52, 487-496.

Stepien, L.; Waskiewicz, A.; Urbaniak, M., 2016. Wildly growing asparagus (asparagus officinalis I.) hosts pathogenic fusarium species and accumulates their mycotoxins, Microb Ecol, 71, 927-937.

Storari, M.; Broggini, G. A. L.; Bigler, L.; Cordano, E.; Eccel, E.; De Filippi, R.; Gessler, C.; Pertot, I., 2012. Risk assessment of the occurrence of black aspergilli on grapes grown in an alpine region under a climate change scenario, European Journal of Plant Pathology, 134, 631-645.

Storari, M.; Dennert, F. G.; Bigler, L.; Gessler, C.; Broggini, G. A. L., 2012. Isolation of mycotoxins producing black aspergilli in herbal teas available on the swiss market, Food Control, 26, 157-161.

Stratakou, I.; van der Fels-Klerx, H. J., 2010. Mycotoxins in grapes and wine in europe: Occurrence, factors affecting the occurrence and related toxicological effects, World Mycotoxin Journal, 3, 283300.

Stumpf, R.; Dos Santos, J.; Gomes, L. B.; Silva, C. N.; Tessmann, D. J.; Ferreira, F. D.; Machinski, M., Jr.; Del Ponte, E. M., 2013. Fusarium species and fumonisins associated with maize kernels produced in rio grande do sul state for the 2008/09 and 2009/10 growing seasons, Braz J Microbiol, 44, 89-95.

Sugita-Konishi, Y.; Nakajima, M.; Tabata, S.; Ishikuro, E.; Tanaka, T.; Norizuki, H.; Itoh, Y.; Aoyama, K.; Fujita, K.; Kai, S.; Kumagai, S., 2006. Occurrence of aflatoxins, ochratoxin a, and fumonisins in retail foods in japan, J Food Prot, 69, 1365-1370.

Sulyok, M.; Berthiller, F.; Krska, R.; Schuhmacher, R., 2006. Development and validation of a liquid chromatography/tandem mass spectrometric method for the determination of 39 mycotoxins in wheat and maize, Rapid Commun Mass Spectrom, 20, 2649-2659.

Sun, G.; Wang, S.; Hu, X.; Su, J.; Zhang, Y.; Xie, Y.; Zhang, H.; Tang, L.; Wang, J. S., 2011. Cocontamination of aflatoxin $b-1$ and fumonisin $b-1$ in food and human dietary exposure in three areas of china, Food Additives and Contaminants Part a-Chemistry Analysis Control Exposure \& Risk Assessment, 28, 461-470.

Sun, G.; Wang, S.; Hu, X.; Su, J.; Huang, T.; Yu, J.; Tang, L.; Gao, W.; Wang, J. S., 2007. Fumonisin b1 contamination of home-grown corn in high-risk areas for esophageal and liver cancer in china, Food Addit Contam, 24, 181-185.

Sun, Y.; Xu, J.; Li, W.; Cao, B.; Wang, D. D.; Yang, Y.; Lin, Q. X.; Li, J. L.; Zheng, T. S., 2014. Simultaneous detection of ochratoxin a and fumonisin b1 in cereal samples using an aptamerphotonic crystal encoded suspension array, Analytical Chemistry, 86, 11797-11802.

Susca, A.; Moretti, A.; Stea, G.; Villani, A.; Haidukowski, M.; Logrieco, A.; Munkvold, G., 2014. Comparison of species composition and fumonisin production in aspergillus section nigri populations in maize kernels from USA and italy, Int J Food Microbiol, 188, 75-82.

Susca, A.; Proctor, R. H.; Mule, G.; Stea, G.; Ritieni, A.; Logrieco, A.; Moretti, A., 2010. Correlation of mycotoxin fumonisin b-2 production and presence of the fumonisin biosynthetic gene fum8 in aspergillus niger from grape, Journal of Agricultural and Food Chemistry, 58, 9266-9272.

Szabo-Fodor, J.; Bors, I.; Szabo, A.; Kovacs, M., 2016. Comparison of the amount of bioaccessible fumonisin b1 and b2 in maize and rice inoculated with fusarium verticillioides ( $\mathrm{mrc} 826$ ) and determined by in vitro digestion-preliminary results, Mycotoxin Res, 32, 173-178. 
Szeitz-Szabo, M.; Szabo, E., 2007. Presence of mycotoxins in food: Can we use the data from the eu rapid alert system for quantitative risk assessment?, Acta Alimentaria, 36, 127-138.

Szekeres, A.; Budai, A.; Bencsik, O.; Nemeth, L.; Bartok, T.; Szecsi, A.; Mesterhazy, A.; Vagvolgyi, C., 2014. Fumonisin measurement from maize samples by high-performance liquid chromatography coupled with corona charged aerosol detector, J Chromatogr Sci, 52, 1181-1185.

Tamura, M.; Mochizuki, N.; Nagatomi, Y.; Harayama, K.; Toriba, A.; Hayakawa, K., 2015. Identification and quantification of fumonisin $a 1, a 2$, and $a 3$ in corn by high-resolution liquid chromatography-orbitrap mass spectrometry, Toxins (Basel), 7, 582-592.

Tamura, M.; Mochizuki, N.; Nagatomi, Y.; Harayama, K.; Toriba, A.; Hayakawa, K., 2015. A method for simultaneous determination of 20 fusarium toxins in cereals by high-resolution liquid chromatography-orbitrap mass spectrometry with a pentafluorophenyl column, Toxins (Basel), 7, 1664-1682.

Tamura, M.; Takahashi, A.; Uyama, A.; Mochizuki, N., 2012. A method for multiple mycotoxin analysis in wines by solid phase extraction and multifunctional cartridge purification, and ultra-highperformance liquid chromatography coupled to tandem mass spectrometry, Toxins (Basel), 4, 476486.

Tamura, M.; Uyama, A.; Mochizuki, N., 2011. Development of a multi-mycotoxin analysis in beerbased drinks by a modified quechers method and ultra-high-performance liquid chromatography coupled with tandem mass spectrometry, Anal Sci, 27, 629-635.

Tanaka, K.; Sago, Y.; Zheng, Y.; Nakagawa, H.; Kushiro, M., 2007. Mycotoxins in rice, Int J Food Microbiol, 119, 59-66.

Tancic, S.; Stankovic, S.; Levic, J.; Krnjaja, V.; Vukojevic, J., 2012. Diversity of the fusarium verticillioides and $\mathrm{f}$. Proliferatum isolates according to their fumonisin b-1 production potencial and origin, Genetika-Belgrade, 44, 163-176.

Tancinova, D.; Labuda, R., 2009. Fungi on wheat bran and their toxinogenity, Ann Agric Environ Med, $16,325-331$.

Tang, Y. Y.; Lin, H. Y.; Chen, Y. C.; Su, W. T.; Wang, S. C.; Chiueh, L. C.; Shin, Y. C., 2013. Development of a quantitative multi-mycotoxin method in rice, maize, wheat and peanut using uplc-ms/ms, Food Analytical Methods, 6, 727-736.

Taye, W.; Ayalew, A.; Chala, A.; Dejene, M., 2016. Aflatoxin b1 and total fumonisin contamination and their producing fungi in fresh and stored sorghum grain in east hararghe, ethiopia, Food Addit Contam Part B Surveill, 1-9.

Torelli, E.; Firrao, G.; Bianchi, G.; Saccardo, F.; Locci, R., 2012. The influence of local factors on the prediction of fumonisin contamination in maize, J Sci Food Agric, 92, 1808-1814.

Torres, A. M.; Reynoso, M. M.; Rojo, F. G.; Ramirez, M. L.; Chulze, S. N., 2001. Fusarium species (section liseola) and its mycotoxins in maize harvested in northern argentina, Food Addit Contam, $18,836-843$.

Torres, O. A.; Palencia, E.; de Pratdesaba, L. L.; Grajeda, R.; Fuentes, M.; Speer, M. C.; Merrill, A. H.; O'Donnell, K.; Bacon, C. W.; Glenn, A. E.; Riley, R. T., 2007. Estimated fumonisin exposure in guatemala is greatest in consumers of lowland maize, Journal of Nutrition, 137, 2723-2729.

Torres, O.; Matute, J.; Gelineau-van Waes, J.; Maddox, J. R.; Gregory, S. G.; Ashley-Koch, A. E.; Showker, J. L.; Voss, K. A.; Riley, R. T., 2015. Human health implications from co-exposure to aflatoxins and fumonisins in maize-based foods in latin america: Guatemala as a case study, World Mycotoxin Journal, 8, 143-159.

Torres, O.; Matute, J.; Gelineau-van Waes, J.; Maddox, J. R.; Gregory, S. G.; Ashley-Koch, A. E.; Showker, J. L.; Zitomer, N. C.; Voss, K. A.; Riley, R. T., 2014. Urinary fumonisin b-1 and estimated 
fumonisin intake in women from high-and low-exposure communities in guatemala, Molecular Nutrition \& Food Research, 58, 973-983.

Trucksess, M. W.; Dombrink-Kurtzman, M. A.; Tournas, V. H.; White, K. D., 2002. Occurrence of aflatoxins and fumonisins in incaparina from guatemala, Food Addit Contam, 19, 671-675.

Trucksess, M. W.; Scott, P. M., 2008. Mycotoxins in botanicals and dried fruits: A review, Food Addit Contam Part A Chem Anal Control Expo Risk Assess, 25, 181-192.

Trung, T. S.; Tabuc, C.; Bailly, S.; Querin, A.; Guerre, P.; Bailly, J. D., 2008. Fungal mycoflora and contamination of maize from vietnam with aflatoxin $b(1)$ and fumonisin $b(1)$, World Mycotoxin Journal, 1, 87-94.

Tseng, T. C.; Liu, C. Y., 2001. Occurrence of fumonisin b-1 in maize imported into taiwan, International Journal of Food Microbiology, 65, 23-26.

Tsitsigiannis, D. I.; Dimakopoulou, M.; Antoniou, P. P.; Tjamos, E. C., 2012. Biological control strategies of mycotoxigenic fungi and associated mycotoxins in mediterranean basin crops, Phytopathologia Mediterranea, 51, 158-174.

Tutelyan, V. A.; Zakharova, L. P.; Sedova, I. B.; Perederyaev, O. I.; Aristarkhova, T. V.; Eller, K. I., 2013. Fusariotoxins in russian federation 2005-2010 grain harvests, Food Addit Contam Part B Surveill, 6, 139-145.

Uegaki, R.; Kobayashi, H.; Tohno, M.; Tsukiboshi, T., 2012. Identification of mycotoxin-producing fusarium spp. Isolated from corn and the changes in concentration of fumonisin during the cultivation period, Grassland Science, 58, 121-126.

Uhlig, S.; Eriksen, G. S.; Hofgaard, I. S.; Krska, R.; Beltran, E.; Sulyok, M., 2013. Faces of a changing climate: Semi-quantitative multi-mycotoxin analysis of grain grown in exceptional climatic conditions in norway, Toxins (Basel), 5, 1682-1697.

Vaclavik, L.; Vaclavikova, M.; Begley, T. H.; Krynitsky, A. J.; Rader, J. I., 2013. Determination of multiple mycotoxins in dietary supplements containing green coffee bean extracts using ultrahighperformance liquid chromatography-tandem mass spectrometry (uhplc-ms/ms), J Agric Food Chem, 61, 4822-4830.

Vaclavikova, M.; MacMahon, S.; Zhang, K.; Begley, T. H., 2013. Application of single immunoaffinity clean-up for simultaneous determination of regulated mycotoxins in cereals and nuts, Talanta, 117, 345-351.

Van de Perre, E.; Deschuyffeleer, N.; Jacxsens, L.; Vekeman, F.; Van Der Hauwaert, W.; Asam, S.; Rychlik, M.; Devlieghere, F.; De Meulenaer, B.; Food2Know,, 2014. Screening of moulds and mycotoxins in tomatoes, bell peppers, onions, soft red fruits and derived tomato products, Food Control, 37, 165-170.

van der Westhuizen, L.; Shephard, G. S.; Scussel, V. M.; Costa, L. L. F.; Vismer, H. F.; Rheeder, J. P.; Marasas, W. F. O., 2003. Fumonisin contamination and fusarium incidence in corn from santa catarina, brazil, Journal of Agricultural and Food Chemistry, 51, 5574-5578.

van der Westhuizen, L.; Shephard, G. S.; Rheeder, J. P.; Burger, H. M.; Gelderblom, W. C. A.; Wild, C. P.; Gong, Y. Y., 2011. Optimising sorting and washing of home-grown maize to reduce fumonisin contamination under laboratory-controlled conditions, Food Control, 22, 396-400.

van der Westhuizen, L.; Shephard, G. S.; Rheeder, J. P.; Burger, H. M.; Gelderblom, W. C. A.; Wild, C. P.; Gong, Y. Y., 2010. Simple intervention method to reduce fumonisin exposure in a subsistence maize-farming community in south africa, Food Additives and Contaminants Part a-Chemistry Analysis Control Exposure \& Risk Assessment, 27, 1582-1588.

van der Westhuizen, L.; Shephard, G. S.; Rheeder, J. P.; Somdyala, N. I. M.; Marasas, W. F. O., 2008. Sphingoid base levels in humans consuming fumonisin-contaminated maize in rural areas of the 
former transkei, south africa: A cross-sectional study, Food Additives and Contaminants Part aChemistry Analysis Control Exposure \& Risk Assessment, 25, 1385-1391.

van Egmond, H. P.; Schothorst, R. C.; Jonker, M. A., 2007. Regulations relating to mycotoxins in food: Perspectives in a global and european context, Anal Bioanal Chem, 389, 147-157.

Van Poucke, K.; Monbaliu, S.; Munaut, F.; Heungens, K.; De Saeger, S.; Van Hove, F., 2012. Genetic diversity and mycotoxin production of fusarium lactis species complex isolates from sweet pepper, Int J Food Microbiol, 153, 28-37.

van Rensburg, B. J.; McLaren, N. W.; Flett, B. C.; Schoeman, A., 2015. Fumonisin producing fusarium spp. And fumonisin contamination in commercial south african maize, European Journal of Plant Pathology, 141, 491-504.

Vanara, F.; Reyneri, A.; Blandino, M., 2009. Fate of fumonisin b-1 in the processing of whole maize kernels during dry-milling, Food Control, 20, 235-238.

Varga, E.; Glauner, T.; Koppen, R.; Mayer, K.; Sulyok, M.; Schuhmacher, R.; Krska, R.; Berthiller, F., 2012. Stable isotope dilution assay for the accurate determination of mycotoxins in maize by uhplc$\mathrm{ms} / \mathrm{ms}$, Anal Bioanal Chem, 402, 2675-2686.

Varga, J.; Kocsube, S.; Szigeti, G.; Man, V.; Toth, B.; Vagvolgyi, C.; Bartok, T., 2012. Black aspergilli and fumonisin contamination in onions purchased in hungary, Acta Alimentaria, 41, 414-423.

Varga, J.; Kocsube, S.; Suri, K.; Szigeti, G.; Szekeres, A.; Varga, M.; Toth, B.; Bartok, T., 2010. Fumonisin contamination and fumonisin producing black aspergilli in dried vine fruits of different origin, Int J Food Microbiol, 143, 143-149.

Vargas, E. A.; Preis, R. A.; Castro, L.; Silva, C. M. G., 2001. Co-occurrence of aflatoxins b(1), b(2), $g(1), g(2)$, zearalenone and fumonisin $b(1)$ in brazilian corn, Food Additives and Contaminants Part a-Chemistry Analysis Control Exposure \& Risk Assessment, 18, 981-986.

Vega, V. A., 2016. A quick assay for the quantitation of fumonisin b-1 and b-2 in maize samples by liquid chromatography and mass spectrometry, Journal of Aoac International, 99, 717-720.

Velluti, A.; Marin, S.; Sanchis, V.; Ramos, A. J., 2001. Note. Occurrence of fumonisin b-1 in spanish corn-based foods for animal and human consumption, Food Science and Technology International, 7, 433-437.

Venkataramana, M.; Navya, K.; Chandranayaka, S.; Priyanka, S. R.; Murali, H. S.; Batra, H. V., 2014. Development and validation of an immunochromatographic assay for rapid detection of fumonisin b1 from cereal samples, J Food Sci Technol, 51, 1920-1928.

Venkataramana, M.; Rashmi, R.; Uppalapati, S. R.; Chandranayaka, S.; Balakrishna, K.; Radhika, M.; Gupta, V. K.; Batra, H. V., 2015. Development of sandwich dot-elisa for specific detection of ochratoxin $a$ and its application on to contaminated cereal grains originating from india, Front Microbiol, 6, 511.

Visconti, A.; Solfrizzo, M.; De Girolamo, A., 2001. Determination of fumonisins b-1 and b-2 in corn and corn flakes by liquid chromatography with immunoaffinity column cleanup: Collaborative study, Journal of Aoac International, 84, 1828-1837.

Vismer, H. F.; Shephard, G. S.; Rheeder, J. P.; van der Westhuizen, L.; Bandyopadhyay, R., 2015. Relative severity of fumonisin contamination of cereal crops in west africa, Food Addit Contam Part A Chem Anal Control Expo Risk Assess, 32, 1952-1958.

Viswanath, P., 2004. Mycotoxin regulations for foods : A global update, Journal of Food Science and Technology-Mysore, 41, 115-123.

von Bargen, S.; Martinez, O.; Schadock, I.; Eisold, A. M.; Gossmann, M.; Buttner, C., 2009. Genetic variability of phytopathogenic fusarium proliferatum associated with crown rot in asparagus officinalis, Journal of Phytopathology, 157, 446-456. 
Voss, K. A.; Meredith, F. I.; Bacon, C. W., 2003. Effect of baking and frying on the in vivo toxicity to rats of cornmeal containing fumonisins, J Agric Food Chem, 51, 5546-5551.

Voss, K. A.; Norred, W. P.; Meredith, F. I.; Riley, R. T.; Saunders, D. S., 2006. Fumonisin concentration and ceramide synthase inhibitory activity of corn, masa, and tortilla chips, Journal of Toxicology and Environmental Health-Part a-Current Issues, 69, 1387-1397.

Voss, K. A.; Poling, S. M.; Meredith, F. I.; Bacon, C. W.; Saunders, D. S., 2001. Fate of fumonisins during the production of fried tortilla chips, J Agric Food Chem, 49, 3120-3126.

Vrabcheva, T.; Stroka, J.; Anklam, E., 2002. Occurrence of fumonisin b1 in bulgarian maize samples determined by elisa and tlc methods using different clean up steps, Mycotoxin Res, 18, 46-56.

Walt, A. M. D.; van der Linde, E.; Alberts, M.; Modjajdi, P.; Jivan, S. D.; Bezuidenhout, C. C., 2006. Fumonisin-producing fusarium strains and fumonisins in traditional, african vegetables (morogo), South African Journal of Science, 102, 151-155.

Waalwijk, C.; Koch, S. H.; Ncube, E.; Allwood, J.; Flett, B.; de Vries, I.; Kema, G. H. J., 2008. Quantitative detection of fusarium spp. And its correlation with fumonisin content in maize from south african subsistence farmers, World Mycotoxin Journal, 1, 39-47.

Wang, H.; Wei, H.; Ma, J.; Luo, X., 2000. The fumonisin b1 content in corn from north china, a highrisk area of esophageal cancer, J Environ Pathol Toxicol Oncol, 19, 139-141.

Wang, J. H.; Zhang, J. B.; Li, H. P.; Gong, A. D.; Xue, S.; Agboola, R. S.; Liao, Y. C., 2014. Molecular identification, mycotoxin production and comparative pathogenicity of fusarium temperatum isolated from maize in china, Journal of Phytopathology, 162, 147-157.

Wang, J. S.; Zhou, Y.; Wang, Q. M., 2008. Analysis of mycotoxin fumonisins in corn products by highperformance liquid chromatography coupled with evaporative light scattering detection, Food Chemistry, 107, 970-976.

Wang, J. S.; Zhou, Y.; Liu, W. B.; Zhu, X. C.; Du, L. C.; Wang, Q. M., 2008. Fumonisin level in cornbased food and feed from linxian county, a high-risk area for esophageal cancer in china, Food Chemistry, 106, 241-246.

Wang, S.; Quan, Y.; Lee, N.; Kennedy, I. R., 2006. Rapid determination of fumonisin b-1 in food samples by enzyme-linked immunosorbent assay and colloidal gold immunoassay, Journal of Agricultural and Food Chemistry, 54, 2491-2495.

Wang, X. C.; Bao, M.; Li, F. H.; Fan, H. X.; Li, H. S.; Li, Y.; Feng, S. B.; Wu, J. J., 2016. Development of a sensitive, competitive, indirect elisa for the detection of fumonisin b-1 in corn originating from anhui province, china, Journal of Environmental Science and Health Part B-Pesticides Food Contaminants and Agricultural Wastes, 51, 107-112.

Wang, X. C.; Fan, H. X.; Fan, M. X.; Li, F. H.; Feng, S. B.; Li, J. C.; Wu, J. J.; Li, Y.; Wang, J. S., 2016. A sensitive immunochromatographic assay using colloidal gold-antibody probe for rapid detection of fumonisin b1 in corn, Food Addit Contam Part A Chem Anal Control Expo Risk Assess.

Wang, Y. K.; Shi, Y. B.; Zou, Q.; Sun, J. H.; Chen, Z. F.; Wang, H. A.; Li, S. Q.; Yan, Y. X., 2013. Development of a rapid and simultaneous immunochromatographic assay for the determination of zearalenone and fumonisin b1 in corn, wheat and feedstuff samples, Food Control, 31, 180-188.

Wang, Y. K.; Yan, Y. X.; Ji, W. H.; Wang, H. A.; Li, S. Q.; Zou, Q.; Sun, J. H., 2013. Rapid simultaneous quantification of zearalenone and fumonisin b1 in corn and wheat by lateral flow dual immunoassay, J Agric Food Chem, 61, 5031-5036.

Wang, Y. K.; Yan, Y. X.; Li, S. Q.; Wang, H. A.; Ji, W. H.; Sun, J. H., 2013. Simultaneous quantitative determination of multiple mycotoxins in cereal and feedstuff samples by a suspension array immunoassay, J Agric Food Chem, 61, 10948-10953. 
Wang, Y. T.; Xiao, C. X.; Guo, J.; Yuan, Y. H.; Wang, J. G.; Liu, L. P.; Yue, T. L., 2013. Development and application of a method for the analysis of 9 mycotoxins in maize by hplc-ms/ms, Journal of Food Science, 78, M1752-M1756.

Wang, Z.; Li, H.; Li, C.; Yu, Q.; Shen, J.; De Saeger, S., 2014. Development and application of a quantitative fluorescence-based immunochromatographic assay for fumonisin b1 in maize, J Agric Food Chem, 62, 6294-6298.

Warth, B.; Braun, D.; Ezekiel, C. N.; Turner, P. C.; Degen, G. H.; Marko, D., 2016. Biomonitoring of mycotoxins in human breast milk: Current state and future perspectives, Chem Res Toxicol, 29, 1087-1097.

Warth, B.; Parich, A.; Atehnkeng, J.; Bandyopadhyay, R.; Schuhmacher, R.; Sulyok, M.; Krska, R., 2012. Quantitation of mycotoxins in food and feed from burkina faso and mozambique using a modern Ic-ms/ms multitoxin method, J Agric Food Chem, 60, 9352-9363.

Waskiewicz, A.; Beszterda, M.; Bocianowski, J.; Golinski, P., 2013. Natural occurrence of fumonisins and ochratoxin $a$ in some herbs and spices commercialized in poland analyzed by uplc-ms $/ \mathrm{ms}$ method, Food Microbiol, 36, 426-431.

Waskiewicz, A.; Beszterda, M.; Golinski, P., 2012. Occurrence of fumonisins in food - an interdisciplinary approach to the problem, Food Control, 26, 491-499.

Waskiewicz, A.; Irzykowska, L.; Bocianowski, J.; Karolewski, Z.; Weber, Z.; Golinski, P., 2013. Fusariotoxins in asparagus - their biosynthesis and migration, Food Addit Contam Part A Chem Anal Control Expo Risk Assess, 30, 1332-1338.

Waskiewicz, A.; Irzykowska, L.; Bocianowski, J.; Karolewski, Z.; Kostecki, M.; Weber, Z.; Golinski, P., 2010. Occurrence of fusarium fungi and mycotoxins in marketable asparagus spears, Polish Journal of Environmental Studies, 19, 219-225.

Waskiewicz, A.; Stepien, L.; Wilman, K.; Kachlicki, P., 2013. Diversity of pea-associated f. Proliferatum and $f$. Verticillioides populations revealed by fum 1 sequence analysis and fumonisin biosynthesis, Toxins (Basel), 5, 488-503.

Waskiewicz, A.; Stepien, L., 2012. Mycotoxins biosynthesized by plant-derived fusarium isolates, Arh Hig Rada Toksikol, 63, 437-446.

Weber, Z.; Kostecki, M.; Bargen, S.; Gossmann, M.; Waskiewicz, A.; Bocianowski, J.; Knaflewski, M.; Buttner, C.; Golinski, P., 2006. Fusarium species colonizing spears and forming mycotoxins in field samples of asparagus from germany and poland, Journal of Phytopathology, 154, 209-216.

Wei, T.; Zhu, W.; Pang, M.; Liu, Y.; Dong, J., 2013. Natural occurrence of fumonisins b1 and b2 in corn in four provinces of china, Food Addit Contam Part B Surveill, 6, 270-274.

Weidenborner, M., 2001. Foods and fumonisins, European Food Research and Technology, 212, 262273.

Whitaker, T. B.; Doko, M. B.; Maestroni, B. M.; Slate, A. B.; Ogunbanwo, B. F., 2007. Evaluating the performance of sampling plans to detect fumonisin b-1 in maize lots marketed in nigeria, Journal of Aoac International, 90, 1050-1059.

WHO (World Health Organization), 2002. Evaluation of certain mycotoxins in food. Fifty-sixth report of the joint fao/who expert committee on food additives, 2002. World Health Organ Tech Rep Ser, 906, i-viii, 1-62.

WHO (World Health Organization), 2011. Evaluation of certain food additives and contaminants, 2011. World Health Organ Tech Rep Ser, 1-136.

Wilson, J. P.; Jurjevic, Z.; Hanna, W. W.; Wilson, D. M.; Potter, T. L.; Coy, A. E., 2006. Host-specific variation in infection by toxigenic fungi and contamination by mycotoxins in pearl millet and corn, Mycopathologia, 161, 101-107. 
Woo, C. S. J.; El-Nezami, H., 2015. Mycotoxins in asia: Is china in danger?, Quality Assurance and Safety of Crops \& Foods, 7, 3-25.

Wu, F., 2004. Mycotoxin risk assessment for the purpose of setting international regulatory standards, Environ Sci Technol, 38, 4049-4055.

Xu, J.; Li, W.; Liu, R.; Yang, Y.; Lin, Q. X.; Xu, J. J.; Shen, P.; Zheng, Q.; Zhang, Y.; Han, Z. F.; Li, J. L.; Zheng, T. S., 2016. Ultrasensitive low-background multiplex mycotoxin chemiluminescence immunoassay by silica-hydrogel photonic crystal microsphere suspension arrays in cereal samples, Sensors and Actuators B-Chemical, 232, 577-584.

Yang, Q. F.; Wu, Y. L., 2012. Fast determination of fumonisin b-1 and b-2 in corn using a modified quechers method and Ic-ms-ms, Chromatographia, 75, 1075-1080.

Yang, Y.; Bouras, N.; Yang, J.; Howard, R. J.; Strelkov, S. E., 2011. Mycotoxin production by isolates of fusarium lactis from greenhouse sweet pepper (capsicum annuum), Int J Food Microbiol, 151, 150-156.

Yassin, M. A.; El-Samawaty, A. R.; Bahkali, A.; Moslem, M.; Abd-Elsalam, K. A.; Hyde, K. D., 2010. Mycotoxin-producing fungi occurring in sorghum grains from saudi arabia, Fungal Diversity, 44, 4552.

Yau, A. T.; Chen, M. Y.; Lam, C. H.; Ho, Y. Y.; Xiao, Y.; Chung, S. W., 2016. Dietary exposure to mycotoxins of the hong kong adult population from a total diet study, Food Addit Contam Part A Chem Anal Control Expo Risk Assess, 33, 1026-1035.

Yazar, S.; Omurtag, G. Z., 2008. Fumonisins, trichothecenes and zearalenone in cereals, Int J Mol Sci, 9, 2062-2090.

Ye, H. C.; Lai, X. W.; Liu, C. L., 2013. Determination of fumonisin b-1 and b-2 in corn using matrixphase dispersion coupled to high performance liquid chromatography, Asian Journal of Chemistry, 25, 6807-6810.

Yogendrarajah, P.; Deschuyffeleer, N.; Jacxsens, L.; Sneyers, P. J.; Maene, P.; De Saeger, S.; Devlieghere, F.; De Meulenaer, B., 2014. Mycological quality and mycotoxin contamination of sri lankan peppers (piper nigrum I.) and subsequent exposure assessment, Food Control, 41, 219-230.

Yogendrarajah, P.; Jacxsens, L.; De Saeger, S.; De Meulenaer, B., 2014. Co-occurrence of multiple mycotoxins in dry chilli (capsicum annum I.) samples from the markets of sri lanka and belgium, Food Control, 46, 26-34.

Yogendrarajah, P.; Van Poucke, C.; De Meulenaer, B.; De Saeger, S., 2013. Development and validation of a quechers based liquid chromatography tandem mass spectrometry method for the determination of multiple mycotoxins in spices, J Chromatogr A, 1297, 1-11.

Yoshinari, T.; Tanaka, T.; Ishikuro, E.; Horie, M.; Nagayama, T.; Nakajima, M.; Naito, S.; Ohnishi, T.; Sugita-Konishi, Y., 2013. Inter-laboratory study of an $\mathrm{lc}-\mathrm{ms} / \mathrm{ms}$ method for simultaneous determination of fumonisin b-1, b-2 and b-3 in corn, Food Hygiene and Safety Science, 54, 266276.

Zainudin, Naim; Perumal, N., 2015. Mycotoxins production by fusarium and aspergillus species isolated from cornmeal, International Journal of Agriculture and Biology, 17, 440-448.

Zangheri, M.; Di Nardo, F.; Anfossi, L.; Giovannoli, C.; Baggiani, C.; Roda, A.; Mirasoli, M., 2015. A multiplex chemiluminescent biosensor for type b-fumonisins and aflatoxin b1 quantitative detection in maize flour, Analyst, 140, 358-365.

Zhang, A. H.; Ma, Y. N.; Feng, L. L.; Wang, Y.; He, C. H.; Wang, X. C.; Zhang, H. B., 2011. Development of a sensitive competitive indirect elisa method for determination of ochratoxin a levels in cereals originating from nanjing, china, Food Control, 22, 1723-1728. 
Zhang, K.; Wong, J. W.; Hayward, D. G.; Vaclavikova, M.; Liao, C. D.; Trucksess, M. W., 2013. Determination of mycotoxins in milk-based products and infant formula using stable isotope dilution assay and liquid chromatography tandem mass spectrometry, J Agric Food Chem, 61, 6265-6273.

Zhang, K.; Wong, J. W.; Krynitsky, A. J.; Trucksess, M. W., 2014. Determining mycotoxins in baby foods and animal feeds using stable isotope dilution and liquid chromatography tandem mass spectrometry, J Agric Food Chem, 62, 8935-8943.

Zhang, K.; Wong, J. W.; Jia, Z. W.; Vaclavikova, M.; Trucksess, M. W.; Begley, T. H., 2014. Screening multimycotoxins in food-grade gums by stable isotope dilution and liquid chromatography/tandem mass spectrometry, Journal of Aoac International, 97, 889-895.

Zhang, L. P.; Wang, J. S.; Zhang, C. L.; Wang, Q. M., 2013. Analysis of potential fumonisin-producing fusarium species in corn products from three main maize-producing areas in eastern china, Journal of the Science of Food and Agriculture, 93, 693-701.

Zhang, W. W.; Deng, X. D.; Yu, X. P.; Pei, X. F.; Fu, G. M.; Wang, X. L.; Li, B. B.; Wang, L. Y., 2015. The recent fusarium mycotoxin situation in grain and feed in china, World Mycotoxin Journal, 8 , 545-551.

Zimmer, I.; Dietrich, R.; Usleber, E.; Martlbauer, E.; Schneider, E., 2001. Development and application of an enzyme-linked immunosorbent assay for the analysis of hydrolyzed fumonisins, Mycotoxin Res, 17 Suppl 1, 120-124.

Zimmer, I.; Usleber, E.; Klaffke, H.; Weber, R.; Majerus, P.; Otteneder, H.; Gareis, M.; Dietrich, R.; Martlbauer, E., 2008. Fumonisin intake of the german consumer, Mycotoxin Res, 24, 40-52.

Zinedine, A.; Brera, C.; Elakhdari, S.; Catano, C.; Debegnach, F.; Angelini, S.; De Santis, B.; Faid, M.; Benlemlih, M.; Minardi, V.; Miraglia, M., 2006. Natural occurrence of mycotoxins in cereals and spices commercialized in morocco, Food Control, 17, 868-874.

Zollner, P.; Mayer-Helm, B., 2006. Trace mycotoxin analysis in complex biological and food matrices by liquid chromatography-atmospheric pressure ionisation mass spectrometry, J Chromatogr A, $1136,123-169$.

Zou, L.; Xu, Y.; Li, Y. P.; He, Q. H.; Chen, B.; Wang, D., 2014. Development of a single-chain variable fragment antibody-based enzyme-linked immunosorbent assay for determination of fumonisin b-1 in corn samples, Journal of the Science of Food and Agriculture, 94, 1865-1871.

Relevant references not retrieved in the literature searches for Area 8 OCCURRENCE IN FOOD:

Belajova, E.; Rauova, D.; Dasko, L., 2007. Retention of ochratoxin a and fumonisin b1 and b2 from beer on solid surfaces: Comparison of efficiency of adsorbents with different origin, European Food Research and Technology, 224, 301-308.

Dowd, P. F.; Johnson, E. T., 2010. Field incidence of mycotoxins in commercial popcorn and potential environmental influences, Mycotoxin Res, 26, 15-22.

Gonzalez Pereyra, M. L.; Rosa, C. A.; Dalcero, A. M.; Cavaglieri, L. R., 2011. Mycobiota and mycotoxins in malted barley and brewer's spent grain from argentinean breweries, Lett Appl Microbiol, 53, 649-655. 


\section{AREA 9 OCCURRENCE IN FEED}

Reference list with all relevant references identified for AREA 9: Data on occurrence in feed and animal exposure (including feed occurrence in the different feed commodities, feed intake and animal exposure) published in English since year 2000.

\section{Relevant references retrieved in the literature searches for Area 9 OCCURRENCE IN FEED:}

Abdallah, M. F.; Girgin, G.; Baydar, T., 2015. Occurrence, prevention and limitation of mycotoxins in feeds, Animal Nutrition and Feed Technology, 15, 471-490.

Abia, W. A.; Simo, G. N.; Warth, B.; Sulyok, M.; Krska, R.; Tchana, A.; Moundipa, P. F., 2013. Determination of multiple mycotoxins levels in poultry feeds from cameroon, Jpn J Vet Res, 61 Suppl, S33-39.

Abrunhosa, L.; Morales, H.; Soares, C.; Calado, T.; Vila-Cha, A. S.; Pereira, M.; Venancio, A., 2016. A review of mycotoxins in food and feed products in portugal and estimation of probable daily intakes, Crit Rev Food Sci Nutr, 56, 249-265.

Acuna, A.; Lozano, M. C.; de Garcia, M. C.; Diaz, G. J., 2005. Prevalence of fusarium species of the liseola section on selected colombian animal feedstuffs and their ability to produce fumonisins, Mycopathologia, 160, 63-66.

Afsah-Hejri, L.; Jinap, S.; Hajeb, P.; Radu, S.; Shakibazadeh, S., 2013. A review on mycotoxins in food and feed: Malaysia case study, Comprehensive Reviews in Food Science and Food Safety, 12, 629651.

Alemu, T.; Birhanu, G.; Azerefgne, F.; Skinnes, H., 2008. Evidence for mycotoxin contamination of maize in southern ethiopia: The need for further multidisciplinary research, Cereal Research Communications, 36, 337-339.

Alexa, E.; Dehelean, C. A.; Poiana, M. A.; Radulov, I.; Cimpean, A. M.; Bordean, D. M.; Tulcan, C.; Pop, G., 2013. The occurrence of mycotoxins in wheat from western romania and histopathological impact as effect of feed intake, Chem Cent J, 7, 99.

Almeida, I.; Martins, H. M.; Santos, S.; Costa, J. M.; Bernardo, F., 2011. Co-occurrence of mycotoxins in swine feed produced in portugal, Mycotoxin Res, 27, 177-181.

Anonymous, 2012. Sampling and sample preparation methods for determining concentrations of mycotoxins in foods and feeds, 2012. IARC Sci Publ, 39-51.

Anukul, N.; Maneeboon, T.; Roopkham, C.; Chuaysrinule, C.; Mahakarnchanakul, W., 2014. Fumonisin and $\mathrm{t}-2$ toxin production of fusarium spp. Isolated from complete feed and individual agricultural commodities used in shrimp farming, Mycotoxin Res, 30, 9-16.

Aoki, T.; O'Donnell, K.; Geiser, D. M., 2014. Systematics of key phytopathogenic fusarium species: Current status and future challenges, Journal of General Plant Pathology, 80, 189-201.

Ashiq, S., 2015. Natural occurrence of mycotoxins in food and feed: Pakistan perspective, Comprehensive Reviews in Food Science and Food Safety, 14, 159-175.

Atukwase, A.; Kaaya, A. N.; Muyanja, C., 2012. Dynamics of fusarium and fumonisins in maize during storage - a case of the traditional storage structures commonly used in uganda, Food Control, 26, 200-205.

Atukwase, A.; Kaaya, A. N.; Muyanja, C., 2009. Factors associated with fumonisin contamination of maize in uganda, Journal of the Science of Food and Agriculture, 89, 2393-2398.

Baglieri, A.; Reyneri, A.; Gennari, M.; Negre, M., 2013. Organically modified clays as binders of fumonisins in feedstocks, J Environ Sci Health B, 48, 776-783. 
Bailly, J. D.; Tardieu, D.; Auvergne, A.; Babile, R.; Guerre, P., 2007. Sphinganine and sphinganine to sphingosine ratio as a biomarker of dietary fumonisins during chronic exposure in ducks, NaunynSchmiedebergs Archives of Pharmacology, 374, 329-329.

Bakan, B.; Melcion, D.; Richard-Molard, D.; Cahagnier, B., 2002. Fungal growth and fusarium mycotoxin content in isogenic traditional maize and genetically modified maize grown in france and spain, J Agric Food Chem, 50, 728-731.

Balconi, C.; Berardo, N.; Locatelli, S.; Lanzanova, C.; Torri, A.; Redaelli, R., 2014. Evaluation of ear rot (fusarium verticillioides) resistance and fumonisin accumulation in italian maize inbred lines, Phytopathologia Mediterranea, 53, 14-26.

Bankole, S. A.; Mabekoje, O. O., 2004. Occurrence of aflatoxins and fumonisins in preharvest maize from south-western nigeria, Food Addit Contam, 21, 251-255.

Batatinha, M. J. M.; Simas, M. M. S.; Botura, M. B.; Bitencourt, T. C.; Reis, T. A.; Correa, B., 2007. Fumonisins in brewers grain (barley) used as dairy cattle feed in the state of bahia, brazil, Food Control, 18, 608-612.

Beg, M. U.; Al-Mutairi, M.; Beg, K. R.; Al-Mazeedi, H. M.; Ali, L. N.; Saeed, T., 2006. Mycotoxins in poultry feed in kuwait, Arch Environ Contam Toxicol, 50, 594-602.

Bennett, J. W.; Klich, M., 2003. Mycotoxins, Clinical Microbiology Reviews, 16, 497-+.

Berardo, N.; Lanzanova, C.; Locatelli, S.; Lagana, P.; Verderio, A.; Motto, M., 2011. Levels of total fumonisins in maize samples from italy during 2006-2008, Food Addit Contam Part B Surveill, 4, 116-124.

Bhat, R.; Rai, R. V.; Karim, A. A., 2010. Mycotoxins in food and feed: Present status and future concerns, Comprehensive Reviews in Food Science and Food Safety, 9, 57-81.

Binder, E. M.; Tan, L. M.; Chin, L. J.; Handl, J.; Richard, J., 2007. Worldwide occurrence of mycotoxins in commodities, feeds and feed ingredients, Animal Feed Science and Technology, 137, 265-282.

Bird, C. B.; Malone, B.; Rice, L. G.; Ross, P. F.; Eppley, R.; Abouzied, M. M., 2002. Determination of total fumonisins in corn by competitive direct enzyme-linked immunosorbent assay: Collaborative study, J AOAC Int, 85, 404-410.

Biro, D.; Juracek, M.; Kacaniova, M.; Simko, M.; Galik, B.; Michalkova, J.; Gyongyova, E., 2009. Occurrence of microscopic fungi and mycotoxins in conserved high moisture corn from slovakia, Ann Agric Environ Med, 16, 227-232.

Bissoqui, L. Y.; Frehse, M. S.; Freire, R. L.; Ono, M. A.; Bordini, J. G.; Hirozawa, M. T.; Oliveira, A. J.; Ono, E. Y., 2016. Exposure assessment of dogs to mycotoxins through consumption of dry feed, J Sci Food Agric.

Blajet-Kosicka, A.; Kosicki, R.; Twaruzek, M.; Grajewski, J., 2014. Determination of moulds and mycotoxins in dry dog and cat food using liquid chromatography with mass spectrometry and fluorescence detection, Food Addit Contam Part B Surveill, 7, 302-308.

Boermans, H. J.; Leung, M. C. K., 2007. Mycotoxins and the pet food industry: Toxicological evidence and risk assessment, International Journal of Food Microbiology, 119, 95-102.

Bohm, J.; Koinig, L.; Razzazi-Fazeli, E.; Blajet-Kosicka, A.; Twaruzek, M.; Grajewski, J.; Lang, C., 2010. Survey and risk assessment of the mycotoxins deoxynivalenol, zearalenone, fumonisins, ochratoxin a, and aflatoxins in commercial dry dog food, Mycotoxin Res, 26, 147-153.

Borutova, R.; Aragon, Y. A.; Nahrer, K.; Berthiller, F., 2012. Co-occurrence and statistical correlations between mycotoxins in feedstuffs collected in the asia-oceania in 2010, Animal Feed Science and Technology, 178, 190-197.

Boudra, H.; Morgavi, D. P., 2008. Reduction in fusarium toxin levels in corn silage with low dry matter and storage time, J Agric Food Chem, 56, 4523-4528. 
Bowers, E. L.; Munkvold, G. P., 2014. Fumonisins in conventional and transgenic, insect-resistant maize intended for fuel ethanol production: Implications for fermentation efficiency and ddgs coproduct quality, Toxins (Basel), 6, 2804-2825.

Bruns, H. A., 2003. Controlling aflatoxin and fumonisin in maize by crop management, Journal of Toxicology-Toxin Reviews, 22, 153-173.

Bryla, M.; Roszko, M.; Szymczyk, K.; Jedrzejczak, R.; Obiedzinski, M. W.; Sekul, J., 2013. Fumonisins in plant-origin food and fodder - a review, Food Additives and Contaminants Part a-Chemistry Analysis Control Exposure \& Risk Assessment, 30, 1626-1640.

Bush, B. J.; Carson, M. L.; Cubeta, M. A.; Hagler, W. M.; Payne, G. A., 2004. Infection and fumonisin production by fusarium verticillioides in developing maize kernels, Phytopathology, 94, 88-93.

Camargos, S. M.; Soares, L. M. V.; Sawazaki, E.; Bolonhezi, D.; Castro, J. L.; Bortolleto, N., 2002. Accumulation of fumonisins $b(1)$ and $b(2)$ in freshly harvested brazilian commercial maize at three locations during two nonconsecutive seasons, Mycopathologia, 155, 219-228.

Campbell, H.; Choo, T. M.; Vigier, B.; Underhill, L., 2002. Comparison of mycotoxin profiles among cereal samples from eastern canada, Canadian Journal of Botany-Revue Canadienne De Botanique, 80, 526-532.

Cavaglieri, L. R.; Keller, K. M.; Pereyra, C. M.; Pereyra, M. L. G.; Alonso, V. A.; Rojo, F. G.; Dalcero, A. M.; Rosa, C. A. R., 2009. Fungi and natural incidence of selected mycotoxins in barley rootlets, Journal of Stored Products Research, 45, 147-150.

Cavret, S.; Lecoeur, S., 2006. Fusariotoxin transfer in animal, Food Chem Toxicol, 44, 444-453.

Cendoya, E.; Monge, M. P.; Palacios, S. A.; Chiacchiera, S. M.; Torres, A. M.; Farnochi, M. C.; Ramirez, M. L., 2014. Fumonisin occurrence in naturally contaminated wheat grain harvested in argentina, Food Control, 37, 56-61.

Chaytor, A. C.; Hansen, J. A.; van Heugten, E.; See, M. T.; Kim, S. W., 2011. Occurrence and decontamination of mycotoxins in swine feed, Asian-Australasian Journal of Animal Sciences, 24, 723-738.

Cheng, Y. H.; Wu, J. F.; Lee, D. N.; Yang, C. M. J., 2002. Prevalence of fumonisin contamination in corn and corn-based feeds in taiwan, Asian-Australasian Journal of Animal Sciences, 15, 610-614.

Chilaka, C. A.; De Kock, S.; Phoku, J. Z.; Mwanza, M.; Egbuta, M. A.; Dutton, M. F., 2012. Fungal and mycotoxin contamination of south african commercial maize, Journal of Food Agriculture \& Environment, 10, 296-303.

Chulze, S. N., 2010. Strategies to reduce mycotoxin levels in maize during storage: A review, Food Addit Contam Part A Chem Anal Control Expo Risk Assess, 27, 651-657.

Conkova, E.; Laciakova, A.; Kovac, G.; Seidel, H., 2003. Fusarial toxins and their role in animal diseases, Vet J, 165, 214-220.

Coradi, P. C.; Maier, D. E.; Channaiah, L. H.; Campabadal, C., 2016. Effects of the processing on the distribution of aflatoxin and fumonisin levels in corn fractions and feeds, Journal of Food Process Engineering, 39, 215-225.

Czembor, E.; Stepien, L.; Waskiewicz, A., 2015. Effect of environmental factors on fusarium species and associated mycotoxins in maize grain grown in poland, PLoS One, 10, e0133644.

da Rocha, M. E. B.; Freire, F. D. O.; Maia, F. B. F.; Guedes, M. I. F.; Rondina, D., 2014. Mycotoxins and their effects on human and animal health, Food Control, 36, 159-165.

Daga, A.; Horn, M. B.; Kottwitz, L. B. M.; de Farina, L. O., 2015. Bromatological and mycotoxin analysis on soybean meal before and after the industrial process of micronization, Ciencia Rural, 45, 1336-1341. 
Dall'Asta, C.; Giorni, P.; Cirlini, M.; Reverberi, M.; Gregori, R.; Ludovici, M.; Camera, E.; Fanelli, C.; Battilani, P.; Scala, V., 2015. Maize lipids play a pivotal role in the fumonisin accumulation, World Mycotoxin Journal, 8, 87-97.

Darwish, W. S.; Ikenaka, Y.; Nakayama, S. M. M.; Ishizuka, M., 2014. An overview on mycotoxin contamination of foods in africa, Journal of Veterinary Medical Science, 76, 789-797.

Das, I. K.; Kumar, B. S. V.; Ratnavathi, C. V.; Komala, V. V.; Annapurna, A.; Seetharama, N., 2010. Toxigenicity of fusarium isolates and fumonisin b-1 contamination in rainy season sorghum (sorghum bicolor), Indian Journal of Agricultural Sciences, 80, 724-729.

De Liguoro, M.; Petterino, C.; Mezzalira, G.; Tenti, S.; Ravarotto, L., 2004. Field observations in pigs exposed to fumonisin b1 contaminated feed, Vet Hum Toxicol, 46, 303-305.

de Rijk, T. C.; van Egmond, H. P.; van der Fels-Klerx, H. J.; Herbes, R.; de Nijs, M.; Samson, R. A.; Slate, A. B.; van der Spiegel, M., 2015. A study of the 2013 western european issue of aflatoxin contamination of maize from the balkan area, World Mycotoxin Journal, 8, 641-651.

de Souza, M. D. M.; Sulyok, M.; Freitas-Silva, O.; Costa, S. S.; Brabet, C.; Machinski, M.; Sekiyama, B. L.; Vargas, E. A.; Krska, R.; Schuhmacher, R., 2013. Cooccurrence of mycotoxins in maize and poultry feeds from brazil by liquid chromatography/tandem mass spectrometry, Scientific World Journal.

Delgado, J. E.; Wolt, J. D., 2010. Fumonisin b-1 and implications in nursery swine productivity: A quantitative exposure assessment, Journal of Animal Science, 88, 3767-3777.

Denli, M., 2015. Implications of mycotoxins in livestock feeds, Agrolife Scientific Journal, 4, 52-55.

Devreese, M.; De Backer, P.; Croubels, S., 2013. Overview of the most important mycotoxins for the pig and poultry husbandry, Vlaams Diergeneeskundig Tijdschrift, 82, 171-180.

Di Gregorio, M. C.; de Neeff, D. V.; Jager, A. V.; Corassin, C. H.; Carao, A. C. D.; de Albuquerque, R.; de Azevedo, A. C.; Oliveira, C. A. F., 2014. Mineral adsorbents for prevention of mycotoxins in animal feeds, Toxin Reviews, 33, 125-135.

Diaz-Gomez, J.; Marin, S.; Capell, T.; Sanchis, V.; Ramos, A. J., 2016. The impact of bacillus thuringiensis technology on the occurrence of fumonisins and other mycotoxins in maize, World Mycotoxin Journal, 9, 475-486.

Dilkin, P.; Mallmann, C. A.; de Almeida, C. A. A.; Correa, B., 2001. Robotic automated clean-up for detection of fumonisins $b-1$ and $b-2$ in corn and corn-based feed by high-performance liquid chromatography, Journal of Chromatography A, 925, 151-157.

Domijan, A. M.; Peraica, M.; Jurjevic, Z.; Ivic, D.; Cvjetkovic, B., 2005. Fumonisin b-1, fumonisin b-2, zearalenone and ochratoxin a contamination of maize in croatia, Food Additives and Contaminants, $22,677-680$.

Domijan, A. M.; Peraica, M.; Cvjetkovic, B.; Turcin, S.; Jurjevic, Z.; Ivic, D., 2005. Mould contamination and co-occurrence of mycotoxins in maize grain in croatia, Acta Pharm, 55, 349356.

dos Reis, T. A.; Zorzete, P.; Pozzi, C. R.; da Silva, V. N.; Ortega, E.; Correa, B., 2010. Mycoflora and fumonisin contamination in brazilian sorghum from sowing to harvest, Journal of the Science of Food and Agriculture, 90, 1445-1451.

Driehuis, F.; Spanjer, M. C.; Scholten, J. M.; Giffel, M. C. T., 2008. Occurrence of mycotoxins in feedstuffs of dairy cows and estimation of total dietary intakes, Journal of Dairy Science, 91, 42614271.

Driehuis, F.; Spanjer, M. C.; Scholten, J. M.; Giffel, M. C. T., 2008. Occurrence of mycotoxins in maize, grass and wheat silage for dairy cattle in the netherlands, Food Additives \& Contaminants Part BSurveillance, 1, 41-50. 
Duan, C.; Qin, Z.; Yang, Z.; Li, W.; Sun, S.; Zhu, Z.; Wang, X., 2016. Identification of pathogenic fusarium spp. Causing maize ear rot and potential mycotoxin production in china, Toxins (Basel), 8.

Dzuman, Z.; Stranska-Zachariasova, M.; Vaclavikova, M.; Tomaniova, M.; Veprikova, Z.; Slavikova, P.; Hajslova, J., 2016. Fate of free and conjugated mycotoxins within the production of distiller's dried grains with solubles (ddgs), J Agric Food Chem, 64, 5085-5092.

Eckard, S.; Wettstein, F. E.; Forrer, H. R.; Vogelgsang, S., 2011. Incidence of fusarium species and mycotoxins in silage maize, Toxins (Basel), 3, 949-967.

Ekici, H.; Yildirim, E.; Yarsan, E., 2016. The effect of seasonal variations on the occurrence of certain mycotoxins in concentrate feeds for cattle collected from some provinces in turkey, Turkish Journal of Veterinary \& Animal Sciences, 40, 298-303.

El-Naggar, M. A.; Thabit, T. M., 2014. Evaluation of beta-d-glucan biopolymer as a novel mycotoxin binder for fumonisin and deoxynivalenol in soybean feed, Foodborne Pathog Dis, 11, 433-438.

Fandohan, P.; Gnonlonfin, B.; Hell, K.; Marasas, W. F. O.; Wingfield, M. J., 2005. Natural occurrence of fusarium and subsequent famonisin contamination in preharvest and stored maize in benin, west africa, International Journal of Food Microbiology, 99, 173-183.

Feng, Y. Z.; Lu, X. H.; Tao, B.; Pang, M. H.; Liu, Y. C.; Dong, J. G., 2011. Natural occurrence of fumonisins $b-1$ and $b-2$ in corn from three main production provinces in china, Journal of Food Protection, 74, 1374-1378.

Fu, M.; Li, R. J.; Guo, C. C.; Pang, M. H.; Liu, Y. C.; Dong, J. G., 2015. Natural incidence of fusarium species and fumonisins $b-1$ and $b-2$ associated with maize kernels from nine provinces in china in 2012, Food Additives and Contaminants Part a-Chemistry Analysis Control Exposure \& Risk Assessment, 32, 503-511.

Gallo, A.; Giuberti, G.; Frisvad, J. C.; Bertuzzi, T.; Nielsen, K. F., 2015. Review on mycotoxin issues in ruminants: Occurrence in forages, effects of mycotoxin ingestion on health status and animal performance and practical strategies to counteract their negative effects, Toxins (Basel), 7, 30573111.

Gamanya, R.; Sibanda, L., 2001. Survey of fusarium moniliforme (f-verticillioides) and production of fumonisin $b-1$ in cereal grains and oilseeds in zimbabwe, International Journal of Food Microbiology, 71, 145-149.

Garcia-Morales, M. H.; Perez-Velazquez, M.; Gonzalez-Felix, M. L.; Burgos-Hernandez, A.; CortezRocha, M. O.; Bringas-Alvarado, L.; Ezquerra-Brauer, J. M., 2015. Effects of fumonisin b-1containing feed on the muscle proteins and ice-storage life of white shrimp (litopenaeus vannamei), Journal of Aquatic Food Product Technology, 24, 340-353.

Gazzotti, T.; Biagi, G.; Pagliuca, G.; Pinna, C.; Scardilli, M.; Grandi, M.; Zaghini, G., 2015. Occurrence of mycotoxins in extruded commercial dog food, Animal Feed Science and Technology, 202, 81-89.

Ghali, R.; Ghorbel, H.; Hedilli, A., 2009. Fumonisin determination in tunisian foods and feeds. Elisa and hplc methods comparison, J Agric Food Chem, 57, 3955-3960.

Ghazvini, R. D.; Mirhendi, H.; Ghiasian, S. A.; Masoudi-Nejad, A.; Shokri, H.; Soltani, M.; Haddadi, S.; Khosravi, A. R., 2011. Genotyping of fusarium verticillioides strains producing fumonisin b-1 in feed associated 309 with animal health problems, Iranian Journal of Veterinary Research, 12, 309-316.

Ghiasian, S. A.; Maghsood, A. H.; Yazdanpanah, H.; Shephard, G. S.; Van der Westhuizen, L.; Vismer, H. F.; Rheeder, J. P.; Marasas, W. F. O., 2006. Incidence of fusarium verticillioides and levels of fumonisins in corn from main production areas in iran, Journal of Agricultural and Food Chemistry, 54, 6118-6122.

Ghiasian, S. A.; Aghamirian, M. R.; Maghsood, A. H.; Shephard, G. S.; van der Westhuizen, L., 2009. Occurrence of fumonisins in maize imported into iran during 2001-2002, Mycotoxin Res, 25, 25-28. 
Girgis, G. N.; Smith, T. K., 2010. Comparative aspects of fusarium mycotoxicoses in poultry fed diets containing naturally contaminated grains, Worlds Poultry Science Journal, 66, 65-86.

Glenn, A. E., 2007. Mycotoxigenic fusarium species in animal feed, Animal Feed Science and Technology, 137, 213-240.

Golinski, P.; Waskiewicz, A.; Gromadzka, K., 2009. Mycotoxins and mycotoxicoses under climatic conditions of poland, Pol J Vet Sci, 12, 581-588.

Gong, H. Z.; Ji, R.; Li, Y. X.; Zhang, H. Y.; Li, B.; Zhao, Y.; Sun, L.; Yu, F.; Yang, J., 2009. Occurrence of fumonisin b-1 in corn from the main corn-producing areas of china, Mycopathologia, 167, 31-36.

Grajewski, J.; Blajet-Kosicka, A.; Twaruzek, M.; Kosicki, R., 2012. Occurrence of mycotoxins in polish animal feed in years 2006-2009, J Anim Physiol Anim Nutr (Berl), 96, 870-877.

Greco, M. V.; Franchi, M. L.; Golba, S. L. R.; Pardo, A. G.; Pose, G. N., 2014. Mycotoxins and mycotoxigenic fungi in poultry feed for food-producing animals, Scientific World Journal.

Greco, M. V.; Pardo, A. G.; Ludemann, V.; Martino, P. E.; Pose, G. N., 2012. Mycoflora and natural incidence of selected mycotoxins in rabbit and chinchilla feeds, ScientificWorldJournal, 2012, 956056.

Grenier, B.; Oswald, I. P., 2011. Mycotoxin co-contamination of food and feed: Meta-analysis of publications describing toxicological interactions, World Mycotoxin Journal, 4, 285-313.

Griessler, K.; Rodrigues, I.; Handl, J.; Hofstetter, U., 2010. Occurrence of mycotoxins in southern europe, World Mycotoxin Journal, 3, 301-309.

Guan, S.; Gong, M.; Yin, Y. L.; Huang, R. L.; Ruan, Z.; Zhou, T.; Xie, M. Y., 2011. Occurrence of mycotoxins in feeds and feed ingredients in china, Journal of Food Agriculture \& Environment, 9, 163-167.

Hammond, B. 2004. A review of the food/feed safety and benefits of bacillus thuringiensis protein containing insect-protected crops. in M. K.; Ridley Bhalgat, W. P.; Felsot, A. S.; Seiber, J. N. (ed.), Agricultural biotechnology: Challenges and prospects.

Hammond, B. G.; Campbell, K. W.; Pilcher, C. D.; Degooyer, T. A.; Robinson, A. E.; McMillen, B. L.; Spangler, S. M.; Riordan, S. G.; Rice, L. G.; Richard, J. L., 2004. Lower fumonisin mycotoxin levels in the grain of bt corn grown in the united states in 2000-2002, J Agric Food Chem, 52, 1390-1397.

Hove, M.; Van Poucke, C.; Njumbe-Ediage, E.; Nyanga, L. K.; De Saeger, S., 2016. Review on the natural co-occurrence of afb1 and fb1 in maize and the combined toxicity of afb1 and fb1, Food Control, 59, 675-682.

Jaksic, S.; Abramovic, B.; Jajic, I.; Balos, M. Z.; Mihaljev, Z.; Despotovic, V.; Sojic, D., 2012. Cooccurrence of fumonisins and deoxynivalenol in wheat and maize harvested in serbia, Bull Environ Contam Toxicol, 89, 615-619.

Joshi, S.; Segarra-Fas, A.; Peters, J.; Zuilhof, H.; van Beek, T. A.; Nielen, M. W. F., 2016. Multiplex surface plasmon resonance biosensing and its transferability towards imaging nanoplasmonics for detection of mycotoxins in barley, Analyst, 141, 1307-1318.

Jouany, J. P., 2007. Methods for preventing, decontaminating and minimizing the toxicity of mycotoxins in feeds, Animal Feed Science and Technology, 137, 342-362.

Jovanovic, M.; Trailovic, D.; Kukolj, V.; Nesic, S.; Marinkovic, D.; Nedeljkovic-Trailovic, J.; Strajn, B. J.; Milicevic, D., 2015. An outbreak of fumonisin toxicosis in horses in serbia, World Mycotoxin Journal, 8, 387-391.

Juri, M. G. F.; Bressan, F.; Astoreca, A. L.; Barberis, C. L.; Cavaglieri, L. R.; Dalcero, A. M.; Magnoli, C. E., 2009. Aflatoxins, fumonisins and toxigenic fungi in raw materials and ready dry dog food in argentina, Revista Brasileira De Medicina Veterinaria, 31, 109-117. 
Juri, M. G. F.; Bressan, F.; Astoreca, A. L.; Barberis, C. L.; de Campos, S. G.; Cavaglieri, L. R.; Dalcero, A. M.; Magnoli, C. E., 2009. Mycotoxicological quality of different commercial extruded dog food in argentina, Revista Brasileira De Medicina Veterinaria, 31, 272-281.

Jurjevic, Z.; Wilson, D. M.; Wilson, J. P.; Geiser, D. M.; Juba, J. H.; Mubatanhema, W.; Widstrom, N. W.; Rains, G. C., 2005. Fusarium species of the gibberella fujiikuroi complex and fumonisin contamination of pearl millet and corn in georgia, USA, Mycopathologia, 159, 401-406.

Kabak, B.; Dobson, A. D. W.; Var, I., 2006. Strategies to prevent mycotoxin contamination of food and animal feed: A review, Critical Reviews in Food Science and Nutrition, 46, 593-619.

Kamala, A.; Kimanya, M.; Haesaert, G.; Tiisekwa, B.; Madege, R.; Degraeve, S.; Cyprian, C.; De Meulenaer, B., 2016. Local post-harvest practices associated with aflatoxin and fumonisin contamination of maize in three agro ecological zones of tanzania, Food Addit Contam Part A Chem Anal Control Expo Risk Assess, 33, 551-559.

Keller, K. M.; Keller, L. A. M.; Queiroz, B. D.; de Oliveira, A. A.; de Almeida, T. X.; Marassi, A. C.; Pereyra, M. L. G.; Cavaglieri, L. R.; Dalcero, A. M.; Rosa, C. A. D., 2008. Study on the mycobiota and mycotoxins of commercial equine feeds in rio de janeiro, brazil, Revista Brasileira De Medicina Veterinaria, 30, 224-229.

Keller, K. M.; Queiroz, B. D.; Keller, L. A. M.; Ribeiro, J. M. M.; Cavaglieri, L. R.; Pereyra, M. L. G.; Dalcero, A. M.; Rosa, C. A. R., 2007. The mycobiota and toxicity of equine feeds, Veterinary Research Communications, 31, 1037-1045.

Keller, L. A. M.; Pereyra, M. L. G.; Keller, K. M.; Alonso, V. A.; Oliveira, A. A.; Almeida, T. X.; Barbosa, T. S.; Nunes, L. M. T.; Cavaglieri, L. R.; Rosa, C. A. R., 2013. Fungal and mycotoxins contamination in corn silage: Monitoring risk before and after fermentation, Journal of Stored Products Research, 52, 42-47.

Khayoon, W. S.; Saad, B.; Salleh, B.; Ismail, N. A.; Manaf, N. H. A.; Latiff, A. A., 2010. A reversed phase high performance liquid chromatography method for the determination of fumonisins $b-1$ and $b-2$ in food and feed using monolithic column and positive confirmation by liquid chromatography/tandem mass spectrometry, Analytica Chimica Acta, 679, 91-97.

Kim, D. H.; Lee, I. H.; Do, W. H.; Nam, W. S.; Li, H.; Jang, H. S.; Lee, C., 2014. Incidence and levels of deoxynivalenol, fumonisins and zearalenone contaminants in animal feeds used in korea in 2012, Toxins (Basel), 6, 20-32.

Kim, E. K.; Maragos, C. M.; Kendra, D. F., 2004. Liquid chromatographic determination of fumonisins b-1, b-2, and b-3 in corn silage, Journal of Agricultural and Food Chemistry, 52, 196-200.

Kiyothong, K.; Rowlinson, P.; Wanapat, M.; Khampa, S., 2012. Effect of mycotoxin deactivator product supplementation on dairy cows, Animal Production Science, 52, 832-841.

Klaric, M. S.; Cvetnic, Z.; Pepeljnjak, S.; Kosalec, I., 2009. Co-occurrence of aflatoxins, ochratoxin a, fumonisins, and zearalenone in cereals and feed, determined by competitive direct enzyme-linked immunosorbent assay and thin-layer chromatography, Arh Hig Rada Toksikol, 60, 427-434.

Kocasari, F. S.; Mor, F.; Oguz, M. N.; Oguz, F. K., 2013. Occurrence of mycotoxins in feed samples in burdur province, turkey, Environ Monit Assess, 185, 4943-4949.

Kononenko, G. P.; Burkin, A. A.; Gavrilova, O. P.; Gagkaeva, T. Y., 2015. Fungal species and multiple mycotoxin contamination of cultivated grasses and legumes crops, Agricultural and Food Science, $24,323-330$.

Kos, J.; Hajnal, E. J.; Skrinjar, M.; Misan, A.; Mandic, A.; Jovanov, P.; Milovanovic, I., 2014. Presence of fusarium toxins in maize from autonomous province of vojvodina, serbia, Food Control, 46, 98101.

Kosicki, R.; Blajet-Kosicka, A.; Grajewski, J.; Twaruzek, M., 2016. Multiannual mycotoxin survey in feed materials and feedingstuffs, Animal Feed Science and Technology, 215, 165-180. 
Kpodo, K.; Thrane, U.; Hald, B., 2000. Fusaria and fumonisins in maize from ghana and their cooccurrence with aflatoxins, Int J Food Microbiol, 61, 147-157.

Krout-Greenberg, N. D.; Puschner, B.; Davidson, M. G.; Depeters, E. J., 2013. Preliminary study to assess mycotoxin concentrations in whole corn in the california feed supply, J Dairy Sci, 96, 27052712.

Krska, R.; Welzig, E.; Boudra, H., 2007. Analysis of fusarium toxins in feed, Animal Feed Science and Technology, 137, 241-264.

Labuda, R.; Parich, A.; Vekiru, E.; Tancinova, D., 2005. Incidence of fumonisins, moniliformin and fusarium species in poultry feed mixtures from slovakia, Ann Agric Environ Med, 12, 81-86.

Labuda, R.; Tancinova, D., 2006. Fungi recovered from slovakian poultry feed mixtures and their toxinogenity, Ann Agric Environ Med, 13, 193-200.

Labuda, R.; Tancinova, D.; Hudec, K., 2003. Identification and enumeration of fusarium species in poultry feed mixtures from slovakia, Ann Agric Environ Med, 10, 61-66.

Lanier, C.; Richard, E.; Heutte, N.; Picquet, R.; Bouchart, V.; Garon, D., 2010. Airborne molds and mycotoxins associated with handling of corn silage and oilseed cakes in agricultural environment, Atmospheric Environment, 44, 1980-1986.

Lanza, F. E.; Zambolim, L.; da Costa, R. V.; Queiroz, V. A. V.; Cota, L. V.; da Silva, D. D.; de Souza, A. G. C.; Figueiredo, J. E. F., 2014. Prevalence of fumonisin-producing fusarium species in brazilian corn grains, Crop Protection, 65, 232-237.

Latorre, A.; Dagnac, T.; Lorenzo, B. F.; Llompart, M., 2015. Occurrence and stability of masked fumonisins in corn silage samples, Food Chem, 189, 38-44.

Lawlor, P. G.; Lynch, P. B., 2001. Mycotoxins in pig feeds - 2: Clinical aspects, Irish Veterinary Journal, 54, 172-176.

Lee, K. M.; Herrman, T. J., 2015. Evaluation of selected nutrients and contaminants in distillers grains from ethanol production in texas, J Food Prot, 78, 1861-1869.

Leggieri, M. C.; Bertuzzi, T.; Pietri, A.; Battilani, P., 2015. Mycotoxin occurrence in maize produced in northern italy over the years 2009-2011: Focus on the role of crop related factors, Phytopathologia Mediterranea, 54, 212-221.

Leslie, J. F.; Zeller, K. A.; Logrieco, A.; Mule, G.; Moretti, A.; Ritieni, A., 2004. Species diversity of and toxin production by gibberella fujikuroi species complex strains isolated from native prairie grasses in kansas, Appl Environ Microbiol, 70, 2254-2262.

Leung, M. C. K.; Diaz-Llano, G.; Smith, T. K., 2006. Mycotoxins in pet food: A review on worldwide prevalence and preventative strategies, Journal of Agricultural and Food Chemistry, 54, 9623-9635.

Li, S. J.; Ediage, E. N.; De Saeger, S.; Van Waeyenberghe, L.; Garmyn, A.; Verlinden, M.; Ducatelle, R.; Croubels, S.; Haesebrouck, F.; Pasmans, F.; Martel, A., 2013. Occurrence and pathology of mycotoxins in commercial parrot feeds, World Mycotoxin Journal, 6, 449-453.

Liesener, K.; Curtui, V.; Dietrich, R.; Martlbauer, E.; Usleber, E., 2010. Mycotoxins in horse feed, Mycotoxin Res, 26, 23-30.

Logrieco, A. F.; Haidukowski, M.; Susca, A.; Mule, G.; Munkvold, G. P.; Moretti, A., 2014. Aspergillus section nigri as contributor of fumonisin b-2 contamination in maize, Food Additives and Contaminants Part a-Chemistry Analysis Control Exposure \& Risk Assessment, 31, 149-155.

Magnoli, C.; Chiacchiera, S.; Miazzo, R.; Palacio, G.; Angeletti, A.; Hallak, C.; Dalcero, A., 2002. The mycoflora and toxicity of feedstuffs from a production plant in cordoba, argentina, Mycotoxin Res, $18,7-22$. 
Maheshwar, P. K.; Janardhana, G. R., 2010. Natural occurrence of toxigenic fusarium proliferatum on paddy (oryza sativa I.) in karnataka, india, Trop Life Sci Res, 21, 1-10.

Manning, B. B.; Abbas, H. K., 2012. The effect of fusarium mycotoxins deoxynivalenol, fumonisin, and moniliformin from contaminated moldy grains on aquaculture fish, Toxin Reviews, 31, 11-15.

Mansfield, M. A.; Archibald, D. D.; Jones, A. D.; Kuldau, G. A., 2007. Relationship of sphinganine analog mycotoxin contamination in maize silage to seasonal weather conditions and to agronomic and ensiling practices, Phytopathology, 97, 504-511.

Mansur, A. R.; Yu, C. C.; Oh, D. H., 2014. Efficiency of gamma irradiation to inactivate growth and fumonisin production of fusarium moniliforme on corn grains, J Microbiol Biotechnol, 24, 209-216.

Martins, H. M.; Guerra, M. M.; Bernardo, F., 2006. Zearalenone, deoxynivalenol and fumonisins in mixed-feed for laying hens, Mycotoxin Res, 22, 206-210.

Martins, H. M. L.; Almeida, I. F. M.; Camacho, C. R. L.; Santos, S. M. O.; Costa, J. M. G.; Bernardo, F. M. A., 2012. Occurrence of fumonisins in feed for swine and horses, Revista Iberoamericana De Micologia, 29, 175-177.

Martins, H. M.; Marques, M.; Almeida, I.; Guerra, M. M.; Bernardo, F., 2008. Mycotoxins in feedstuffs in portugal: An overview, Mycotoxin Res, 24, 19-23.

Mashinini, K.; Dutton, M. F., 2006. The incidence of fungi and mycotoxins in south africa wheat and wheat-based products, J Environ Sci Health B, 41, 285-296.

McClurkin, J. D.; Ileleji, K. E., 2015. The effect of storage temperature and percentage of condensed distillers solubles on the shelf-life of distillers wet grains stored aerobically, Journal of Stored Products Research, 62, 58-64.

Mendes, G. D. L.; dos Reis, T. A.; Correa, B.; Badiale-Furlong, E., 2015. Mycobiota and occurrence of fumonisin b-1 in wheat harvested in southern brazil, Ciencia Rural, 45, 1050-1057.

Mezes, M.; Balogh, K., 2009. Mycotoxins in rabbit feed: A review, World Rabbit Science, 17, 53-62.

Milani, J.; Maleki, G., 2014. Effects of processing on mycotoxin stability in cereals, J Sci Food Agric, 94, 2372-2375.

Miller, J. D.; Schaafsma, A. W.; Bhatnagar, D.; Bondy, G.; Carbone, I.; Harris, L. J.; Harrison, G.; Munkvold, G. P.; Oswald, I. P.; Pestka, J. J.; Sharpe, L.; Sumarah, M. W.; Tittlemier, S. A.; Zhou, T., 2014. Mycotoxins that affect the north american agri-food sector: State of the art and directions for the future, World Mycotoxin Journal, 7, 63-82.

Mngadi, P. T.; Govinden, R.; Odhav, B., 2008. Co-occurring mycotoxins in animal feeds, African Journal of Biotechnology, 7, 2239-2243.

Mngqawa, P.; Shephard, G. S.; Green, I. R.; Ngobeni, S. H.; de Rijk, T. C.; Katerere, D. R., 2016. Mycotoxin contamination of home-grown maize in rural northern south africa (limpopo and mpumalanga provinces), Food Addit Contam Part B Surveill, 9, 38-45.

Monbaliu, S.; Van Poucke, C.; Detavernier, C.; Dumoulin, F.; Van De Velde, M.; Schoeters, E.; Van Dyck, S.; Averkieva, O.; Van Peteghem, C.; De Saeger, S., 2010. Occurrence of mycotoxins in feed as analyzed by a multi-mycotoxin Ic-ms/ms method, J Agric Food Chem, 58, 66-71.

Monge Mdel, P.; Magnoli, C. E.; Chiacchiera, S. M., 2012. Survey of aspergillus and fusarium species and their mycotoxins in raw materials and poultry feeds from cordoba, argentina, Mycotoxin Res, $28,111-122$.

Monge, M. P.; Dalcero, A. M.; Magnoli, C. E.; Chiacchiera, S. M., 2013. Natural co-occurrence of fungi and mycotoxins in poultry feeds from entre rios, argentina, Food Addit Contam Part B Surveill, 6, $168-174$. 
Moreno, E. C.; Garcia, G. T.; Ono, M. A.; Vizoni, E.; Kawamura, O.; Hirooka, E. Y.; Ono, E. Y. S., 2009. Co-occurrence of mycotoxins in corn samples from the northern region of parana state, brazil, Food Chemistry, 116, 220-226.

Morgavi, D. P.; Riley, R. T., 2007. An historical overview of field disease outbreaks known or suspected to be caused by consumption of feeds contaminated with fusarium toxins, Animal Feed Science and Technology, 137, 201-212.

Mudili, V.; Siddaih, C. N.; Nagesh, M.; Garapati, P.; Kumar, K. N.; Murali, H. S.; Mattila, T. Y.; Batra, $\mathrm{H}$. V., 2014. Mould incidence and mycotoxin contamination in freshly harvested maize kernels originated from india, Journal of the Science of Food and Agriculture, 94, 2674-2683.

Murugesan, G. R.; Ledoux, D. R.; Naehrer, K.; Berthiller, F.; Applegate, T. J.; Grenier, B.; Phillips, T. D.; Schatzmayr, G., 2015. Prevalence and effects of mycotoxins on poultry health and performance, and recent development in mycotoxin counteracting strategies, Poultry Science, 94, 1298-1315.

Mutiga, S. K.; Hoffmann, V.; Harvey, J. W.; Milgroom, M. G.; Nelson, R. J., 2015. Assessment of aflatoxin and fumonisin contamination of maize in western kenya, Phytopathology, 105, 12501261.

Nacher-Mestre, J.; Serrano, R.; Beltran, E.; Perez-Sanchez, J.; Silva, J.; Karalazos, V.; Hernandez, F.; Berntssen, M. H. G., 2015. Occurrence and potential transfer of mycotoxins in gilthead sea bream and atlantic salmon by use of novel alternative feed ingredients, Chemosphere, 128, 314-320.

Nayaka, S. C.; Shankar, A. C. U.; Niranjana, S. R.; Wulff, E. G.; Mortensen, C. N.; Prakash, H. S., 2010. Detection and quantification of fumonisins from fusarium verticillioides in maize grown in southern india, World Journal of Microbiology \& Biotechnology, 26, 71-78.

Njobeh, P. B.; Dutton, M. F.; Aberg, A. T.; Haggblom, P., 2012. Estimation of multi-mycotoxin contamination in south african compound feeds, Toxins (Basel), 4, 836-848.

Nuryono, ; Noviandi, C. T.; Bohm, J.; Agus, A.; Wedhastri, S.; Maryudani, Y. B.; Razzazi-Fazeli, E., 2004. Occurrence of fumonisins (b1, b 2, b 3) in maize-based food and feed samples from indonesia, Mycotoxin Res, 20, 2-9.

Nuryono, ; Noviandi, C. T.; Agus, A.; Wedhastri, S.; Maryudani, Y. B.; Bohm, J.; Razzazi, E., 2002. A survey of fumonisins (b1, b2, b3) in indonesian corn-based food and feed samples, Mycotoxin Res, 18 Suppl 2, 117-120.

Okabe, I.; Hiraoka, H.; Miki, K., 2015. Influence of harvest time on fumonisin contamination of forage maize for whole-crop silage, Mycoscience, 56, 470-475.

Oliveira, G. R.; Ribeiro, J. M.; Fraga, M. E.; Cavaglieri, L. R.; Direito, G. M.; Keller, K. M.; Dalcero, A. M.; Rosa, C. A., 2006. Mycobiota in poultry feeds and natural occurrence of aflatoxins, fumonisins and zearalenone in the rio de janeiro state, brazil, Mycopathologia, 162, 355-362.

Oliveira, M. S.; Diel, A. C. L.; Rauber, R. H.; Fontoura, F. P.; Mallmann, A.; Dilkin, P.; Mallmann, C. A., 2015. Free and hidden fumonisins in brazilian raw maize samples, Food Control, 53, 217-221.

Ono, E. Y. S.; da Silva, M.; Hashimoto, E. H.; Vizoni, E.; Kawamura, O.; Sugiura, Y.; Hirooka, E. Y., 2008. Mycotoxicological quality evaluation of corn samples used by processing industries in the northern region of parana state, brazil, Food Additives and Contaminants Part a-Chemistry Analysis Control Exposure \& Risk Assessment, 25, 1392-1399.

Ono, E. Y. S.; Fungaro, M. H. P.; Sofia, S. H.; Miguel, T. D.; Sugiura, Y.; Hirooka, E. Y., 2010. Fusarium verticillioides strains isolated from corn feed: Characterization by fumonisin production and rapd fingerprinting, Brazilian Archives of Biology and Technology, 53, 953-960.

Ono, E. Y. S.; Fungaro, M. H. P.; Sofia, S. H.; Figueira, E. L. Z.; Gerage, A. C.; Ichinoe, M.; Sugiura, Y.; Ueno, Y.; Hirooka, E. Y., 2004. Trends of fumonisin contamination and animal intoxication 
through monitoring 1991 to 1997 corn crop in the state of parana, brazil, Mycopathologia, 158, 451-455.

Orsi, R. B.; Correa, B.; Possi, C. R.; Schammass, E. A.; Nogueira, J. R.; Dias, S. M. C.; Malozzi, M. A. B., 2000. Mycoflora and occurrence of fumonisins in freshly harvested and stored hybrid maize, Journal of Stored Products Research, 36, 75-87.

Oruc, H. H.; Cengiz, M.; Kalkanli, O., 2006. Comparison of aflatoxin and fumonisin levels in maize grown in turkey and imported from the USA, Animal Feed Science and Technology, 128, 337-341.

Osweiler, G. D., 2001. Mycotoxins, Vet Clin North Am Equine Pract, 17, 547-566, viii.

Pagliuca, G.; Lugoboni, B.; Gazzotti, T.; Cipollini, I.; Zaghini, G., 2011. Fumonisin b-1 and b-2 in dry dog food: Preliminary study on commercial samples, World Mycotoxin Journal, 4, 439-446.

Palacios, S. A.; Susca, A.; Haidukowski, M.; Stea, G.; Cendoya, E.; Ramirez, M. L.; Chulze, S. N.; Farnochi, M. C.; Moretti, A.; Torres, A. M., 2015. Genetic variability and fumonisin production by fusarium proliferatum isolated from durum wheat grains in argentina, Int J Food Microbiol, 201, $35-41$.

Pascual, C. B.; Barcos, A. K. S.; Mandap, J. A. L.; Ocampo, E. T. M., 2016. Fumonisin-producing fusarium species causing ear rot of corn in the philippines, Philippine Journal of Crop Science, 41, 12-21.

Pereyra, C. M.; Cavaglieri, L. R.; Chiacchiera, S. M.; Dalcero, A. M., 2010. Fungi and mycotoxins in feed intended for sows at different reproductive stages in argentina, Vet Med Int, 2010, 569108.

Pereyra, C. M.; Cavaglieri, L. R.; Chiacchiera, S. M.; Dalcero, A. M., 2011. Mycobiota and mycotoxins contamination in raw materials and finished feed intended for fattening pigs production in eastern argentina, Vet Res Commun, 35, 367-379.

Pereyra, M. L. G.; Alonso, V. A.; Sager, R.; Morlaco, M. B.; Magnoli, C. E.; Astoreca, A. L.; Rosa, C. A. R.; Chiacchiera, S. M.; Dalcero, A. M.; Cavaglieri, L. R., 2008. Fungi and selected mycotoxins from pre- and postfermented corn silage, Journal of Applied Microbiology, 104, 1034-1041.

Pereyra, M. L. G.; Chiacchiera, S. M.; Rosa, C. A. R.; Sager, R.; Dalcero, A. M.; Cavaglieri, L., 2011. Comparative analysis of the mycobiota and mycotoxins contaminating corn trench silos and silo bags, Journal of the Science of Food and Agriculture, 91, 1474-1481.

Pereyra, M. L. G.; Keller, K. M.; Keller, L. A. M.; Cavaglieri, L. R.; Queiroz, B. D.; Tissera, J.; Dalcero, A. M.; Magnoli, C.; Rosa, C. A. D., 2009. Mycobiota and mycotoxins of equine feedstuffs in the central region of argentina, Revista Brasileira De Medicina Veterinaria, 31, 24-29.

Pereyra, M. L. G.; Pereyra, C. M.; Ramirez, M. L.; Rosa, C. A. R.; Dalcero, A. M.; Cavaglieri, L. R., 2008. Determination of mycobiota and mycotoxins in pig feed in central argentina, Letters in Applied Microbiology, 46, 555-561.

Phuong, N. H.; Thieu, N. Q.; Ogle, B.; Pettersson, H., 2015. Aflatoxins, fumonisins and zearalenone contamination of maize in the southeastern and central highlands provinces of vietnam, Agriculture-Basel, 5, 1195-1203.

Pietri, A.; Battilani, P.; Gualla, A.; Bertuzzi, T., 2012. Mycotoxin levels in maize produced in northern italy in 2008 as influenced by growing location and fao class of hybrid, World Mycotoxin Journal, 5, 409-418.

Pietri, A.; Bertuzzi, T.; Pallaroni, L.; Piva, G., 2004. Occurrence of mycotoxins and ergosterol in maize harvested over 5 years in northern italy, Food Addit Contam, 21, 479-487.

Pleadin, J.; Persi, N.; Mitak, M.; Zadravec, M.; Sokolovic, M.; Vulic, A.; Jaki, V.; Brstilo, M., 2012. The natural occurrence of $\mathrm{t}-2$ toxin and fumonisins in maize samples in croatia, Bull Environ Contam Toxicol, 88, 863-866. 
Pleadin, J.; Vahcic, N.; Persi, N.; Sevelj, D.; Markov, K.; Frece, J., 2013. Fusarium mycotoxins' occurrence in cereals harvested from croatian fields, Food Control, 32, 49-54.

Pleadin, J.; Zadravec, M.; Persi, N.; Vulic, A.; Jaki, V.; Mitak, M., 2012. Mould and mycotoxin contamination of pig feed in northwest croatia, Mycotoxin Res, 28, 157-162.

Queiroz, B.; Pereyra, C. M.; Keller, K. M.; Almeida, T.; Cavaglieri, L. R.; Magnoli, C. E.; Rosa, C. A. D., 2013. Fungal contamination and determination of fumonisins and aflatoxins in commercial feeds intended for ornamental birds in rio de janeiro, brazil, Letters in Applied Microbiology, 57, 405-411.

Reddy, K. R. N.; Salleh, B., 2011. Co-occurrence of moulds and mycotoxins in corn grains used for animal feeds in malaysia, Journal of Animal and Veterinary Advances, 10, 668-673.

Reed, K. F. M.; Moore, D. D., 2009. A preliminary survey of zearalenone and other mycotoxins in australian silage and pasture, Animal Production Science, 49, 696-703.

Reyes-Velazquez, W. P.; Espinoza, V. H. I.; Rojo, F.; Jimenez-Plasencia, C.; Palacios, E. D.; Hernandez-Gobora, J.; Ramirez-Alvarez, A., 2008. Occurrence of fungi and mycotoxins in corn silage, jalisco state, mexico, Revista Iberoamericana De Micologia, 25, 182-185.

Reyes-Velazquez, W. P.; Figueroa-Gomez, R. M.; Barberis, M.; Reynoso, M. M.; Rojo, F. G.; Chulze, S. N.; Torres, A. M., 2011. Fusarium species (section liseola) occurrence and natural incidence of beauvericin, fusaproliferin and fumonisins in maize hybrids harvested in mexico, Mycotoxin Res, $27,187-194$.

Rheeder, J. P.; Van der Westhuizen, L.; Imrie, G.; Shephard, G. S., 2016. Fusarium species and fumonisins in subsistence maize in the former transkei region, south africa: A multi-year study in rural villages, Food Addit Contam Part B Surveill, 9, 176-184.

Rocha, L. O.; Barroso, V. M.; Andrade, L. J.; Pereira, G. H. A.; Ferreira-Castro, F. L.; Duarte, A. P.; Michelotto, M. D.; Correa, B., 2016. Fum gene expression profile and fumonisin production by fusarium verticillioides inoculated in bt and non-bt maize, Frontiers in Microbiology, 6.

Rocha, L. O.; Nakai, V. K.; Braghini, R.; Reis, T. A.; Kobashigawa, E.; Correa, B., 2009. Mycoflora and co-occurrence of fumonisins and aflatoxins in freshly harvested corn in different regions of brazil, Int J Mol Sci, 10, 5090-5103.

Rodrigues, I.; Chin, L. J., 2012. A comprehensive survey on the occurrence of mycotoxins in maize dried distillers' grain and solubles sourced worldwide, World Mycotoxin Journal, 5, 83-88.

Rodrigues, I.; Handl, J.; Binder, E. M., 2011. Mycotoxin occurrence in commodities, feeds and feed ingredients sourced in the middle east and africa, Food Addit Contam Part B Surveill, 4, 168-179.

Rodrigues, I.; Naehrer, K., 2012. Prevalence of mycotoxins in feedstuffs and feed surveyed worldwide in 2009 and 2010, Phytopathologia Mediterranea, 51, 175-192.

Rodrigues, I.; Naehrer, K., 2012. A three-year survey on the worldwide occurrence of mycotoxins in feedstuffs and feed, Toxins (Basel), 4, 663-675.

Rodriguez-Cervantes, C. H.; Ramos, A. J.; Robledo-Marenco, M. L.; Sanchis, V.; Marin, S.; GironPerez, M. I., 2013. Determination of aflatoxin and fumonisin levels through elisa and hplc, on tilapia feed in nayarit, mexico, Food and Agricultural Immunology, 24, 269-278.

Rossi, C. N.; Takabayashi, C. R.; Ono, M. A.; Bordini, J. G.; Kawamura, O.; Vizoni, E.; Hirooka, E. Y.; Ono, E. Y. S., 2013. Assessment of exposure of broiler chicken in brazil to mycotoxins through naturally contaminated feed, Food Security, 5, 541-550.

Rossi, C. N.; Takabayashi, C. R.; Ono, M. A.; Bordini, J. G.; Itano, E. N.; Kawamura, O.; Pinheiro, J. W.; Hirooka, E. Y.; Ono, E. Y. S., 2013. Exposure of laying hens to mycotoxins through naturally contaminated feed, World Mycotoxin Journal, 6, 199-207.

Rossi, F.; Morlacchini, M.; Fusconi, G.; Pietri, A.; Mazza, R.; Piva, G., 2005. Effect of bt corn on broiler growth performance and fate of feed-derived DNA in the digestive tract, Poult Sci, 84, 1022-1030. 
Sacchi, C.; Gonzalez, H. H. L.; Broggi, L. E.; Pacin, A.; Resnik, S. L.; Cano, G.; Taglieri, D., 2009. Fungal contamination and mycotoxin natural occurrence in oats for race horses feeding in argentina, Animal Feed Science and Technology, 152, 330-335.

Santiago, R.; Cao, A.; Butron, A., 2015. Genetic factors involved in fumonisin accumulation in maize kernels and their implications in maize agronomic management and breeding, Toxins (Basel), 7, 3267-3296.

Scarpino, V.; Reyneri, A.; Vanara, F.; Scopel, C.; Causin, R.; Blandino, M., 2015. Relationship between european corn borer injury, fusarium proliferatum and $\mathrm{f}$. Subglutinans infection and moniliformin contamination in maize, Field Crops Research, 183, 69-78.

Scauflaire, J.; Gourgue, M.; Callebaut, A.; Munaut, F., 2012. Fusarium temperatum, a mycotoxinproducing pathogen of maize, European Journal of Plant Pathology, 133, 911-922.

Schatzmayr, G.; Streit, E., 2013. Global occurrence of mycotoxins in the food and feed chain: Facts and figures, World Mycotoxin Journal, 6, 213-222.

Schjoth, J. E.; Visconti, A.; Sundheim, L., 2009. Fumonisins in maize in relation to climate, planting time and hybrids in two agroecological zones in zambia, Mycopathologia, 167, 209-219.

Schmidt, P.; Novinski, C. O.; Junges, D.; Almeida, R.; de Souza, C. M., 2015. Concentration of mycotoxins and chemical composition of corn silage: A farm survey using infrared thermography, J Dairy Sci, 98, 6609-6619.

Schaafsma, A. W.; Limay-Rios, V.; Tamburic-Illincic, L., 2008. Mycotoxins and fusarium species associated with maize ear rot in ontario, canada, Cereal Research Communications, 36, 525-527.

Scudamore, K. A.; Patel, S., 2009. Occurrence of fusarium mycotoxins in maize imported into the uk, 2004-2007, Food Addit Contam Part A Chem Anal Control Expo Risk Assess, 26, 363-371.

Scudamore, K. A.; Patel, S., 2000. Survey for aflatoxins, ochratoxin a, zearalenone and fumonisins in maize imported into the united kingdom, Food Addit Contam, 17, 407-416.

Segvic, M.; Pepeljnjak, S., 2003. Distribution and fumonisin b-1 production capacity of fusarium moniliforme isolated from corn in croatia, Periodicum Biologorum, 105, 275-279.

Seo, D. G.; Phat, C.; Kim, D. H.; Lee, C., 2013. Occurrence of fusarium mycotoxin fumonisin b-1 and b-2 in animal feeds in korea, Mycotoxin Research, 29, 159-167.

Shala-Mayrhofer, V.; Varga, E.; Marjakaj, R.; Berthiller, F.; Musolli, A.; Berisha, D.; Kelmendi, B.; Lemmens, M., 2013. Investigations on fusarium spp. And their mycotoxins causing fusarium ear rot of maize in kosovo, Food Addit Contam Part B Surveill, 6, 237-243.

Sharma, M., 2007. Detection of hydrolyzed fumonisins $b-1$ and $b-2$ by use of high performance liquid chromatography in sorghum, Asian Journal of Chemistry, 19, 499-504.

Sharma, M.; Montes, R.; Marques, C.; Bravo, L. L.; Flores, M. H. E., 2007. Incidence and quantification of fumonisins b-1 and b-2 at harvest stage in sorghum, Asian Journal of Chemistry, $19,396-400$.

Shephard, G. S.; Burger, H. M.; Gambacorta, L.; Krska, R.; Powers, S. P.; Rheeder, J. P.; Solfrizzo, M.; Sulyok, M.; Visconti, A.; Warth, B.; van der Westhuizen, L., 2013. Mycological analysis and multimycotoxins in maize from rural subsistence farmers in the former transkei, south africa, J Agric Food Chem, 61, 8232-8240.

Shephard, G. S.; Marasas, W. F. O.; Leggott, N. L.; Yazdanpanah, H.; Rahimian, H.; Safavi, N., 2000. Natural occurrence of fumonisins in corn from iran, Journal of Agricultural and Food Chemistry, 48, 1860-1864.

Shephard, G. S.; van der Westhuizen, L.; Sewram, V.; van Zyl, J.; Rheeder, J. P., 2011. Occurrence of the c-series fumonisins in maize from the former transkei region of south africa, Food Addit Contam Part A Chem Anal Control Expo Risk Assess, 28, 1712-1716. 
Shimshoni, J. A.; Cuneah, O.; Sulyok, M.; Krska, R.; Galon, N.; Sharir, B.; Shlosberg, A., 2013. Mycotoxins in corn and wheat silage in israel, Food Addit Contam Part A Chem Anal Control Expo Risk Assess, 30, 1614-1625.

Siruguri, V.; Ganguly, C.; Bhat, R. V., 2009. Utilization of mouldy sorghum and cassia tora through fermentation for feed purposes, African Journal of Biotechnology, 8, 6349-6354.

Skladanka, J.; Nedelnik, J.; Adam, V.; Dolezal, P.; Moravcova, H.; Dohnal, V., 2011. Forage as a primary source of mycotoxins in animal diets, Int J Environ Res Public Health, 8, 37-50.

Smith, M. C.; Madec, S.; Coton, E.; Hymery, N., 2016. Natural co-occurrence of mycotoxins in foods and feeds and their in vitro combined toxicological effects, Toxins (Basel), 8.

Soares, C.; Calado, T.; Venancio, A., 2013. Mycotoxin production by aspergillus niger aggregate strains isolated from harvested maize in three portuguese regions, Rev Iberoam Micol, 30, 9-13.

Stoev, S. D., 2008. Complex etiology, prophylaxis and hygiene control in mycotoxic nephropathies in farm animals and humans, Int J Mol Sci, 9, 578-605.

Stoev, S. D., 2013. Food safety and increasing hazard of mycotoxin occurrence in foods and feeds, Critical Reviews in Food Science and Nutrition, 53, 887-901.

Stoev, S. D., 2015. Foodborne mycotoxicoses, risk assessment and underestimated hazard of masked mycotoxins and joint mycotoxin effects or interaction, Environmental Toxicology and Pharmacology, 39, 794-809.

Streit, E.; Naehrer, K.; Rodrigues, I.; Schatzmayr, G., 2013. Mycotoxin occurrence in feed and feed raw materials worldwide: Long-term analysis with special focus on europe and asia, J Sci Food Agric, 93, 2892-2899.

Streit, E.; Schatzmayr, G.; Tassis, P.; Tzika, E.; Marin, D.; Taranu, I.; Tabuc, C.; Nicolau, A.; Aprodu, I.; Puel, O.; Oswald, I. P., 2012. Current situation of mycotoxin contamination and co-occurrence in animal feed-focus on europe, Toxins, 4, 788-809.

Stumpf, R.; Dos Santos, J.; Gomes, L. B.; Silva, C. N.; Tessmann, D. J.; Ferreira, F. D.; Machinski, M., Jr.; Del Ponte, E. M., 2013. Fusarium species and fumonisins associated with maize kernels produced in rio grande do sul state for the 2008/09 and 2009/10 growing seasons, Braz J Microbiol, 44, 89-95.

Szabo-Fodor, J.; Dall'Asta, C.; Falavigna, C.; Kachlek, M.; Szecsi, A.; Szabo, A.; Kovacs, M., 2015. Determination of the amount of bioaccessible fumonisin b-1 in different matrices after in vitro digestion, World Mycotoxin Journal, 8, 261-267.

Taffarel, L. E.; Mesquita, E. E.; Castagnara, D. D.; Costa, P. B.; Neres, M. A.; Horn, M. B.; de Oliveira, P. S. R.; Meinerz, C. C., 2013. Dehydration curve, fungi and mycotoxins in tifton 85 hay dehydrated in the field and in shed, Revista Brasileira De Zootecnia-Brazilian Journal of Animal Science, 42, 395-403.

Tamura, M.; Mochizuki, N.; Nagatomi, Y.; Harayama, K.; Toriba, A.; Hayakawa, K., 2015. Identification and quantification of fumonisin $\mathrm{a} 1, \mathrm{a} 2$, and $\mathrm{a} 3$ in corn by high-resolution liquid chromatography-orbitrap mass spectrometry, Toxins (Basel), 7, 582-592.

Teller, R. S.; Schmidt, R. J.; Whitlow, L. W.; Kung, L., Jr., 2012. Effect of physical damage to ears of corn before harvest and treatment with various additives on the concentration of mycotoxins, silage fermentation, and aerobic stability of corn silage, J Dairy Sci, 95, 1428-1436.

Torres, A. M.; Reynoso, M. M.; Rojo, F. G.; Ramirez, M. L.; Chulze, S. N., 2001. Fusarium species (section liseola) and its mycotoxins in maize harvested in northern argentina, Food Addit Contam, $18,836-843$. 
Trung, T. S.; Tabuc, C.; Bailly, S.; Querin, A.; Guerre, P.; Bailly, J. D., 2008. Fungal mycoflora and contamination of maize from vietnam with aflatoxin $b(1)$ and fumonisin $b(1)$, World Mycotoxin Journal, 1, 87-94.

Tseng, T. C.; Liu, C. Y., 2001. Occurrence of fumonisin b-1 in maize imported into taiwan, International Journal of Food Microbiology, 65, 23-26.

Uegaki, R.; Kobayashi, H.; Inoue, H.; Tohno, M.; Tsukiboshi, T., 2013. Changes of fumonisin production in rice grain during ensiling, Anim Sci J, 84, 48-53.

Uegaki, R.; Kobayashi, H.; Tohno, M.; Tsukiboshi, T., 2012. Identification of mycotoxin-producing fusarium spp. Isolated from corn and the changes in concentration of fumonisin during the cultivation period, Grassland Science, 58, 121-126.

Uegaki, R.; Tohno, M.; Yamamura, K.; Tsukiboshi, T., 2014. Changes in the concentration of fumonisins in forage rice during the growing period, differences among cultivars and sites, and identification of the causal fungus, J Agric Food Chem, 62, 3356-3362.

Uegaki, R.; Tsukiboshi, T.; Tohno, M., 2013. Changes in the concentrations of fumonisin, deoxynivalenol and zearalenone in corn silage during ensilage, Anim Sci J, 84, 656-662.

Uegaki, R.; Tohno, M.; Yamamura, K.; Tsukiboshi, T.; Uozumi, S., 2015. Natural occurrence of mycotoxins in forage maize during crop growth in japan: Case study, Mycotoxin Res, 31, 51-56.

van Rensburg, B. J.; McLaren, N. W.; Flett, B. C.; Schoeman, A., 2015. Fumonisin producing fusarium spp. And fumonisin contamination in commercial south african maize, European Journal of Plant Pathology, 141, 491-504.

van Rensburg, B. J.; Mc Laren, N. W.; Schoeman, A.; Flett, B. C., 2015. The effects of cultivar and prophylactic fungicide spray for leaf diseases on colonisation of maize ears by fumonisin producing fusarium spp. And fumonisin synthesis in south africa, Crop Protection, 79, 56-63.

Vargas, E. A.; Preis, R. A.; Castro, L.; Silva, C. M. G., 2001. Co-occurrence of aflatoxins b(1), b(2), $g(1), g(2)$, zearalenone and fumonisin $b(1)$ in brazilian corn, Food Additives and Contaminants Part a-Chemistry Analysis Control Exposure \& Risk Assessment, 18, 981-986.

Velluti, A.; Marin, S.; Sanchis, V.; Ramos, A. J., 2001. Note. Occurrence of fumonisin b-1 in spanish corn-based foods for animal and human consumption, Food Science and Technology International, 7, 433-437.

Vrabcheva, T.; Stroka, J.; Anklam, E., 2002. Occurrence of fumonisin b1 in bulgarian maize samples determined by elisa and tlc methods using different clean up steps, Mycotoxin Res, 18, 46-56.

Walt, A. M. D.; van der Linde, E.; Alberts, M.; Modjajdi, P.; Jivan, S. D.; Bezuidenhout, C. C., 2006. Fumonisin-producing fusarium strains and fumonisins in traditional, african vegetables (morogo), South African Journal of Science, 102, 151-155.

Wang, H.; Wei, H.; Ma, J.; Luo, X., 2000. The fumonisin b1 content in corn from north china, a highrisk area of esophageal cancer, J Environ Pathol Toxicol Oncol, 19, 139-141.

Wang, J. S.; Zhou, Y.; Liu, W. B.; Zhu, X. C.; Du, L. C.; Wang, Q. M., 2008. Fumonisin level in cornbased food and feed from linxian county, a high-risk area for esophageal cancer in china, Food Chemistry, 106, 241-246.

Wang, Y. K.; Yan, Y. X.; Li, S. Q.; Wang, H. A.; Ji, W. H.; Sun, J. H., 2013. Simultaneous quantitative determination of multiple mycotoxins in cereal and feedstuff samples by a suspension array immunoassay, ] Agric Food Chem, 61, 10948-10953.

Wang, Y.; Liu, S. L.; Zheng, H.; He, C. H.; Zhang, H. B., 2013. T-2 toxin, zearalenone and fumonisin b-1 in feedstuffs from china, Food Additives \& Contaminants Part B-Surveillance, 6, 116-122. 
Warth, B.; Parich, A.; Atehnkeng, J.; Bandyopadhyay, R.; Schuhmacher, R.; Sulyok, M.; Krska, R., 2012. Quantitation of mycotoxins in food and feed from burkina faso and mozambique using a modern Ic-ms/ms multitoxin method, J Agric Food Chem, 60, 9352-9363.

Wei, T.; Zhu, W.; Pang, M.; Liu, Y.; Dong, J., 2013. Natural occurrence of fumonisins b1 and b2 in corn in four provinces of china, Food Addit Contam Part B Surveill, 6, 270-274.

Wisniewska-Dmytrow, H.; Kozak, A.; Zmudzki, J., 2004. Occurrence of fusarium mycotoxins in feedstuffs from farms with husbandry problems, Bulletin of the Veterinary Institute in Pulawy, 48, $117-122$.

Wu, F., 2007. Measuring the economic impacts of fusarium toxins in animal feeds, Animal Feed Science and Technology, 137, 363-374.

Wu, F.; Munkvold, G. P., 2008. Mycotoxins in ethanol co-products: Modeling economic impacts on the livestock industry and management strategies, J Agric Food Chem, 56, 3900-3911.

Waalwijk, C.; Koch, S. H.; Ncube, E.; Allwood, J.; Flett, B.; de Vries, I.; Kema, G. H. J., 2008. Quantitative detection of fusarium spp. And its correlation with fumonisin content in maize from south african subsistence farmers, World Mycotoxin Journal, 1, 39-47.

Yazar, S.; Omurtag, G. Z., 2008. Fumonisins, trichothecenes and zearalenone in cereals, Int J Mol Sci, 9, 2062-2090.

Yiannikouris, A.; Jouany, J. P., 2002. Mycotoxins in feeds and their fate in animals: A review, Animal Research, 51, 81-99.

Zachariasova, M.; Dzuman, Z.; Veprikova, Z.; Hajkova, K.; Jiru, M.; Vaclavikova, M.; Zachariasova, A.; Pospichalova, M.; Florian, M.; Hajslova, J., 2014. Occurrence of multiple mycotoxins in european feedingstuffs, assessment of dietary intake by farm animals, Animal Feed Science and Technology, 193, 124-140.

Zainudin, Naim; Perumal, N., 2015. Mycotoxins production by fusarium and aspergillus species isolated from cornmeal, International Journal of Agriculture and Biology, 17, 440-448.

Zhang, W. W.; Deng, X. D.; Yu, X. P.; Pei, X. F.; Fu, G. M.; Wang, X. L.; Li, B. B.; Wang, L. Y., 2015. The recent fusarium mycotoxin situation in grain and feed in china, World Mycotoxin Journal, 8 , 545-551.

Zhang, Y. H.; Caupert, J.; Imerman, P. M.; Richard, J. L.; Shurson, G. C., 2009. The occurrence and concentration of mycotoxins in us distillers dried grains with solubles, Journal of Agricultural and Food Chemistry, 57, 9828-9837.

Zhang, Y. H.; Caupert, J., 2012. Survey of mycotoxins in U.S. Distiller's dried grains with solubles from 2009 to 2011, Journal of Agricultural and Food Chemistry, 60, 539-543.

Relevant references not retrieved in the literature searches for Area 9 OCCURRENCE IN FEED:

Stoev, S. D.; Denev, S.; Dutton, M. F.; Njobeh, P. B.; Mosonik, J. S.; Steenkamp, P. A.; Petkov, I., 2010. Complex etiology and pathology of mycotoxic nephropathy in south african pigs, Mycotoxin Res, 26, 31-46.

Yiannikouris, A.; Jouany, J. P., 2002. Mycotoxins in feeds for ruminants; fate and effects on animals, Productions Animales, 15, 3-16. 